\begin{abstract}
Title of Dissertation:

AN ACOUSTIC ANALYSIS OF VALVELESS PULSEJET ENGINES

Daanish Maqbool, Doctor of Philosophy, 2015

Dissertation directed by: $\quad$ Associate Professor, Christopher P. Cadou, Department of Aerospace Engineering

Valveless pulsejets are extremely simple aircraft engines; essentially cleverly designed tubes with no moving parts. These engines utilize pressure waves, instead of machinery, for thrust generation, and have demonstrated thrust-to-weight ratios over 8 and thrust specific fuel consumption levels below $1 \mathrm{lbm} / \mathrm{lbf}-\mathrm{hr}$ - performance levels that can rival many gas turbines. Despite their simplicity and competitive performance, they have not seen widespread application due to extremely high noise and vibration levels, which have persisted as an unresolved challenge primarily due to a lack of fundamental insight into the operation of these engines. This thesis develops two theories for pulsejet operation (both based on electro-acoustic analogies) that predict measurements better than any previous theory reported in the literature, and then uses them to devise and experimentally validate effective noise reduction strategies.
\end{abstract}


The first theory analyzes valveless pulsejets as acoustic ducts with axially varying area and temperature. An electro-acoustic analogy is used to calculate longitudinal mode frequencies and shapes for prescribed area and temperature distributions inside an engine. Predicted operating frequencies match experimental values to within $6 \%$ with the use of appropriate end corrections. Mode shapes are predicted and used to develop strategies for suppressing higher modes that are responsible for much of the perceived noise. These strategies are verified experimentally and via comparison to existing models/data for valveless pulsejets in the literature.

The second theory analyzes valveless pulsejets as acoustic systems/circuits in which each engine component is represented by an acoustic impedance. These are assembled to form an equivalent circuit for the engine that is solved to find the frequency response. The theory is used to predict the behavior of two interacting pulsejet engines. It is validated via comparison to experiment and data in the literature. The technique is then used to develop and experimentally verify a method for operating two engines in anti-phase without interfering with thrust production. Finally, Helmholtz resonators are used to suppress higher order modes that inhibit noise suppression via anti-phasing. Experiments show that the acoustic output of two resonator-equipped pulsejets operating in anti-phase is $9 \mathrm{dBA}$ less than the acoustic output of a single pulsejet. 


\section{AN ACOUSTIC ANALYSIS OF VALVELESS PULSEJET ENGINES}

by

\section{Daanish Maqbool}

Dissertation submitted to the Faculty of the Graduate School of the University of Maryland, College Park, in partial fulfillment of the requirements for the degree of

Doctor of Philosophy 2015

Advisory Committee:

Associate Professor Christopher P. Cadou, Chair

Associate Professor Kenneth Yu

Associate Professor James Baeder

Professor Douglas Hamilton

Professor Kenneth Kiger, Dean's Representative 
(C) Copyright by

Daanish Maqbool

2015 
To my mother;

This is where

The Hunt for Red October

meets Top Gun. 


\section{Table of Contents}

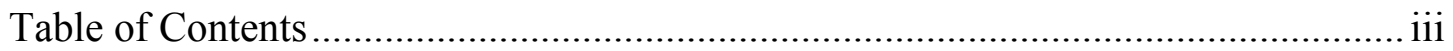

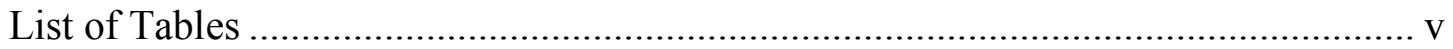

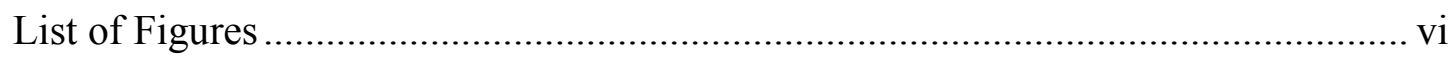

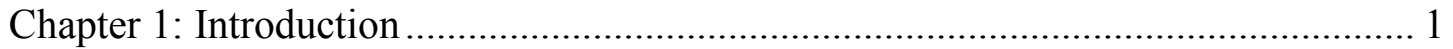

1.1 What is a Pulsejet? ...................................................................................... 1

1.2 Principle of Operation .................................................................................. 3

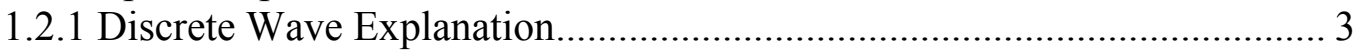

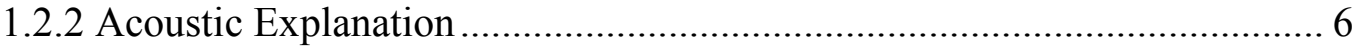

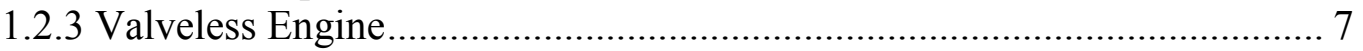

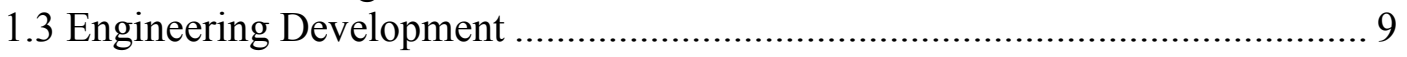

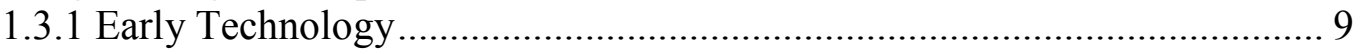

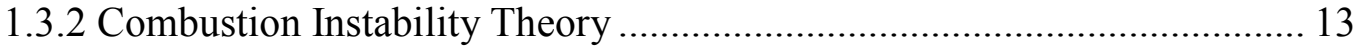

1.3.3 Developments in Nazi Germany during World War II............................ 13

1.3.4 Post-War Developments in France ............................................................ 18

1.3.4 Post-War Developments in the United States ........................................ 21

1.4 Scientific Studies ...................................................................................... 26

1.4.1 Analytical - Valved Pulsejets .......................................................... 26

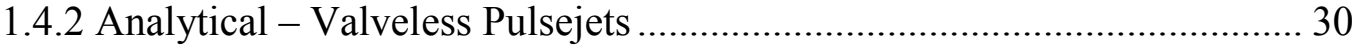

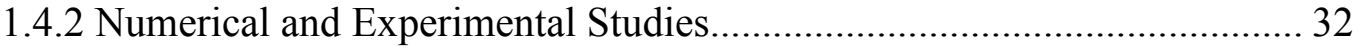

1.4.3 Studies on Multiple-Engine Configurations ........................................... 41

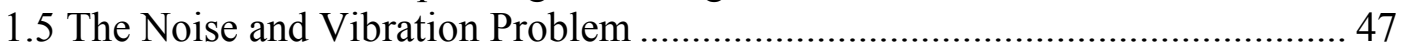

1.5.1 Background: A Deafening Dead End ................................................... 47

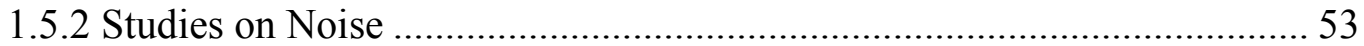

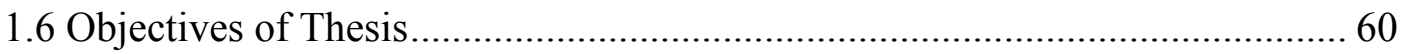

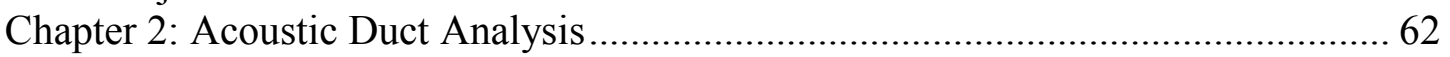

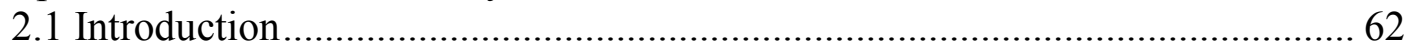

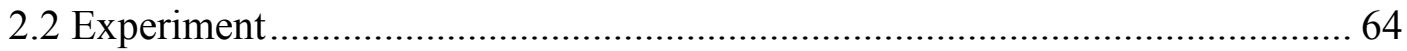

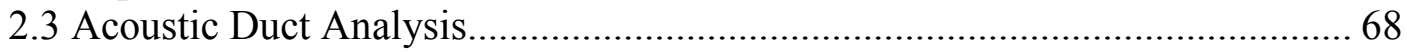

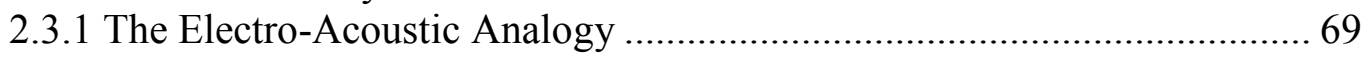

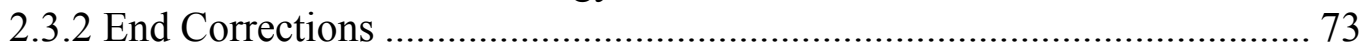

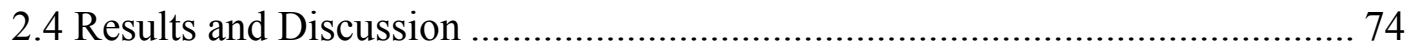

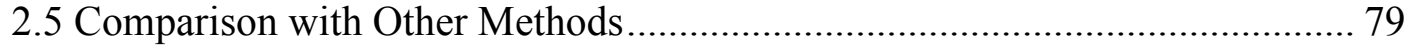

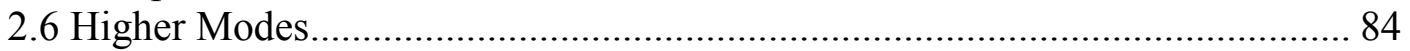

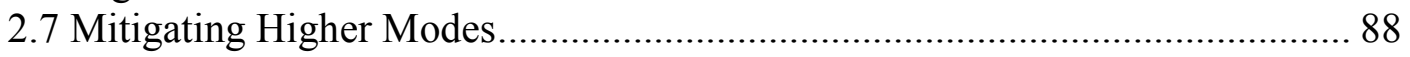

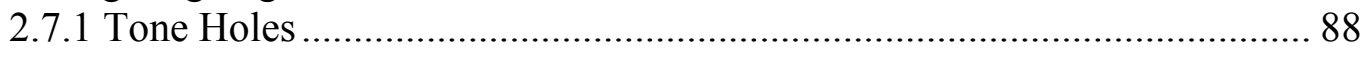

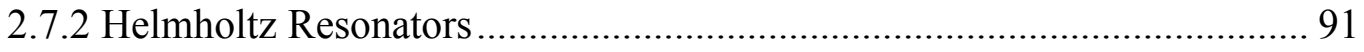

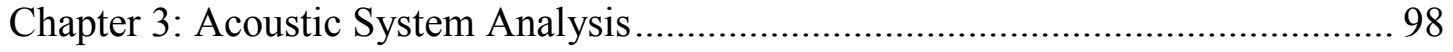

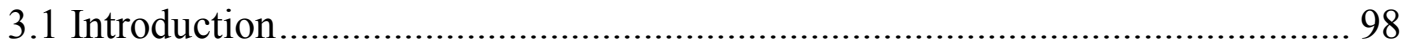

3.2 Acoustic System for a Single Valveless Pulsejet......................................... 99

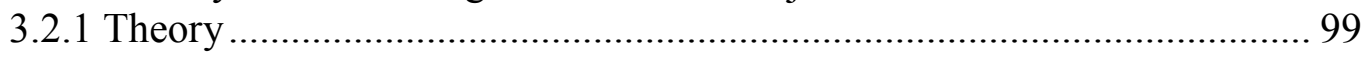

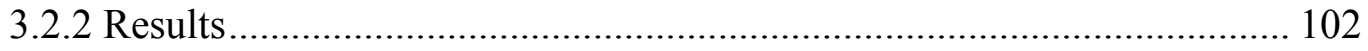


3.3Acoustic Systems for Multiple Pulsejets ...................................................... 104

3.3.1 Connection via Short Duct.................................................................. 104

3.3.2 Connection via Decoupling Chamber ................................................... 109

3.3.4 Connection via Half-Wave Tube ........................................................ 113

3.3.5 Connection via Helmholtz Chamber.................................................... 117

3.4 Experimental Verification of Acoustic System Analysis .............................. 120

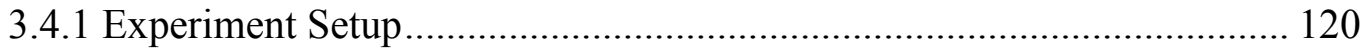

3.4.2 Connection via Short Duct................................................................... 122

3.4.3 Connection via Decoupling Chamber ..................................................... 125

3.4.4 Connection via Half-Wave Tube ....................................................... 125

3.4.5 Connection via Helmholtz Chamber...................................................... 127

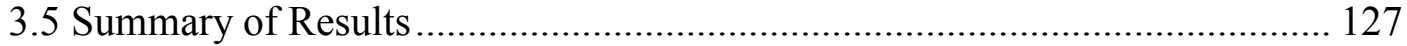

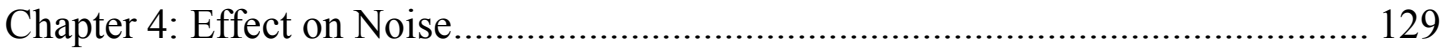

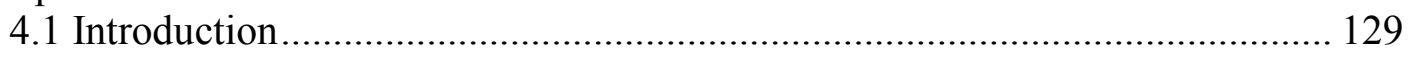

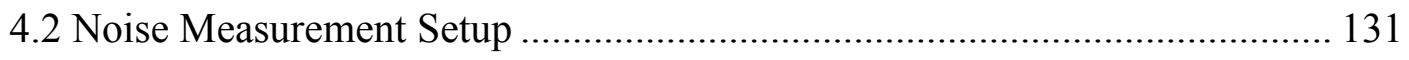

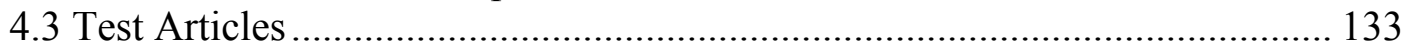

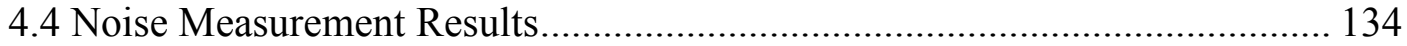

4.4.1 Effect of Helmholtz Resonator .......................................................... 134

4.4.2 Effect of Half-Wave Tube ................................................................ 138

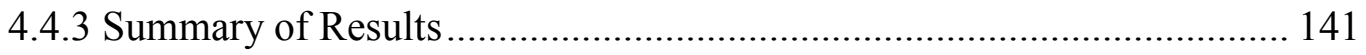

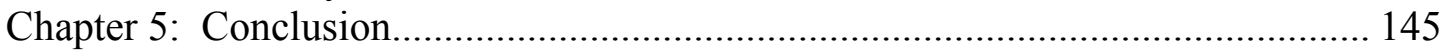

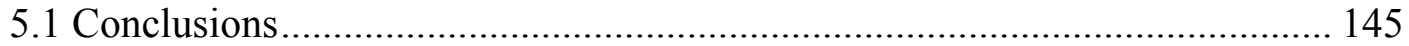

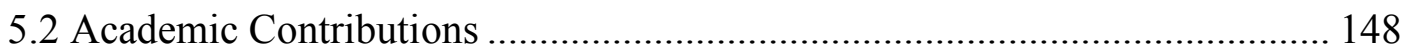

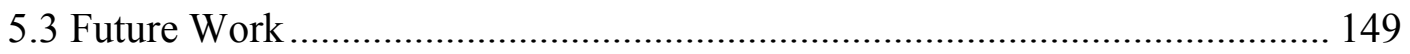

Appendix A: Analytical Impedance Expressions ................................................... 156

Appendix B: Acoustic Duct MATLAB Script..................................................... 159

Appendix C: Acoustic System/Circuit MATLAB Script ……………………........ 164

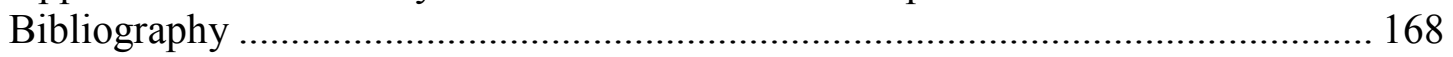




\section{List of Tables}

Table 1-1: Fi-103 (V-1) Specifications

Table 2-1: Valveless Pulse Jet Geometries Tested

Table 2-2: Comparison of predicted and measured frequencies

Table 3-1: Averaged values and results of acoustic system calculation

Table 3-2: Summary of engine interaction results

Table 4-1: A-weighted noise level vs. resonator chamber heights

page 14

page 68

page 77

page 103

page 128

page 136 


\section{List of Figures}

Fig. 1-1: The German V-1

page 2

Fig. 1-2a: Steps 1 and 2 of the pulsejet cycle

page 3

Fig. 1-2b: Steps 3 and 4 of the pulsejet cycle

page 4

Fig. 1-2c: Steps 5 and 6 of the pulsejet cycle

page 5

Fig. 1-2d: Steps 7 and 8 of the pulsejet cycle

page 6

Fig. 1-3: Pressure and velocity variations in a pulsejet engine

Fig. 1-4: A valveless pulsejet engine

page 7

Fig. 1-5: Esnault-Pelterie's 1906 patent

Fig. 1-6: Marconnet's 1909 patent for a valveless pulsejet

Fig. 1-7: Evolution of the pulsejet

Fig. 1-8: Schematic of the V-1 (Fi-103)

Fig. 1-9: Method of characteristics solution

Fig. 1-10: The SNECMA “Escopette" Valveless Engine

Fig. 1-11: An 'Emouchet' sailplane

Fig. 1-12: The larger SNECMA 'Ecrevisse' Valveless Engine

Fig. 1-13: Pulsejet studied by Logan for tip-jet applications

Fig. 1-14: Augmenters for a valveless pulsejet engine

Fig. 1-15: The Hiller/Lockwood HH-5.25" series engine

Fig. 1-16: Momentum difference of outflow and inflow

Fig. 1-17: Geometries for frequency calculation method of Zheng et al.

Fig. 1-18: Primary and secondary gas flow paths in a valveless pulsejet

Fig. 1-19: Multiple peaks observed in a 15-cm valveless pulsejet

Fig. 1-20: Anti-phase pulsejet configuration of Esnault-Pelterie

Fig. 1-21: Anti-phase arrangement of Kentfield

Fig. 1-22: Pulse combustor for heating applications

Fig. 1-23: Valveless pulsejet powered aircraft at the Paris Air Show

Fig. 1-24: SNECMA pulsejet-powered VTOL test article

Fig. 1-25: Boeing VTOL concept

Fig. 1-26: Noise spectra comparisons for different powerplants

Fig. 1-27: The A-weighting for sound pressure level (dBA)

Fig. 1-28: Interference of acoustic signals due to anti-phase operation

Fig. 1-29: Effect of anti-phasing on pulsejet noise

Fig. 2-1: Photograph of one pulsejet prior to testing

Fig. 2-2: Geometry of tested pulsejet

Fig. 2-3: Side and isometric view of cap showing fuel injectors

Fig. 2-4: Electro-acoustic analogy

Fig. 2-5: Effect of exhaust length on internal temperature profile

Fig. 2-6: Effect of exhaust length on internal temperature profile

Fig. 2-7: Combustion chamber pressure fluctuations

Fig. 2-8: Calculated mode shapes scaled by experimental data

Fig. 2-9: Comparison of different frequency calculation methods

Fig. 2-10: Mode shapes

Fig. 2-11: Measured exhaust pressure as a function of the phase angle

Fig. 2-12: Measured inlet plane, chamber, and exhaust plane pressure

page 8

page 10

page 11

page 12

page 14

page 17

page 19

page 20

page 21

page 23

page 24

page 25

page 29

page 31

page 36

page 38

page 42

page 43

page 45

page 49

page 51

page 52

page 55

page 56

page 58

page 59

page 65

page 65

page 66

page 70

page 75

page 76

page 77

page 78

page 82

page 84

page 85

page 86 
Fig. 2-13: (a) Pressure, and (b) volume velocity profiles

page 87

Fig. 2-14: Equivalent circuit for an open tone hole at the $n^{\text {th }}$ node. page 89

Fig. 2-15: Mode shapes with increasing tone hole diameter. page 91

Fig. 2-16: Suppression of mode using a Helmholtz resonator page 92

Fig. 2-17: Equivalent circuit for a Helmholtz resonator at the $n^{\text {th }}$ node page 92

Fig. 2-18: Mode shapes with and without Helmholtz resonator page 96

Fig. 3-1: Valveless pulse acoustic system/circuit page 100

Fig. 3-2: Bode plots for valveless pulsejet acoustic circuit page 104

Fig. 3-3: Two interconnected pulsejet engines page 105

Fig. 3-4: Acoustic system/circuit for two interconnected pulsejet engines page 105

Fig. 3-5: Frequency response for interconnected pulsejet engines page 108

Fig. 3-6: Pulsejet engines connected via a decoupling chamber page 110

Fig. 3-7: Acoustic circuit for pulsejet engines w/ decoupling chamber page 110

Fig. 3-8: Frequency response for pulsejet engines w/ decoupling chamber page 112

Fig. 3-9: Pressure and velocity profiles in a half-wave tube page 114

Fig. 3-10: Acoustic circuit for pulsejet engines $w /$ half-wave tube page 115

Fig. 3-11: Frequency response for pulsejet engines w/ half-wave tube page 117

Fig. 3-12: Pulsejets connected via a Helmholtz chamber page 118

Fig. 3-13: Acoustic circuit for pulsejet engines w/ Helmholtz chamber page 118

Fig. 3-14: Frequency response for pulsejet engines w/ Helmholtz chamber page 120

Fig. 3-15: Pulsejet configuration for interaction studies page 121

Fig. 3-16: Pulsejet in operation page 122

Fig. 3-17: Pulsejets inter-connected with a short duct page 123

Fig. 3-18: Experimental chamber pressure measurements page 124

Fig. 3-19: Pulsejets connected with a half-wave tube page 126

Fig. 3-20: Chamber pressure measurements for pulsejets $\mathrm{w} / 1 / 2$-wave tube page 126

Fig. 3-21: Pulsejets connected with a Helmholtz chamber page 127

Fig. 4-1: Noise measurement locations page 132

Fig. 4-2: Frequency response of Shure SM58 microphone page 133

Fig. 4-3: Geometry for noise reduction modifications page 133

Fig. 4-4: Helmholtz resonator attached to a single pulsejet engine page 134

Fig. 4-5: Audio waveforms with increasing chamber heights page 136

Fig. 4-6: Thrust as a function of resonator chamber height/volume page 138

Fig. 4-7: Paired engines in anti-phase operation page 139

Fig. 4-8: Acoustic waveforms with resonators and anti-phasing page 140

Fig. 4-9: Spectra with resonators and anti-phasing page 141

Fig. 4-10: Effect of modifications on noise level at location 1 page 142

Fig. 4-11: A- and C-weighted sound pressure level measurements page 143

Fig. 5-1: Alternative configuration for ant-phasing page 151

Fig. 5-2: Wave engine concept with $1 / 4$-wave duct page 153

Fig. 503: Wave engine concept with $1 / 2$-wave duct page 155 


\section{Chapter 1: Introduction}

\subsection{What is a Pulsejet?}

A pulsejet is the simplest type of air-breathing aircraft engine capable of producing thrust under static conditions. A typical pulsejet consists of a hollow tube that is open at one end and fitted with a one-way reed valve at the other end. The principle of operation is explained in a later section, but this arrangement allows it to produce discrete and repetitive combustion events, which cause pulses of hot gas to exhaust out the open end to produce thrust. Another arrangement does away with the reed valves and replaces them with a small length of pipe. Such an arrangement has the advantage of no moving parts, and is commonly referred to as a 'Valveless' or 'Aerovalved' pulsejet.

The concept of a pulsejet has been in existence since the early $20^{\text {th }}$ century, but it first saw practical use in World War II, powering the German V-1 (Fig. 1-1) [1]. After the war, development efforts started in the United States and France and lasted until the 1960s [2] [3]. Potential applications included not just aircraft propulsion, but also liftengines for Vertical Take-off and Landing (VTOL) aircraft [2], tip-mounted jet engines for rotorcraft [4] [5], and pressure-gain combustors for gas turbines [6] [7]. Research efforts ultimately dwindled in the 1960s due to a number of unresolved problems and also due to the much-faster paced development of the gas turbine 
engine. In recent times, interest in pulsejets has been renewed due to their potential as microengines [8].

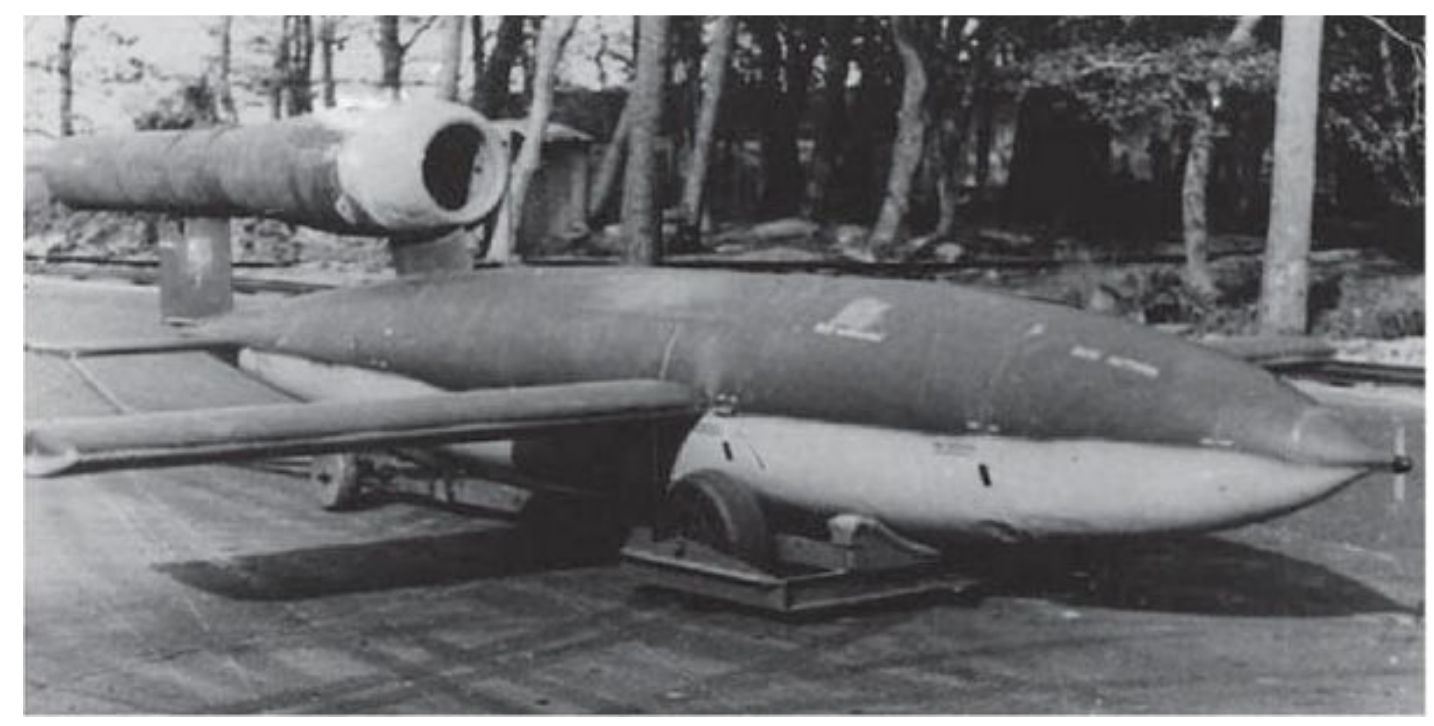

Figure 1-1: The German V-1 which was used extensively in World War II (Adapted from ref. [1]).

Aside of aircraft propulsion, pulsejets have been employed for heating and drying applications [9]. These engines are quite suitable as heaters because they are essentially self-aspirating combustors, although for these applications, they are often referred to as 'pulse combustors'. These engines are also sometimes referred to as 'wave engines' in the literature [10]. 


\section{$\underline{1.2 \text { Principle of Operation }}$}

1.2.1 Discrete Wave Explanation

A typical pulsejet consists of a hollow tube that is open at one end and fitted with a one-way reed valve at the other end. Fuel is introduced into the valved end of the engine and ignited (step 1, Fig. 1-2a). As shown in Fig. 1-2a, the ensuing combustion process creates a pressure rise. This closes the reed valves and sends a compression wave down the tube (step 2, Fig. 1-2a), forcing the combustion products out of the open end [11] [12] [13] [14].

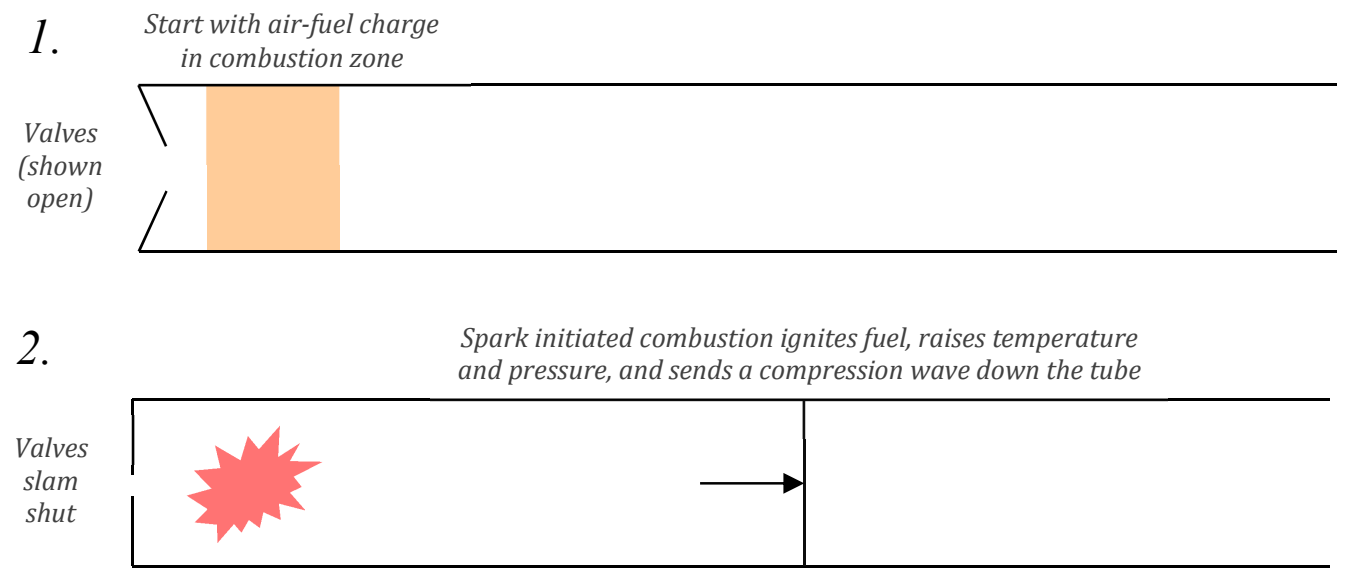

Figure 1-2a: Steps 1 and 2 of the pulsejet cycle.

When the compression wave reaches the open end, an outflow of gases takes place producing thrust and the wave reflects off the open end as an expansion wave due to the open boundary condition [15] (step 3, Fig. 1-2b). This expansion wave travels back up the tube and upon reaching the valved end, a net negative pressure is induced 
behind the valves. This net negative pressure opens the valves and induces the flow of a fresh fuel-air charge (step 4, Fig. 1-2b).

3.

Compression wave travels down the tube and reflects as an expansion wave

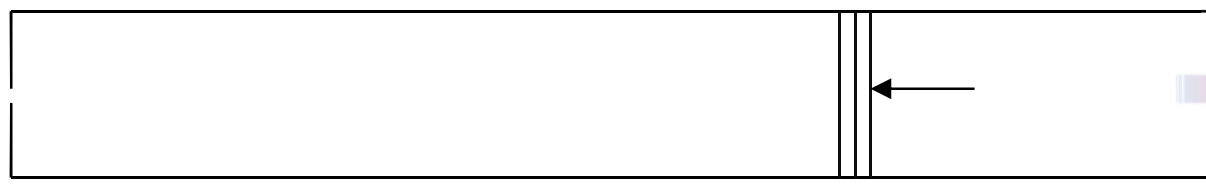

positive thrust

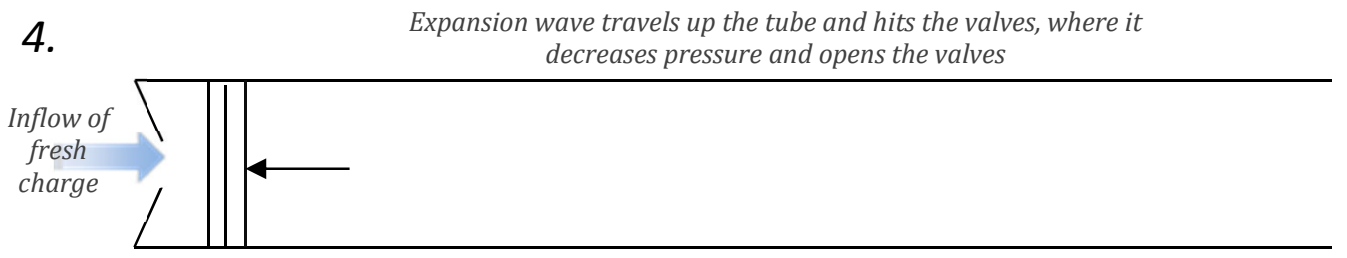

Figure 1-2b: Steps 3 and 4 of the pulsejet cycle.

As the fresh charge of fuel and air enters the combustion zone of the engine, the expansion wave that is incident on the valved end reflects as an expansion wave (because the open valve area is small and this can be effectively treated as a closed end). As shown in Fig. 1-2c, step 5, the expansion wave continues down the tube where, upon encountering the open end, it reflects as a compression wave (step 6, Fig. 1-2c). During this process, the expansion wave induces an inflow of air from the exhaust end. This inflow produces some negative thrust. However, the momentum of this inflow in the thrust direction is smaller than that of the outflow because the exhaust end behaves as a sink at this time, with gas entering radially from all directions. The axial momentum of the exhaust gases (behaving as a jet) is higher than the axial momentum of the inflow gases (exhibiting sink-flow), and this 
difference in momentum is the thrust production mechanism of the engine [11] [10]. A more detailed discussion of this thrust-production mechanism was presented by Mankbadi and Golubev [16].

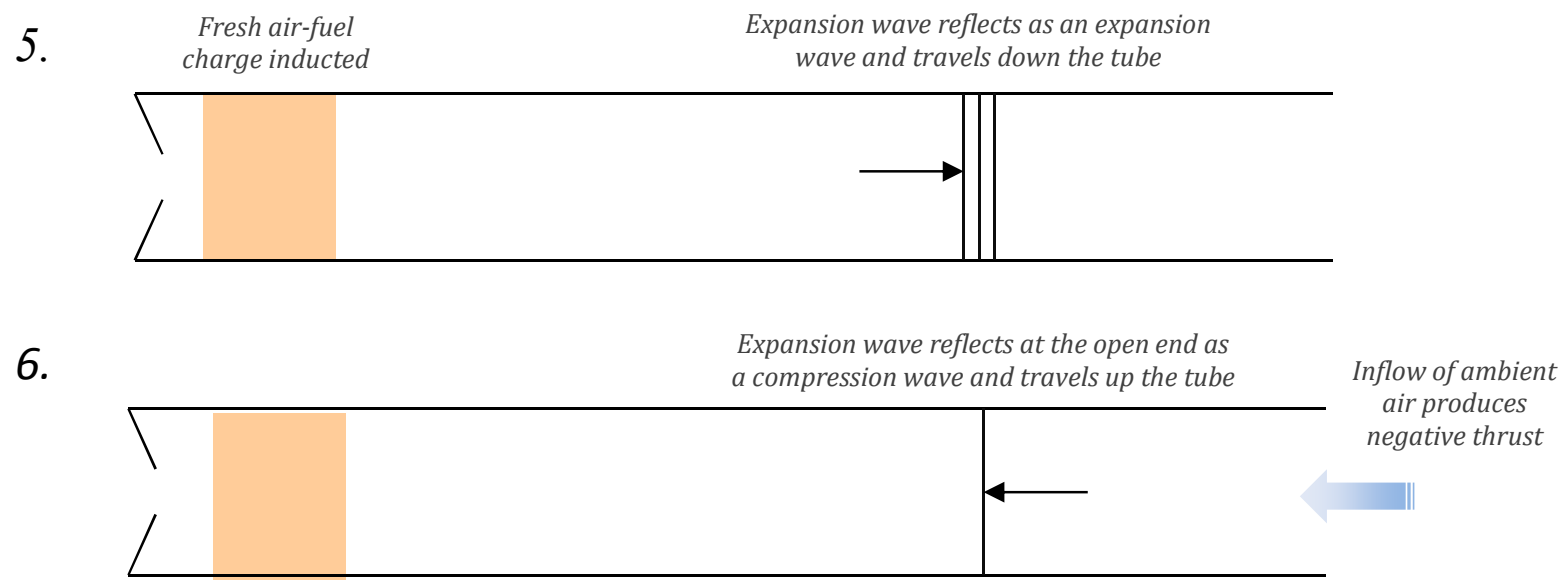

Figure 1-2c: Steps 5 and 6 of the pulsejet cycle.

At this point in the cycle, the engine is poised for another combustion event (step 7, Fig. 1-2d); the compression wave travelling up the tube carrying hot combustion products from the last combustion event slams into the fuel-air charge. The compression wave compresses the fuel-air charge and the hot gases ignite it. This causes another combustion event and another cycle (step 8, Fig. 1-2d). The process repeats indefinitely. 

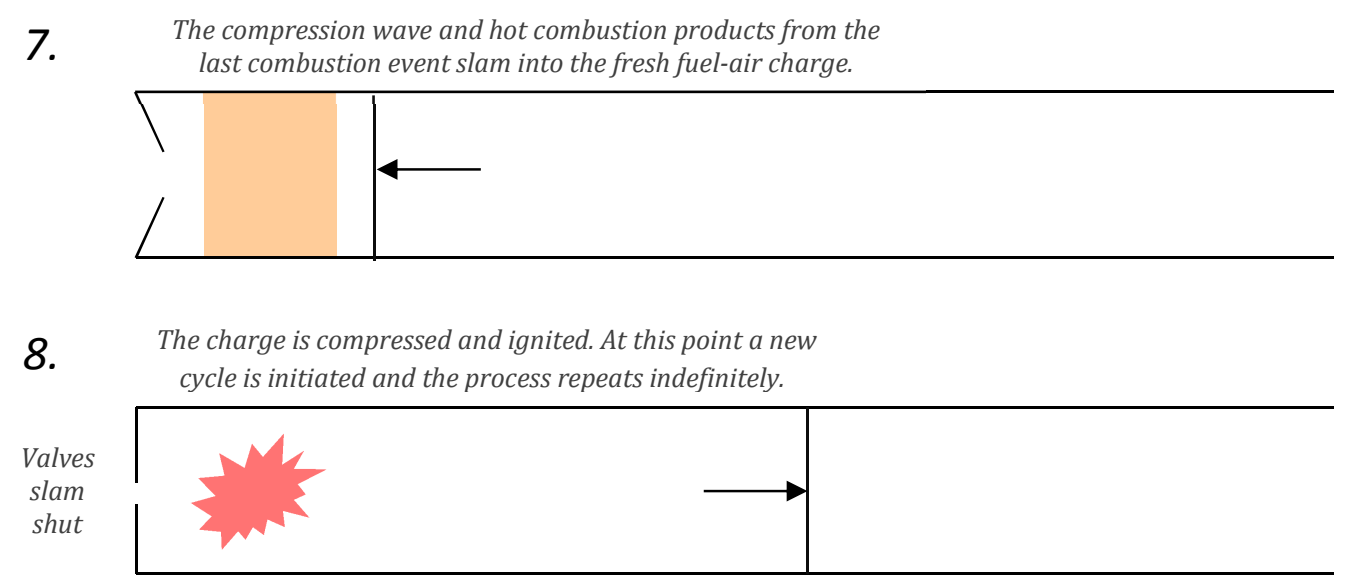

Figure 1-2d: Steps 7 and 8 of the pulsejet cycle.

As is evident from this description, a pulsejet has discontinuous operation and relies on intermittent combustion events. This intermittent operation is the fundamental cause of the high noise and vibration levels that characterize these engines.

\subsubsection{Acoustic Explanation}

While the preceding explanation is sufficient to explain the basic concept of the pulsejet, in reality the waves travel back and forth simultaneously and are not discrete, but rather smeared across the length of the engine due to their large wavelengths. This phenomenon can be described by the well-known standing $1 / 4$-wave tube in acoustics. As shown in Fig. 1-3, the engine behaves as a tube in which a standing wave resides, with the pressure node at the exhaust (open) end and the pressure anti-node at the valved end [17] [18]. This means that the pressure fluctuates sinusoidally at the valved end, and is constant (atmospheric) at the open end, with a variation in between that is $1 / 4$ of the wavelength corresponding to the frequency of operation. The frequency can be calculated as 


$$
f=\frac{c}{4 l}
$$

where $c$ is the speed of sound and $l$ is the length of the engine. The pressure fluctuation induces a velocity fluctuation that is $90^{\circ}$ out of phase with the driving pressure fluctuation. This implies that the valved end is a velocity node (so the velocity is zero there), and the open end is a velocity anti-node (so the velocity varies at the open end). While the assumption of zero velocity at the valved end is not strictly applicable throughout the cycle, any flow there is small compared to the flow at the exhaust end so this is an effective approximation.

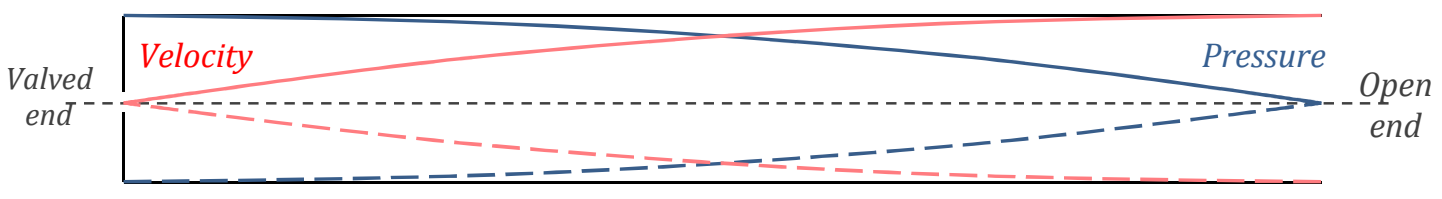

Figure 1-3: Pressure and velocity variations in a pulsejet engine.

\subsubsection{Valveless Engine}

While the mechanically valved pulsejet is the most widely known and has been the most widely used, another type of pulsejet saw significant development after World War II: the 'valveless' or 'aerovalved' type [19] [18]. This type of engine replaces the mechanical valves with a short length of pipe that provides a calibrated amount of resistance to the flow. Valveless engines are also characterized by a distinct, larger diameter combustion chamber between the inlet and exhaust tubes (Fig. 1-4). It has 
been suggested that that the valveless pulsejet works in a manner similar to its mechanically valved counterpart with the only difference being that some outflow through the inlet (which generates negative thrust) is tolerated during the high pressure part of the cycle [20] [18]. Air is inducted through the inlet pipe when the pressure is negative in the combustion chamber just as in a mechanically-valved pulsejet (fuel can be entrained using a carbureted intake or injected directly into the combustion chamber). After the combustion event when the pressure is higher, air also moves out of the combustion chamber through the inlet pipe. However, because the air in the inlet pipe immediately after the combustion event is colder than the air in the exhaust tube immediately after the combustion event (because the exhaust tube contains combustion products from the last cycle), the inlet pipe offers higher impedance to the high pressure gas than the exhaust pipe and it has been suggested that the gas prefers to flow out the exhaust pipe [20].

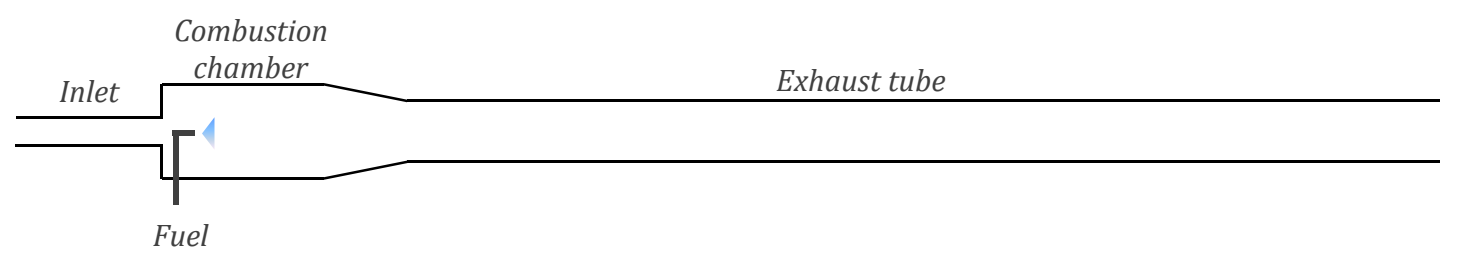

Figure 1-4: A valveless pulsejet engine.

Regardless of the higher impedance of the inlet pipe, any backflow through the inlet is undesirable and leads to negative thrust. Several arrangements have been proposed to correct or counter this reverse flow. Flow rectifiers, such as those suggested by Kentfield [21] and Foa [20] reverse the direction of the backward flow in order to 
make it produce positive thrust. Other strategies have focused on designing the inlet to behave as a diode [3] [22], so that it presents low resistance to flow moving into the combustion chamber and high resistance to flow moving out of the combustion chamber. "Permeability ratios" have been used to indicate the rate of forward flow (into the combustor) divided by the rate of backward flow (out of the combustor).

\subsection{Engineering Development}

\subsubsection{Early Technology}

The mysterious relationship between sound and fire has intrigued scientists for centuries. The first concept for an intermittent-combustion propulsive device was reportedly proposed in 1670 by Christiaan Huygens [23], who observed a drop in pressure to sub-atmospheric levels after rapid decompression of a vessel, and correctly conjectured that this effect could be used to refuel the device. A century later, Dr. Higgins discovered in 1777 [18] what is today commonly known as a 'Rijke Tube'; when a flame (or heated element) is held inside a vertical tube at a certain location (usually at $1 / 4$ of the tube length from the bottom), a strong acoustic tone is produced. This phenomenon was studied by many scientists and eventually explained by Lord Rayleigh as a thermo-acoustic instability [24]. The tone produced in a Rijke tube corresponds to the fundamental acoustic mode of the tube that hosts the flame.

Aside of the Rijke tube, other perplexing sonic phenomena were also observed. In the early $19^{\text {th }}$ century, glass blowers noticed that a sound is produced when a hot glass bulb is attached to a cool glass stem [18]. This phenomenon is known as the 'Sondhauss-tube' and was also explained by Lord Rayleigh [24]. The fact that these 
strange phenomena were well-understood by the end of the $19^{\text {th }}$ century indicated that the field of thermo-acoustics had matured to the point where useful devices could be conceived.

At the turn of the $20^{\text {th }}$ century, a number of designs for useful machines employing thermo-acoustic effects were patented in France. In 1906, Esnault-Pelterie patented a design for a machine for driving a turbine. It was essentially a tube with combustors on either side that were connected to the tube via flapper valves (Fig. 1-5) [19] [18]. A standing half-wave (with pressure node at the center of the tube) would create alternating vacuum and high pressure at each end of the tube. This vacuum would suck in fuel-air charges that would ignite and power the standing wave. At the center of the tube was a duct for channeling a steady stream of high pressure gas towards a turbine.

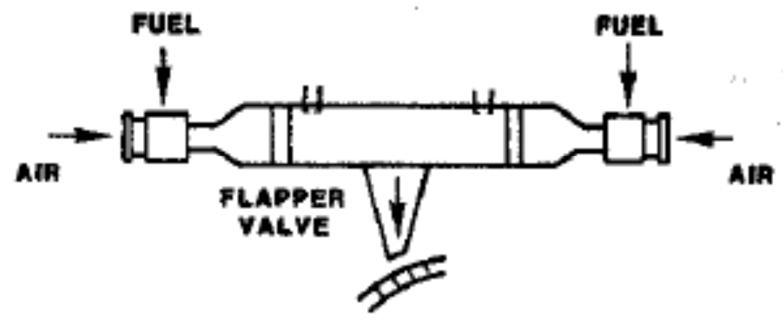

Figure 1-5: Esnault-Pelterie's 1906 patent (Adapted from ref. [19]).

The next year, French inventor Victor de Karavodine patented a device that is remarkably similar to the thrust-producing pulsejets employed in World War II. The only difference was that it was intended to drive a turbine [19]. It consisted of a combustion chamber with a spring loaded flapper valve to induct fuel and air. The 
combustion chamber was also connected to a long resonance tube, open/exhausting at the other end, that provided periodic swings of positive and negative pressure for the induction of fresh charge. In 1909, Marconnet revealed his design for a pulse combustor in which the mechanical valves are replaced by a short length of pipe to provide a calibrated amount of resistance to the flow so that pulsating operation can be sustained [19] (Fig. 1-6). Again, this design bears a striking similarity to the most recent valveless pulsejet designs. A curious feature of the design from that era is the flaring exhaust which today is known to be essential for maximizing performance in a valveless unit. Marconnet also proposed a mechanical-valved pulsejet design for thrust production in 1909 , which had all the basic features of the well-developed pulsejets that came many decades later [25] (Fig. 1-7). While designs were proposed by multiple inventors, it was Holzwarth who developed the first functional gas turbine based on thermo-acoustic effects, using a design similar to that of Karavodine [10].

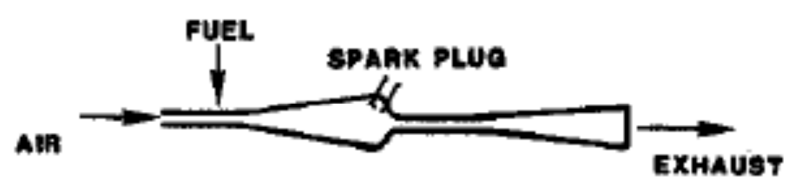

Figure 1-6: Marconnet's 1909 patent for a valveless pulsejet (Adapted from ref. [19]). 


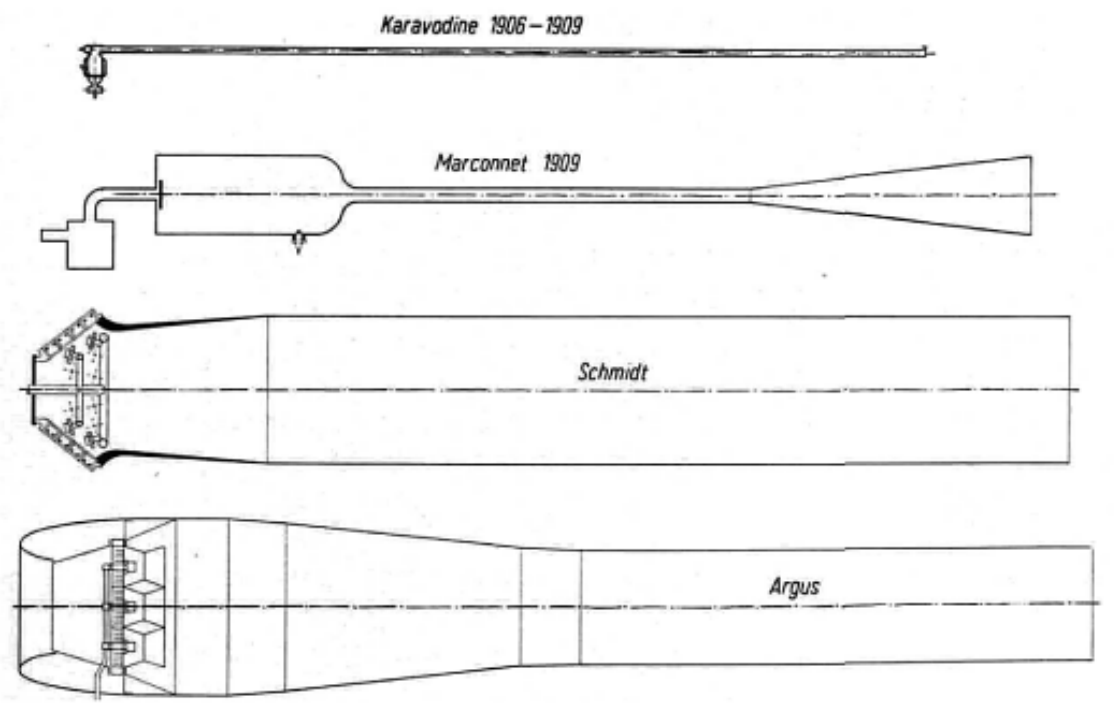

Figure 1-7: Evolution of the pulsejet (Adapted from ref. [25]).

Another active and important actor in the history of pulse combustion was F. H. Reysnt. Reynst was best known for the 'Reynst combustor' [18] [19] [17]. A Reynst combustor is geometrically similar to a Helmholtz resonator, i.e. it consists of a chamber connected to the atmosphere via a relatively small hole or neck. Fuel is supplied to the chamber which is ignited (initially by an external source, e.g. a spark plug), raising the pressure and temperature. This impulse sets the gas in the chamber into acoustic resonance. The resonant motion (with frequency close to the Helmholtz frequency [18]) is powered by periodic combustion events that take place every time fresh air enters the combustion chamber during the negative part of the cycle and reacts with the supplied fuel in the presence of hot remnants from the last combustion events. The Reynst combustor was a precursor to the commercially successful pulse combustors for domestic heating that have been extensively studied and marketed [26]. 


\subsubsection{Combustion Instability Theory}

At the end of the $19^{\text {th }}$ century Lord Rayleigh developed the theory for self-sustaining heat driven acoustic oscillations which is essential for understanding any wave engine-type device [24]. He showed that the criterion for achieving self-sustaining oscillations is that the heat release should occur in phase with the pressure. This can be written mathematically as [27] [18]

$$
\int_{V} \int_{0}^{T} p^{\prime}(\vec{x}, t) Q^{\prime}(\vec{x}, t) d t d V \geq \int_{V} \int_{0}^{T} \sum_{i} L_{i}(\vec{x}, t) d t d V
$$

In this expression $p^{\prime}$ is the unsteady component of the pressure, $Q^{\prime}$ is the unsteady component of the heat release, $\boldsymbol{x}$ is the location vector, $t$ is time, $T$ is time period, $V$ is the control volume, and $L_{i}$ is the $i^{\text {th }}$ wave energy dissipation process. The integral on the right hand side represents losses due to viscous dissipation, heat transfer, acoustic radiation, etc. The integral on the left hand side must be equal or greater than the integral on the right hand side in order to achieve resonance. To see why phase is important, consider a sinusoidal pressure variation where heat is released during the negative part of the pressure variation - i.e. out of phase with the pressure. In this case, the integral on the left hand side is negative and oscillations will be damped. On the other hand, if heat is released during the positive part of the pressure cycle, the integral on the left will be positive and the oscillation amplitude will increase.

\subsubsection{Developments in Nazi Germany during World War II}

While it was the French who first conceived and experimented with pulse combustion, it was the Germans who developed pulsejets for aeronautical use and 
utilized them on a mass scale during World War II as part of their V-weapons. The V1, RLM (Reich Air Ministry) designation: Fi-103, Luftwaffe (Air Force) designation: Flakzielgerat/FZG-76 (translated 'anti-aircraft aiming device-76' for deceiving Allied intelligence), was the world's first cruise missile and was powered by an Argus 109014 pulsejet (Fig. 1-8, Table 1-1). Over 30,000 V-1s were produced [1] and the pulsejet proved itself to be an effective and inexpensive powerplant.

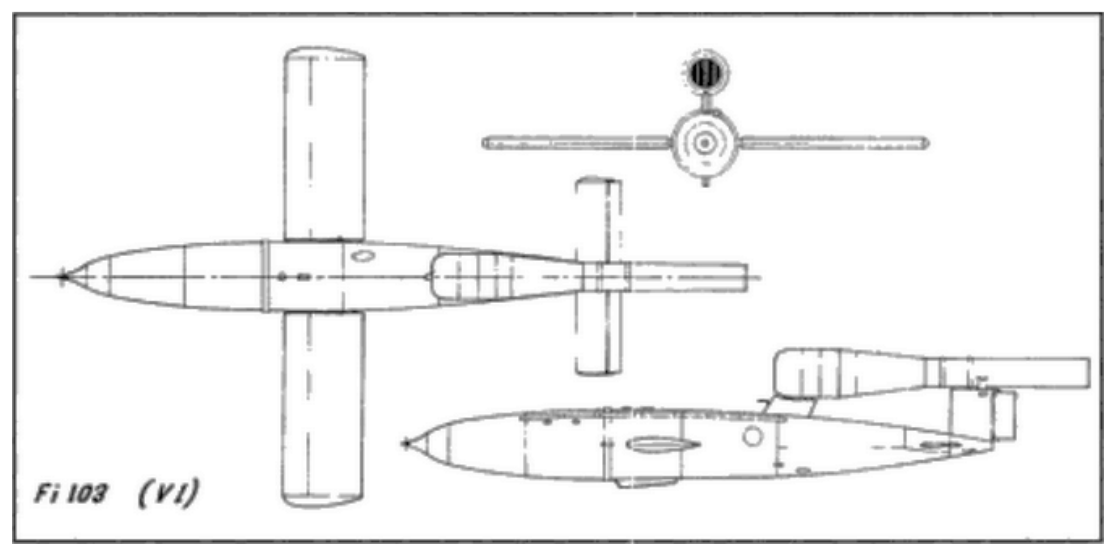

Figure 1-8: Schematic of the V-1 (Fi-103) (Adapted from ref. [1]).

Table 1-1: Fi-103 (V-1) Specifications [1].

\begin{tabular}{|c|c|c|}
\hline \multicolumn{3}{|c|}{ Fieseler Fi-103 (V-1) } \\
\hline Wingspan & \multicolumn{2}{|c|}{16 feet } \\
\hline Length & \multicolumn{2}{|c|}{22 feet $7-3 / 8$ in } \\
\hline Ceiling & \multicolumn{2}{|c|}{8,840 feet } \\
\hline Range & \multicolumn{2}{|c|}{$240 \mathrm{~km}$} \\
\hline Max. Operational Speed & \multicolumn{2}{|c|}{$645 \mathrm{~km} / \mathrm{h}$} \\
\hline \multirow[t]{3}{*}{ Powerplant } & \multicolumn{2}{|c|}{ Argus 109-014 Pulsejet } \\
\hline & Static Thrust & 770 lbs. \\
\hline & Firing Frequency & $47 \mathrm{~Hz}$ \\
\hline
\end{tabular}

Pulsejet research in Germany was started by Paul Schmidt in 1928 but his proposal to the RLM for a pulsejet-based cruise missile was rejected as 'technically dubious' 
[28]. However, several eminent scientists including Wernher von Braun ultimately backed the concept and the RLM agreed to sponsor it in 1935 [1]. Paul Schmidt had been successful in developing a working pulsejet. His first prototype, the SR 500, developed just less than $1000 \mathrm{lbf}$ thrust but was destroyed after 13 minutes of operation [25]. Curiously, the RLM also sponsored the Argus Motor Corporation to develop a pulsejet in 1939 under the direction of Fritz Gosslau, without informing them of Paul Schmidt's efforts. Therefore, Argus also independently developed a working pulsejet in 1939. Perhaps the RLM was very skeptical of this new technology, but they eventually informed both parties of each other's efforts in 1940 and encouraged them to collaborate.

The development was not straightforward and the Germans discovered that pulsejet engines can be tricky to test because of their unsteady nature. The basic engine was ready for airspeed tests in October, 1942. Thus began a series of strange events. Simultaneous tests were performed in a wind tunnel in Braunshweig and on an aircraft. The first problems arose when the wind tunnel tests showed a disastrous drop in thrust with increasing airspeed that was clearly contradicted by the flight tests. In addition, when stiffening collars were added to the pulsejet (which were expected to increase drag and reduce effective thrust), the flight test data showed an increase in effective thrust. These conflicting and confusing results caused the German Air Ministry to convene a session of the 'Working Committee on Jet Propulsion Units' a nationwide group of experts. 
In November, 1942, Dr. Volland discovered a flaw in the flight test measurement system that caused it to incorrectly record negative thrust as positive thrust. However, correcting the problem only made the disagreement between the flight test data and the wind tunnel tests larger. To make matters worse, Dr. Dietrich - a central figure in the program - had a disagreement with Dr. Gosslau and left the program after he had somehow convinced himself that the engine could not produce any useful thrust over $600 \mathrm{~km} / \mathrm{h}$.

After struggling with baffling results for months, Argus decided to test the engines on their own. They constructed a structure that housed a thrust stand with a blower (a wind tunnel of sorts). They also tested the engine on an open-air test stand. The results of these tests are best summarized in their own logs (January, 1943): 'With a blowing velocity of $300 \mathrm{~km} / \mathrm{h}$ the first test runs showed a thrust of $170 \mathrm{~kg}$ only. Running without blowing resulted in a thrust of $200 \mathrm{~kg}$ only. On the open-air test stand the same pulsejet showed the normal thrust of $320 \mathrm{~kg}$...The pulsejet measurements on the blower test stand were stopped due to the lack of coincidence with the measurements in the open, and following heavy damage caused by the tests to the brickwork.' [25] All these challenges were eventually overcome and the V-1 entered service on $13^{\text {th }}$ June, 1944. The Argus pulsejet eventually propelled the V-1 to speeds of over $790 \mathrm{~km} / \mathrm{h} \mathrm{[1]}$.

While Paul Schmidt and Dr. Gosslau's team understood the basic concept behind the pulsejet engine, they were mainly concerned with the development of a practical 
flight engine and as a result did not seem to devote much attention to a detailed quantitative, theoretical study of the engine. Such a study was undertaken by F. Shultz-Grunow at the Technical High School in Aachen, Germany in 1943-1944 [29] while the engine was being developed. Shultz-Grunow carried out an exhaustive study using the method of characteristics and a graphical solution method. Calculations were started assuming a pressure-rise due to a fresh charge in the combustion zone of the tube. This was assumed to be $1 / 7^{\text {th }}$ of the length of the tube next to the valves based on information provided by Paul Schmidt. The ensuing compression and rarefaction waves were plotted/solved for several different tube shapes (Fig. 1-9).
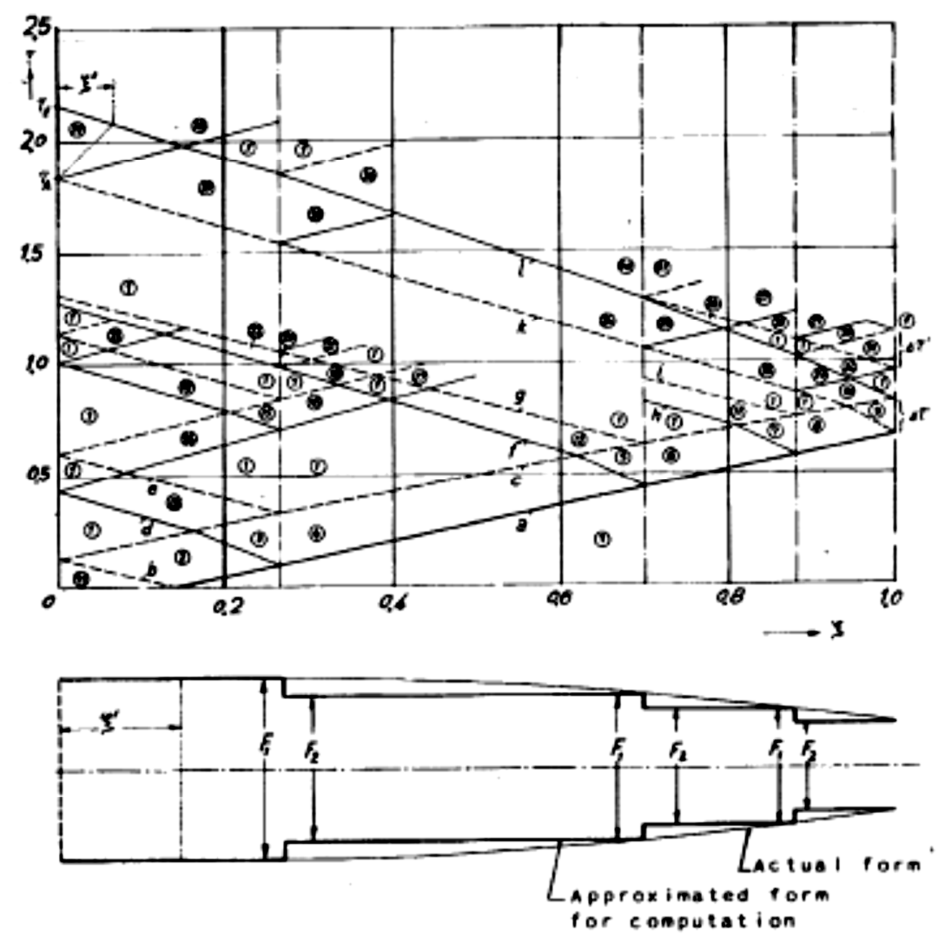

Figure 1-9: Method of characteristics solution for a particular pulsejet engine geometry (Adapted from ref. [29]). 
This method was useful for studying the effect of geometry and airspeed effects but relied heavily on knowledge of the initial pressure pulse profile. While the initial study assumed the charge to be an adiabatically compressed packet of gas that is suddenly allowed to expand, this was clearly not an accurate assumption. In the second part of Shultz-Grunow's investigation, he obtained from Paul Schmidt a profile of the pressure-time pulse and used it as an initial condition to predict the ensuing wave pattern. The pressure-time profile predicted using this strategy showed good agreement with the experimentally observed profile.

As one might expect, pulsejet research in Germany came to a standstill after the war ended in 1945. The V-1 and its powerplant were subsequently reverse-engineered and variants were developed by the United States (Republic-Ford JB-2 'Loon'), the Soviet Union (the 10Kh), and Japan (the Kawanishi Baika was in development when the war ended) [30]. However, the major research fronts, where the bulk of post-war development took place, were in France and the United States, which will be discussed next.

\subsubsection{Post-War Developments in France}

Considerable practical developments took place in France -especially with valveless pulsejets - after the war. The work was performed by SNECMA (Société nationale d'études et de construction de moteurs d'aviation) which was the national aero-engine manufacturer led by J. H. Bertin. These studies appear to be first methodical experimental studies aimed at understanding the fundamental operation of a valveless 
engine [3] [31]. SNECMA also produced a number of practical designs that powered experimental aircraft [23] [32].

The first of SNECMA's designs was the 3340 'Escopette' valveless pulsejet [31] (Fig. 1-10). Bertin and his colleagues instrumented and studied this engine extensively in the laboratory and charted the valveless pulsejet cycle in their papers too. In addition to very useful pressure and temperature measurements along the length of the engine, Bertin also examined the effect of different fuels and different doping agents in the fuels. It was found that changing the fuels and adding doping agents had no significant impact on the performance of the engine [3]. Therefore, it was concluded that the engine's performance was not limited by a chemical timescale but rather by an acoustic timescale.

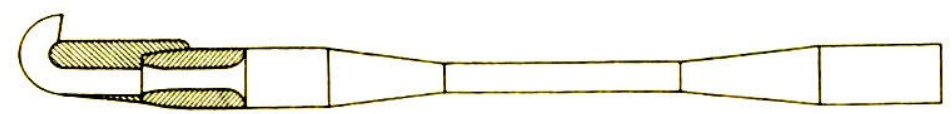

Figure 1-10: The SNECMA "Escopette" Valveless Engine (Adapted from ref. [20]).

Bertin also noted the problem of backflow from the inlet: after a combustion event, some flow exits the engine from the inlet creating negative thrust. He discussed inlet configurations for mitigating this problem. The idea was to incorporate a geometry that would allow air to pass with little resistance into the engine but offer high resistance to flow leaving the engine. At least one such inlet was proposed but it appears that no such geometries were utilized and it was decided that the best way to 
deal with the problem of backflow would be to turn the inlet around to utilize its thrust. The 'Escopette' was the first valveless engine to feature a U-shaped inlet that exploited inlet backflow for thrust generation. It could deliver $10 \mathrm{~kg}(22 \mathrm{lbs})$ of thrust with a Specific Fuel Consumption (SFC) of $1.8 \mathrm{~kg} / \mathrm{kg}$-hr. (1.8 lbs/lbs-hr.) and 4 of these pulsejets ( 2 under each wing) were subsequently used to successfully power a small airplane in 1950. Later versions incorporated 6 'Escopette' engines (Fig. 1-11).

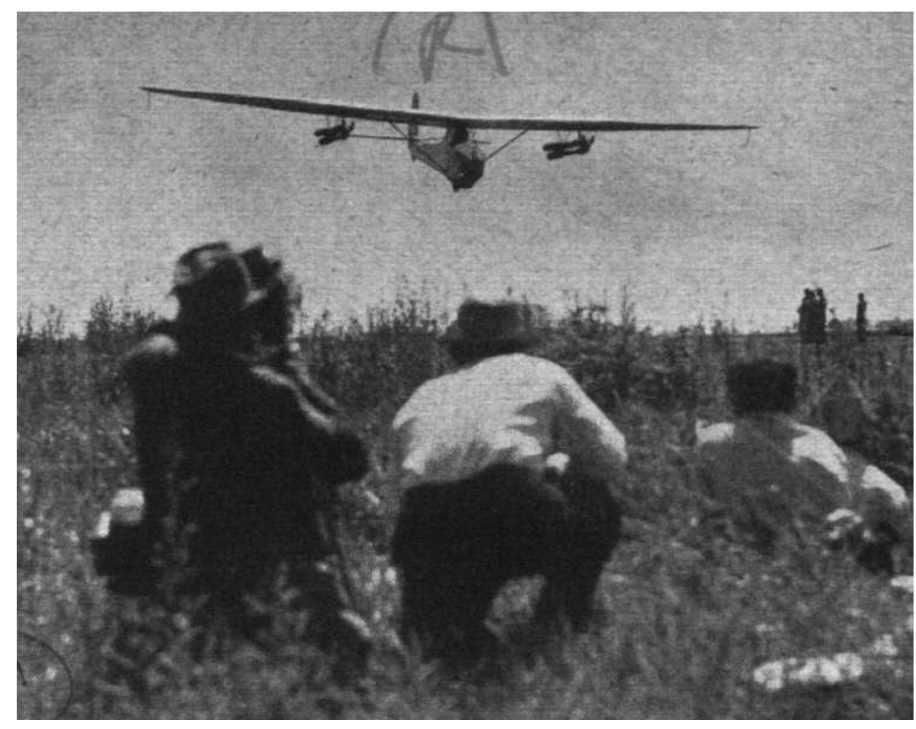

Figure 1-11: An 'Emouchet' sailplane powered by 6 'Ecsopette' engines, 1951 (Adapted from ref. [32]).

SNECMA later introduced another design, the 'Ecrevisse', in 1953 [19] (Fig. 1-12). This was a larger, more powerful design producing $30 \mathrm{~kg}(66 \mathrm{lbs}$.) of thrust at a more economical SFC of $1.2 \mathrm{~kg} / \mathrm{kg}$-hr. (1.2 lbs/lbs-hr.), while weighing $10 \mathrm{~kg}$ (22 lbs) [33]. This engine differed from the 'Escopette' in that the tailpipe was turned $180^{\circ}$ instead of the inlet. Later versions were reported to produce well over $100 \mathrm{lbs}$ of thrust. The 
'Ecrevisse' was used for a Vertical Take-Off and Landing (VTOL) platform [34] [35] and also powered the Dutch Aviolanda AT-21 target drone [36] [37].

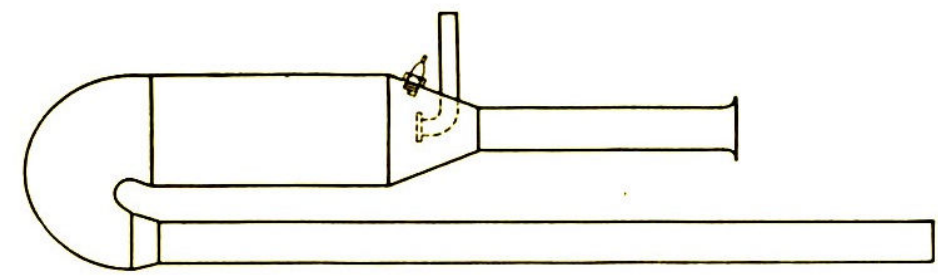

Figure 1-12: The larger SNECMA 'Ecrevisse' Valveless Engine (Adapted from ref. $[20])$.

In the early 1960s, SNECMA also worked with the Hiller Aircraft Corporation of the United States to develop pulsejets for VTOL applications. The Hiller Aircraft Corporation purchased several SNECMA patents and SNECMA also provided Hiller a $250+$ lbs. thrust pulsejet engine (the 'HS-1B pulse reactor') which was scaled by Hiller to develop smaller engines [2]. Under a subcontract from Hiller, SNECMA also developed and tested a number of unconventional geometries (with multiple inlets and exhaust tubes) specifically suited for VTOL aircraft [38]. While workable, it appears that these configurations were abandoned in favor of the more conventional, 'Ecrevisse'-type, configuration.

\subsubsection{Post-War Developments in the United States}

Pulsejet research in the United States began with the capture of a German V-1 engine which was shipped to Dayton, Ohio, and reverse-engineered to produce the PJ-31 [30] [39] powerplant for the JB-2 'Loon'. The ensuing experimentation also led to what is most likely the first functional valveless pulsejet, the 'Resojet', developed by 
W. Schubert [19] [40] in 1944 - the first working valveless pulsejet was therefore, most likely, made in the United States. Shortly thereafter, serious efforts began to study and develop pulsating combustion engines for multiple applications including direct aircraft propulsion and tip-jet helicopters under a large government-sponsored multi-institutional program codenamed 'Project Squid'.

Several tests of the PJ-31 engine were conducted by New York University starting in 1947 [41] under Project Squid. The goal was to instrument the engine to acquire interior flame imagery and temperature and pressure data in order develop a theoretical model for the engine. A valveless pulsejet study was also undertaken by J. G. Logan at Cornell Aeronautical Labs also as part of Project Squid [42] [4]. Logan studied many different valveless configurations for a potential tip-jet helicopter. These differed from conventional pulsejets in that the intake pointed sideways (Fig. 1-13). The idea was that such an engine, embedded in the rotor, would draw air through the rotor so as to make use of centrifugal compression to increase air mass flow and, therefore, power. The engines tested in this study were in the $0.5-40 \mathrm{lbs}$. thrust range and thus much smaller than the engines developed by SNECMA and later by the Hiller Aircraft Corporation (discussed later). Logan pointed out that the engines were very sensitive to changes in geometry and also to changes in the type of fuel. This sensitivity to fuel is not see in studies at SNECMA and Hiller but it is important to note that those were larger engines. The engines tested by Logan also had much shorter tailpipes (length-to-diameter, L/D, of approximately 10-15) than those developed by SNECMA and Hiller. These differences are the likely cause of the 
sensitivity to fuel type. However, the minimum SFC reported by Logan was $1.5 \mathrm{lbs}-$ $\mathrm{hr} / \mathrm{lbs}$, which is comparable to values reported by Hiller (1.8 lbs-hr/lbs). Later studies by Russo and Logan [43] utilized valveless pulsejets with forward facing inlets to exploit ram pressure when tip-mounted. These engines were tested on a 10 -foot whirling arm to simulate a helicopter rotor. The SFC of these engines was much higher ( $7 \mathrm{lbs}-\mathrm{hr} / \mathrm{lbs})$ than the earlier side-inlet engines. It is important to note that the exhaust lengths for these new engines were much smaller - the exhaust L/D was as low as 4 - and this unusually stubby geometry was the likely cause of the poor efficiency. It was shown, however, that pulsejets are more economical than ramjets in the speed range of interest to tip-jets.

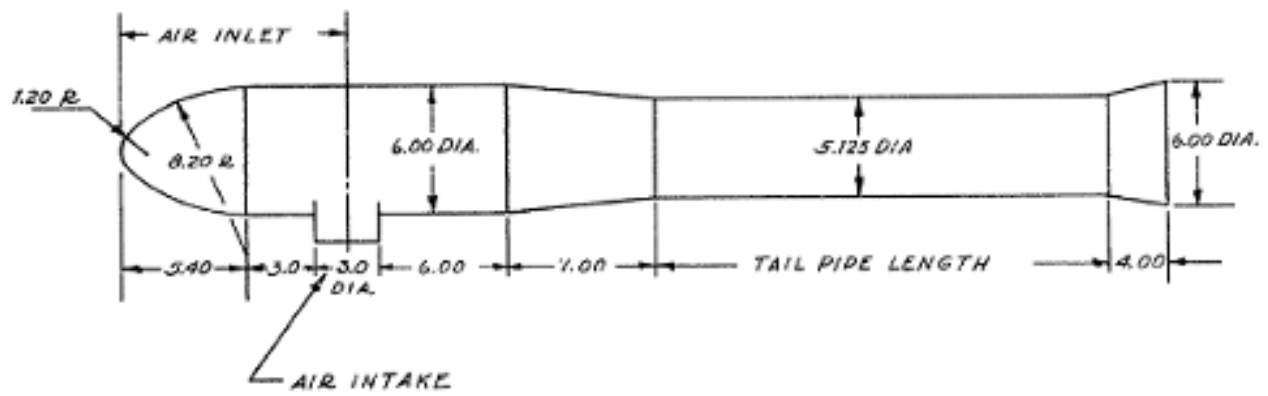

Figure 1-13: Pulsejet studied by Logan for tip-jet applications (Adapted from ref. [4]).

Arguably the most comprehensive development effort ever directed towards valveless pulsejets was by the Hiller Aircraft Corporation in the early 1960s. Hiller was assisted by SNECMA [2] which had significant prior experience in this field. Under government contracts, Hiller studied pulsejets that ranged from 2 to over $250 \mathrm{lbs}$. of thrust under the supervision of R. M. Lockwood [2] and later J. R. Cloyd [44], producing some of the most effective valveless designs to date. The goal was to 
develop a powerplant suitable for direct-lift/VTOL applications and pulsejets were attractive due to their high thrust-to-weight ratio, simplicity, and competitive SFC [45].

The Hiller Aircraft Corporation also experimented and championed the use of 'augmenters' for pulsejets [2] [46]. Augmenters are short lengths of tube approximately twice the diameter of the inlet and exhaust tubes that are attached at the exit as shown in Fig. 1-14 and promote entrainment of additional outside air into the exhaust stream. The result is that a larger amount of air is pumped but at a lower average velocity. This increases the thrust greatly - by as much as 2.4 times - in a way that is similar to bypass in a turbofan engine. Thrust-to-weight ratios as high as 12 have been achieved using augmentors [45]. Thus, adding carefully designed tubes to a valveless engine doubles thrust [47] [48] and halves SFC.

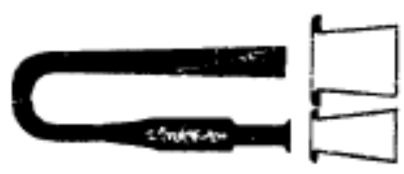

Figure 1-14: Augmenters for a valveless pulsejet engine (Adapted from ref. [2]).

Hiller presented results for several valveless pulsejet designs. Testing began on an engine delivered by SNECMA, the HS-1B. This was a fairly large engine, with a combustion chamber diameter of 9.1 inches, a total length of approximately 15 feet (but 6-7 feet lengthwise when folded), a maximum unaugmented thrust of $280 \mathrm{lbs}$., and an SFC of 2.0 (SFC of 1.0 with augmenters). The Hiller Corporation developed 
several other engines based on the HS-1B by essentially scaling down the dimensions. Among these engines, the most developed and successful was the HH5.25" series (Fig. 13). The HH-5.25" had a combustion chamber diameter of 5.25", a total length of 7.5 feet (approximately 3-4 feet when folded), an SFC of 1.8 (0.87 with augmenters), providing an unaugmented thrust of $76 \mathrm{lbs}$. for a weight of $11 \mathrm{lbs}$ $[2]$.

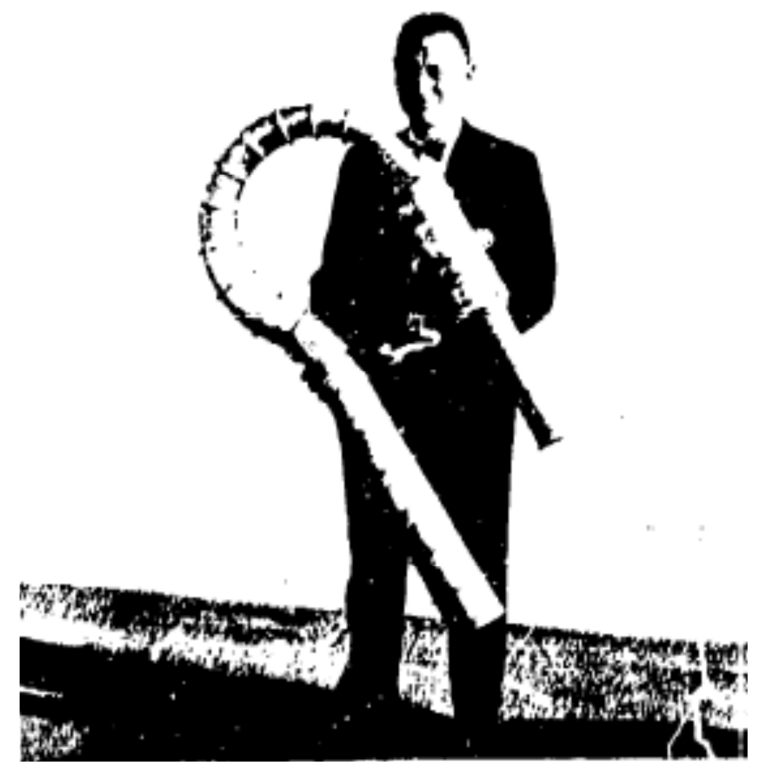

Figure 1-15: The Hiller/Lockwood HH-5.25" series engine. Total thrust 76 lbs., weight 11 lbs. (Adapted from ref. [2]).

Hiller Inc. studied engines on a wide range of scales and the data show that larger engines are more efficient. Smaller engines in the vicinity of $20 \mathrm{lbs}$. thrust can also produce high thrust-to-weight ratios (as high as 8.5 was demonstrated, and as high as 12 was deemed possible even without augmentation) but the SFC is almost twice that of larger engines like the HH-5.25" [44]. The smaller engines were run on propane 
and gasoline with essentially the same performance. However, like SNECMA, they also pointed out that the engines are extremely sensitive to the fuel supply system. The location and type of fuel injector was critical for good performance. It should also be mentioned that the most developed HH-5.25" series fuel system had a constant supply pressure which was varied (throttled) between 6 and 10 psig. This allowed the fuel flow to stop when the chamber was at high pressure (maximum pressure in the chamber was $30 \mathrm{psig}$ ).

\subsection{Scientific Studies}

\subsubsection{Analytical - Valved Pulsejets}

In spite of the fact that the pulsejet has existed for nearly as long as the gas turbine, there is no comprehensive theory for its performance that can be used in design. While good progress has been made in identifying the general phenomena responsible for resonant operation and the mechanism of thrust production, these ideas have not yet come together to produce an all-encompassing theory. As a result, pulsejet design is largely practiced using some established rules of thumb.

The first purely analytical approach to modeling pulsejet behavior appears to have been attempted as part of a report on jet propulsion concepts overseen by H. S. Tsien at the Daniel Guggenheim Aeronautical Laboratory (Caltech) in 1946 [49], where pulsejet research started as part of the war effort. In this analysis, the air was assumed to go through the process of valve intake (where a pressure drop was encountered), constant-volume heat addition, and then a discharge assuming isentropic expansion. The authors admitted the analysis was simple, but it permitted some performance 
estimates. The analysis indicated that the SFC increases with flight Mach number and decreases with increasing combustion-induced pressure rise.

In a more comprehensive analytical approach along similar lines, Foa [20] calculated the performance of an ideal pulsejet using a rather clever entropy method. Foa derived an expression for the efficiency of a thrust generator that only depends upon the entropy accrued by the fluid between the freestream and engine exit station. All processes that the fluid undergoes within an engine - expansion through a turbine, combustion, etc. -are represented as entropy changes. This idea is used to derive an expression that predicts the performance of a thrust generator without any other knowledge of the individual processes.

For the pulsejet, Foa assumed that the air undergoes two processes before arriving at the exit station: induction through the valves (which could cause a pressure drop) and a heat addition process. For an ideal pulsejet, which does not induce any pressure drop across the valves and expands the gas isentropically through the exhaust in an intermittent square-wave-fashion, he showed that the performance (efficiency) approaches that of a ramjet as flight Mach number increases regardless of the combustion characteristics. This analysis makes practical and necessary simplifying assumptions but it is unclear if the effect of negative momentum due to backflow is accounted for. The momentum associated with exhaust backflow was also neglected by Erickson and Zinn [10] but experiments have shown that negative thrust in a 
pulsejet can be quite significant. Therefore, more accurate treatment of exhaust backflow [11] seems warranted.

While using traditional thermodynamic methods to analyze pulsejets was a good start, acoustic treatments that naturally account for backflow appear necessary. Even during World War II, the British were quick to note that the operating frequency of the V-1 engine $(47 \mathrm{~Hz}$ [1]) was close to that of an acoustic quarter-wave tube of similar dimensions and acoustic theories were entertained in the United States from the very early stages of development [39].

In 1965, Tharratt [50] used an acoustic approach to describe the behavior of the gas in a pulsejet. The equations essentially treated the pulsejet as an acoustic quarter-wave tube, and Tharratt also incorporated non-linear effects due to high amplitudes. In another important step, he identified that the oscillation will be damped due to energy transfer to the atmosphere at the open end (which is well-known as 'radiation impedance' in acoustics), and that the energy required to drive the ideal pulsejet will have to overcome this energy lost to the atmosphere. This methodology, unlike prior 'conventional' ones, correctly captured the acoustic, oscillating nature of the pulsejet. While the analysis of Tharratt is comprehensive and correctly captures the essence of ideal pulsejet operation, the final step, his method of calculating thrust, deserves some attention (scrutiny). Tharratt calculates the total thrust by integrating the pressure at the closed (valved) end over time (and unit surface area). With this method, any low amplitude pressure wave, i.e. an acoustic wave, will be sinusoidal and therefore 
integrate to zero and produce zero thrust. This, however, is not true, since acoustic resonators excited by acoustic waves have been shown to produce thrust. A flow exiting a straight duct has all its momentum in the axial momentum, whereas a flow being sucked into a duct behaves as a sink and has little axial momentum (Fig. 1-16). This difference in momentum can produce positive thrust [10] [16].

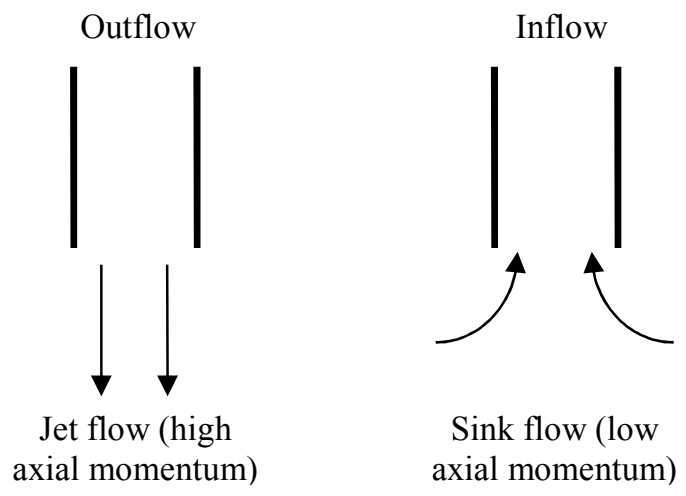

Figure 1-16: Momentum difference between outflow and inflow produces net thrust.

In Tharratt's analysis, as the pressure amplitude rises and non-linear effects start to become more important, the positive part of the pressure swing becomes disproportionately stronger and the integral of pressure over time (thrust) becomes non-zero. As a result, the SFC approaches infinity at low pressure amplitudes and tends to a low value at high amplitude. Tharratt's method relies on the non-linear behavior of the pressure variation to produce thrust, and while the Guggenheim Aeronautical Lab [49], Foa [20], and Erickson and Zinn [10] did not give enough importance to the momentum due to backflow, Tharratt [50] may have given it too much importance. 
More recent work by Travis et al. in 2006 [51] calculated the fundamental acoustic frequency of a 50-cm long valved pulsejet. They accounted for the area increase due to the combustion chamber, the opening and closing of mechanical valves (as a loss of potential energy because valve opening does not allow the gas to be compressed or expanded), and the temperature distribution. They showed good agreement between experiment and acoustic equations: they predicted an operating frequency of $225 \mathrm{~Hz}$ whereas the actual operating frequency was $232 \mathrm{~Hz}$.

\subsubsection{Analytical - Valveless Pulsejets}

Unlike valved pulsejets, valveless pulsejets have not undergone as much analytical assault. An acoustic treatment should be more natural for valveless pulsejets because they are not subject to impulsive phenomena associated with the openings and closings of mechanical valves.

In 1987, Smith [52] suggested that a valveless pulsejet could be modeled as the combination of a Helmholtz resonator (the combustion chamber and inlet pipe) and a quarter-wave tube (the exhaust pipe) although no quantitative results based on this notion were presented. Zheng et al. [53] [54] followed a similar line proposing that the frequency of a valveless pulsejet is the average of the natural frequency of a Helmholtz resonator (represented by the combustion chamber and the inlet tube, Geometry 1 in Fig. 1-17) and the natural frequency of the combustion chamber coupled with the tailpipe (Geometry 2 in Fig. 1-17). 


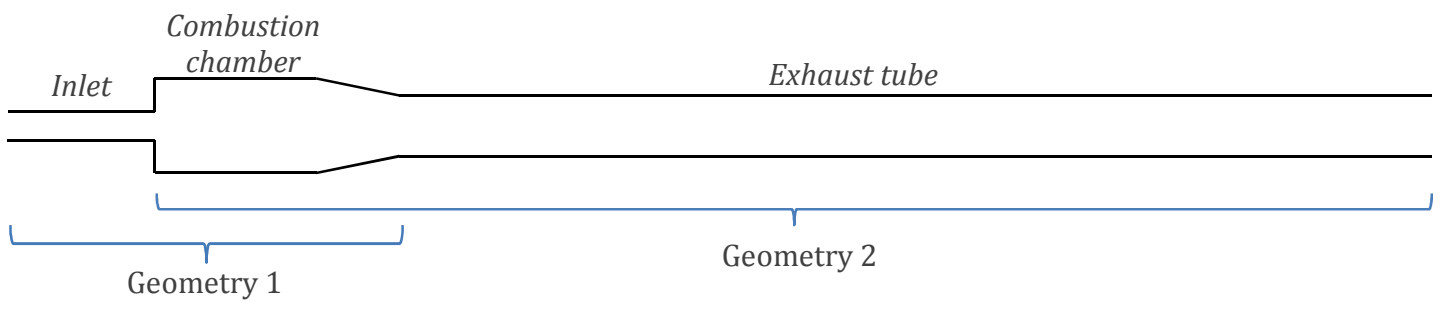

Figure 1-17: Geometries for frequency calculation method of Zheng et al. [53]

The expression for the frequency of Geometry $1\left(f_{1}\right)$, a Helmholtz resonator, is wellknown [55]:

$$
f_{1}=\frac{c}{2 \pi} \sqrt{\frac{S}{V L}}
$$

In this expression, $c$ is the speed of sound, $S$ is the surface area of the neck (inlet), $L$ is the length of the neck (inlet), and $V$ is the volume of the combustion chamber. The natural frequency of Geometry $2\left(f_{2}\right)$ is not as straight-forward because the length of the exhaust pipe length is comparable to the acoustic wavelength and has resonant behavior on its own. In other words, the exhaust/tailpipe is long, and so accommodates wave motion, and so does not behave as a simple mass. The frequency can be calculated using the following implicit equation [55]:

$$
\frac{2 \pi f_{2} V}{S c} \tan \left(\frac{2 \pi f_{2} L}{c}\right)=1
$$

Zheng et al. [53] conjectured that the frequency of operation of a valveless pulsejet is the mean of $f_{1}$ and $f_{2}$. They then experimented with a $50-\mathrm{cm}$ nominal length pulsejet 
changing the exhaust length, inlet length, and inlet diameter, to determine the effects of these geometrical parameters on operating frequency. The frequencies they observed were within $5 \%$ of those predicted using their conjecture. This was encouraging for acoustic theories of pulsejet operation but this thesis will show that the success of this conjecture was coincidental.

\subsubsection{Numerical and Experimental Studies}

The first methodical effort to analyze a pulsejet was likely that of Shultz-Grunow [29] in 1944 who used the method of characteristics to solve for the pressure wave patterns in an Argus pulsejet engine, as has been discussed in section 1.C.ii. Since then, other studies have also taken this approach, some as part of Project Squid [39] [41]. While the method of characteristics can provide useful and realistic results, a disadvantage is that it requires inputs derived from experimental data. MacDonald [39] identified four inputs required for a method of characteristics approach: 1) Engine dimensions, 2) Empirical constants describing the intake/valve boundary condition, 3) Fuel flow rate, and 4) Combustion constants.

The method of characteristics was also applied by Ponizy and Wojcicki [56] to a valveless pulsejet using an experimentally derived heat release model. Ponizy and Wojcicki instrumented a 2-meter valveless pulsejet to obtain pressure traces and the heat release profile in the combustion chamber using chemi-luminescence. The heat release was subsequently used as an input to a method of characteristics solver, which resulted in decent qualitative agreement with experimental results for pressure and temperature variations. 
A few years later, Smith [52] published the results of another application of the method of characteristics with an integrated combustion model to a valveless pulsejet. The parameters of the simulation (e.g. turbulent mixing length, Stanton number) were calibrated against experimental data, which was available for at least three different engines (one being an $\mathrm{HH}-1 \mathrm{M}$ pulsejet developed by Hiller [44]). Good quantitative agreement was obtained between the numerical model and experimental data for the combustion chamber pressure-time profile after calibration (of simulation parameters). Smith proceeded to use the model to investigate the effect of timed injection or 'synchronous injection' of fuel into the engine, whereby fuel is injected into the engine in discrete, timed pulses at the most advantageous point in the cycle. The results indicated that the SFC could be reduced by approximately $50 \%$. In particular, the minimum SFC of a Saunders-Roe pulsejet was predicted to go from $2.17 \mathrm{lbs} / \mathrm{lbf}-\mathrm{hr}$ to $1.18 \mathrm{lbs} / \mathrm{lbf}-\mathrm{hr}$, with the potential for even more reduction. Such dramatic reductions in fuel consumption were also echoed in a more recent experimental study by Offord et al. [57]

Another method of characteristics study was conducted by Olorunmaiye and Kentfield [58]. They assumed one-dimensional flow in the inlet and tailpipe of a valveless pulsejet but uniform conditions in the combustion chamber. The latter is a reasonable assumption given the large cross-sectional area of the combustion chamber compared with the inlet and tailpipe. The combustion model assumed complete oxidation of the fuel and, like the previous method of characteristics 
simulations, it could be tuned to produce results consistent with experimental data. An important conclusion of this study was that the upper and lower throttle limits of the engine are due to the lean-ness and rich-ness of the fuel-air mixture.

There are other studies that have also applied the method of characteristics to simulate pulse combustors [59] [60], but like almost all numerical models, given that a significant amount of information needs to be collected experimentally before the model can be used to make an assessment, the method of characteristics cannot be used a priori in the design of an engine. It is useful, however, in understanding the wave processes and determining the effect of flight condition and design changes.

As computational power increased over the years, the method of characteristics gave way to other numerical simulation techniques. Erickson and Zinn [10] [61] developed a quasi one-dimensional model to simulate a valved pulsejet engine. They solved onedimensional conservation equations (mass, momentum, energy) over a linear grid along the length of the engine. They also incorporated a mixing model (Linear Eddy Mixing) to account for turbulence and chemical kinetic modelling to account for the combustion process (CHEMKIN [62]). After validating their model with some experimental data, they studied the effectiveness of different heat release models and then the effect of heat release timing on pulsejet performance. As expected, they found that the thrust produced by a pulsejet is quite sensitive to the timing of the heat release (as explained in section 1.C.i., heat release should coincide with periods of maximum pressure to maximize the oscillation strength) and also showed that a 
change in heat release timing can affect the frequency of operation. The latter effect has also been observed experimentally [57] [63].

Mason, Miller, and Taylor [64] also performed a similar numerical simulation of a valveless pulsejet. They solved a set of discretized one-dimensional conservation equations and modeled combustion with a single step Arrhenius rate equation. Eexperimental studies using $\mathrm{OH}^{*}$ chemiluminescence revealed that the combustion process - and thus the heat release - is not discrete or instantaneous. Rather, it is a continuous, oscillating process. The heat release was plotted with the pressure oscillations to show that they were not exactly in phase (but were close) for the particular engine under study ${ }^{1}$. The numerical model was validated against the experimental data, and it was used to chart pathlines for discrete fluid elements passing through the engine. The authors identified two different types of flows: primary and secondary (Fig. 1-18). Primary flow refers to fluid elements that enter the combustion chamber through the inlet, undergo chemical reaction, and are exhausted out the tailpipe over the course of several cycles. This is the flow that is used to sustain chemical reaction and the cycle. The larger secondary flow is flow refers to fluid elements that enter the inlet or tailpipe but do not make it to the combustion chamber before being ejected during the outflow phase of the cycle. The authors found that most of the work is done on the secondary flow and it is therefore the most important contributor to pressure-gain performance (and also, thrust).

\footnotetext{
${ }^{1}$ At this point it is interesting to note that the heat release profile obtained by Mason et. al. is similar to that obtained by Tang et al. [108] for a valved pulse combustor and Saito et al. [78] for a valveless pulse combustor. However, the profile obtained by Ponizy and Wojcicki [56] for a valveless pulsejet was not as smooth or continuous. Therefore, the nature of this profile may be a property of the particular engine and/or fuel injection system
} 


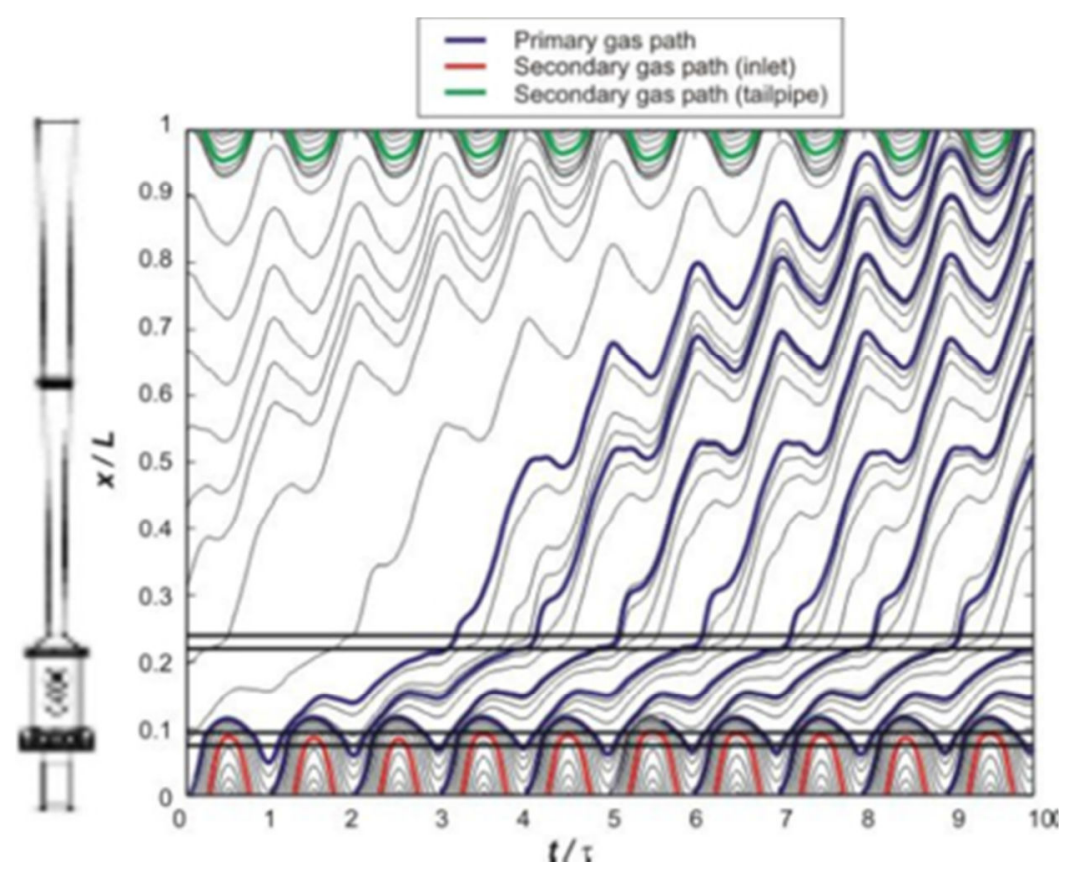

Figure 1-18: Primary and secondary gas flow paths in a valveless pulsejet (Adapted from ref. [64]).

In a comprehensive experimental and numerical study, a research group at North Carolina State University, Geng et al. [11] studied a 50-cm long valved pulsejet engine. Measurements included pressure and temperature at three axial locations, instantaneous thrust, $\mathrm{CH}^{*}$ chemiluminescence for heat release, Laser Doppler Velocimetry (LDV) for exhaust velocity, and high-speed imaging to infer valve opening and closing. The results illustrated the oscillating nature of pressure along the length of the engine. It is interesting to note that the pressure was almost sinusoidal at the chamber, but experienced significant distortion at the exhaust with a'double-peak' which was also reflected in the instantaneous thrust measurements. The 
measurements also showed a large amount of negative thrust during the inflow part of the cycle which was also consistent with the trends captured by LDV measurements.

The experimental studies were used to validate the results of a three-dimensional numerical solution to the compressible, viscous, Reynolds-Averaged Navier-Stokes

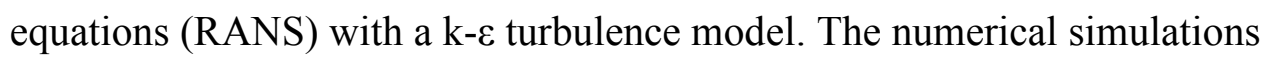
successfully resolved the mode of operation and the frequency of operation to within $10 \%$. Key trends like the shape of the pressure pulse were captured correctly, although somewhat larger discrepancies were observed in temperature and minimum pressure values. Overall, the model was good enough to provide very useful insight into the operation of a pulsejet engine. Contour plots of pressure, temperature, velocity, and fuel mass fraction were particularly valuable because they delineate the state of the gas along the engine at different stages of the cycle.

Geng et al. [65] were interested in pulse jets' potential as micro-engines so they also conducted a combined experimental/numerical study of a $15-\mathrm{cm}$ long pulsejet. An engine this small operates at very high frequencies $(1000+\mathrm{Hz})$ and needs to use Hydrogen fuel because the time-scale available for combustion is so small. Geng et. al. investigated different combinations of exhaust lengths, inlet lengths, and inlet cross-sectional areas. They found that shorter inlets permitted shorter exhaust lengths and that the frequency of operation was affected by total length and also the inlet area. A larger inlet area increased operating frequency and was explained later by the same group's Helmholtz resonator model. The authors also tried different inlet 
configurations, whereby the inlet was attached and oriented in different directions in order to make use of the thrust that the inlet generates. Successful operation was achieved with all inlet configurations, and the numerical model once again provided good (within 10\%) agreement with key experimental indicators (frequency, peak pressure). However, it is interesting to note that the 'double-peak' feature observed in the previous $50-\mathrm{cm}$ pulsejet study was also present in the $15 \mathrm{~cm}$ version. This feature was clearly visible in both pressure and thrust data (Fig. 1-19) and seen in both experiment and simulation. The authors conjectured that this was probably caused by wave reflections from within the combustor.

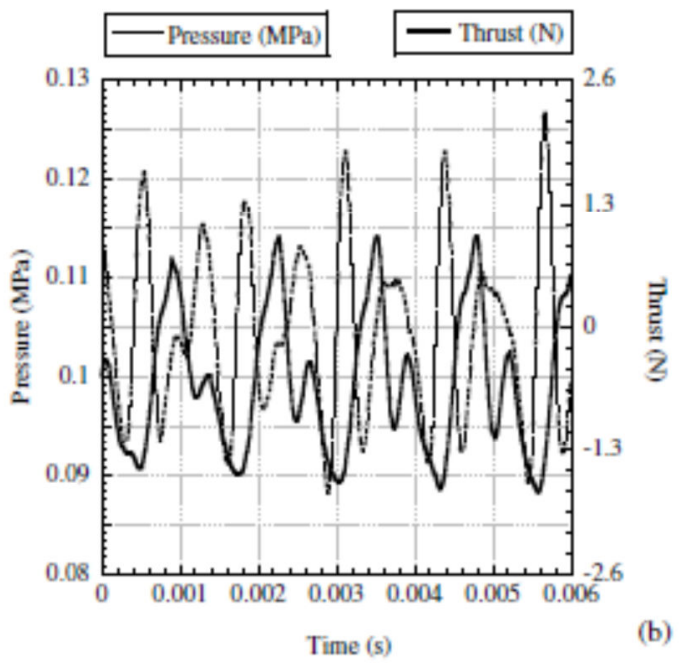

Figure 1-19: Multiple peaks observed in a 15-cm valveless pulsejet (Adapted from ref. [65]).

Pushing to even smaller dimensions, the same research group also constructed an 8$\mathrm{cm}$ long pulsejet, which is probably the smallest pulsejet ever tested [8]. Successful operation was achieved, producing a nominal thrust of about $1 \mathrm{~N}$ at a frequency of 
about $1000 \mathrm{~Hz}$ running on Hydrogen as fuel. Pressure and thrust measurements also showed the strange 'double peaks', which were conjectured to be an artifact of the thrust stand (since the resonant frequency of the thrust stand was only three times the operational frequency).

Wenxiang et al. [66] also performed a numerical investigation of a valveless pulsejet using a RANS approach. This study demonstrated the same broad operational characteristics suggested by other studies, but also predicted that the operating frequency increases non-linearly with tailpipe length. This is contrary to expectations based on models and other experimental studies. Since this numerical study was not validated against any experimental data, it is difficult to arrive at any definitive conclusions.

Pulsejets have long been proposed as replacements for conventional gas turbine combustors [17] [67] [6]. Stagnation pressure losses range from $4-8 \%$ in steady gas turbine combustors [7] which are manifested as a loss of power output and higher SFC. Replacing the combustor with a pulsed combustor (or pulsejet engine) could produce a stagnation pressure gain across the heat addition process, improving power output and lowering SFC. Calculations by Kentfield [6] suggest that such an arrangement could increase cycle efficiency by a few percent although the exact amount of improvement is a strong function of cycle pressure and temperature ratio. 
Kentfield, Rehman, and Cronje [68] developed a combustor for such an application and reported a stagnation pressure gain of $6 \%$. The combustor was small (2.875 in. combustion chamber diameter) relative to what would be required in a full-scale gas turbine so the authors undertook a study to determine the effect of physical size on pulse combustor performance. The authors studied the effects of ignition delay time, droplet evaporation time, mixing time, friction, and surface heat transfer. It was concluded that frictional and heat transfer effects are most responsible for scaling effects, and so a larger pulse combustor for full-scale application can be expected to achieve a pressure-gain up to twice that of the small-scale combustor.

These results are consistent with other studies showing that there is a very marked improvement in the performance (specific thrust and fuel consumption) of pulsejet engines as the physical size of the engine increases [69] [2]. These results make sense because increasing the physical size of an engine decreases its operational frequency $(f)$. Lower frequencies imply longer time per cycle and therefore more time for fuelair mixing and chemical reaction. Lower frequencies also imply lower frictional and heat transfer losses, which scale with $f^{1 / 2}$ in acoustic waves [70]. A larger engine also implies less wall surface area, or a smaller wall perimeter, per unit flow, which translates to less wall viscous effects.

More recently, Paxson and Dougherty [7] explored the use of a pulsejet and ejector assembly in a shroud as a gas turbine combustor while a numerical study of the assembly was conducted by Yungster, Paxson, and Perkins [12]. This Pulsejet- 
Ejector-Shroud (PES) assembly delivered a maximum stagnation pressure gain of $3.5 \%$ at a temperature ratio of nominally 2 (typical for gas turbines) while the rootmean-square unsteadiness in pressure at the combustor exit was approximately $4.5 \%$ of the total downstream pressure. They also pointed out that such a pulse combustor may lead to lower $\mathrm{NO}_{\mathrm{X}}$ formation. The potential emissions advantages of pulse combustion have also been pointed out by Putnam et al. [19], Zinn [71], and Hongo and Saito [72] - the latter measured $\mathrm{NO}_{\mathrm{X}}$ emissions from a gas-fired pulse combustor for residential heating. An important caveat pointed out by Paxson and Dougherty [7] is that implementing a pressure-gain combustor in a gas turbine will make it impossible to bleed air off the compressor and use it to cool the turbine. This poses a significant challenge as turbine cooling air remains a critical requirement in modern engines.

\subsubsection{Studies on Multiple-Engine Configurations}

The advantages of operating two pulsejets in anti-phase have been recognized for a long time [17] [73] [9]. This allows the unsteady nature of one engine (which causes serious noise and vibration problems) to be countered by the unsteady nature of the other (via destructive cancellation). There are also many applications of pulsejets requiring multiple engines and even arrays of engines (VTOL, distributed propulsion, etc.). Therefore, it is important to study how pulsejets behave in close proximity to one another, if there is any fixed phase relationship that develops between adjacent engines, and whether this phase relationship can be controlled (i.e. can they be made to work in- or out-of-phase). 
The French inventor, Esnault-Pelterie, who patented one of the first machines to utilize thermo-acoustic principles for useful work in 1906 (discussed in section 1.3.1) was well aware of the idea of a pulsejet (it had been proposed by his contemporary, Marconnet, also discussed in section 1.3.1). In 1910, Esnault-Pelterie patented a dual pulsejet configuration which would force them to work out-of-phase (anti-phase, Fig. 1-20) [19] [17]. In this configuration, the exhausts of two valved pulsejets were connected to a common chamber with an opening to the atmosphere. The principle of operation was explained by Reynst [17]: if the engines are analogous to acoustic quarter-wave tubes, the connecting chamber has to be a common pressure node for the engines which would only be possible if the engines operate out-of-phase. It should be noted, however, that such a configuration would be disastrous for thrust production because this chamber obstructs the high-speed, thrust-producing exhaust flow.

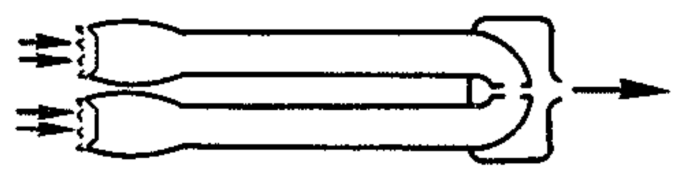

Figure 1-20: Anti-phase pulsejet configuration of Esnault-Pelterie (Adapted from ref. [19]).

This concept lay dormant until the 1970s, after which a number of applications for this concept came to light. It is reported that Briffa [74] [75] first successfully implemented the configuration in Fig. 1-20, followed by Kentfield [73]. Kentfield's apparatus consisted of two valveless pulsejets that were connected to each other via 
common chambers at the inlet and exhaust (Fig. 1-21). It was shown that this configuration produced anti-phase operation, but it was also shown that in order to obtain anti-phase operation, it was only necessary to have a common chamber at just the inlet or exhaust, i.e. connecting the engines via a chamber at only the inlets or exhausts was also enough to attain anti-phase operation - it was not necessary to have both chambers at the same time. The author did acknowledge that this arrangement is unacceptable for pressure-gain (and therefore, thrust) applications.

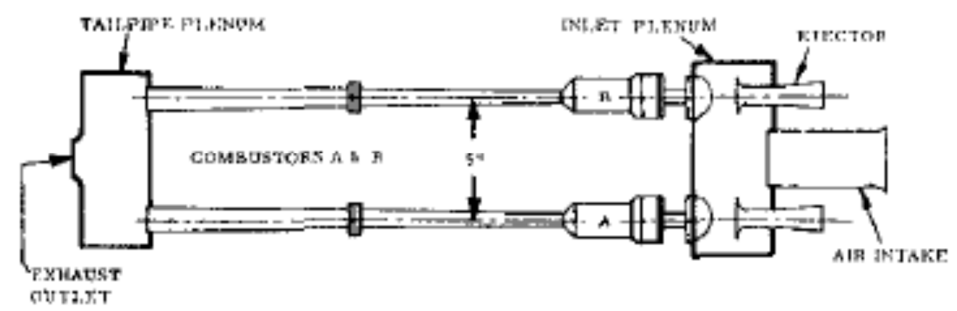

Figure 1-21: Anti-phase arrangement of Kentfield (Adapted from ref. [73])

This effect of such an arrangement was also noted by Lockwood [45] who observed that placing two engines in a common shroud can also lead to anti-phase operation. A shroud would essentially act as a large common chamber for the exhaust and/or inlet, leading to anti-phase operation. Lockwood [2] also studied how these engines behaved in close proximity to one another. Two HH-5.25" series engines (Fig. 1-15) were mounted close to one another (centerlines 14 inches apart) and the performance of two engines operating simultaneously was compared with the sum of the engines operating individually. No notable change in performance was recorded, suggesting that these engines can operate close to one another without interference. 
In a parallel study by Cloyd [44] at Hiller Inc., six valveless pulsejets were operated in a linear array with no per-engine performance change as compared with a single pulsejet operating in isolation. There was some performance change, however, with some rectangular arrangements. Most interestingly, this study also examined the effect of interconnecting pulsejets at their combustion chambers. It was found that when the combustion chambers were connected with short lengths of pipe, the engines became synchronized (i.e. they operated in-phase). This was also reported by Giammar and Putnam [76] who investigated the effect of connecting two similar pulsejets at their combustion chambers. Most of the connections caused the pulsejets to operate in phase, but they stumbled, fortuitously, upon one connection arrangement that produced anti-phase operation. As with most other studies, no explanation was given for this behavior.

Experimenting with different arrangements has produced both in-phase and out-ofphase operation but no common theory or design methodology capable of explaining all these results is available. This makes it difficult to explain the results or apply them to other engines in a predictable way.

While pulsejets have been studied by the aerospace sector for propulsion applications, they have also been studied for residential and industrial use as heaters and dryers. They are referred to as pulse combustors in these applications although the basic design of the devices developed for thrust production and heating is the same. The main qualitative difference between pulse combustors for heating purposes and those 
for propulsion is that the former have their tailpipes connected to a chamber before venting to the atmosphere (Fig. 1-22) [71] [77]. This chamber is called a 'decoupling chamber' and acts as a very effective acoustic muffler. Of course, this would be unacceptable for thrust production.

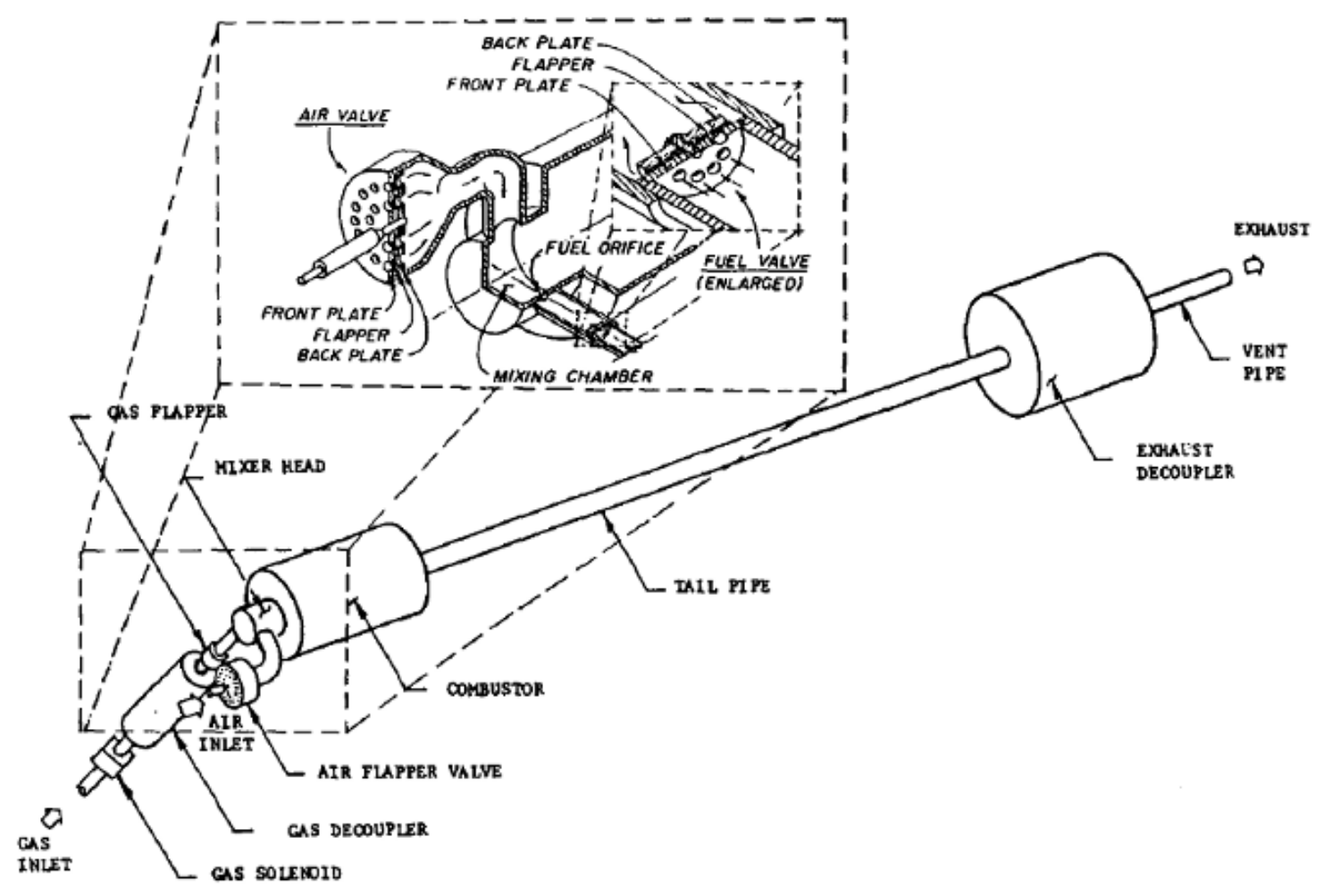

Figure 1-22: Pulse combustor for heating applications (Adapted from ref. [71]).

There have also been several successful attempts at anti-phasing pulse combustors in heating and drying applications by coupling the combustors at a common exhaust decoupling chamber. This is essentially the same geometry that Kentfield [73] investigated (Fig. 1-21) but these studies have also incorporated some numerical models to provide further insight. 
In the early 1990s, Hongo and Saito [9] [72] developed a pair of valveless pulse combustors that were coupled at their inlet and exhaust ends by common chambers. As expected, this produced anti-phase behavior. However, the authors also presented a numerical model of this behavior. The model was based on a Helmholtz resonator in which the chambers were treated as compressible volumes of gas and the inlet and tailpipe were treated as incompressible slugs (a lumped parameter analysis [15]). The model was simple but justified for heating applications because the combustor dimensions are generally smaller than those of thrust-producing pulsejets ${ }^{2}$.

Later (in 1993) Kazuo et al. [78] provided more measurements on what is probably the same apparatus developed by Hongo and Saito [9] [72]. Kazuo et al. [78] provided heat release rates obtained using $\mathrm{OH}^{*}$ chemiluminescence. The heat release rate was plotted with the combustion pressure. As expected, they were close in phase but the phase difference was found to be a function of equivalence ratio and not on the total mass flow rate. The strength of the oscillation is therefore strongly dependent on the equivalence ratio. This conclusion supports the numerical results of Olorunmaiye and Kentfield [58] which indicated that the upper and lower throttle limits are set by the rich-ness and lean-ness of the fuel-air mixture.

In an effort to reduce noise from pulse combustors, Inui et al. [79] proposed using multiple combustors. It was argued that for the same heat output, two smaller

\footnotetext{
${ }^{2}$ The dimensions of the device should be much smaller than the wavelength to justify a lumped parameter analysis. This is usually not the case in thrust-producing pulsejets
} 
combustors with one-half capacity each would be quieter than a single, larger combustor. However, two combustors running in isolation drift in- and out-of-phase, producing an undesirable beating effect. It was discovered that if the decoupling chambers of the two combustors (the two combustors did not share a decoupling chamber) were connected to each other by means of a small communicating passage, synchronization (in-phase operation) could be achieved. Such behavior should also be explainable by a lumped parameter model, but no such model was developed. However, a good discussion of the mechanism of synchronization was presented.

Coupling the inlet and exhaust via common chambers (Fig. 1-21) was also employed by Evans and Alshami [80] [81] to achieve anti-phase operation of two valveless pulse combustors in a heating application. Zeutzius et al. [82] and Nakano et al. [83] also achieved anti-phase operation for driving a turbine.

\subsection{The Noise and Vibration Problem}

\subsubsection{Background: A Deafening Dead End}

Throughout the 1950s and early 1960s there was great optimism for pulsejets. These intriguing machines had no moving parts and, therefore, were simple and extraordinarily inexpensive to manufacture and maintain. They also demonstrated very high thrust-to-weight ratios (Lockwood [2] had demonstrated up to 10) and SFCs that were beginning to encroach turbofan territory (as low as $0.85 \mathrm{lbs} / \mathrm{lbs}-\mathrm{hr}$ had been demonstrated [2]). A wide range of applications were in sight including aircraft propulsion, direct-lift engines for VTOL platforms, tip-jet helicopters, turbine engine starting units, and hybrid pulsejet-ramjet engines to name a few [75]. Of these, 
aircraft propulsion and direct-lift engines for VTOL platforms were particularly promising and were being actively developed.

Yet, it was not to be. This rising star had a serious problem: extremely high noise and vibration levels. A pulsejet, unlike other jet engines, relies on unsteady operation, and it is no surprise that this produces very high noise and vibration levels. This has been known since the first application of pulsejets; the V-1 was nicknamed the 'Buzz Bomb' for the ominous $47 \mathrm{~Hz}$ buzzing sound that could be heard for miles across London.

Noise is a problem for all types of aircraft engines: Gas turbines and particularly turbojets can also be very loud but the problem is particularly severe in pulsejets. Reynst's [17] combustor is reported to have been audible for miles and the SNECMA 'Ecrevisse' engine for the Aviolanda AT-21 at full throttle is reported to have impeded conversations up to 4 miles away! [84] Vibration from the engines also made it impossible to integrate with airframes that were expected to have any reasonable lifetime. The Germans learned this while trying to integrate the Messerschmitt 328 with pulsejet engines [85].

The conclusion of Hiller Inc.'s comprehensive study on valveless pulsejets read [44]:

"Operational problems were primarily (1) noise (as is typical of jet engines, 124-130 decibels range overall level at 25 feet from jet outlets, but without significant increase 
due to multi-engine operation), (2) vibration (operating cycle frequency range 180$320 \mathrm{cps}$ ) and (3) combustor shell temperatures up to $1850^{\circ} \mathrm{F} . .$.

The last of these problems (high shell temperature) is not particularly troublesome and has not been given much (if any) attention in other studies, but the noise and vibration problem has been a subject of consistent criticism in the press and scientific literature. It seems that everywhere one finds mention of pulsejets in the press, it is accompanied by some mention of the phenomenal noise.

Fig. 1-11 shows a glider fitted with SNECMA valveless pulsejets. It has been adapted from the July, 1951, issue of Flight magazine covering an air show from Le Bourget (the Paris Air Show). A wider part of the page is presented as Fig. 1-11 to accommodate the caption, which points out the noisy nature of these machines.

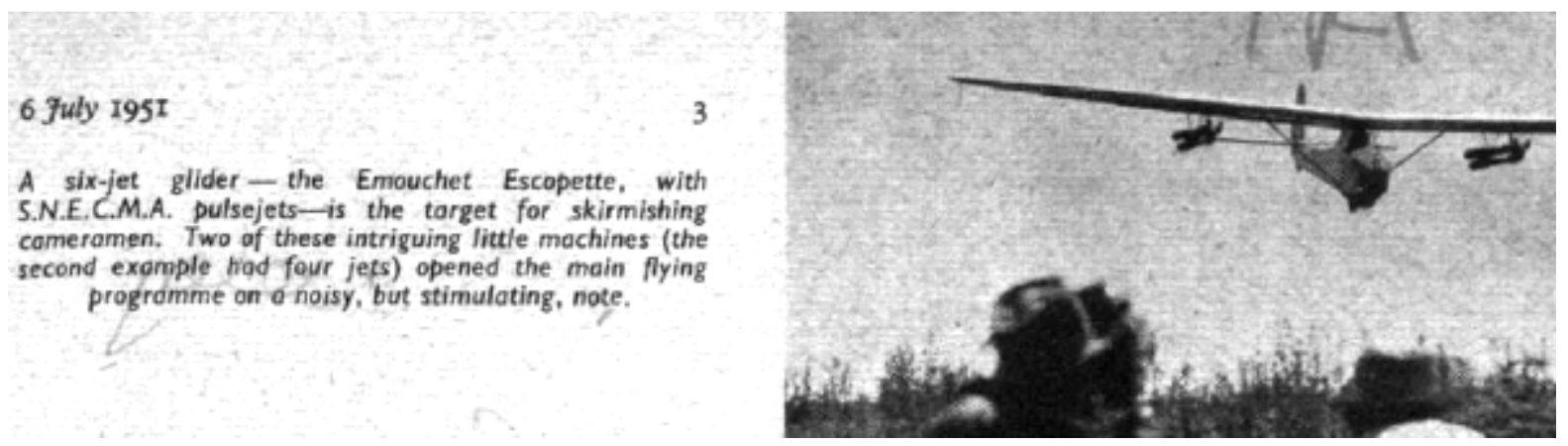

Figure 1-23: Valveless pulsejet powered aircraft at the Paris Air Show, 1951. Note the caption (Adapted from ref. [32]) 
Two years later, from Le Bourget again, the July, 1953, edition of Flight magazine reports [86]:

"The first performer was M. Goue, pilot of an Emouchet sailplane fitted with what appeared to be four drain-pipes slung in pairs beneath its high wing. These attachments were, in fact, four S.N.E.C.M.A. pulsejets which lifted the Emouchet from the runway with a noise which would have done justice to a mass formation of V.I flying bombs. After a very brief take-off run, this unique aircraft jettisoned its trolley undercarriage, climbed quite steeply and circled noisily until, not a moment too soon, the pulsejets were cut for a glide landing. Quieter and altogether more pleasing was the Cessna 180, powered by a 225 h.p. Continental engine, and featuring a new tail design."

As reported in section 1.3.4, SNECMA continued to develop larger pulsejet units including the 'Ecrevisse' (which eventually produced over 150 lbs of thrust [37] [84]) for aircraft and VTOL applications. Figure 1-24 shows the SNECMA pulsejetpowered VTOL test rig in flight (again, note the caption). Developments on the 'Ecrevisse' were reported in the press [87]:

"Valveless pulsejets of the Bertin type are remarkable power units, obtaining their thrust entirely by resonance, which is controlled solely by the profile of the duct interior...Development of the Ecrevisse and its successors is proving most encouraging. Flight trials have taken place on various gliders, and have proved that 
the units are properly developed and controllable, although tremendous noise is something of a problem."

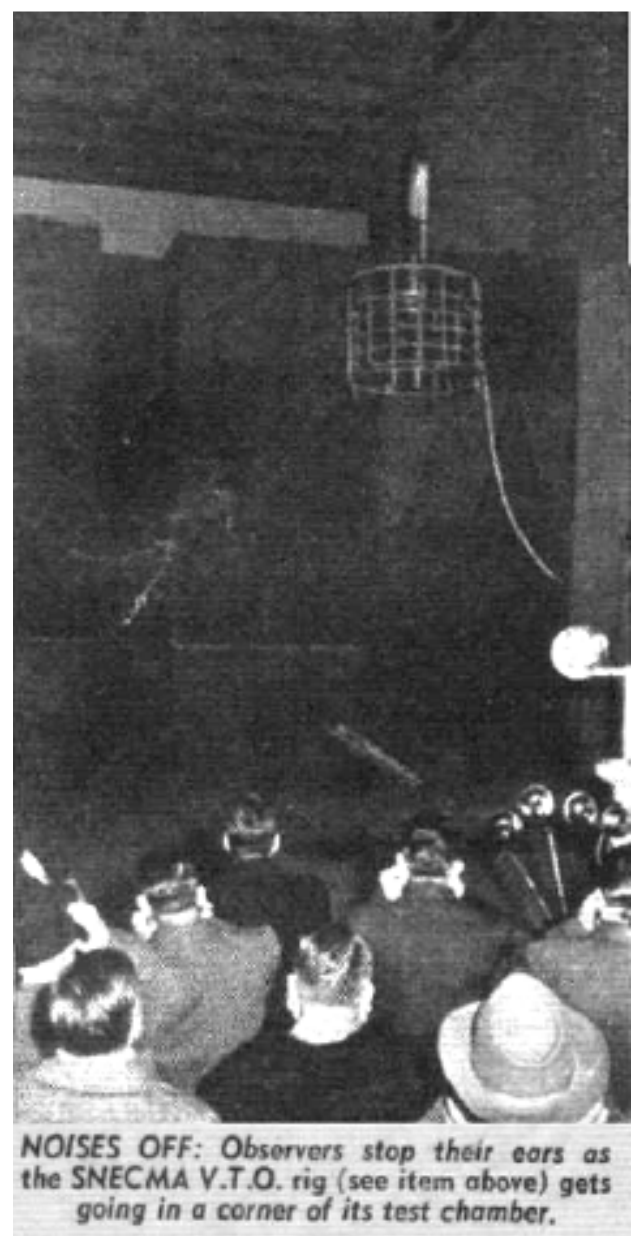

Figure 1-24: SNECMA pulsejet-powered VTOL test article. Note the caption (Adapted from ref. [88]).

The pulsejet is an ideal powerplant for VTOL applications. It has a high thrust-toweight ratio, it is simple and therefore reliable, it is inexpensive and can be clustered in arrays to provide good flight control and redundancy during the vertical part of a flight, and the exhaust is also relatively benign [45] [2] [89] which means that it is 
less damaging to the surfaces upon which it lands (as compared with other jet lift options) and is virtually immune to ingestion of debris. The Boeing Company recognized these advantages and in 2003 proposed a family of VTOL aircraft that would lift off using arrays of pulsejets and then use conventional engines in the forward part of the flight [89] [90] (Fig. 1-25). Boeing referred to its augmented pulsejet design as a 'Pulsed Ejector Thrust Augmentor' (PETA). Described as 'disruptive' technology, the proposed aircraft in this family ranged from heavy military transport to small personal air vehicles and it was hoped that a prototype could be operational by 2008 . However, the challenge of noise and vibration was recognized by Boeing in their published studies [89] and in private communication with the present author, and a number of patents for potential noise abatement techniques were filed in the coming years [90] [91]. However, this problem has remained unresolved.

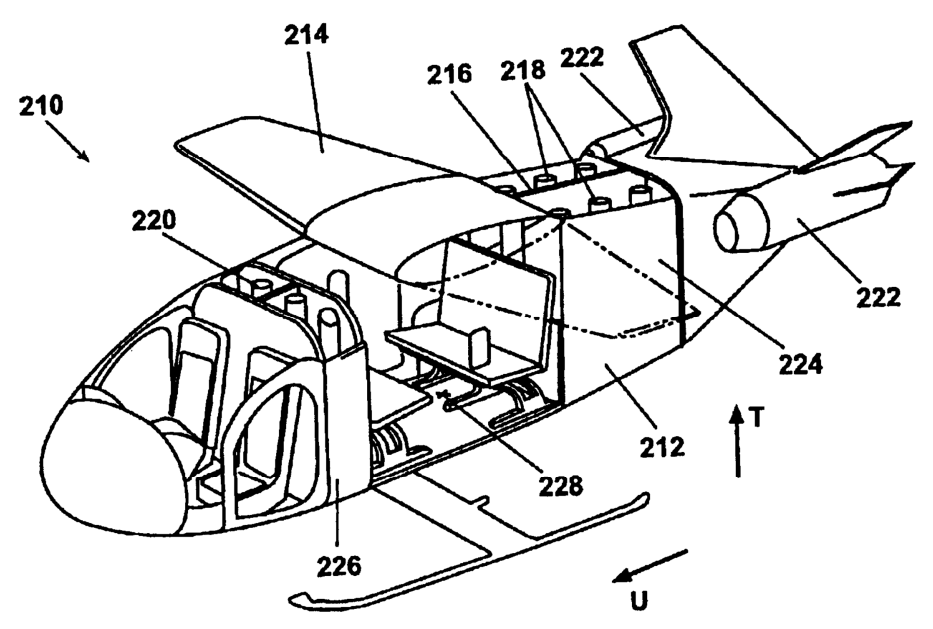

Figure 1-25: One of Boeing Inc.'s concepts for a pulsejet-powered VTOL aircraft. Note the pulsejets embedded in the fuselage (Adapted from ref. [92]). 
Boeing's concept was reviewed by M. D. Moore [93] of NASA Langley, who also singled out the noise problem:

"Another high-speed V/STOL concept developed in a partnership between Boeing and NASA Langley under this project is the Pulsed Ejector Thrust Augmenter (PETA) Concept... Tens to hundreds of these small-pulsed engines can be utilized to reduce the engine-out penalty to a negligible level, while using a similar exhaust vane control system as the Tilt-Nacelle. One drawback of the concept however is that all prior attempts at pulsed engines have resulted in engines that produced incredible levels of noise, with these devices essentially demonstrating themselves to be the best noise generation devices ever designed... Demonstrations have not yet been performed of the PETA concept, and a noise demonstration will certainly be required to address critics. Noise is a critical constraint for all of the V/STOL concepts..."

Throughout history, it seems that whenever the unique qualities of the pulsejet are recognized and practical use has been considered, the noise issue blocks further implementation.

\subsubsection{Studies on Noise}

Since noise has been the major barrier to broader application of pulsejets, it is not surprising that a number of studies were devoted to characterizing and exploring solutions to the noise problem. In a NACA study, Lassiter [94] obtained acoustic 
measurements around a $90 \mathrm{lbf}$ thrust valved pulsejet engine. Measurements were made at a distance of 20 exhaust diameters from $0^{\circ}$ (right behind the exhaust) to $90^{\circ}$ (perpendicular to the exhaust). It was found that the noise level is slightly directional, with the maximum occurring right behind the exhaust. The waveforms were periodic but not perfectly sinusoidal. The noise spectrums revealed a strong component at the firing frequency followed by a few weaker peaks at harmonic locations.

As part of the American Helicopter Company's efforts to develop a tip-jet helicopter (the XH-26 'Jet Jeep'), Veneklasen [5] presented results on the noise characteristics of 6.75 in. and 9.4 in. ( 100 lbf thrust) diameter valved pulsejet engines. Noise spectra were presented in frequency bands and the spectra were compared to those of turbojet engines and a twin-engine airplane to provide some measure of the amount of noise reduction required before the pulsejet could be deemed acceptable (Fig. 1-26). The results indicated that noise reduction on the order of 10-15 $\mathrm{dB}$ was needed to bring pulsejet noise at par with that of a twin-engine airplane. 


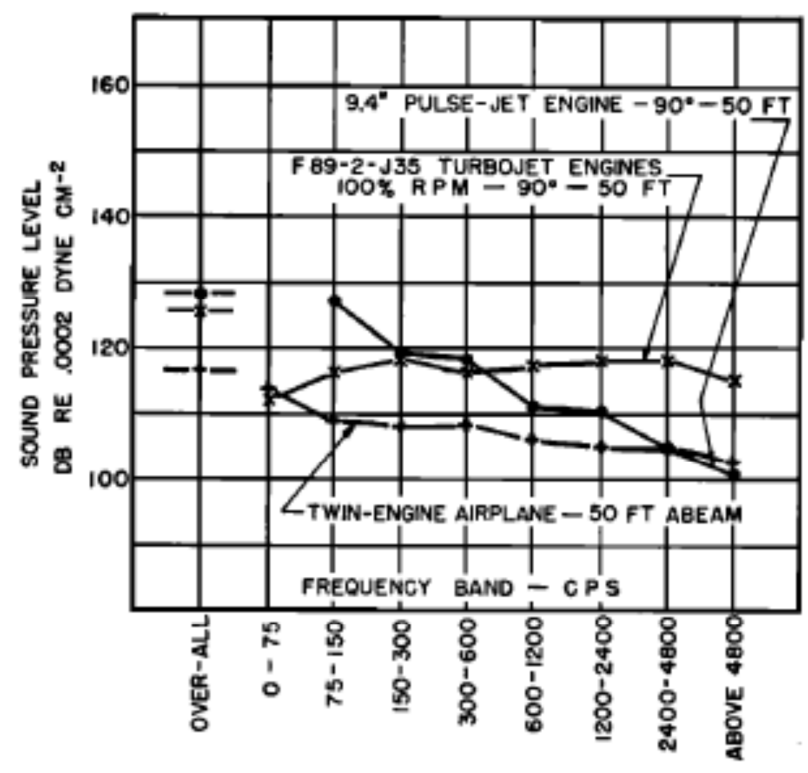

Figure 1-26: Noise spectra comparisons for different powerplants (Adapted from ref. [5])

The noise spectrums also revealed some important features: low frequency noise consisted of a few discrete components/peaks at the fundamental firing frequency $(\sim 100 \mathrm{~Hz})$ and the first few harmonics whereas higher frequency noise $(\sim 1 \mathrm{kHz}+)$ was of a continuous nature. Although the higher frequency bands $(500 \mathrm{~Hz}-4 \mathrm{kHz})$ contain less energy, they are more important for noise evaluation because of the way the human ear perceives noise. The A-weighting for Sound Pressure Level approximates the frequency response of the human ear and thus is the relevant metric for environmental noise regulations (Fig. 1-27). It was also found that the maximum noise level is in the direction approximately $45^{\circ}$ from the exhaust centerline. Similar results were obtained for the noise spectrum and location of maximum noise for a small 4.5 lbs. thrust valved pulsejet in a study by Oleson and the well-known Uno Ingard [95]. 


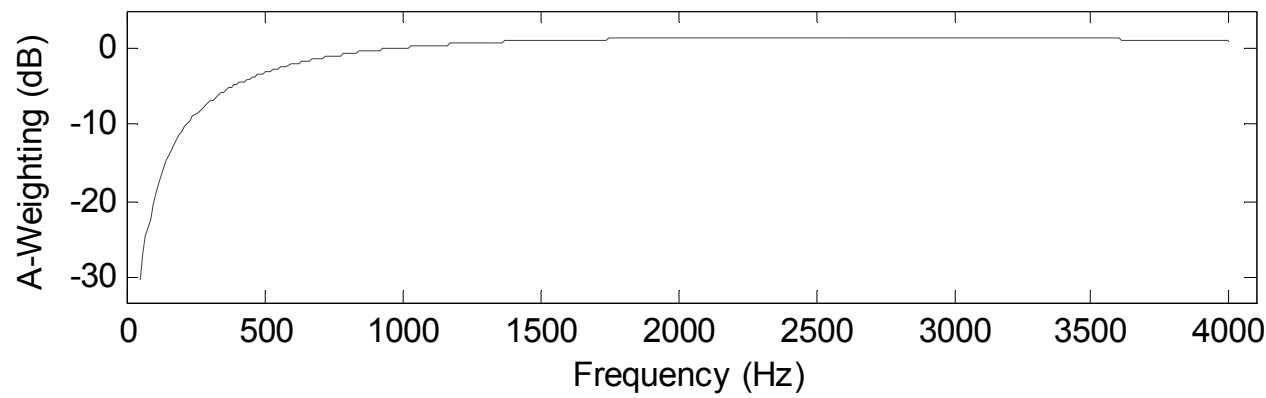

Figure 1-27: The A-weighting for sound pressure level (dBA).

In a later study, Veneklasen and McJones [96] indicated that the continuous high frequency component is dependent upon the exit velocity of the gases. In this sense, it bears some similarity to jet noise. In the same study, Veneklasen and McJones [96] also found that the sound pressure level produced by a pulsejet is largely independent of its size. Therefore, a $200 \mathrm{lbf}$ thrust engine would have about the same overall noise level as a $40 \mathrm{lbf}$ thrust unit.

In their study of valveless engines, Giammar and Putnam [76] presented a noise spectrum for two 2.75 in. combustion chamber diameter valveless pulsejets operating in phase. The spectrum is similar to those of valved pulsejets, i.e. distinct lowfrequency peaks at fundamental and a few low order harmonic locations followed by more continuous high-frequency noise around $1 \mathrm{kHz}$ onwards (Fig. 26). As said before, Veneklasen and McJones [96] suspected that the continuous high frequency noise was related to the exit velocity of the gases. 
A number of attempts have been made to silence pulsejets without destroying thrust production. None has met with any spectacular success. Pairing the engines to operate in anti-phase by means of decoupling chambers (Fig. 1-21) did produce dramatic $(20+\mathrm{dB}[80]$ [79]) reductions in noise levels, but these engines could not be used for thrust production (as discussed in section 1.4.3). Note that there was nothing surprising about the noise reduction: the chambers at the inlet and exhaust simply served as mufflers - a very standard noise control method. Other standard methods of noise control like shrouding, acoustic filters, acoustic liners, and some unconventional methods like attaching tabs and cutting slots in the tailpipes have also proven to be inadequate [96]. Given the extreme nature of the pulse jet noise problem, the usual methods of noise control (e.g. shrouding) are akin to putting a bandage on the problem. In order to effectively silence a pulsejet, quoting Veneklasen [5], "The noise must be attacked at the source."

Operating the engines in anti-phase to eliminate noise is a potentially promising strategy that is worthy of more discussion. As mentioned earlier, the use of decoupling chambers produces excellent noise reduction because the chambers themselves act as mufflers, but this also destroys thrust. Nevertheless, it would be worthwhile to see how the noise would be affected if the engines could be made to operate in anti-phase without chambers - i.e. with exhausts that are open to the atmosphere and thus conserve the thrust-producing quality of the device. From a theoretical standpoint, anti-noise/noise-cancellation techniques work if the sound signals destructively interfere in the time domain. So, a sine wave would be cancelled 
if another identical signal with $180^{\circ}$ phase difference is superimposed (Fig. 1-28). However, if the signals contain higher frequency components, e.g. a second harmonic, these signals may not cancel and could even add constructively to produce a stronger signal (Fig. 1-28). Given that the human ear is more sensitive to higher frequency sounds (A-weighting, Fig. 1-27), this could lead to a higher perceived noise level, even though the strong fundamental component has been eliminated.

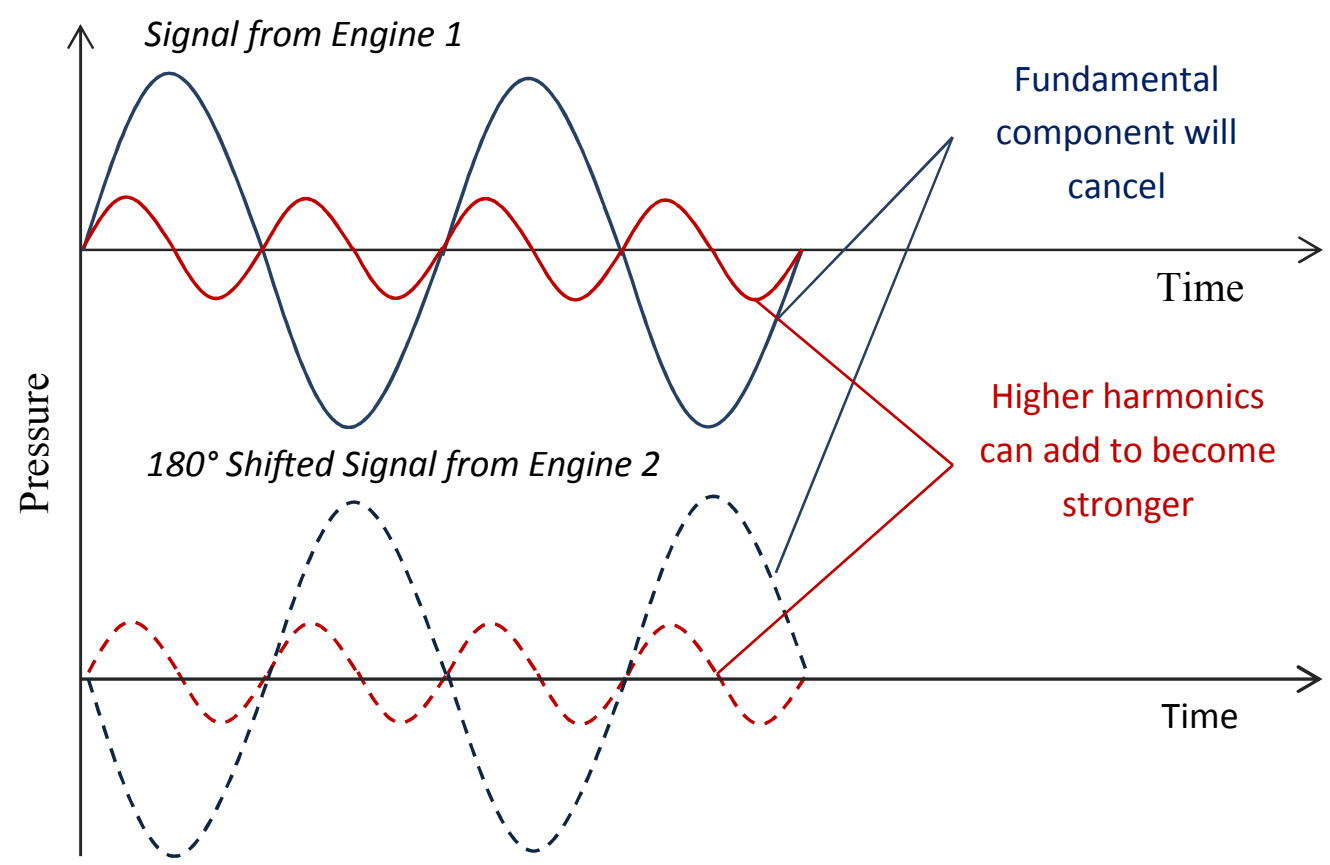

Fig. 1-28: Interference of acoustic signals due to anti-phase operation.

Such behavior has indeed been observed experimentally. Giammar and Putnam [76] who did manage (accidentally) to make two valveless pulsejets operate in anti-phase without the use of any decoupling chambers, noticed that only the fundamental component of the noise spectrum experienced a major reduction (Fig. 1-29). Given that higher harmonics can be about as strong as the fundamental, the elimination of 
the fundamental alone has a very modest effect on the overall noise level. Cancelling the fundamental becomes even less important when the A-weighting is accounted for. Similar results for valved pulsejets have also been reported: anti-phasing resulted in a drop in the fundamental and lower frequency bands, but resulted in an increase in the higher frequency bands [45]. This will likely produce an increase in A-weighted noise levels. Thus, anti-phase operation of the engines can actually increase noise depending upon the noise characteristics of the individual engines. As Kentfield [73] noted, the acoustic waveforms produced by pulsejets are often not of a cancellable nature and anti-phasing will therefore, on its own, not produce the desired effect on noise.

In-Phase Operation

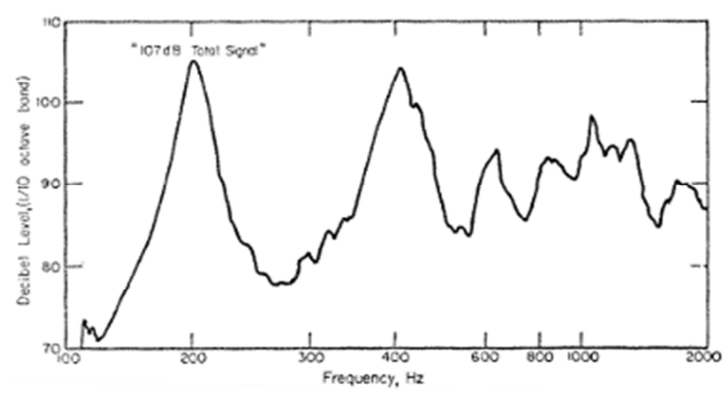

Anti-Phase Operation

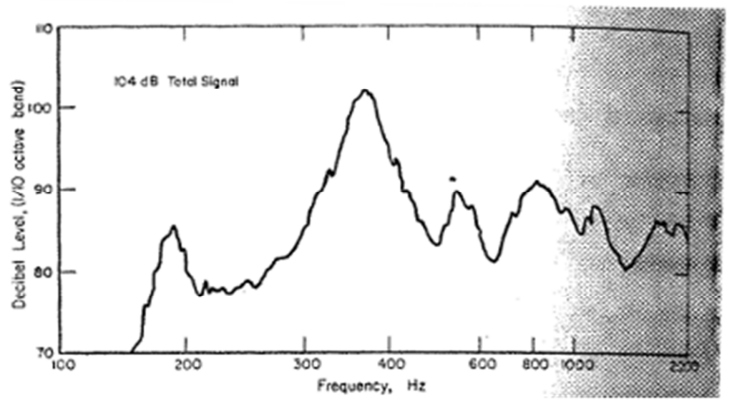

Figure 1-29: Effect of anti-phasing on pulsejet noise (Adapted from ref. [76]).

Before concluding this section, one should reflect on the following: if a notoriously loud V-1 "Buzz Bomb" engine, operating at $47 \mathrm{~Hz}$, behaves as an acoustic quarterwave tube (as it has often been modelled), then it should be producing a sinusoidal acoustic waveform at $47 \mathrm{~Hz}$. However, this frequency is at the lower limit of human hearing. Why, then, was the V-1 so loud? The answer is harmonics. This thesis will 
explain why and show how the problem can be, in the words of Veneklasen [5] “... attacked at its source."

\subsection{Objectives of Thesis}

The specific objectives of this thesis are:

1. To develop a theoretical and quantitative framework that explains the acoustic behaviour of valveless pulsejet engines.

2. To experimentally validate the aforementioned theoretical framework.

3. To use the theoretical framework to gain insight into the source of high noise levels.

4. To use the theoretical framework to devise a strategy that forces a valveless pulsejet to produce an acoustic signal that is amenable to anti-phase cancellation ('signal conditioning') with another similar pulse jet.

5. To experimentally validate the aforementioned 'signal conditioning' strategy.

6. To develop a theoretical framework to explain the behaviour of multiple interacting engines reported in the literature. 
7. To use this theoretical framework to devise technology for achieving antiphase operation of valveless pulsejets that does not interfere with the natural flow paths of the engine (and therefore does not interfere with thrust production).

8. To experimentally verify the anti-phase technology.

9. To incorporate the anti-phase technology with the 'signal conditioning' strategy to produce effective noise-cancellation and experimentally characterize the noise reduction.

Finally, it is important to note that a detailed acoustic and performance (thrust, fuel consumption, etc.) characterization of valveless pulsejets is not an objective of this thesis. Rather, the purpose is to develop and verify acoustic theories that can be used to develop pulsejet noise reduction strategies that do not degrade performance - i.e. thrust and SFC. 


\section{Chapter 2: Acoustic Duct Analysis}

\subsection{Introduction}

Towards an acoustic theory for valveless pulsejets, the first acoustic models involved a lumped-parameter Helmholtz resonator -type analysis (Lee,Dhar and Soedel [97], Hongo and Saito [9]) in which the inlet and exhaust pipes were treated as incompressible masses, and the chamber volume was treated as a compressible volume of fluid. This model has been found to generally overpredict operational frequency. Smith [52] suggested that a valveless pulsejet could be analyzed as the marriage of a Helmholtz resonator (the combustion chamber and inlet pipe) to a quarter-wave tube (the exhaust pipe), although he did not proceed to present any quantitative results based on this notion. Along similar lines, in an important development, Zheng et al. [53] proposed that the frequency of a valveless pulsejet is the average of the natural (fundamental) frequency of a Helmholtz resonator (represented by the combustion chamber and the short inlet tube) and the natural frequency of the combustion chamber coupled with the tailpipe (also similar to a Helmholtz resonator, but with a long neck in which wave motion is accounted for). Zheng et al. [53] obtained good agreement between this acoustic model and experimental results, an encouraging omen for an acoustic theory for the valveless pulsejet. While the preceding models and methods can be used to predict approximate frequencies, they do not explain many operational and design aspects, e.g. the effect 
of diverging tubes [44], or the presence of 'sub-peaks' or 'multiple-peaks' in pressure and velocity signals inside the engine [65] [8] [64]. Furthermore, high-performance engines for aerospace applications often have very large diameter inlets (relative to the combustion chamber). This implies very high frequencies, or short wavelengths, for the front end (inlet-chamber; supposed Helmholtz resonator), in which case one of the key assumptions for the Helmholtz resonator model $(l<<\lambda)$ cannot be guaranteed.

An all-encompassing acoustic theory for valveless pulsejets is desirable, because it will not only further clarify how and why the device functions, but it will also predict and explain the effect of design changes, leading to guidelines for design. In this paper, the valveless pulsejet will be analyzed as an acoustic duct with a non-uniform area and temperature distribution. Instead of assuming the pulsejet to be the hybrid of a Helmholtz resonator and another well-known acoustic device, the engine will be analyzed as a single duct incorporating area changes. The operational frequencies predicted by this analysis will be compared with those obtained from experiment, and it will be shown how this analysis differs from prior analyses.

This technique can also be used to predict the presence of higher modes that have been frequently observed in experimental and numerical studies. Higher modes are important because they give rise to harmonic content in the acoustic waveforms generated by the pulsejet. Not only are higher harmonics responsible for much of perceived noise levels (as represented by the decibel A-weighting), they also keep the acoustic signal from cancelling during anti-phase operation of two pulsejets. It is 
therefore, essential to develop a theory that not only explains and predicts the presence of higher oscillation modes, but also allows for studying methods of mitigating or eliminating them. This chapter aims to develop such a theory and validate it against a set of experimental data.

\subsection{Experiment}

Figure 2-1 is a photograph of one of the valveless pulsejets investigated in this study. It is 45 in. (1.14 m) long and Fig. 2-2 shows the dimensions used for the acoustic calculations. Most of the engine was constructed using off-the-shelf black pipe to make it simple and inexpensive to alter its geometry. The combustion chamber is a 6.9 in. $(17.5 \mathrm{~cm})$ long pipe with an internal diameter of 3.07 in. $(7.8 \mathrm{~cm})$. It is connected to the tailpipe on one end by a tapered steel section that reduces the diameter to 1.38 in $(3.5 \mathrm{~cm})$ over 2 in. $(5.1 \mathrm{~cm})$. The tailpipe has two sections. The first is welded to the 1.38 in diameter end of the tapered section, is 18.5 in $(47 \mathrm{~cm})$ long, and also 1.38 in in diameter. The second section has a larger internal diameter of $1.61 \mathrm{in} .(4.1 \mathrm{~cm})$ that permits it to slide (or telescope) over the first section of the tailpipe making it simple to adjust the total tailpipe length. The far (open) end of the second tailpipe section is fitted with a divergent flare to $2.25 \mathrm{in} .(5.7 \mathrm{~cm})$ in diameter over a length of 1 in. $(2.5 \mathrm{~cm})$. 


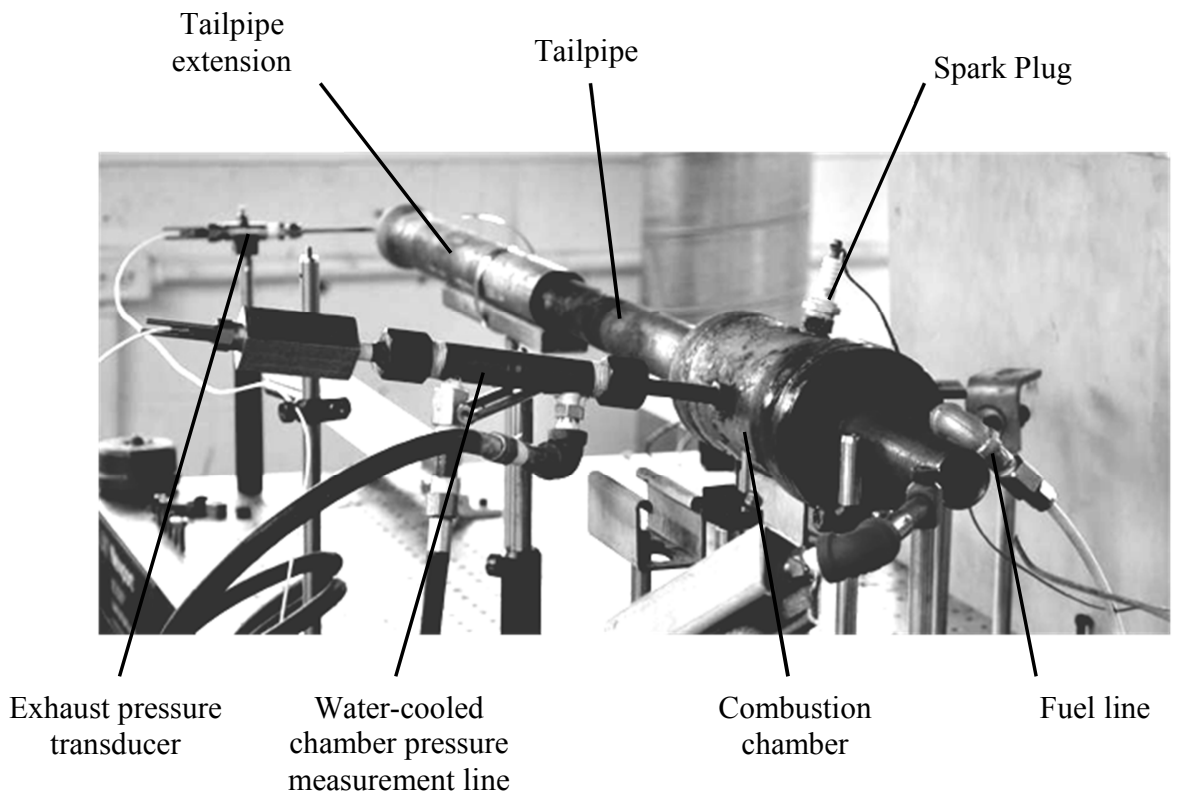

Figure 2-1: Photograph of one pulsejet prior to testing.

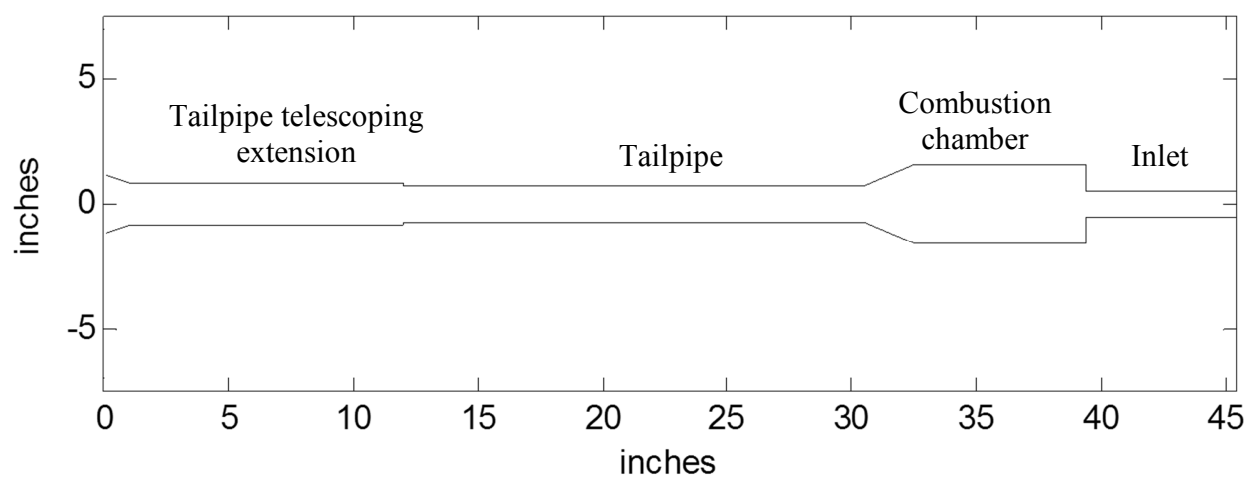

Figure 2-2: Geometry of one of the pulse jets investigated here.

The other end of the combustion chamber is externally threaded to accommodate a removable cap (Fig. 2-3). The cap forms the front face of the combustion chamber (also called the chamber-inlet interface) and contains another threaded opening to support an inlet pipe. The effect of changing inlet length is investigated by screwing 
pipes of various lengths into the cap until their ends are flush with the front face of the combustion chamber. The internal diameter of all inlet pipes is 1.05 in. $(2.7 \mathrm{~cm})$. The cap is also equipped with a pressurized fuel chamber (plenum) connected to the combustion chamber via eight equally spaced fuel injection holes 0.075 in. $(1.9 \mathrm{~mm})$ in diameter and 0.2 in. $(5 \mathrm{~mm})$ long. These holes are oriented at $45^{\circ}$ with respect to the centerline of the engine and exit the front surface of the combustion chamber near the inlet (at a radial location of $0.75 \mathrm{in} .(1.9 \mathrm{~cm})$ ) to facilitate mixing with flow entering from the inlet. Propane at $6 \mathrm{psig}(41.4 \mathrm{kPa})$ plenum pressure is used in all experiments.
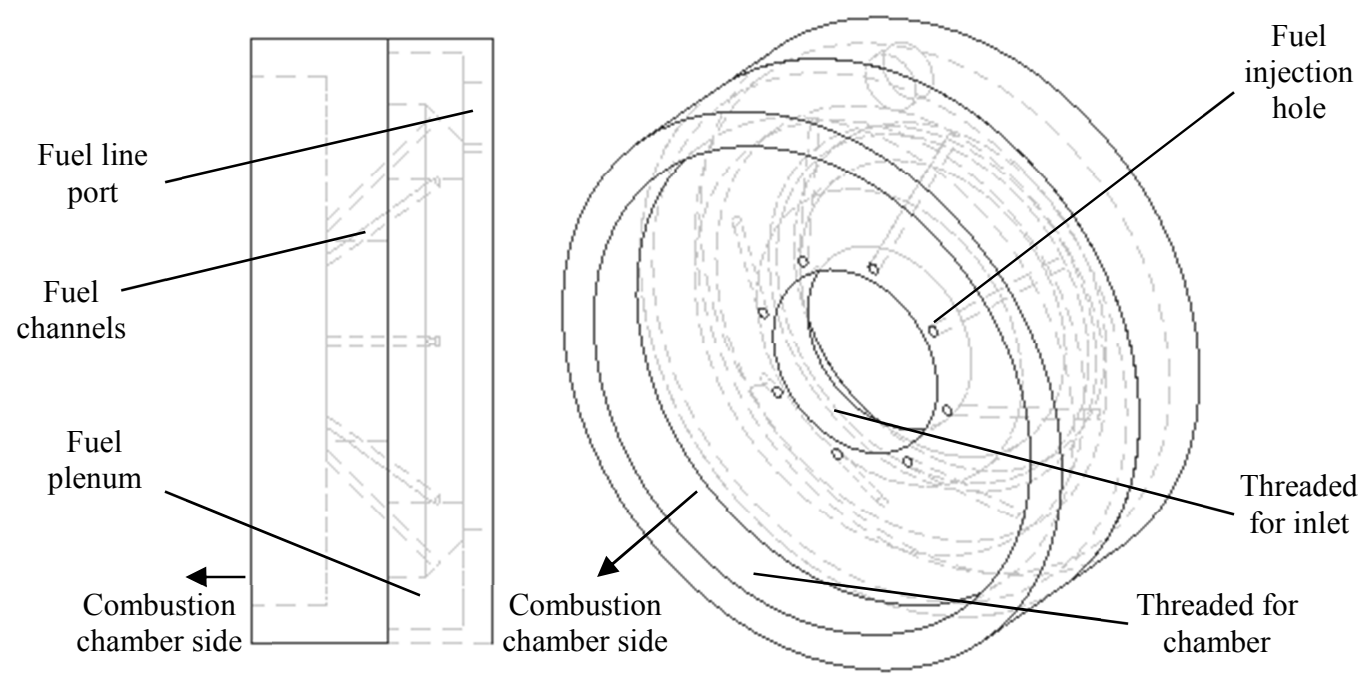

Figure 2-3: Side and isometric view of cap showing fuel injectors around the inlet pipe opening.

Pressures are measured using two Kistler 211B5 piezoelectric pressure transducers powered by a Kistler 5134B Power Supply/Coupler. The voltage output is recorded using LabView and a National Instruments (NI) 9205 voltage module mounted in an NI cDAQ-9172 chassis. One transducer (in a Kistler 228P mount) measures 
combustor pressure via a 9 in. $(22.9 \mathrm{~cm})$ long water-cooled pipe. The pipe intersects the combustor wall 3 in. $(7.6 \mathrm{~cm})$ downstream of the chamber-inlet interface which is approximately in the middle of the combustion chamber. The other transducer measures pressure at the exhaust plane. This was accomplished by mating the transducer to a 5 in. $(12.7 \mathrm{~cm})$ long tube bent 90 degrees and oriented so that the open end faces the pulsejet exhaust (tailpipe) exit plane. In both cases, the tubes separating the transducers from the measurement planes are much shorter than the wavelengths of the acoustic disturbances being measured $(l / \lambda<8)$ so as to avoid complications due to wave-motion inside the connecting tubes.

Internal temperatures at various axial locations are measured using a 24 in. $(61 \mathrm{~cm})$ long Omega K-type exposed-junction thermocouple probe mounted on a rail that permits it to be traversed through the engine while it operates. Separate traverses through the inlet and outlet are required to construct the temperature distribution along the full length of the engine. Measurements are made at 1 in. $(2.5 \mathrm{~cm})$ intervals in the inlet pipe and 2 in. $(5.1 \mathrm{~cm})$ into the combustion chamber from the inlet end where temperature gradients are larger. Temperatures are measured at 2 in. $(5.1 \mathrm{~cm})$ intervals in the rest of the engine. The thermocouple is allowed to settle for approximately one minute at each measuring station before being recorded.

The pulsejet is started by blowing compressed air into the inlet and using an automotive spark plug to ignite the mixture in the combustion chamber. The compressed air and spark plug are turned off once the engine starts and all 
measurements are made at least five minutes after startup in order to ensure that the engine is in steady state. This is determined by establishing that the operating frequency has reached a constant value. Table 2-1 shows the five different geometries that have been tested. The baseline configuration (Configuration 1) has a tailpipe length of 30 in. $(76.2 \mathrm{~cm})$ and an inlet length of 6 in. $(15.2 \mathrm{~cm})$. Configurations $2 \mathrm{a}$ and $2 \mathrm{~b}$ have the same inlet length as Configuration 1 but shorter tail pipes. Configurations $3 \mathrm{a}$ and $3 \mathrm{~b}$ have the same tail pipe length as Configuration 1 , but have shorter inlets. These configurations are chosen to enable investigation of the effects of inlet length and tailpipe length independently.

Table 2-1: Valveless Pulse Jet Geometries Tested.

\begin{tabular}{c|cc} 
Configuration & Inlet Length & Exhaust Length \\
\hline 1 & 6 in. $(15.2 \mathrm{~cm})$ & 30 in. $(76.2 \mathrm{~cm})$ \\
$2 \mathrm{a}$ & 6 in. $(15.2 \mathrm{~cm})$ & 27 in. $(68.6 \mathrm{~cm})$ \\
$2 \mathrm{~b}$ & 6 in. $(15.2 \mathrm{~cm})$ & 24 in. $(61 \mathrm{~cm})$ \\
$3 \mathrm{a}$ & 4 in. $(10.2 \mathrm{~cm})$ & 30 in. $(76.2 \mathrm{~cm})$ \\
$3 \mathrm{~b}$ & 2 in. $(5.1 \mathrm{~cm})$ & 30 in. $(76.2 \mathrm{~cm})$
\end{tabular}

\subsection{Acoustic Duct Analysis}

The basic premise of the analysis is that valveless pulsejets are acoustic ducts in which the fundamental mode is excited and periodically energized by combustion events as per Rayleigh's criterion [18] [24] [27] (section 1.3.2). Therefore, it is necessary to calculate its longitudinal acoustic modes. This will be accomplished using transmission line theory and an electrical analogy for a fluid. Plane waves are assumed. Since area and temperature vary substantially along the axis of the pulsejet 
and are inputs to the analysis, numerical solutions to the governing equations are required.

\subsubsection{The Electro-Acoustic Analogy}

Figure 2-4 is a schematic illustration of fluid in a tube in which the flow is broken into a set of $n$ interacting elements. Assuming that the length of each element is small compared to the wavelength of an acoustic wave passing through it (i.e. $k L<<1$ ) enables each element to be treated as a lumped mechanical system that responds to a difference in pressure across it. The behavior of such systems can be modeled using an electrical analogy where the compliance of the fluid element corresponds to a capacitance, its inertia corresponds to an inductance, pressure corresponds to voltage, and fluid volume velocity corresponds to current [15]. The distributed compliance and inertia associated with interacting fluid elements gives rise to wave behavior in duct flows in the same way that distributed inductance and capacitance gives rise to wave behavior in electrical transmission lines. Therefore, one may use transmission line theory to model the acoustic behavior of ducts as illustrated in Fig. 2-4b. The electrical element corresponding to single fluid element is illustrated in Fig. 2-4a. The associated capacitances and inductances are given by eqs. 2-1 and 2-2 respectively.

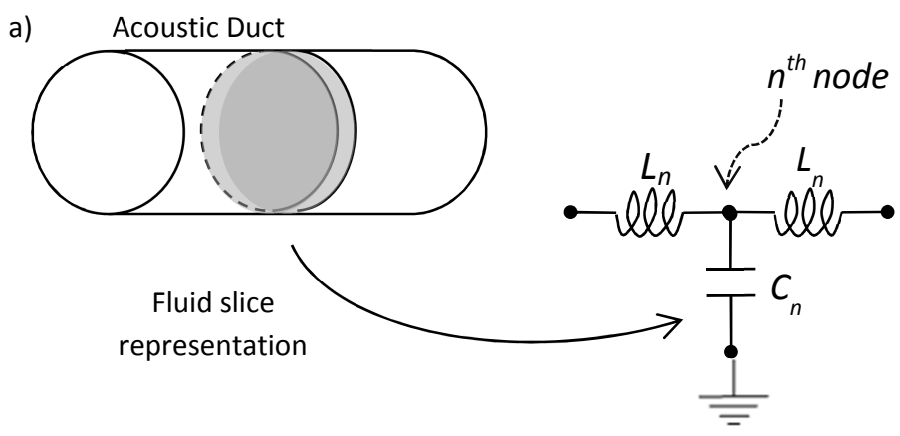




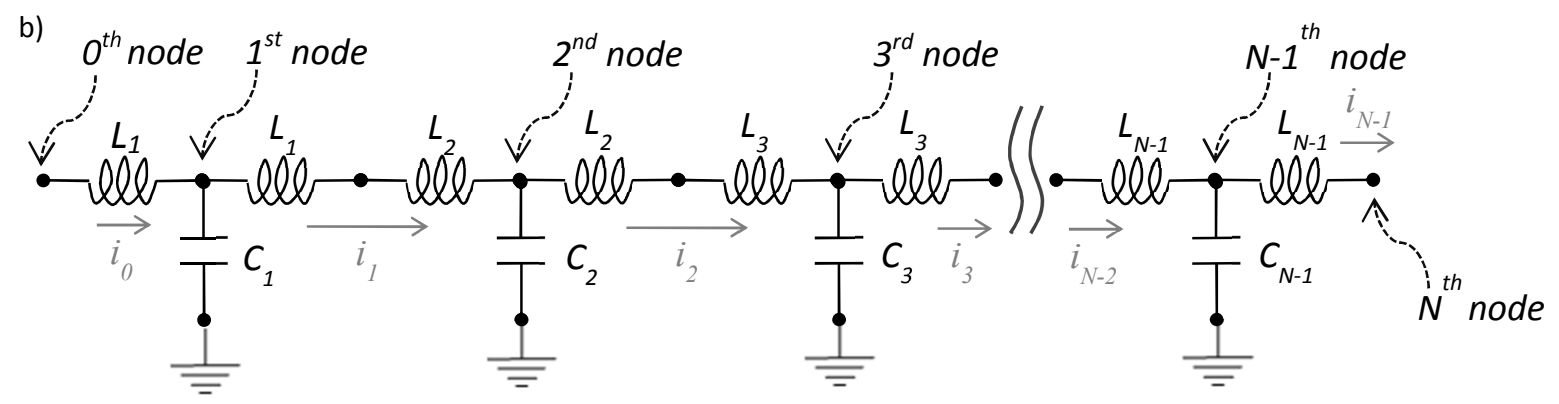

Figure 2-4: (a) Electrical analogy for a fluid element in a tube, and (b) the electric circuit for a transmission line, analogous to an acoustic duct.

$$
\begin{aligned}
C_{n} & =\frac{A_{n} \Delta l_{n}}{\rho_{n} c_{n}^{2}} \\
L_{n} & =\frac{\rho_{n} \Delta l_{n}}{2 A_{n}}
\end{aligned}
$$

In these expressions, $A_{n}$ is the cross-sectional area of the $n^{\text {th }}$ duct element, $\Delta l_{n}$ is its length, $\rho_{n}$ is the local density of the fluid, and $c_{n}$ is the local speed of sound. It should be noted that the inductance in Eq. 2-2 is the inductance of each inductor shown in Fig. 2-4 and the total inductance of a gas element would be twice that value (as shown in Fig. 2-4a). The density is calculated using the ideal gas equation (Eq. 2-3). The mean pressure $(P)$ is assumed to be constant and equal to atmospheric pressure (101325 Pa). The temperature $\left(T_{n}\right)$, however, varies considerably along the length of the engine so its value is computed at each node by linearly interpolating between internal gas temperature measurements. This means that the speed of sound also varies from node to node and is calculated using eq. 2-4. 


$$
\begin{aligned}
& \rho_{n}=\frac{P}{R T_{n}} \\
& c_{n}=\sqrt{\gamma R T_{n}}
\end{aligned}
$$

In eqs. $2-3$ and $2-4, R$ is the gas constant for air $(287 \mathrm{~J} / \mathrm{kg}-\mathrm{K}), T_{n}$ is the local gas temperature, and $\gamma$ is the ratio of specific heats for air (1.4).

The arrows in Fig. 2-4b illustrate the direction of positive current flow between nodes. Current flowing from the capacitors to ground is also designated positive. Appying Kirchoff's laws to the circuit illustrated in Fig. 2-4b and incorporating the definitions of capacitance and inductance presented above leads to the following system of $2 n+1$ equations for the transmission line:

$$
\begin{array}{rlrl}
\frac{d V_{0}}{d t}=0 & \frac{d i_{0}}{d t} & =\frac{V_{1}-V_{0}}{L_{1}} \\
\frac{d V_{1}}{d t}=\frac{i_{0}-i_{1}}{C_{1}} & \frac{d i_{1}}{d t} & =\frac{V_{2}-V_{1}}{L_{1}+L_{2}} \\
\frac{d V_{2}}{d t}=\frac{i_{1}-i_{2}}{C_{2}} & \frac{d i_{2}}{d t}=\frac{V_{3}-V_{2}}{L_{2}+L_{3}} \\
\frac{d V_{N-1}}{d t}=\frac{i_{N-2}-i_{N-1}}{C_{N-1}} & \frac{d i_{N-1}}{d t}=\frac{V_{N}-V_{N-1}}{L_{N-1}} \\
\frac{d V_{N}}{d t}=0 &
\end{array}
$$

Eqs. (2-5)

Boundary conditions are applied at nodes $O$ and $N$ and specify the pressures at the ends of the duct. To first order, the pressure at each end of the duct is atmospheric 
and thus the pressure difference there should be zero. In practice, however, the pressure needs some distance outside the duct to fall to zero and 'end corrections' are required. This will be discussed later. The pressure at the open ends is also assumed to be steady which is why the time derivatives of voltage (pressure) at the duct ends are set to zero. Eqs. 2-5 show that the absolute value of the pressure (voltage) at the ends has no impact on the mode calculation. For this reason, the voltage at the end nodes $\left(V_{0}\right.$ and $\left.V_{N}\right)$ can be set to zero. This is analogous to measuring everything in gauge pressure. Taking the derivative of the voltage equations and substituting in the current equations yields the system of $n+1$ equations of eqs. 2-6.

$$
\begin{gathered}
\frac{d^{2} V_{0}}{d t^{2}}=0 \\
\frac{d^{2} V_{1}}{d t^{2}}=\frac{1}{C_{1} L_{1}\left(L_{1}+L_{2}\right)}\left[V_{0}\left(-L_{1}-L_{2}\right)+V_{1}\left(2 L_{1}+L_{2}\right)+V_{2}\left(-L_{1}\right)\right] \\
\frac{d^{2} V_{2}}{d t^{2}}=\frac{1}{C_{2}\left(L_{1}+L_{2}\right)\left(L_{2}+L_{3}\right)}\left[V_{1}\left(-L_{2}-L_{3}\right)+V_{2}\left(L_{1}+2 L_{2}+L_{3}\right)+V_{3}\left(-L_{1}-L_{2}\right)\right] \\
\frac{1}{d t^{2}}=\frac{1}{C_{N-1} L_{N-1}\left(L_{N-2}+L_{N-1}\right)}\left[\begin{array}{c}
V_{N-2}\left(-L_{N-1}\right)+V_{N-1}\left(L_{N-2}+2 L_{N-1}\right) \\
+V_{N}\left(-L_{N-2}-L_{N-1}\right)
\end{array}\right] \\
\frac{d^{2} V_{N}}{d t^{2}}=0
\end{gathered}
$$

Eqs. (2-6)

These equations are now well-posed for modal analysis [98] [99]. $V_{0}$ and $V_{N}$ are set to zero and Eqs 2-6. are written as a matrix $M$ (Eq. 2-7). Notice that the matrix does not include equations for nodes 0 and $N$ which represent the boundary conditions. The matrix $M$ represents the system we are trying to solve. The eigenvalues of $M$ are the 
squares of the angular frequencies of the modes and the eigenvectors are the corresponding mode shapes.

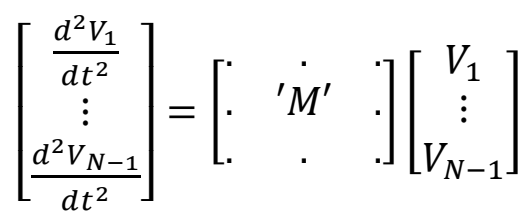

\subsubsection{End Corrections}

So far, it has been assumed that the gage pressure is zero (atmospheric) at the ends of the duct, i.e. at nodes 0 and $N$. This is an idealization of the actual physical process in which some distance beyond the end of the duct is required for the gage pressure to fall to zero. Therefore, it is standard practice when analyzing acoustic ducts or resonators to add 'end corrections'. End correction lengths can be the subject of debate and are often determined experimentally but values of $0.3 d$ for unbaffled ducts and $0.425 d$ for baffled ducts (where $d$ is the duct diameter) are generally accepted in the literature for acoustic devices [15] [100] $]^{3}$.

However, this end correction $(0.3 \mathrm{~d})$ is insufficient for two reasons: 1) At high oscillation amplitudes, non-linear phenomena such as jetting and vortex-shedding often necessitate larger end corrections [101] [102] and end corrections for combustion instabilities are $\sim 0.5 d$ [103] [104]. 2) The area increase at the inletchamber interface also requires an end correction (as is commonly done for Helmholtz resonators). However, the temperature variation there makes it more complicated to determine the correct value. The approach taken here is based on the

\footnotetext{
${ }^{3}$ Baffled ducts include geometries with sudden area increases like Helmholtz resonators. In this case, the appropriate end correction for the neck of a Helmholtz resonator opening into a chamber is $0.425 d$.
} 
fact that the radiation impedance scales with the density of the fluid into which power is being radiated [15] [55]. Temperature measurements indicate that the ratio of combustor to atmosphere gas density is at least 0.3 . This suggests that that the external end of the inlet should be increased by a length of $0.3 \times 0.5 d=0.15 d$ to account for the area increase at the inlet-combustor interface. Taken together, the corrections for large amplitude oscillations and the inlet-combustor interface add to produce a total end correction at the inlet of $0.5 d+0.15 d=0.65 d$. The end correction at the exhaust end remains $0.5 d$.

\section{$\underline{2.4 \text { Results and Discussion }}$}

Figure 2-5 shows measured internal temperature profiles in a pulsejet with three different exhaust lengths (cases 1, 2a, and 2b). Figure 2-6 shows the same for three different inlet lengths (cases 1, 3a, and 3b ). Together, the figures show that changing the exhaust length has little impact on the internal temperature distribution while decreasing the inlet length raises temperatures significantly. The consistent temperature 'dip' at the chamber-inlet interface is associated with the cooler fuel that is injected there. 

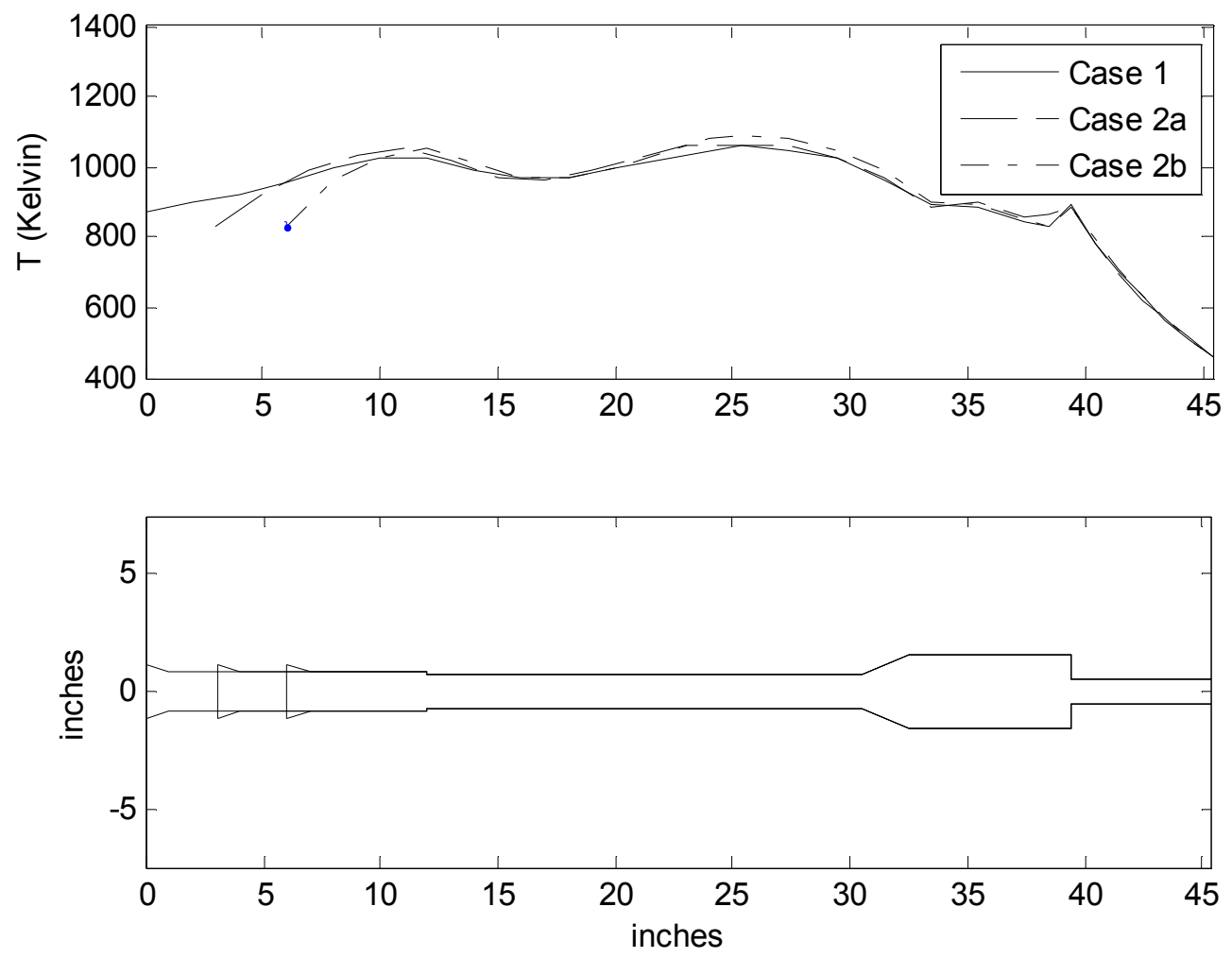

Figure 2-5: Effect of exhaust length on internal temperature profile (configurations/cases 1, 2a, and 2b). 

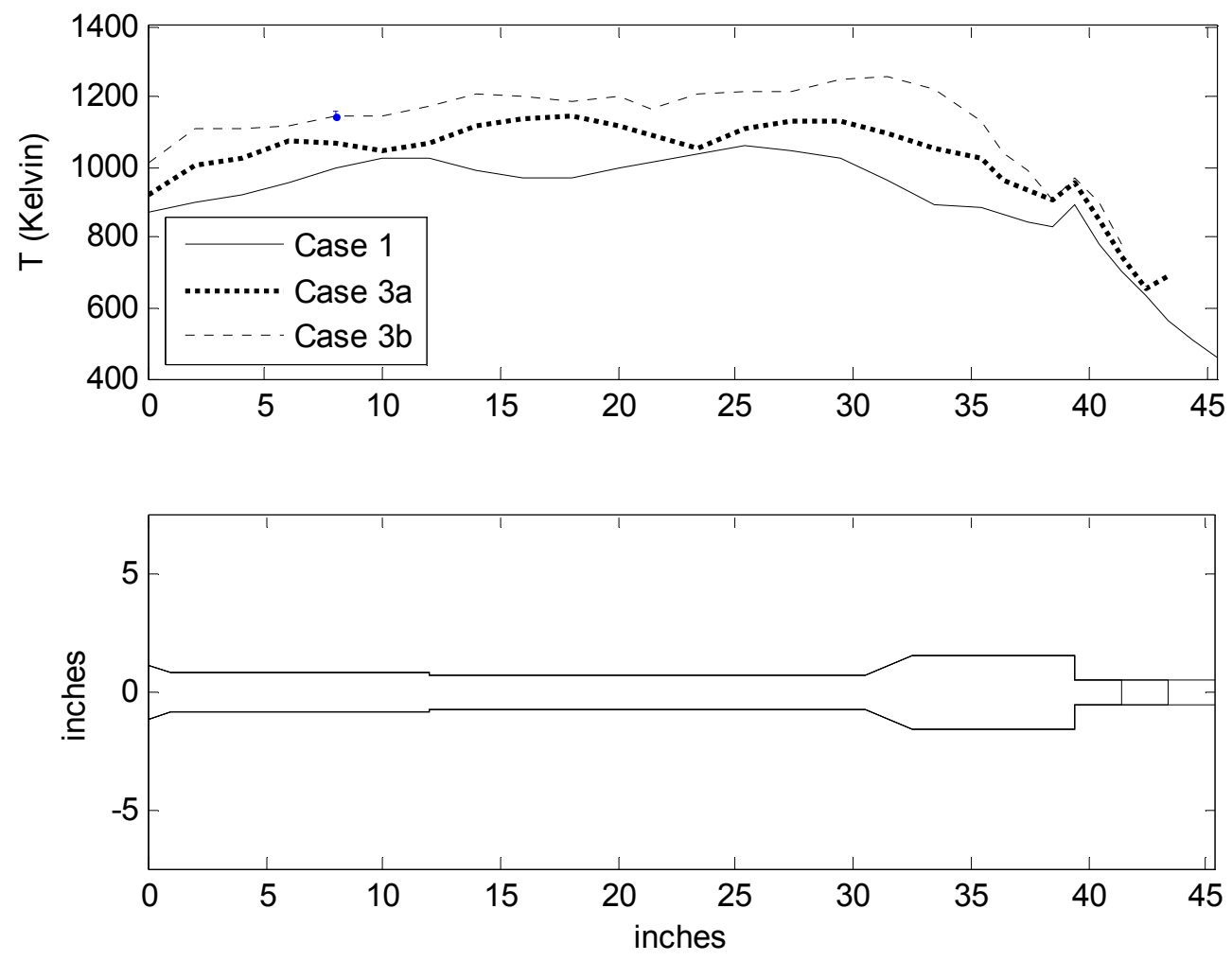

Figure 2-6: Effect of inlet length on internal temperature profile (configurations/cases

$$
1,3 a \text {, and } 3 b) \text {. }
$$

Figure 2-7 shows time variations in chamber pressure over one firing cycle for all five test cases. The variations in Fig. 2-7 are single cycle averages computed using data acquired over approximately 500 cycles for each test case. The frequencies and periods of the pressure signals are presented in Table 2-2 and compared to frequencies predicted using the acoustic theory with the two types of end corrections discussed above ( $0.3 d$ at each end, and $0.65 d$ and $0.5 d$ for the inlet and exhaust respectively). The temperatures of each acoustic element are determined by interpolating in the profiles presented in Figs. 2-5 and 2-6. Note that the latter end correction scheme ( $0.65 d$ and $0.5 d$ for the inlet and exhaust respectively) reduces the 
error of the analytical result from $<15 \%$ to $<6 \%$. As a result, the latter end correction scheme is used in all subsequent calculations.

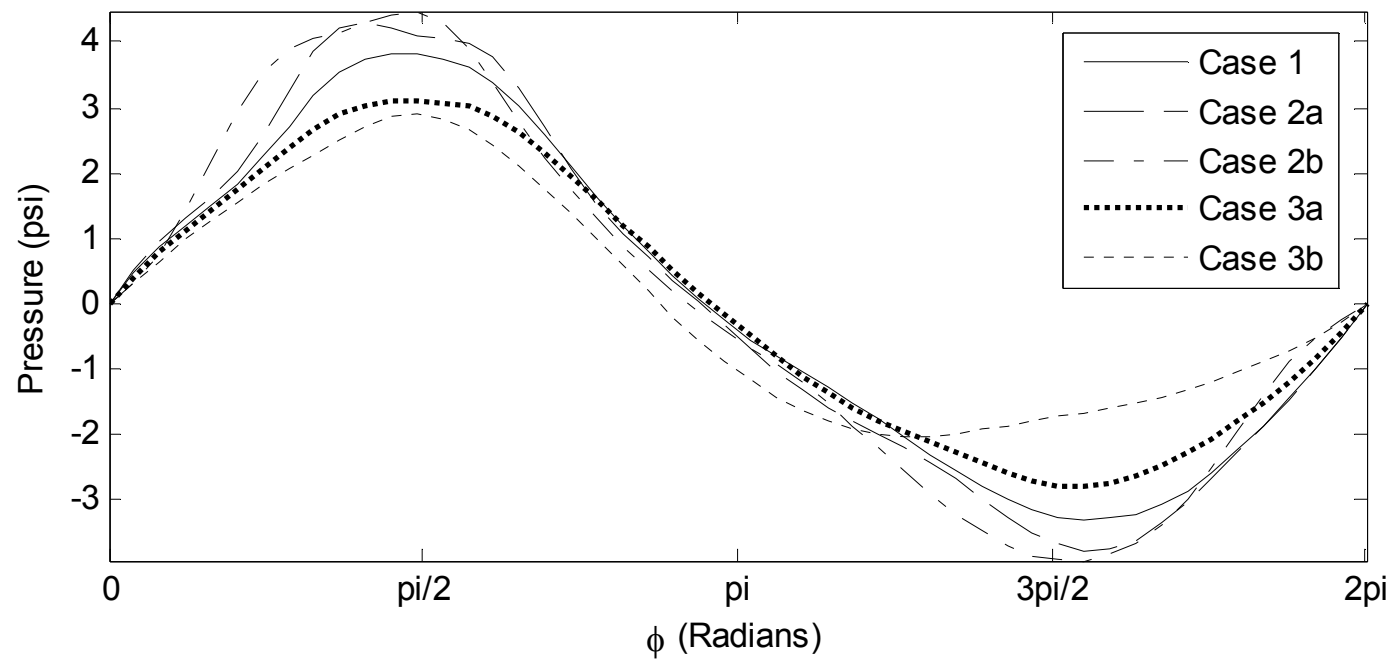

Figure 2-7: Measured combustion chamber pressure fluctuations.

Table 2-2: Comparison of predicted and measured frequencies.

\begin{tabular}{|c|c|c|c|c|c|c|}
\hline \multirow{2}{*}{ Configuration } & \multicolumn{2}{|c|}{ Measurements } & \multicolumn{4}{|c|}{ Calculations } \\
\cline { 2 - 7 } & \multirow{2}{*}{ Period } & \multirow{2}{*}{ Freq. } & \multicolumn{2}{|c|}{$0.3 \mathrm{~d}$ End Corr. } & \multicolumn{2}{c|}{$\begin{array}{c}\text { 0.65d/0.5d End } \\
\text { Corr. }\end{array}$} \\
\cline { 4 - 7 } & & & Freq. & Error & Freq. & Error \\
\hline \hline 1 & 6.25 & 160 & 162 & +1.3 & 156 & -2.5 \\
$2 \mathrm{a}$ & 6.1 & 164 & 167 & +1.8 & 161 & -1.8 \\
$2 \mathrm{~b}$ & 5.95 & 168 & 174 & +3.6 & 167 & -0.6 \\
$3 \mathrm{a}$ & 5.81 & 172 & 193 & +12.2 & 182 & +5.8 \\
$3 \mathrm{~b}$ & 4.74 & 211 & 240 & +13.7 & 218 & +3.3 \\
\hline
\end{tabular}

The mode shapes are given by the eigenvectors of $M$ as described earlier. Scaling these shapes using chamber pressure measurements and plotting as a function of axial position leads to Fig. 2-8. Similar shapes have been observed in experimental and 
numerical studies [64] which supports the acoustic method for understanding pulse jet behavior. The plot also suggests another way of understanding valveless pulsejets: they are, in essence, open half-wave tubes whose pressure anti-nodes are shifted by area and temperature variations. Shifting the pressure anti-node to one side of the duct makes it easier to deliver fresh oxidizer (air) to the anti-node so that combustion can occur close to it. This is important because it maximizes instability (per Rayleigh's criterion) where efficient coupling between the heat release and pressure oscillation sustains the thermoacoustic instability. Finally, increasing the area at the pressure anti-node (by forming a combustion chamber) lowers the velocity there making it easier to keep the reaction zone near the pressure anti-node where the heat release can act in phase with the pressure.

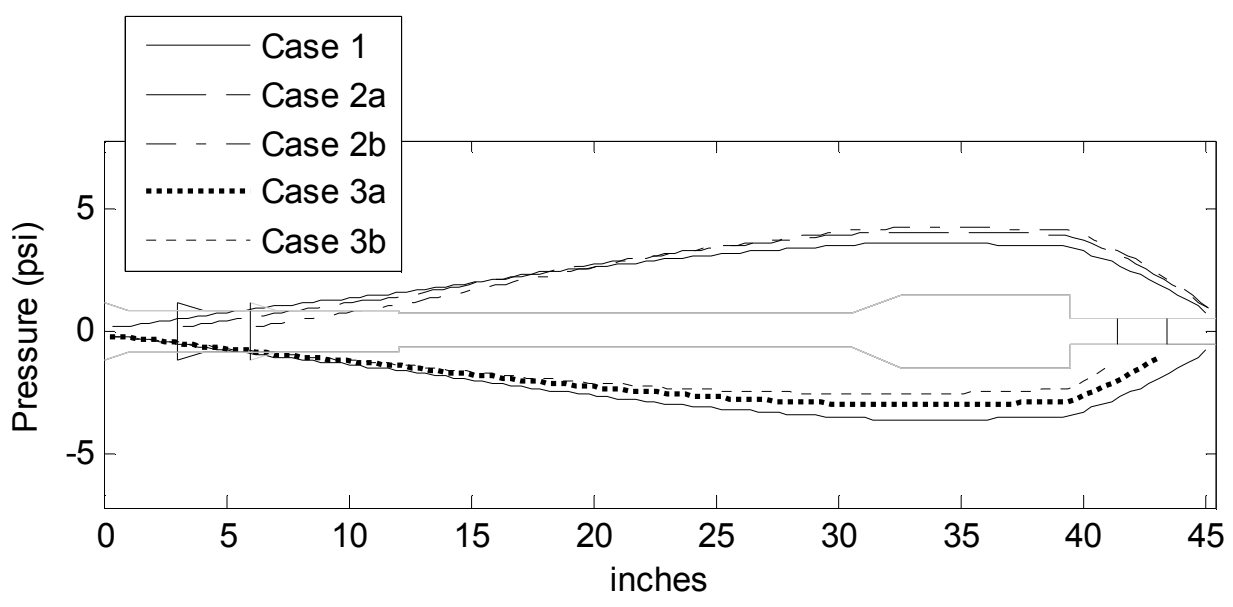

Figure 2-8: Calculated mode shapes scaled by experimental data. 


\subsection{Comparison with Other Methods}

As mentioned in the introduction, there are other models for (or ways of thinking about) valveless pulsejets, and the purpose of this section is to use the acoustic analysis developed in section 2.3 to evaluate the applicability of the models in the literature. This will be accomplished by using the experimental data of the present study as inputs to the models. The first model (model 1) is the lumped-parameter Helmholtz resonator [97] [9] in which the inlet and exhaust tubes are treated as incompressible masses and the chamber is treated as a compressible volume. The fundamental operating frequency of this system is given by

$$
f_{L P}=\frac{1}{2 \pi} \sqrt{\frac{\gamma P_{A}}{V_{C}}\left(\frac{S_{i}}{\rho_{i} L_{i}}+\frac{S_{e}}{\rho_{e} L_{e}}\right)}
$$

where $P_{A}$ is atmospheric pressure, $V_{c}$ is the volume of the combustion chamber, $S$ is the cross sectional area, $\rho$ is the density and $L$ is the length where the subscripts $i$ and $e$ denote inlet and exhaust respectively. Note that single temperatures associated with the inlet and exhaust tubes must be selected as bases for calculating the densities. The approach taken here is to compute average temperatures for each component from the measured temperature distributions in each respective segment of the engine. The surface area of the tailpipe (exhaust) is taken to be the volume of the tailpipe divided by its length.

The second model (model 2) is by Zheng et al. [53]. It postulates that the valveless pulsejet is a combination of a Helmholtz resonator (the inlet and combustion 
chamber) and a long resonance-tube attached to a large volume (the tailpipe and combustion chamber respectively). The fundamental operating frequency is assumed to be the average of the Helmholtz resonator and resonance tube-chamber frequencies. Expressions for each frequency are given by equations 2-9 and 2-10 where $f$ is the frequency, $S$ is the cross-sectional area, $V$ is the volume, and $c$ is the speed of sound.

$$
\begin{gathered}
f_{\text {inlet-chamber }}=\frac{c}{2 \pi} \sqrt{\frac{S}{V L}} \\
\frac{2 \pi f_{\text {tailpipe-chamber } V}}{S c} \tan \left(\frac{2 \pi f_{\text {tailpipe-chamber } L}}{c}\right)=1
\end{gathered}
$$

This model is expected to be more accurate than the lumped parameter model because it accounts for some wave motion in the tailpipe. However, it also double counts the combustion chamber - a point that will be discussed further later - and still requires the user to select average temperatures for the various components.

At this point one could compute the fundamental operating frequencies of the five pulse jets considered here (i.e. cases 1, 2a, 2b, 3a, and 3b) using models 1 and 2 and compare them to the measurements and the predictions of the new acoustic theory developed in section 2.3. However, it would be difficult to know whether the differences arise from the appropriateness of the modeling philosophies (single Helmholtz resonator vs. Helmholtz resonator + resonance tube) or the choices of temperatures for each component. There is not much that can be done for model 1 one must choose temperatures and doing so from measurements is the most logical 
method. The temperatures of the inlet, chamber, and tailpipe are determined by averaging the measured temperature distributions in each component. However, one can use the distributed acoustic model developed in section 2.3 and the measured temperature distributions to eliminate the need to choose temperatures in model 2. Here is how: the Helmholtz resonator is also an acoustic duct with a known area distribution so its acoustic behavior can be represented using the methods of section 2.3 with the closed end wall incorporated into the numerical scheme by setting the current (volume flow) in the last segment to zero and letting the voltage (pressure) adjust itself accordingly. Similarly, the distributed model can be used to calculate the fundamental frequency of the chamber-resonance tube component. This enables one to modify model 2 to account for the temperature distribution in the real device without altering its overall modeling philosophy. Of course, one could also assume uniform temperatures in the various postulated components and doing so would produce results identical to those produced using equations 2-9 and 2-10.

Having reduced the sensitivity of the models' predictions to temperature choices, we are finally ready to make comparisons. The results are presented in Fig. 2-9 where the horizontal axis is the measured frequency and the vertical axis is the predicted frequency. The solid diagonal line indicates perfect correspondence between model prediction and experiment. The results show that model 1 (lumped-parameter, Eq. 29; stars) is the worst and the distributed model presented in section 2.3 (circles) is the best. Adding end corrections of $0.65 \mathrm{~d}$ to the inlet and $0.5 \mathrm{~d}$ to the tailpipe improves model 1 predictions (crosses) but not by enough. The fact that model 2 (diamonds) is 
also close is very interesting because it suggests that the Helmholtz resonator + cavity/resonance tube modeling philosophy is correct.

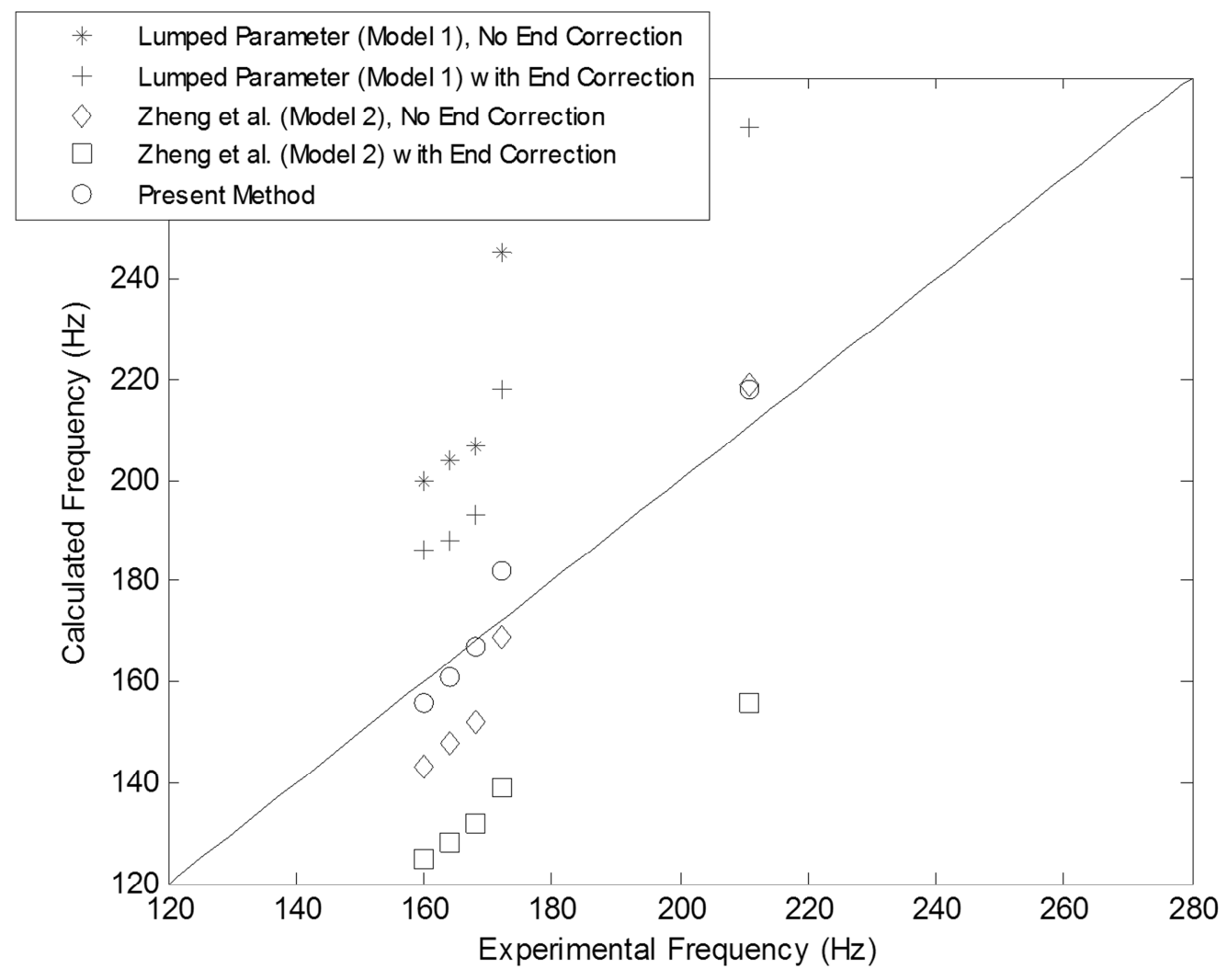

Figure 2-9: Comparison of different frequency calculation methods against experiment. Solid line indicates perfect agreement between experiment and calculation.

To investigate this further, the distributed calculation scheme of section 2.3 is used to compute the pressure amplitude distributions associated with the Helmholtz resonator (Fig. 2-10a) and volume-resonance tube (Fig 2-10b) components postulated in model 2 for Configuration 1. These are compared to the pressure amplitude distribution of the fundamental mode computed using the fully distributed acoustic scheme of 
section 2.3 (Fig 2-10c). Fig. 2-10c shows that the pressure gradient (and thus fluid velocity) approaches zero in the combustion chamber. This 'plane of acoustic symmetry' can be thought of as a wall dividing two segments of the duct that are effectively separate. It also suggests that the chamber volume is really 'shared' by the inlet and exhaust pipes where the location of the plane of symmetry indicates how much space the inlet or exhaust can 'use'.

This contrasts with model 2 which asserts that the inlet and exhaust pipes both use the full volume of the chamber. The result is somewhat surprising because 'doublecounting' the chamber should cause model 2 to underpredict operating frequency just like increasing the volume of a Helmholtz resonator chamber decreases its frequency - but for some reason it does not: Fig. 2-9 shows that the predictions of model 2 compare well with experiment. 

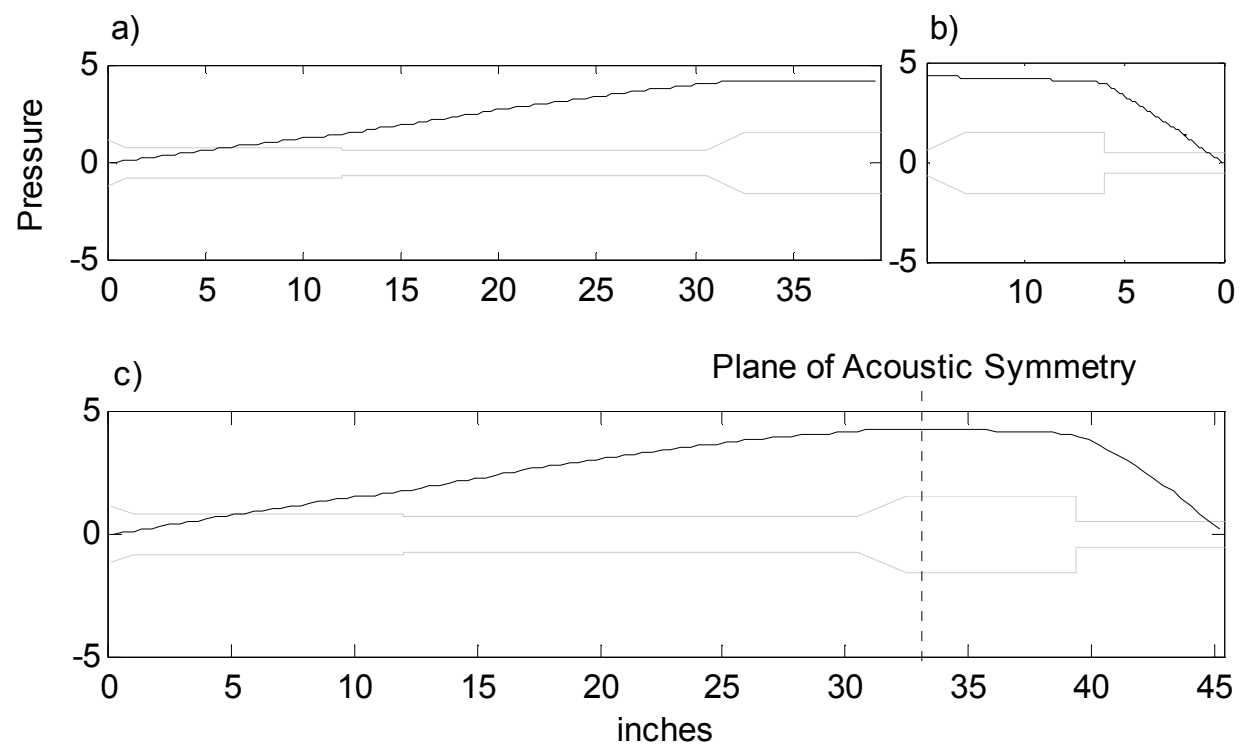

Figure 2-10: Mode shapes corresponding to (a) open tailpipe and closed chamber, (b) open inlet and closed chamber, and (c) present method.

The explanation lies with end corrections which are not incorporated in model 2. While end corrections would not normally have a major impact on the frequency of a resonator of this size, they are important here because of the large differences in temperature between the inside of the engine and the atmosphere. Incorporating end corrections of $0.65 \mathrm{~d}$ for the inlet and $0.5 \mathrm{~d}$ for the exhaust drives the predictions of model 2 (squares) away from the diagonal. Thus, it appears that the good correspondence between predictions of model 2 and measurements is serendipitous rather than physical: neglecting end corrections just so happens to offset the effect of double counting the volume of the combustion chamber volume.

\section{$\underline{2.6 \text { Higher Modes }}$}

Figure 2-11 shows pressure fluctuations at the exhaust exit plane over the course of one combustion cycle for all cases. The fluctuations are not sinusoidal and exhibit 
two peaks. Double peaking is also evident at the inlet but to a much lesser degree than the exhaust (Fig. 2-12). This double-peaking has also been observed in other studies [65] [8] but it is difficult to explain using lumped parameter theories that only consider fundamental operating frequencies. However, they are simple to explain using the present acoustic theory: If the valveless pulsejet is an acoustic duct, it will have an infinite number of acoustic modes. These higher modes appear superimposed upon the fundamental and produce the double- or multiple-peaks observed here and by others.

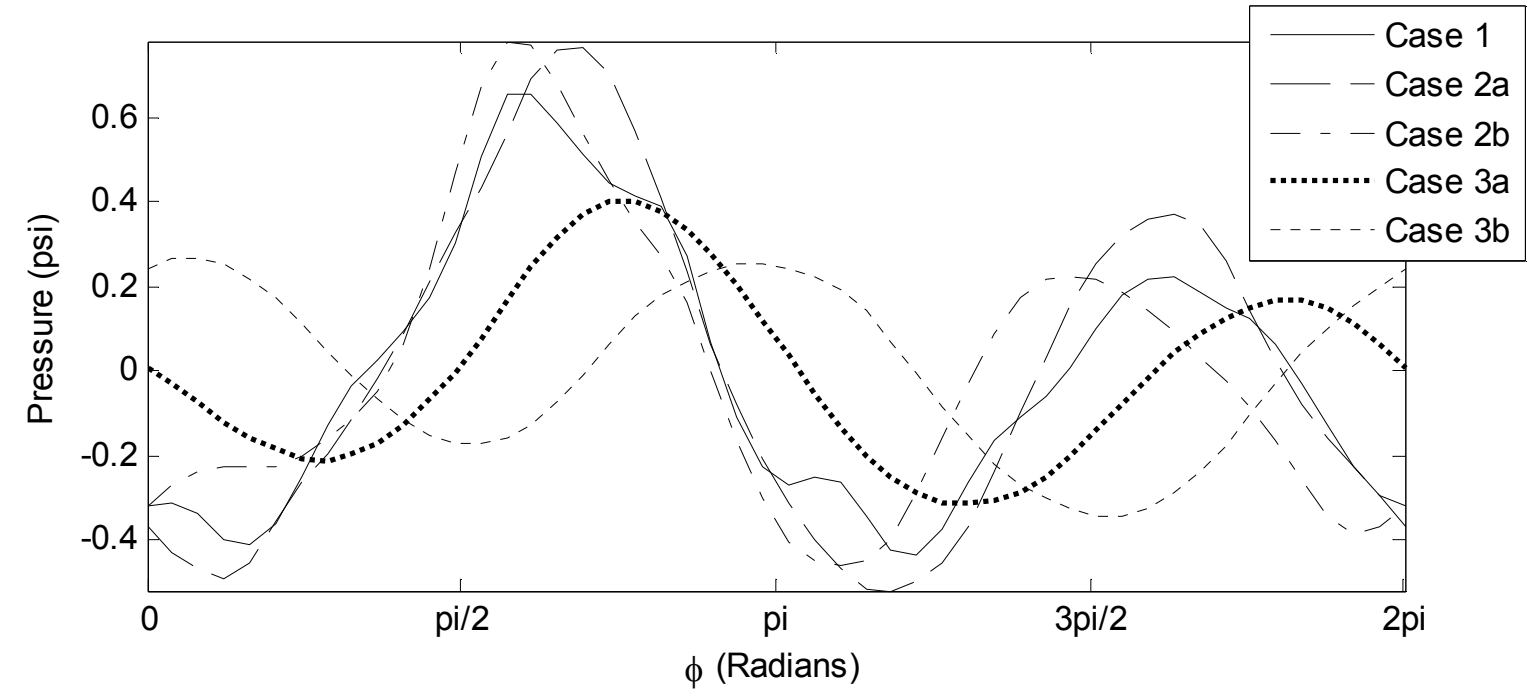

Figure 2-11: Measured exhaust pressure as a function of the phase angle of the fundamental for all test cases. 

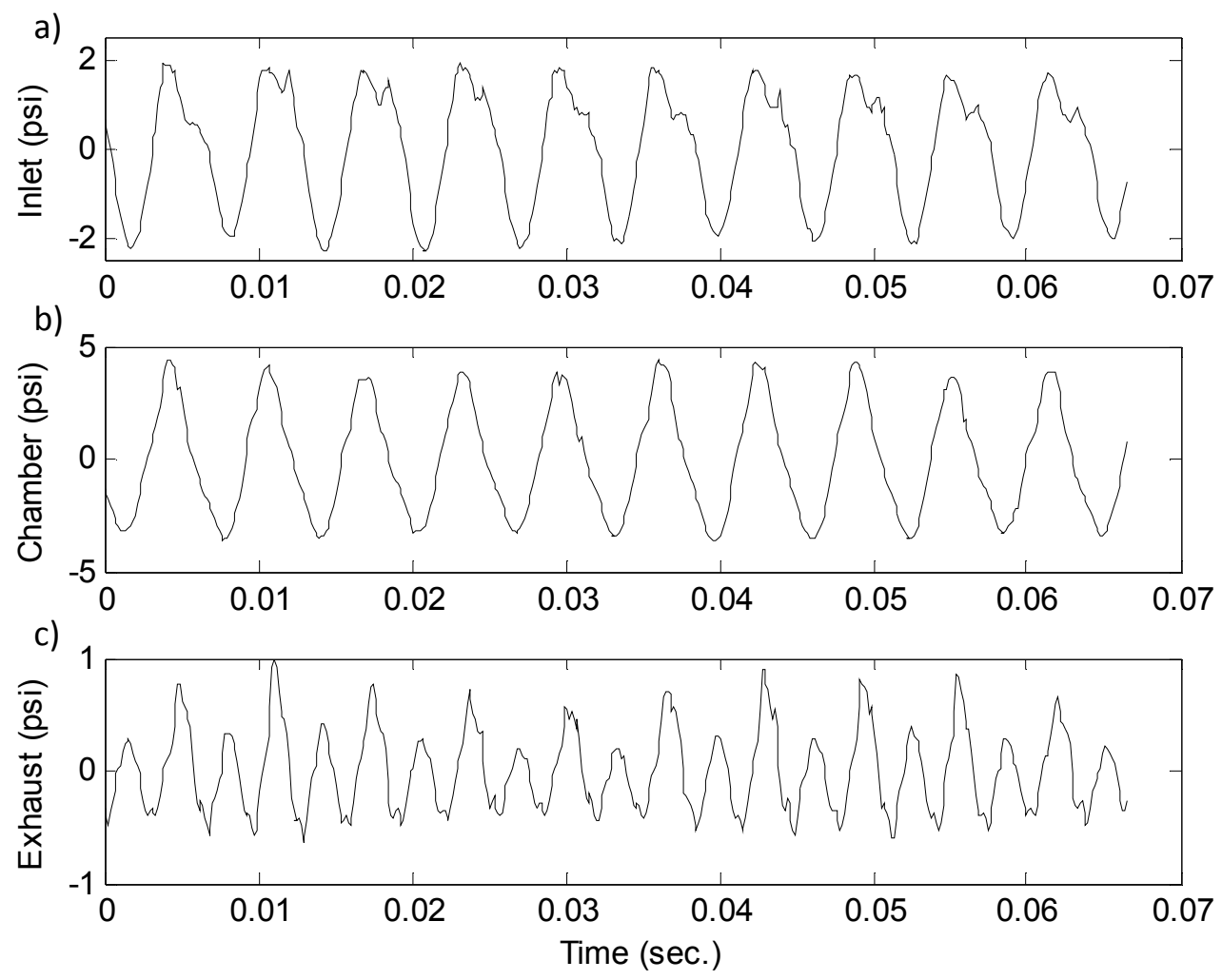

Figure 2-12: Measured (a) inlet plane, (b) chamber, and (c) exhaust plane pressure fluctuations in Configuration 1. Note: the signals in this figure are not phase-locked, i.e. the $\mathrm{x}$-axis for each plot is independent of the other plots.

Acoustic theory also explains why higher modes are less prevalent (i.e. there is less double-peaking) in the pressure signal at the inlet than at the exhaust. Figure 2-13a shows calculated pressure amplitude profiles of the first (fundamental) and second modes of Configuration 1 calculated using the experimental temperature data. Figure $2-13 b$ shows corresponding volume velocities. For the same volume velocities at the exhaust end, it can be seen that the volume velocity of the second mode is much less than the volume velocity of the fundamental at the inlet end - this is why the higher mode is less pronounced at the inlet end. 


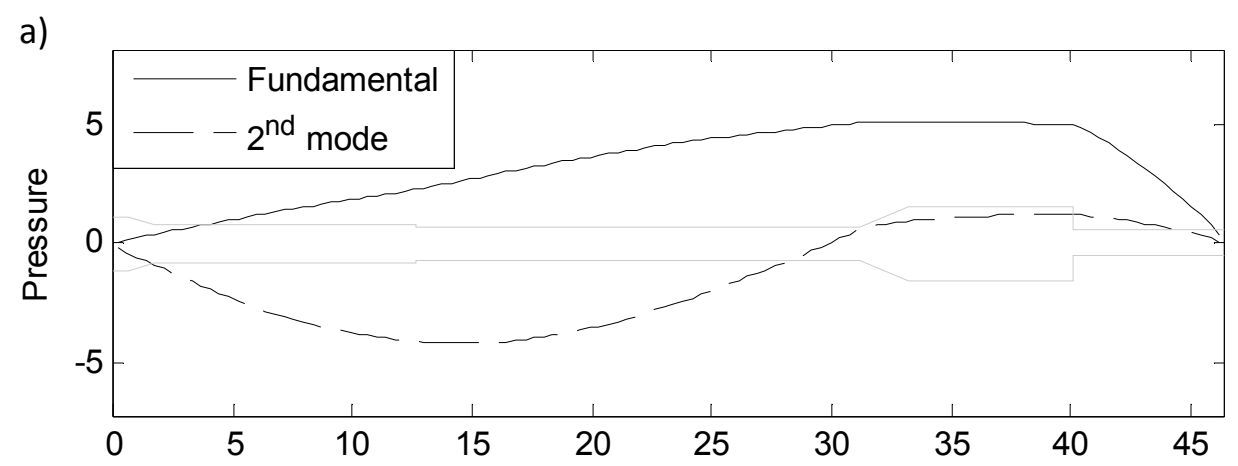

b)

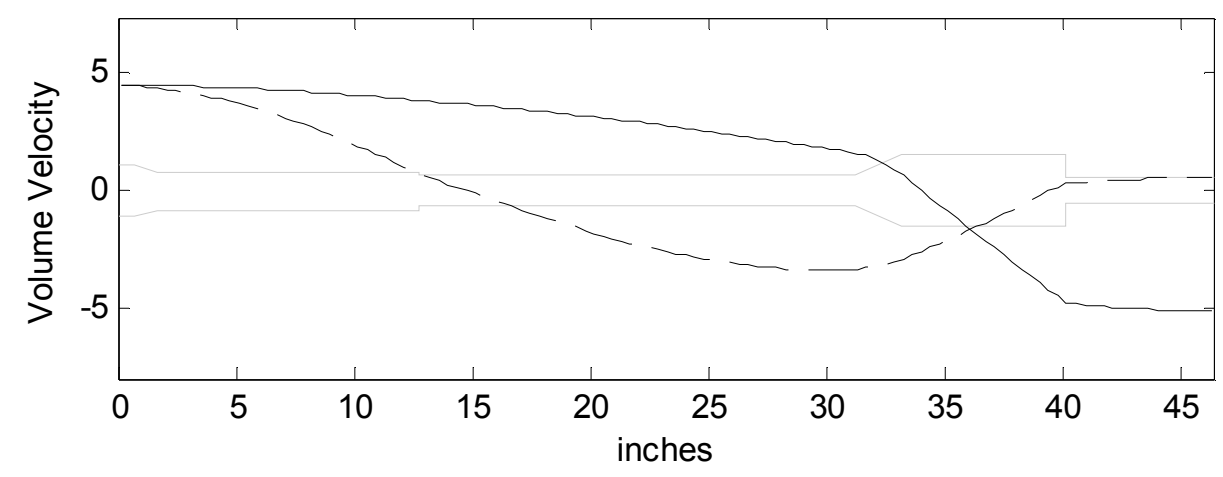

Figure 2-13: (a) Pressure, and (b) volume velocity profiles of the first two modes of Configuration 1.

Another way to explain the second mode is that the tailpipe acts like a sub-resonator within a larger resonator, i.e. the engine. The tailpipe has one end open to the atmosphere and the other end open to the chamber. The chamber is a large enough volume to also act as an open end and thus the tailpipe acts as a half-wave tube/resonator. This view is substantiated by the pressure profile of the second mode (Fig. 2-13a) which approaches zero at approximately the ends of the tube. Since the frequency of the second mode is higher than the fundamental, it is suppressed by the 
combustion chamber whose large volume (analogous to a capacitor) acts like a lowpass filter that prevents transmission of the second mode to the inlet end.

\subsection{Mitigating Higher Modes}

\subsubsection{Tone Holes}

As mentioned earlier, higher modes must be eliminated in order to enable acoustic cancellation. Higher modes can be predicted using transmission line theory (Fig. 212), but the objective of this section is to eliminate these. A potential strategy for accomplishing this is to open a tone hole near the pressure anti-node of the undesirable mode. Tone holes are one or more small holes in the duct wall and are common in musical instruments (e.g. flutes) for altering their modal behavior. One could argue that opening a tone hole at the pressure anti-node of a mode will force the pressure at that location to zero (atmospheric) thereby severely weakening or eliminating the undesirable higher mode. While there is merit in this argument, one must remember that a tone hole also has an associated inductance - the air within and around the tone hole will be set into motion by the pressure oscillations inside the engine. This air has mass which is represented by an inductance and so a calculation is necessary before any conclusions on the effectiveness of this method can be made.

A tone hole can be incorporated into transmission line analysis. If a tone hole is opened at a location corresponding to the $n^{\text {th }}$ node, the analogous electric circuit at that location is shown in Fig. 2-14. Also shown are the designated positive currents. 


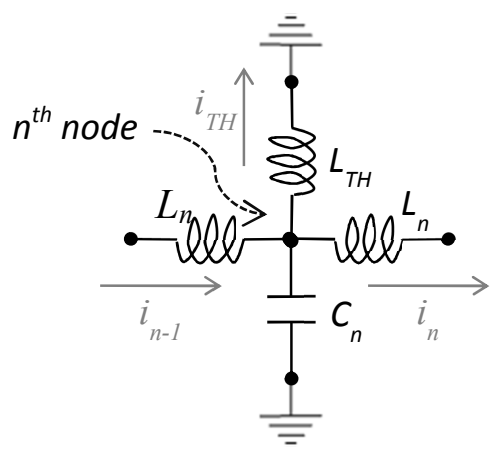

Figure 2-14: Equivalent circuit for an open tone hole at the $n^{\text {th }}$ node.

The corresponding inductance of the tone hole can be represented as [105]

$$
L_{T H}=\frac{4 \rho_{T H}(t+0.3 b)}{\pi b^{2}}
$$

where $\rho_{\mathrm{TH}}$ is the density inside and immediately outside the tone hole (which can be assumed to be atmospheric), $t$ is the thickness of hole (wall), and $b$ is the diameter of the tone hole. The purpose of this exercise is not to predict the exact value of the tone hole inductance but rather to examine the effect of a tone hole on the higher modes. In practice, the actual value of the inductance can be empirically set by changing the diameter of the tone hole. With the tone hole in the circuit, the voltage equation for the $n^{\text {th }}$ node and the current equation for the tone hole inductance are

$$
\begin{gathered}
\frac{d V_{n}}{d t}=\frac{i_{n-1}-i_{n}-i_{T H}}{C_{n}} \\
\frac{d i_{T H}}{d t}=-\frac{V_{n}}{L_{T H}}
\end{gathered}
$$


By taking the derivative of the voltage equation (eq. 2-12) and substituting in the current equation (eq. 2-13), it can be seen that the equation for the $n^{\text {th }}$ node is of the same form as in eqs. 2-6 except for the $V_{n} / C_{n} L_{T H}$ term so the tone hole can be accounted for by adding $+1 / C_{n} L_{T H}$ in the $(n, n)$ entry of the matrix $M$ described in eqs. 2-7.

Using a wall thickness of 0.145 in. $(0.37 \mathrm{~cm})$ and external atmospheric gas density in the tone hole leads to Fig. 2-15 which shows the results of mode shape calculations for tone holes of 0 in. $(0 \mathrm{~cm}), 0.3$ in. $(0.76 \mathrm{~cm})$, and 0.6 in. $(1.5 \mathrm{~cm})$ at a longitudinal location corresponding to the pressure anti-node of the undesirable second mode. The fundamental responds as expected and in a manner typically observed in musical instruments [105]: the tone hole forces the fundamental to approach zero (atmospheric) pressure faster than it would otherwise and increasing the frequency in the process. However, the second mode responds differently. Fig 2-15 shows that opening a tone hole does not eliminate the second mode. Unfortunately, the uselessness of a tone hole for suppressing higher modes was only realized after several fruitless experimental attempts at the same. 


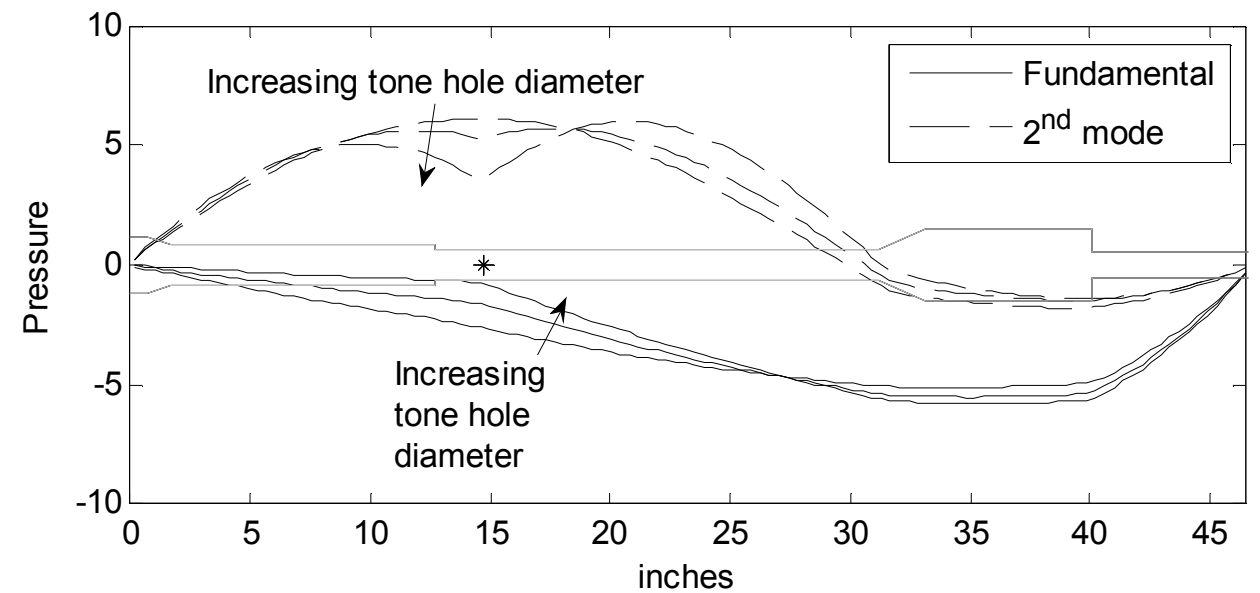

Figure 2-15: Mode shapes with increasing tone hole diameter.

\subsubsection{Helmholtz Resonators}

Another possible method for suppressing higher modes involves the use of Helmholtz resonators. If a Helmholtz resonator is tuned to the same frequency as the mode to be eliminated and (its neck is) attached to the engine/duct wall as shown in Fig. 2-16, then it should be possible to suppress that mode because the Helmholtz resonator will absorb or cancel disturbances at its resonant frequency. The use of Helmholtz resonators to suppress tonal noise transmitted through ducts is well established [106], but the goal here is to suppress a standing wave inside a duct. In other words, acoustic ducts admit the possibility of many oscillation modes, but a Helmholtz resonator should be able to render a prescribed mode mathematically and physically inaccessible. 


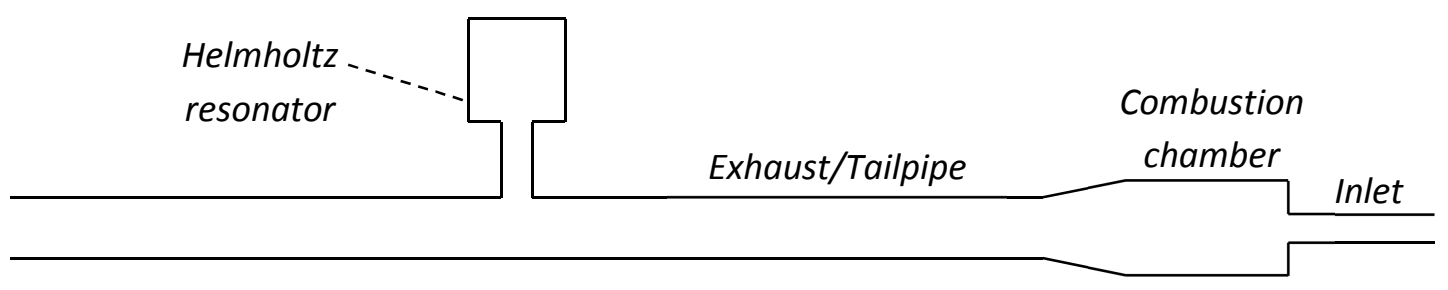

Figure 2-16: Suppression of mode using a Helmholtz resonator.

To see this, we will incorporate a Helmholtz resonator into the transmission line analysis method (Fig. 2-4). If a Helmholtz resonator is attached at a location corresponding to the $n^{\text {th }}$ node, the analogous electric circuit at that location is shown in Fig. 2-17 [15] [55]. Also shown are the designated positive currents.

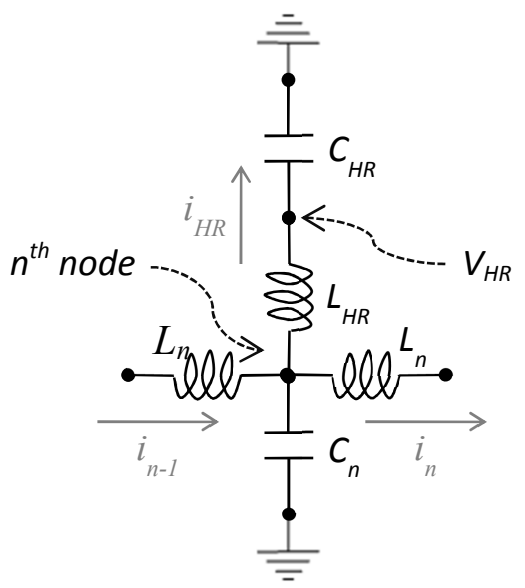

Figure 2-17: Equivalent circuit for a Helmholtz resonator at the $n^{\text {th }}$ node.

The voltage equation for the $n^{\text {th }}$ node is

$$
\frac{d V_{n}}{d t}=\frac{i_{n-1}-i_{n}-i_{H R}}{C_{n}}
$$


The voltage and current equations for the Helmholtz resonator are

$$
\begin{aligned}
& \frac{d V_{H R}}{d t}=\frac{i_{H R}}{C_{H R}} \\
& \frac{d i_{H R}}{d t}=\frac{V_{H R}-V_{n}}{L_{H R}}
\end{aligned}
$$

Since another node $\left(V_{\mathrm{HR}}\right)$ has been added to the system, another equation must also be added to the system of equations (Eqs. 2-6 and 2-7) to describe it. Consequently, the matrix $M$ will also grow by one index in both dimensions. Physically, this node is the pressure inside the Helmholtz resonator chamber. The equation for the secondderivative of $V_{\mathrm{n}}$ can be obtained by taking the second-derivative of Eq. 2-14 and substituting for the Helmholtz resonator current with Eq. 2-16. It can be verified that the equation is the same as those in Eqs. 2-6, except for the addition of the term $\left(V_{n}-V_{H R}\right) / C_{n} L_{H R}$. The corresponding terms should be incorporated into the matrix $M$. Taking the second derivative of eq. 2-15 and substituting into eq. 2-16 gives:

$$
\frac{d^{2} V_{H R}}{d t^{2}}=\frac{1}{C_{H R}} \frac{d i_{H R}}{d t}=\frac{\left(V_{H R}-V_{n}\right)}{C_{H R} L_{H R}}
$$

Equation 2-17 enables the population of relevant entries for $V_{\mathrm{HR}}$ in the matrix $M$.

The capacitance of the chamber $\left(C_{\mathrm{HR}}\right)$, and the inductance of the neck $\left(L_{\mathrm{HR}}\right)$, of the Helmholtz resonator are given by [15] [55] 


$$
\begin{aligned}
& C_{H R}=\frac{V_{H R-C}}{\rho_{H R-C} c_{H R-C}^{2}} \\
& L_{H R}=\frac{\rho_{H R-N} l_{H R-N}}{A_{H R-N}}
\end{aligned}
$$

where $V_{\mathrm{HR}-\mathrm{C}}$ is the volume of the chamber, $\rho_{\mathrm{HR}-\mathrm{C}}$ is the density of the gas inside the chamber, and $c_{\mathrm{HR}-\mathrm{C}}$ is the speed of sound inside the chamber, $\rho_{\mathrm{HR}-\mathrm{N}}$ is the density of the gas inside the neck, $l_{\mathrm{HR}-\mathrm{N}}$ is the length of the neck, and $A_{\mathrm{HR}-\mathrm{N}}$ is the cross-sectional area of the neck. Note that the length of the neck should include end corrections but the purpose of this exercise is not to calculate the exact value of the analogous inductance and capacitance of the Helmholtz resonator but instead to examine the effect of adding to an acoustic duct a Helmholtz resonator tuned to the same frequency as an undesirable mode. In practice, the dimensions of the resonator are adjusted experimentally to obtain a given resonance frequency.

Transmission line calculations were performed with a Helmholtz resonator at the axial (longitudinal) location corresponding to the pressure anti-node of the undesirable second mode. The temperature (and therefore density and speed of sound) inside the Helmholtz resonator was assumed to be the same as inside the engine at that axial location $(994 \mathrm{~K})$. The Helmholtz resonator should be tuned to the same frequency as the mode to be eliminated. With a neck diameter and length of 1 in. (2.5 $\mathrm{cm})$ and 2 in. $(5.1 \mathrm{~cm})$ respectively, it can be shown that the required volume is 35.4 in. ${ }^{3}\left(580 \mathrm{~cm}^{3}\right)$ to achieve the same resonance frequency as the second mode $(417.3$ $\mathrm{Hz}$ ). The corresponding capacitance and inductance for transmission line analysis is 4.1 $\mathrm{nF}$ and $35.6 \mathrm{H}$. It will be stressed again that the dimensions calculated here are 
only of academic relevance. In practice, the geometry of acoustic resonators are often adjusted experimentally to 'tune' them. Also note that the particular values of the dimensions can be chosen differently as long as the capacitance and inductance of the Helmholtz resonator circuit produce the same resonant frequency.

Figure 2-18 (a) shows the fundamental and second mode shapes in Configuration 1 without a Helmholtz resonator (this is the same result as Fig. 2-13). Figure 2-18 (b) shows the mode shapes with the Helmholtz resonator at the pressure anti-node of the second mode (indicated by the asterisk on the engine). The figure clearly shows that adding the Helmholtz resonator severely weakens the second mode reducing nearly to zero. One might be tempted to conclude that the Helmholtz resonator has eliminated the second mode. However, one must recall that the absolute magnitude of the eigenvectors (the mode shapes) is meaningless as they only define the shape. Sure enough, the re-scaled view in Fig. 2-18 (c) shows that the second mode still exists with the same shape. However, the system of equations with the Helmholtz resonator has an additional node $\left(V_{\mathrm{HR}}\right)$ that produces another eigenmode. This mode is also plotted in Fig. 18 (c) where it is clear that this mode is equal and opposite in magnitude to the second mode. Since the frequencies of the two modes are exactly the same $(417.3 \mathrm{~Hz})$, these modes will always exist (mathematically) but will always perfectly cancel each other. Taken together, this analysis suggests that undesirable modes can be eliminated or mitigated by the use of a tuned Helmholtz resonator attached to the engine. Finally, another way of looking at the effect of a Helmholtz 
resonator is to think of the resonator circuit as a band-pass filter that shorts signals at its resonance frequency to ground.
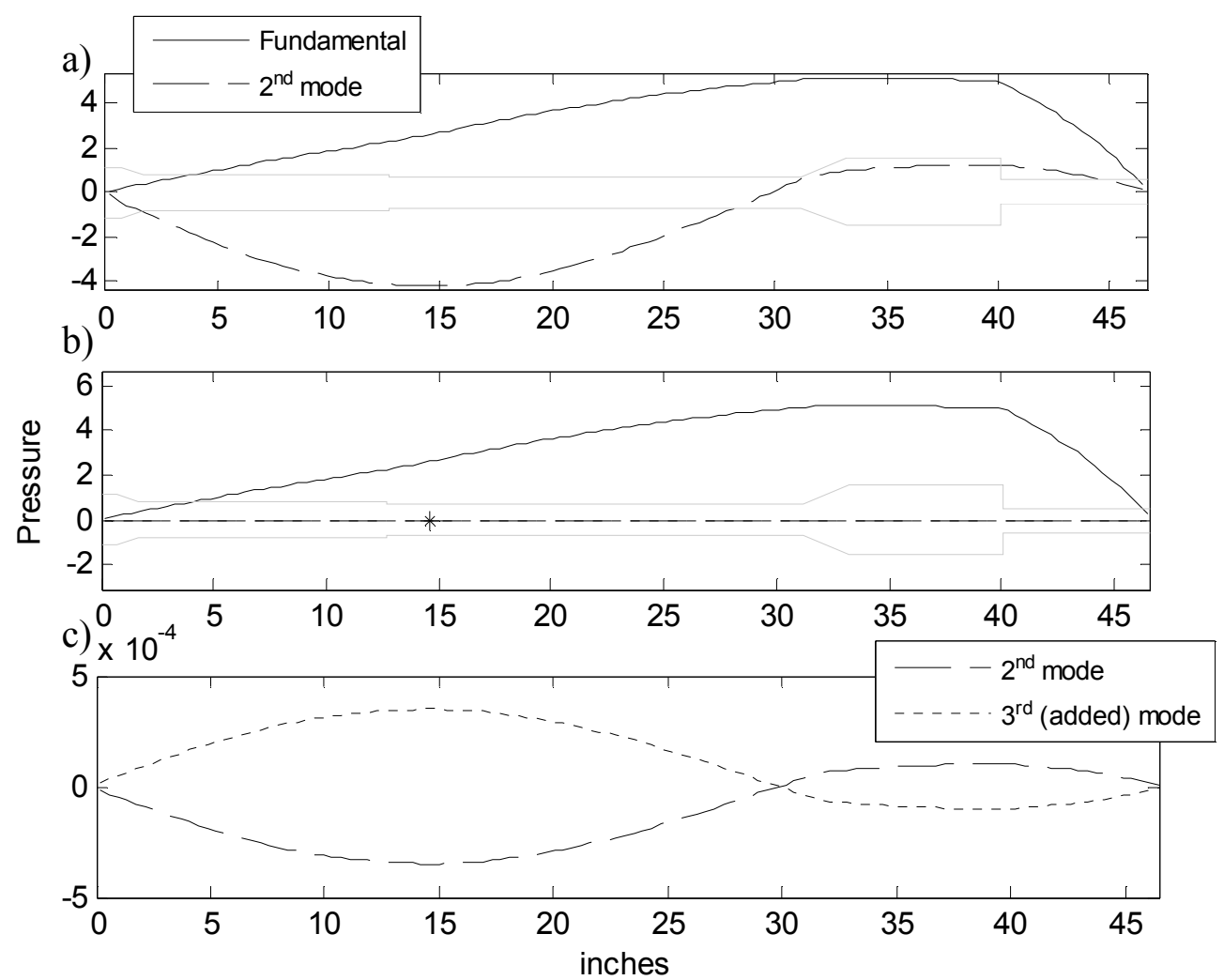

Figure 2-18: a) Mode shapes without Helmholtz resonator, b) Mode shapes with Helmholtz resonator, and c) Mode shapes of $2^{\text {nd }}$ and $3^{\text {rd }}$ modes.

The preceding calculation assumes that the Helmholtz resonator is attached at the pressure anti-node of the undesirable mode, but the calculation result will not be different if the location is changed. In practice, however, the resonator should be placed at the pressure anti-node to ensure maximum pressure amplitude for the Helmholtz resonator to interact with (cancel). To substantiate this, consider the opposite: a Helmholtz resonator placed at the pressure node. In this case there will be 
no pressure fluctuations at the resonator inlet and consequently the resonator will have no effect on that mode.

Lastly, other types of resonators like quarter-wave tubes can also be used to eliminate particular modes inside the engine. However, quarter wave tubes may be difficult to implement in practice because of their narrow bandwidths (as compared with Helmholtz resonators). 


\section{Chapter 3: Acoustic System Analysis}

\section{$\underline{3.1 \text { Introduction }}$}

The preceding chapter analyzed the valveless pulsejet as an acoustic duct using transmission line theory. Using information from the previous chapter, this chapter will build an analogous acoustic system/circuit for the engine. Other models exist and have been compared with experiment in the previous chapter, but they are deficient in one way or another; lumped parameter models do not account for wave motion inside the tailpipe and therefore over-predict frequency, whereas the model of Zheng et al. [53] does not account for radiation impedance and subsequently loses accuracy, and is also limited to frequency predictions. This chapter will build a theoretical framework that will incorporate all phenomena, quantifying and separating the effects of individual components (chamber, inlet, tailpipe), and most importantly, will explain the interaction of multiple engines. The influence of each component on overall engine behaviour provides important insight for engine design, because it allows one to isolate the effect of and subsequently manipulate particular component geometries to achieve desired performance outcomes. Furthermore, as discussed in section 1.4.3, multiple engines can be made to work in- and out-of-phase with different coupling arrangements. Many of these arrangements have been studied experimentally and numerically, but their results have not been explained by a comprehensive theory, which is the objective of this chapter. 


\subsection{Acoustic System for a Single Valveless Pulsejet}

\subsubsection{Theory}

A valveless pulsejet consists of three main components: the inlet, the combustion chamber, and the tailpipe (exhaust). When provoked with a periodic disturbance, the response of each component can be represented by an impedance. The inlet is a short tube, (usually) much smaller than a wavelength, so it can be represented as an acoustic inertance (analogous to an electrical inductance). The combustion chamber is a relatively large volume so it can be represented as an acoustic compliance (analogous to an electrical capacitance), but the tailpipe is of a length comparable to the wavelength, and so it must be modelled as a transmission line.

These impedances can be arranged to form a representative circuit for the engine with $p$ being pressure and $U$ being flow velocity. However, radiation impedance (end effects) must also be accounted for. As shown in the previous chapter, radiation impedances (end corrections) can have a substantial impact on the calculated frequency of the engine because of the large temperature (and therefore density) difference between the inside of the engine and the atmosphere. With this in mind, the circuit describing a valveless pulsejet (excited by an external pressure source) is shown in Fig. 3-1. 


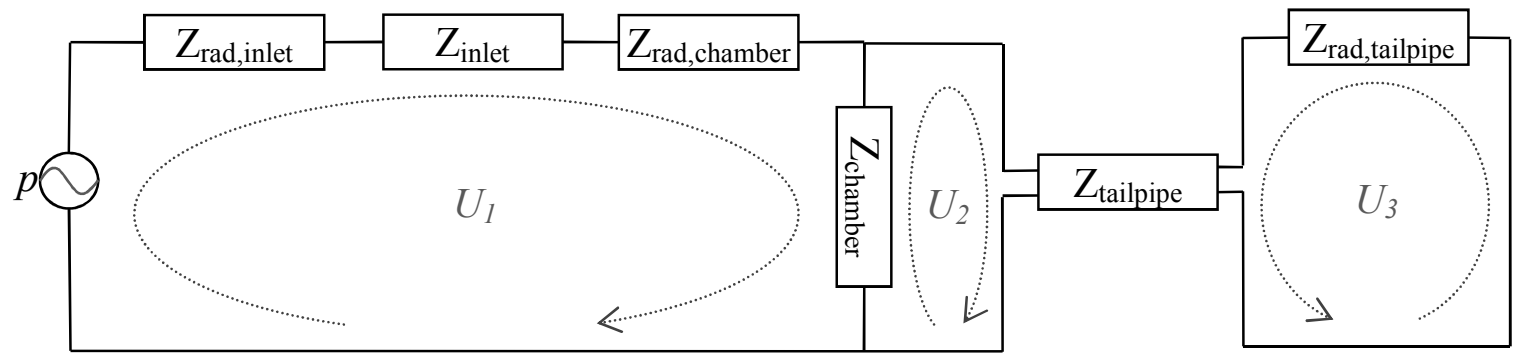

Figure 3-1: Valveless pulse acoustic system/circuit.

The corresponding inlet and chamber impedances are [100]

$$
\begin{aligned}
& Z_{\text {inlet }}=j \omega\left(\frac{\rho l}{S}\right) \\
& Z_{\text {chamber }}=-\frac{j \rho c^{2}}{V \omega}
\end{aligned}
$$

The tailpipe has to be characterized by two impedances, because the pressure at one end is affected by flow at both ends of the tailpipe. In physical terms, the pressure at one end of the tailpipe is not only influenced by the flow moving into (or out of) that end, but also the flow moving into (or out of) the other end. In a short duct (relative to the wavelength), represented as an impedance, the flow is in phase, so the flow going into one end has to be same as the flow coming out the other end. However, a tube with length comparable to the wavelength, admits the possibility of wave motion and it is no longer necessary that the flow going into one end is the same as that coming out the other end, hence the need for two impedances to describe that component. Figure 3-1 also illustrates the notation to be used, for example, $Z^{23}$ is the impedance for loop $U_{2}$ due to $U_{3}$ ). For this analysis, the tailpipe is assumed to be of constant area 
and symmetric, leading to the conditions $Z^{22}=Z^{33}$ and $Z^{23}=Z^{32}$. The impedances are [100]

$$
\begin{aligned}
& Z_{\text {tailpipe }}^{22}=Z_{\text {tailpipe }}^{33}=-j \frac{\rho c}{S} \cot \left(\frac{\omega l}{c}\right) \\
& Z_{\text {tailpipe }}^{23}=Z_{\text {tailpipe }}^{32}=-j \frac{\rho c}{S} \operatorname{cosec}\left(\frac{\omega l}{c}\right)
\end{aligned}
$$

Lastly, radiation impedance is [100] [15]

$$
Z_{\text {rad }} \approx 0.16 \frac{\rho \omega}{c}+j \omega \frac{\rho a}{S}
$$

where $a$ and $S$ are the radius and surface area of the duct respectively. At low frequencies, the real part of the radiation impedance is often neglected. The appropriateness of this assumption can be checked by examining the relative strengths of the real and imaginary parts of the radiation impedance for the pulsejet exhaust. Using $f=200 \mathrm{~Hz}, \rho=1.18 \mathrm{~kg} / \mathrm{m}^{3}, c=340 \mathrm{~m} / \mathrm{s}$, and $a=0.0254 \mathrm{~m}$ (radius of inlet), and keeping in mind that $\omega=2 \pi f$, the radiation impedance $\left(Z_{r a d}\right)$ is $875+$ $j 11,095$. Thus, the real part of the impedance is an order of magnitude less than the reactive (imaginary) part. At lower frequencies and in smaller diameter ducts (like the inlet), the real part will be even smaller so the assumption appears justified and will be made here. The real part is also of little consequence to the calculated resonance frequency, which the objective here. 
The total pressure across each loop must be zero (analogous to Kirchhoff's voltage law). This produces three equations corresponding to the three loops:

$$
\begin{array}{cc}
U_{1}\left(Z_{\text {rad,inlet }}+Z_{\text {inlet }}+Z_{\text {rad,chamber }}\right)+\left(U_{1}-U_{2}\right) Z_{\text {chamber }}=p & \text { Eq. (3-6) } \\
\left(U_{2}-U_{1}\right) Z_{\text {chamber }}+U_{2} Z_{\text {tailpipe }}^{22}+U_{3} Z_{\text {tailpipe }}^{23}=0 & \text { Eq. (3-7) } \\
U_{3} Z_{\text {rad,tailpipe }}+U_{3} Z_{\text {tailpipe }}^{33}+U_{2} Z_{\text {tailpipe }}^{32}=0 & \text { Eq. (3-8) }
\end{array}
$$

We can eliminate variables $U_{2}$ and $U_{3}$ from these equations to arrive at an equation for $p$ as a function of $U_{1}$ (also using $Z^{22}=Z^{33}$ and $Z^{23}=Z^{32}$ ):

$p=\left[Z_{\text {rad,inlet }}+Z_{\text {inlet }}+Z_{\text {rad,chamber }}+Z_{\text {chamber }}-\frac{\left(Z_{\text {chamber }}\right)^{2}\left(z_{\text {rad,tailpipe }}+Z_{\text {tailpipe }}^{22}\right)}{\left(z_{\text {chamber }}+Z_{\text {tailpipe }}^{22}\right)\left(z_{\text {rad,tailpipe }}+Z_{\text {tailpipe }}^{22}\right)-\left(z_{\text {tailpipe }}^{23}\right)^{2}}\right] U_{1}$

Eq. (3-9)

The term in brackets is complex and describes the frequency response of the valveless pulsejet engine. The magnitude of this function can be plotted as a function of frequency (a Bode plot). The peak and trough will indicate anti-resonance and resonance respectively. The phase of such functions will also be useful in explaining the interaction of multiple engines, i.e. why they work in- and out-of-phase in certain arrangements.

\subsubsection{Results}

As was done in the lumped parameter analysis of the previous chapter, mean temperatures for each component (inlet, chamber, tailpipe) were computed using the 
experimental data (temperature distribution). Furthermore, the tailpipe was assumed to be a constant area tube where the area is taken to be the tailpipe volume divided by its length. These quantities (tabulated in table 3-1) along with atmospheric properties for the radiation impedance, were used to calculate the impedances and the resulting term in brackets in eq. 3-9. The magnitude of this term is plotted for configurations 15 in Fig. 3-2. The resonances and anti-resonances are clearly visible in this plot. The resonant frequencies, which should correspond with the operational frequencies of the pulsejet, are also tabulated in table $3-1$. Note that they are nearly identical (within $3 \%$ ) to the values reported in table $2-2$ in the previous section demonstrating that the acoustic impedance theory produces the same results as the transmission line theory.

Table 3-1: Averaged values and results of acoustic system calculation.

\begin{tabular}{|c|c|c|c|c|c|c|c|c|c|}
\hline $\begin{array}{c}\text { Test } \\
\text { Case }\end{array}$ & $\begin{array}{c}\rho_{\text {inlet }} \\
\left(\mathrm{kg} / \mathrm{m}^{3}\right)\end{array}$ & $\begin{array}{c}\rho_{\text {chamber }} \\
\left(\mathrm{kg} / \mathrm{m}^{3}\right)\end{array}$ & $\begin{array}{c}\rho_{\text {tailpipe }} \\
\left(\mathrm{kg} / \mathrm{m}^{3}\right)\end{array}$ & $\begin{array}{c}c_{\text {chamber }} \\
(\mathrm{m} / \mathrm{s})\end{array}$ & $\begin{array}{c}c_{\text {tailpipe }} \\
(\mathrm{m} / \mathrm{s})\end{array}$ & $\begin{array}{c}S_{\text {tailpipe }} \\
\left(\mathrm{m}^{2}\right)\end{array}$ & $\begin{array}{c}f_{\text {resonance }} \\
(\mathrm{Hz})\end{array}$ & $\begin{array}{c}f_{\text {experiment }} \\
(\mathrm{Hz})\end{array}$ & $\begin{array}{c}\text { Error } \\
(\%)\end{array}$ \\
\hline 1 & 0.54 & 0.4 & 0.35 & 599 & 626 & 0.0011 & 157 & 160 & -1.8 \\
\hline $2 a$ & 0.53 & 0.39 & 0.35 & 602 & 630 & 0.0011 & 163 & 164 & -0.6 \\
\hline $2 b$ & 0.55 & 0.39 & 0.34 & 602 & 635 & 0.0011 & 168 & 168 & 0 \\
\hline $3 a$ & 0.46 & 0.35 & 0.33 & 638 & 657 & 0.0011 & 187 & 182 & 2.7 \\
\hline $3 b$ & 0.34 & 0.32 & 0.3 & 669 & 683 & 0.0011 & 224 & 211 & 6.2 \\
\hline
\end{tabular}




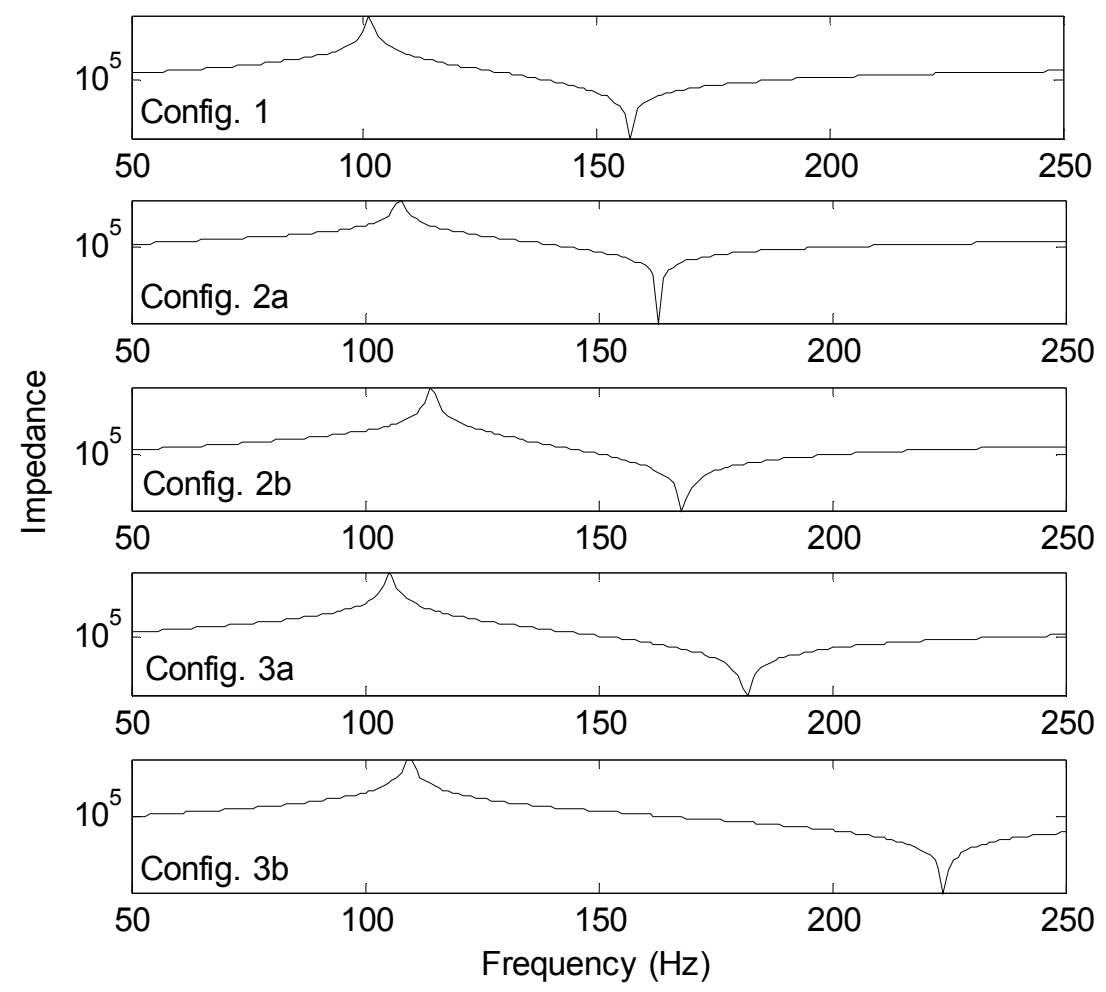

Figure 3-2: Bode plots for valveless pulsejet acoustic circuit.

\subsection{Acoustic Systems for Multiple Pulsejets}

\subsubsection{Connection via Short Duct}

As explained in the introduction, it has been observed by several researchers that connecting the combustion chambers of valveless pulsejets with short ducts will cause the engines to operate in-phase [44] [76]. While this has been established experimentally, a theoretical basis for explaining this behavior is desirable in order to understand how to get them to operate out of phase. This understanding can be derived using the acoustic system concept described in the previous section. Figure 33 shows two identical pulsejets connected at their combustion chambers by a short 
duct and Fig. 3-4 shows the corresponding acoustic circuit. The impedance of the short connecting duct is of the same form as that of the inlet (Eq. 1):

$$
Z_{\text {connect }}=j \omega\left(\frac{\rho l}{S}\right)
$$

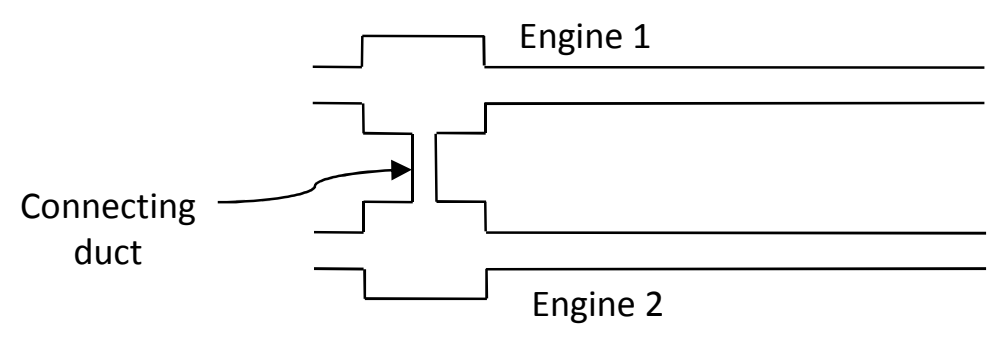

Figure 3-3: Two interconnected pulsejet engines.

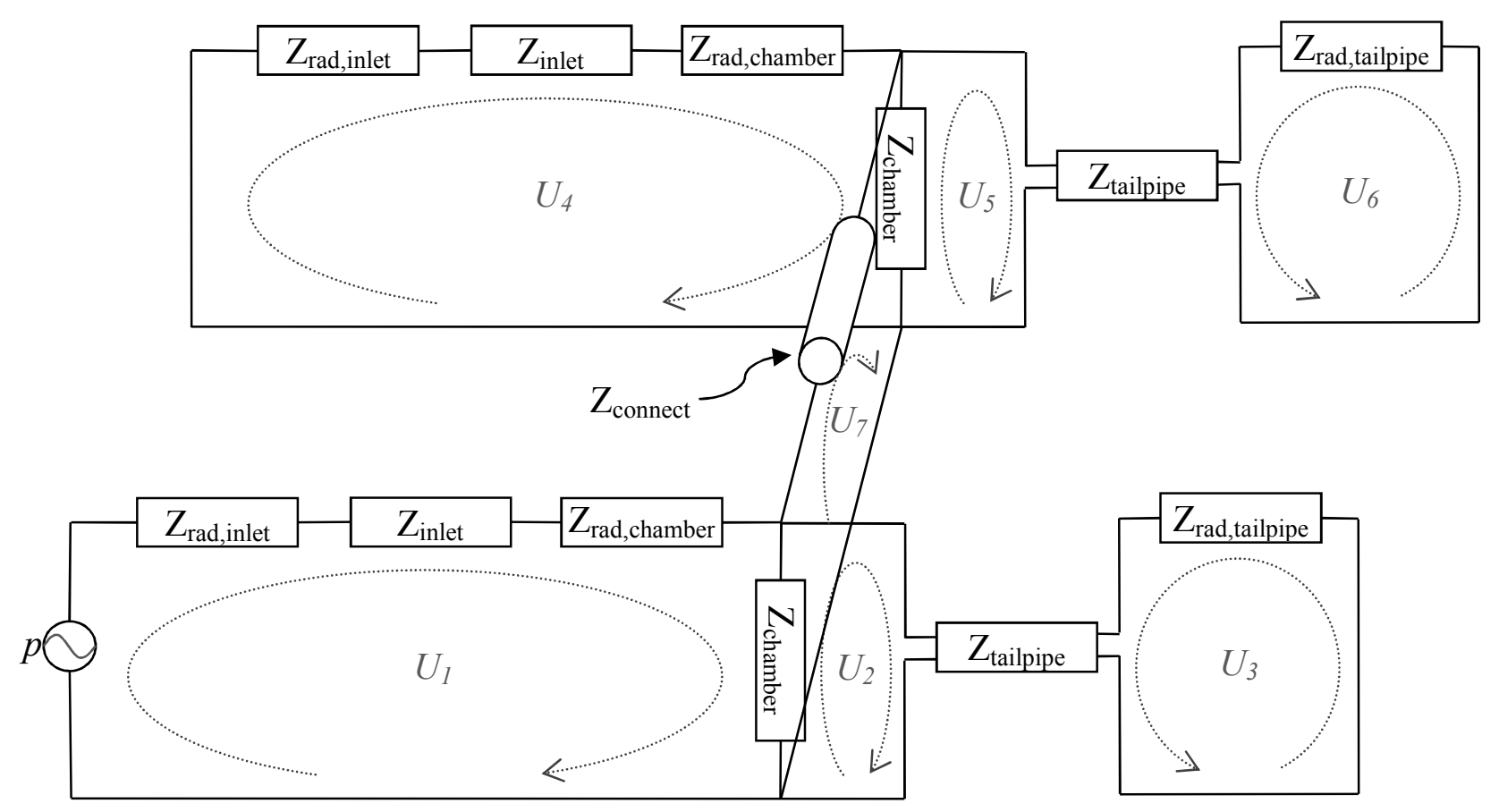

Figure 3-4: Acoustic system/circuit for two interconnected pulsejet engines. 
This figure shows that there are now seven current loops to contend with. Kirchoff's equations are:

$$
\begin{gathered}
U_{1}\left(Z_{\text {rad,inlet }}+Z_{\text {inlet }}+Z_{\text {rad,chamber }}\right)+\left(U_{1}-U_{2}-U_{7}\right) Z_{\text {chamber }}=p \\
\left(U_{2}-U_{1}+U_{7}\right) Z_{\text {chamber }}+U_{2} Z_{\text {tailpipe }}^{22}+U_{3} Z_{\text {tailpipe }}^{23}=0 \\
U_{3} Z_{\text {rad,tailpipe }}+U_{3} Z_{\text {tailpipe }}^{33}+U_{2} Z_{\text {tailpipe }}^{32}=0 \\
\left(U_{7}+U_{2}-U_{1}\right) Z_{\text {chamber }}+U_{7} Z_{\text {connect }}+\left(U_{7}+U_{4}-U_{5}\right) Z_{\text {chamber }}=0 \\
U_{4}\left(Z_{\text {rad,inlet }}+Z_{\text {inlet }}+Z_{\text {rad,chamber }}\right)+\left(U_{7}+U_{4}-U_{5}\right) Z_{\text {chamber }}=0 \\
\left(U_{5}-U_{7}-U_{4}\right) Z_{\text {chamber }}+U_{5} Z_{\text {tailpipe }}^{55}+U_{6} Z_{\text {tailpipe }}^{56}=0 \\
U_{6} Z_{\text {rad,tailpipe }}+U_{6} Z_{\text {tailpipe }}^{66}+U_{5} Z_{\text {tailpipe }}^{65}=0
\end{gathered}
$$

Because of the symmetry of the tailpipe and the assumption that the engines are identical, $\quad Z_{\text {tailpipe }}^{22}=Z_{\text {tailpipe }}^{33}=Z_{\text {tailpipe }}^{55}=Z_{\text {tailpipe }}^{66}$ and $Z_{\text {tailpipe }}^{23}=Z_{\text {tailpipe }}^{32}=$ $Z_{\text {tailpipe }}^{56}=Z_{\text {tailpipe }}^{65}$. These values are given by eqs. 3-3 and 3-4 respectively. Equations 3-11 to 3-17 can be solved to yield impedances for current/velocity loops (i.e. the relationship between velocity loops and pressure). To observe the interaction between the two engines, one should consider the impedance of a current loop in one engine (e.g. $U_{1}$ ), and its corresponding counterpart in the other engine (e.g. $\left.U_{4}\right)$. These are defined as:

$$
\begin{aligned}
& Z_{1}=\frac{p}{U_{1}} \\
& Z_{4}=\frac{p}{U_{4}}
\end{aligned}
$$


It is possible to derive analytical expressions for these impedances. The calculation is tedious and best performed using a mathematical solver (MATLAB, Mathematica, etc.). The expressions are very long and impractical (and not useful) to state here (see Appendix A), but the results using the values of test case 1 are plotted in Fig. 3-5. Figure 3-5 shows that the fundamental frequency (resonance at $157 \mathrm{~Hz}$ ) of the combined system is the same as that of a single engine. It also shows that the phase difference between the two engines at this resonant mode is zero, i.e. the engines operate in-phase as has been observed experimentally. Furthermore, Fig. 3-5 predicts that there is another resonant mode at a slightly higher frequency $(191 \mathrm{~Hz})$, at which the engines will prefer to operate at a phase difference of $\pi$ radians. This is the coveted anti-phase solution. 

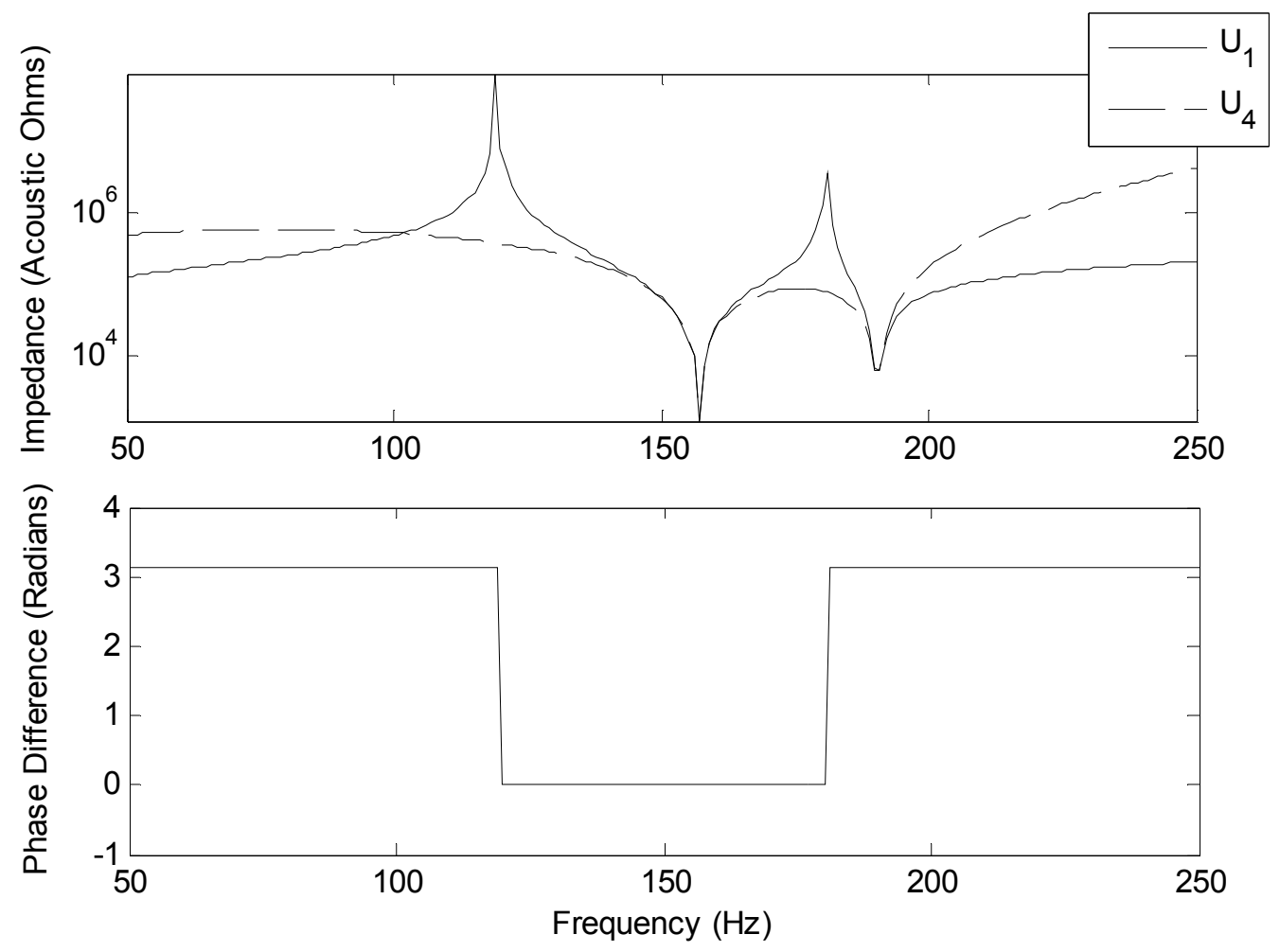

Figure 3-5: Frequency response for interconnected pulsejet engines.

The individual engines have been designed, given their frequencies, pressure profiles, and fuel injection/heat release schemes, to operate at their individual fundamental mode of instability. If they are incorporated into a larger system, this larger system will have other modal possibilities, but all of them may not be practically realizable because different modes imply different frequencies and pressure profiles across the engines that may or may not be compatible with the existing heat release mechanisms of the engine to produce a self-sustaining instability (according to Rayleigh's criterion). Given a mode of the larger system that corresponds to the fundamental mode of the individual engines; the system will prefer to operate at this mode because the individual engines prefer this mode. Nevertheless, it can still sometimes possible 
to force the system into another mode, even though it is not naturally preferred by the system. For the case in study, with two engines interconnected by a short duct, the engines will prefer to lock in-phase because this mode is consistent with their isolated/natural operation. However, if one engine is turned off, the in-phase mode of operation is not physically realizable because that engine cannot, by itself, produce a pressure rise and must be driven by the other engine. In this case, flow/current will flow from one combustion chamber to the other via the connecting duct, and the system must switch to the higher, anti-phase mode. The results of this section are explored experimentally later in this chapter.

\subsubsection{Connection via Decoupling Chamber}

As also explained in the introduction, several researchers have shown that connecting either the inlets or tailpipes (exhaust) ends of two engines to one another by means of a large chamber will cause the engines to operate in anti-phase [73] [9] [80]. This chamber is often called a 'decoupling chamber,' and it is vented to the atmosphere by another short duct as illustrated in Fig. 3-6. The acoustic system methodology can also be used to explain why decoupling chambers cause these engines to operate outof-phase (anti-phase). Figure 3-7 shows the representative acoustic system for two valveless pulsejets connected at their exhausts via a decoupling chamber which, in turn, is connected to the atmosphere by a short duct. 


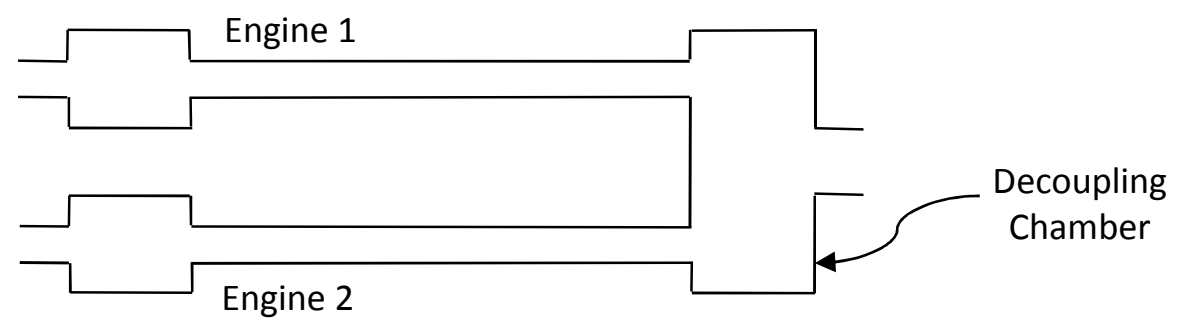

Figure 3-6: Pulsejet engines connected via a decoupling chamber.

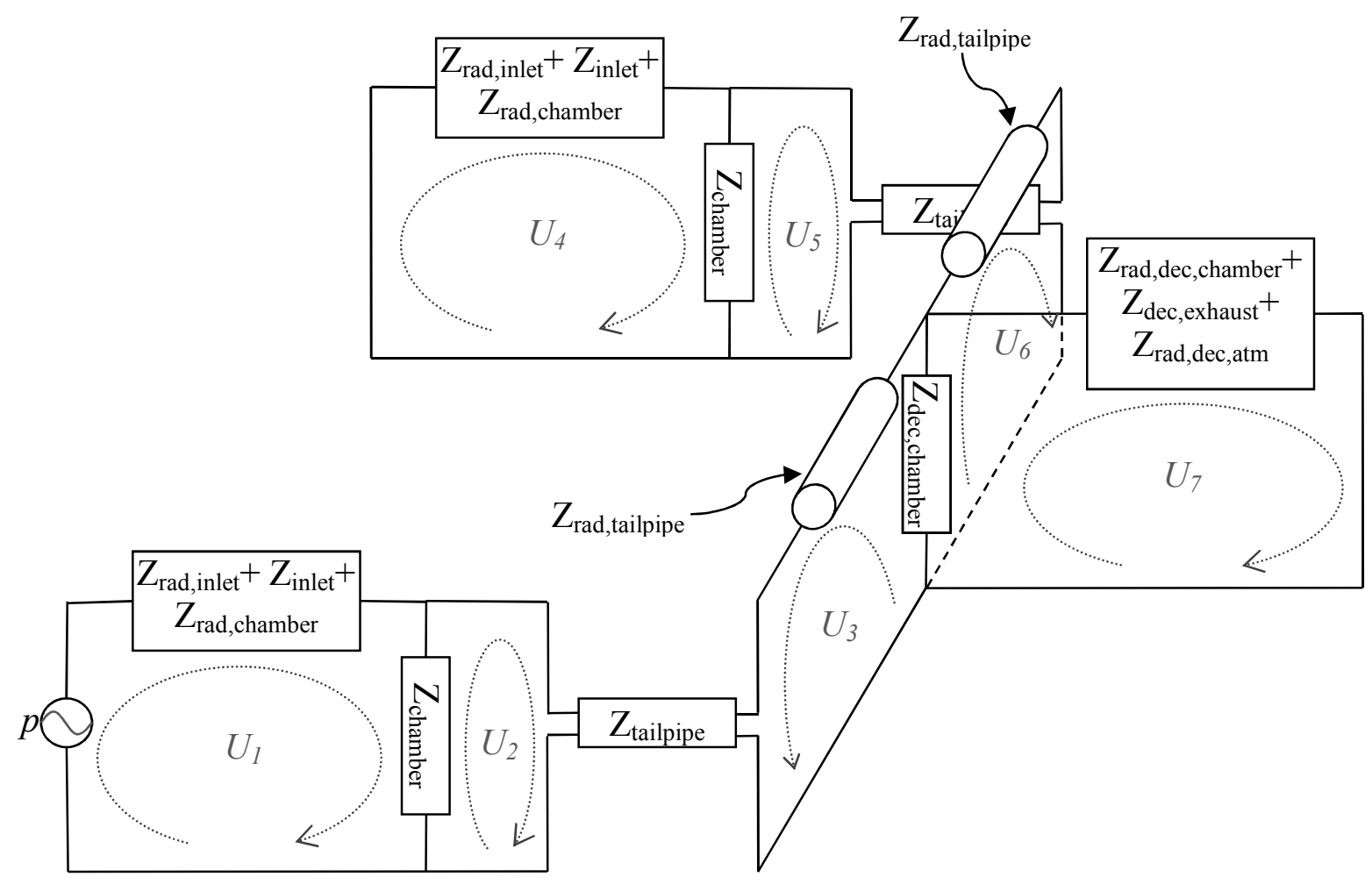

Figure 3-7: Acoustic system/circuit for pulsejet engines connected via a decoupling chamber.

The decoupling chamber acts as a capacitance with impedance $Z_{\text {dec,chamber, }}$, which is of the same form as eq. 3-2. The decoupling chamber vents to the atmosphere by a short 
duct for which the impedance is $Z_{\text {dec,exhaust }}$ (eq. 3-1). The corresponding radiation impedances for the decoupling chamber and the atmosphere are $Z_{\text {rad,dec,chamber }}$ and $Z_{\text {rad,dec,atm }}$ (eq. 3-5). There are now seven loops (Fig. 3-7) and therefore seven equations:

$$
\begin{array}{cc}
U_{1}\left(Z_{\text {rad,inlet }}+Z_{\text {inlet }}+Z_{\text {rad,chamber }}\right)+\left(U_{1}-U_{2}\right) Z_{\text {chamber }}=p & \text { Eq. }(3-20) \\
\left(U_{2}-U_{1}\right) Z_{\text {chamber }}+U_{2} Z_{\text {tailpipe }}^{22}+U_{3} Z_{\text {tailpipe }}^{23}=0 & \text { Eq. }(3-21) \\
\left(U_{3}+U_{7}+U_{6}\right) Z_{\text {dec,chamber }}+U_{3} Z_{\text {rad,tailpipe }}+U_{3} Z_{\text {tailpipe }}^{33}+U_{2} Z_{\text {tailpipe }}^{32}=0 & \text { Eq. (3-22) } \\
U_{4}\left(Z_{\text {rad,inlet }}+Z_{\text {inlet }}+Z_{\text {rad,chamber }}\right)+\left(U_{4}-U_{5}\right) Z_{\text {chamber }}=0 & \text { Eq. (3-23) } \\
\left(U_{5}-U_{4}\right) Z_{\text {chamber }}+U_{5} Z_{\text {tailpipe }}^{55}+U_{6} Z_{\text {tailpipe }}^{56}=0 & \text { Eq. (3-24) } \\
\left(U_{3}+U_{7}+U_{6}\right) Z_{\text {dec,chamber }}+U_{6} Z_{\text {rad,tailpipe }}+U_{6} Z_{\text {tailpipe }}^{66}+U_{5} Z_{\text {tailpipe }}^{65}=0 & \text { Eq. }(3-25) \\
\left(U_{7}+U_{3}+U_{6}\right) Z_{\text {dec,chamber }}+U_{7}\left(Z_{\text {rad,dec,chamber }}+Z_{\text {dec,exhaust }}+Z_{\text {rad,dec,atm })}\right) &
\end{array}
$$

For calculation purposes, it is assumed that the volume of the decoupling chamber is four times larger than that of each combustion chamber, the area of the decoupling chamber exhaust duct is twice the area of each tailpipe, and the length of the decoupling chamber exhaust duct is the same as that of the inlet. Furthermore, it is assumed that the temperature in the decoupling chamber and exhaust duct is the average of the tailpipe exhaust and ambient temperatures. The results are plotted in Fig. 3-8. While these geometrical assumptions approximate systems that have been 
studied experimentally by other researchers, the numbers are only chosen to be representative because they do not alter the qualitative nature of the modes (in-phase, anti-phase, relative frequency, etc.).
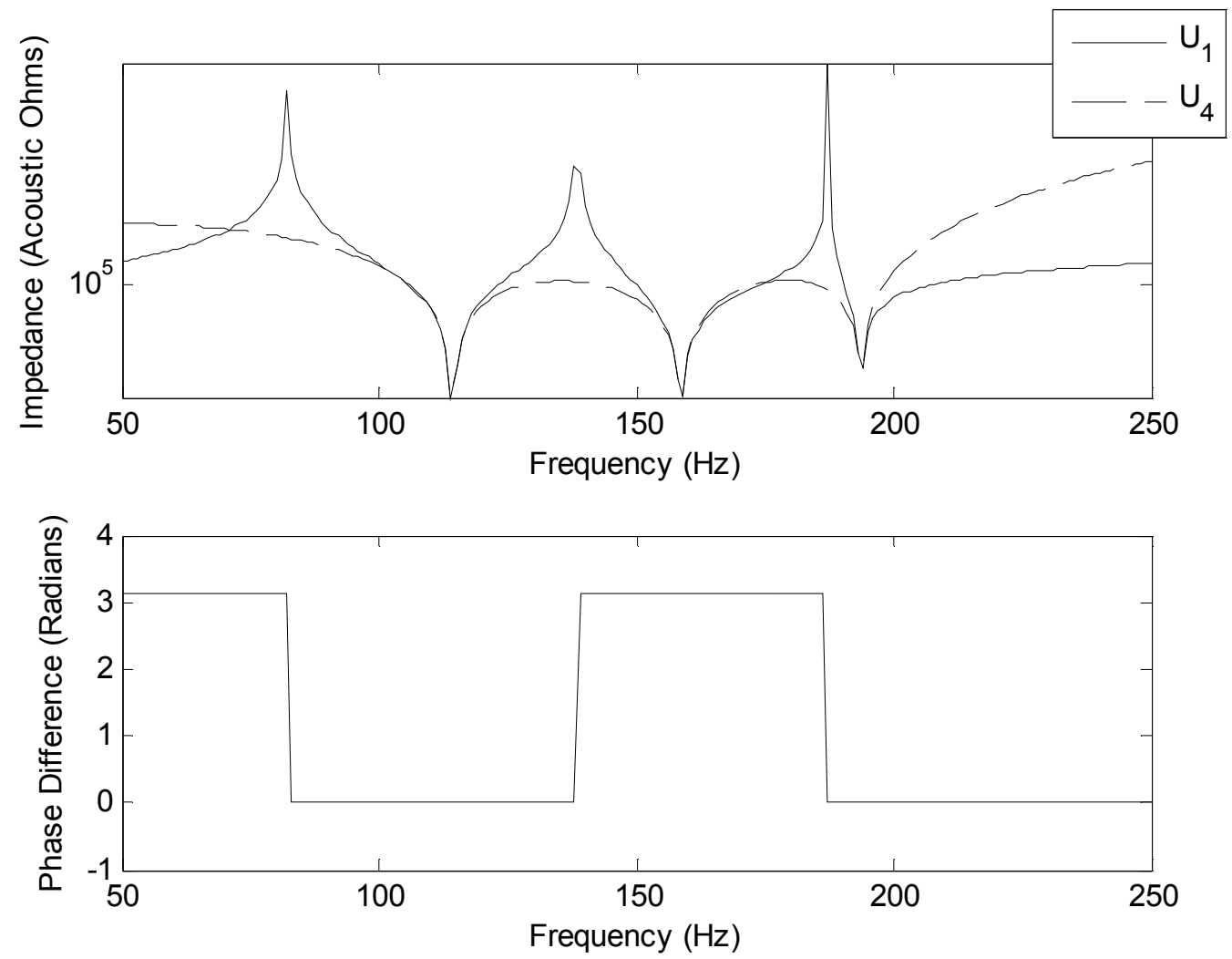

Figure 3-8: Frequency response for pulsejet engines connected via decoupling chamber.

As with the previous interconnection scheme, Fig. 3-8 shows several resonant modes for the system. The natural mode preferred by the system corresponds to the resonant mode for an isolated, individual engine, which is at $159 \mathrm{~Hz}$ and of an anti-phase nature. The frequency is very slightly higher than the isolated, single engine case (157 $\mathrm{Hz}$ ) because of the reduced radiation impedance at the tailpipe exhaust (due to the 
increased temperature at that end), but nevertheless, it is the same mode in principal, and is therefore the one that the system locks into. The preceding calculation explains why valveless pulsejets, connected via decoupling chambers, operate out-of-phase (i.e. anti-phase).

\subsubsection{Connection via Half-Wave Tube}

As discussed in the introduction, forcing two valveless pulsejet engines to operate in anti-phase can be used to destructively cancel and suppress noise and vibration. However, the standard method for doing so (using decoupling chambers) interferes with the intake and/or exhaust streams, and thus is unacceptable for propulsive applications. The objective of this section is to find a way to force two engines to operate in anti-phase without interfering with their propulsive abilities. This will be accomplished using the acoustic system methodology developed above.

The results of the experiments and acoustic system analyses presented so far have shown that several different operating modes are possible for coupled valveless pulsejets but the mode that is 'preferred' and thus observed experimentally, is the one that is closest to its isolated, natural mode. This knowledge can be used to devise an arrangement in which the preferred coupled mode is anti-phase in nature but does not require thrust-killing decoupling chambers.

Intuition suggests that connecting the combustion chambers with a half-wave tube (length equal to one-half of the wavelength of the natural mode of a single engine) should force two engines to operate in anti-phase. The fundamental mode of a half- 
wave tube is shown in Fig. 3-9. This connecting tube will not admit any transfer of fluid between the combustion chambers and the connecting tube because the velocity amplitude is zero at each end. In order to be consistent with this mode, the pressures in each engine must be 180 degrees out of phase. Since no mass is passing into the tube, the engines can theoretically operate out-of-phase and interference-free. Said another way, the engines can operate interference-free, because the connecting tube poses infinite impedance at the natural frequency and effectively acts as a closed end. The acoustic system for this arrangement is shown in Fig. 3-10.

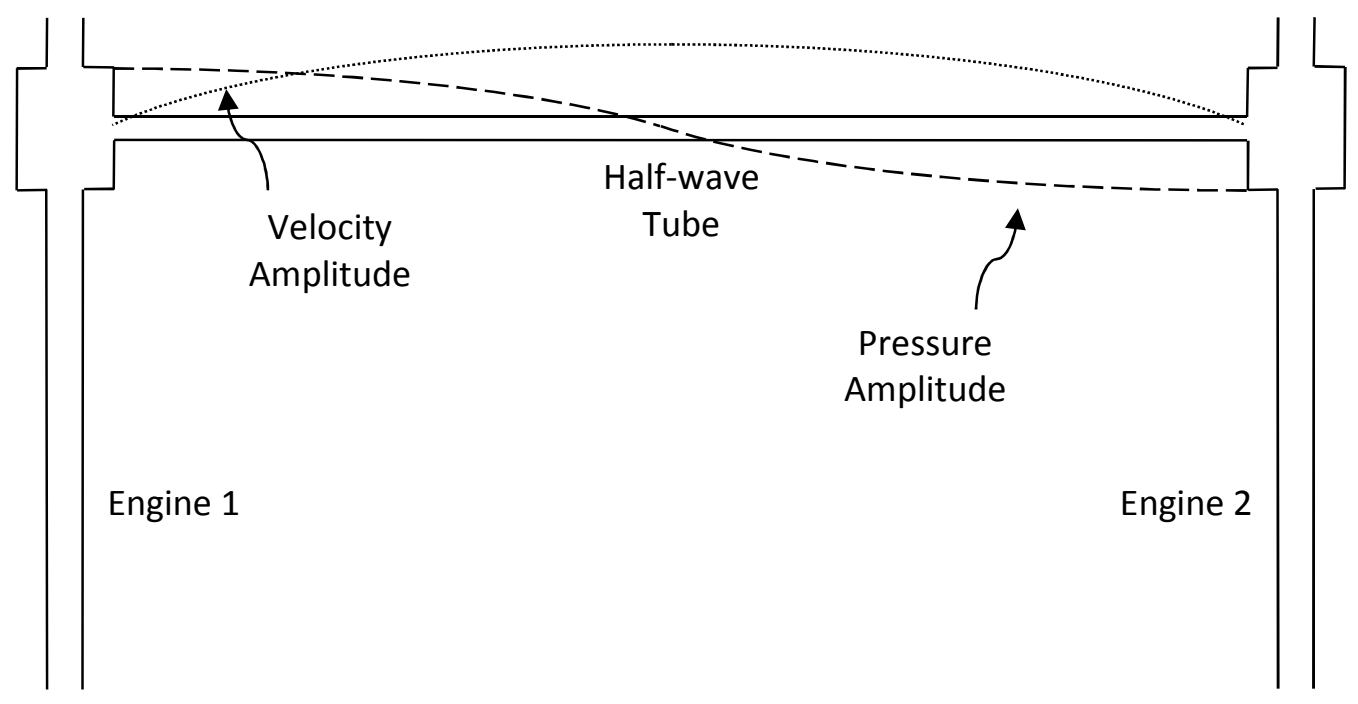

Figure 3-9: Fundamental mode pressure and velocity profiles in a half-wave tube connecting two valveless pulsejet engines. 


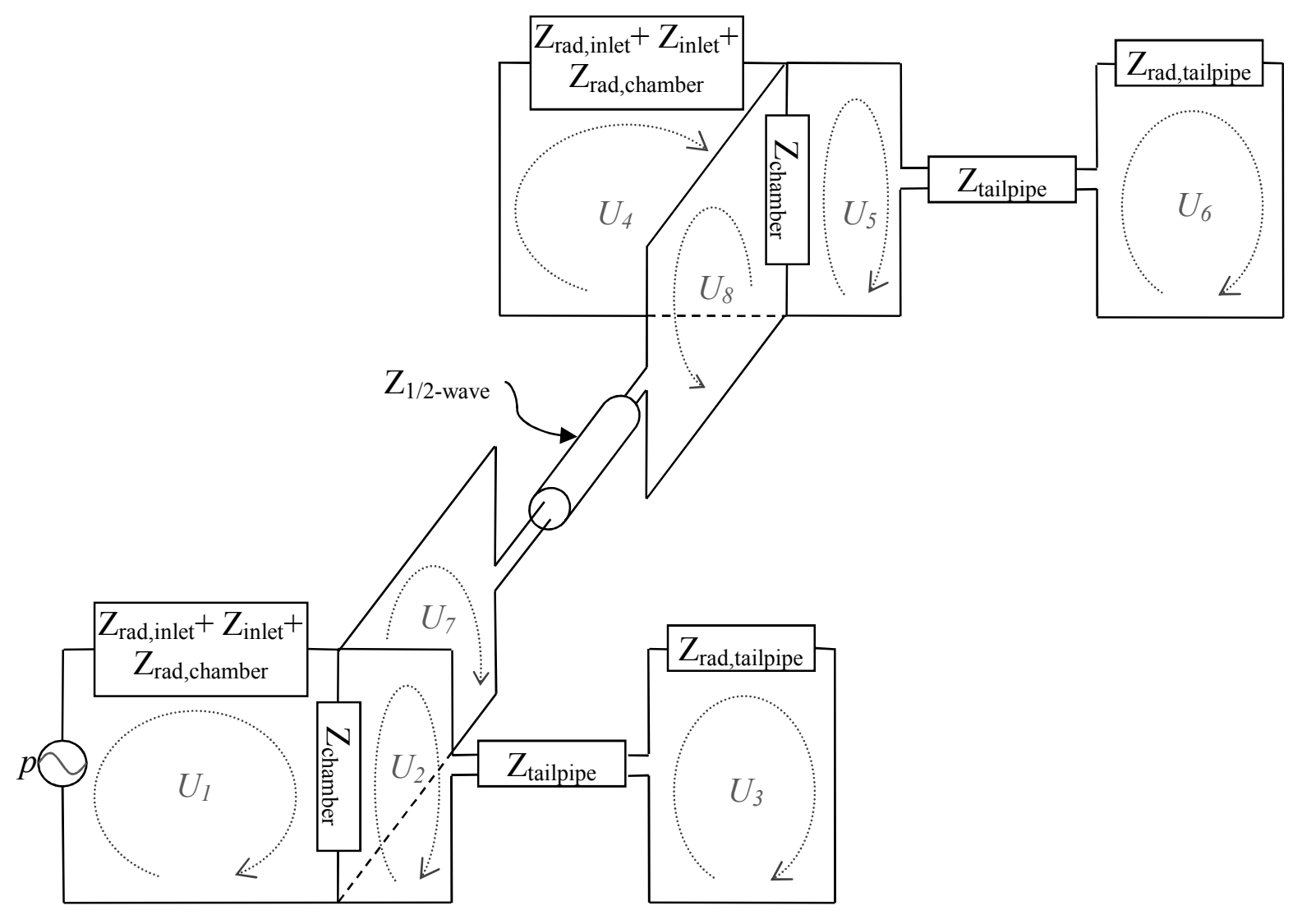

Figure 3-10: Acoustic system/circuit for pulsejet engines connected with a half-wave tube.

The system of 7 equations corresponding to the acoustic system illustrated in Fig. 310 is:

$$
\begin{gathered}
U_{1}\left(Z_{\text {rad,inlet }}+Z_{\text {inlet }}+Z_{\text {rad,chamber }}\right)+\left(U_{1}-U_{2}-U_{7}\right) Z_{\text {chamber }}=p \\
\left(U_{2}-U_{1}+U_{7}\right) Z_{\text {chamber }}+U_{2} Z_{\text {tailpipe }}^{22}+U_{3} Z_{\text {tailpipe }}^{23}=0 \\
U_{3} Z_{\text {rad,tailpipe }}+U_{3} Z_{\text {tailpipe }}^{33}+U_{2} Z_{\text {tailpipe }}^{32}=0 \\
U_{4}\left(Z_{\text {rad,inlet }}+Z_{\text {inlet }}+Z_{\text {rad,chamber }}\right)+\left(U_{4}-U_{5}-U_{8}\right) Z_{\text {chamber }}=0
\end{gathered}
$$




$$
\begin{gathered}
\left(U_{5}-U_{4}+U_{8}\right) Z_{\text {chamber }}+U_{5} Z_{\text {tailpipe }}^{55}+U_{6} Z_{\text {tailpipe }}^{56}=0 \\
U_{6} Z_{\text {rad,tailpipe }}+U_{6} Z_{\text {tailpipe }}^{66}+U_{5} Z_{\text {tailpipe }}^{65}=0 \\
\left(U_{7}+U_{2}-U_{1}\right) Z_{\text {chamber }}+U_{7} Z_{1 / 2-\text { wave }}^{77}+U_{8} Z_{1 / 2 \text {-wave }}^{78}=0 \\
\left(U_{8}+U_{5}-U_{4}\right) Z_{\text {chamber }}+U_{8} Z_{1 / 2-\text { wave }}^{88}+U_{7} Z_{1 / 2 \text {-wave }}^{87}=0
\end{gathered}
$$

As with the tailpipe, the connecting tube impedances are [100]

$$
\begin{aligned}
& Z_{\text {tailpipe }}^{77}=Z_{\text {tailpipe }}^{88}=-j \frac{\rho c}{S} \cot \left(\frac{\omega l}{c}\right) \\
& Z_{\text {tailpipe }}^{78}=Z_{\text {tailpipe }}^{87}=-j \frac{\rho c}{S} \operatorname{cosec}\left(\frac{\omega l}{c}\right)
\end{aligned}
$$

The length in these equations is the length of a half wave resonator tube operating at the natural frequency of a single engine:

$$
l_{1 / 2-w a v e}=\frac{c}{2 f}
$$

For calculation purposes, the speed of sound inside the connecting half-wave tube is assumed to be same as that inside the combustion chamber. In practice, this temperature and speed of sound inside the connecting tube may be different which means that some tuning may be needed, for which the length can be empirically adjusted. The system of equations 27-34 can be solved to produce the frequency response of the system (Fig. 3-11). As the qualitative argument suggested, the 
calculation confirms that the preferred mode of the system $(157 \mathrm{~Hz})$ should be antiphase in nature.
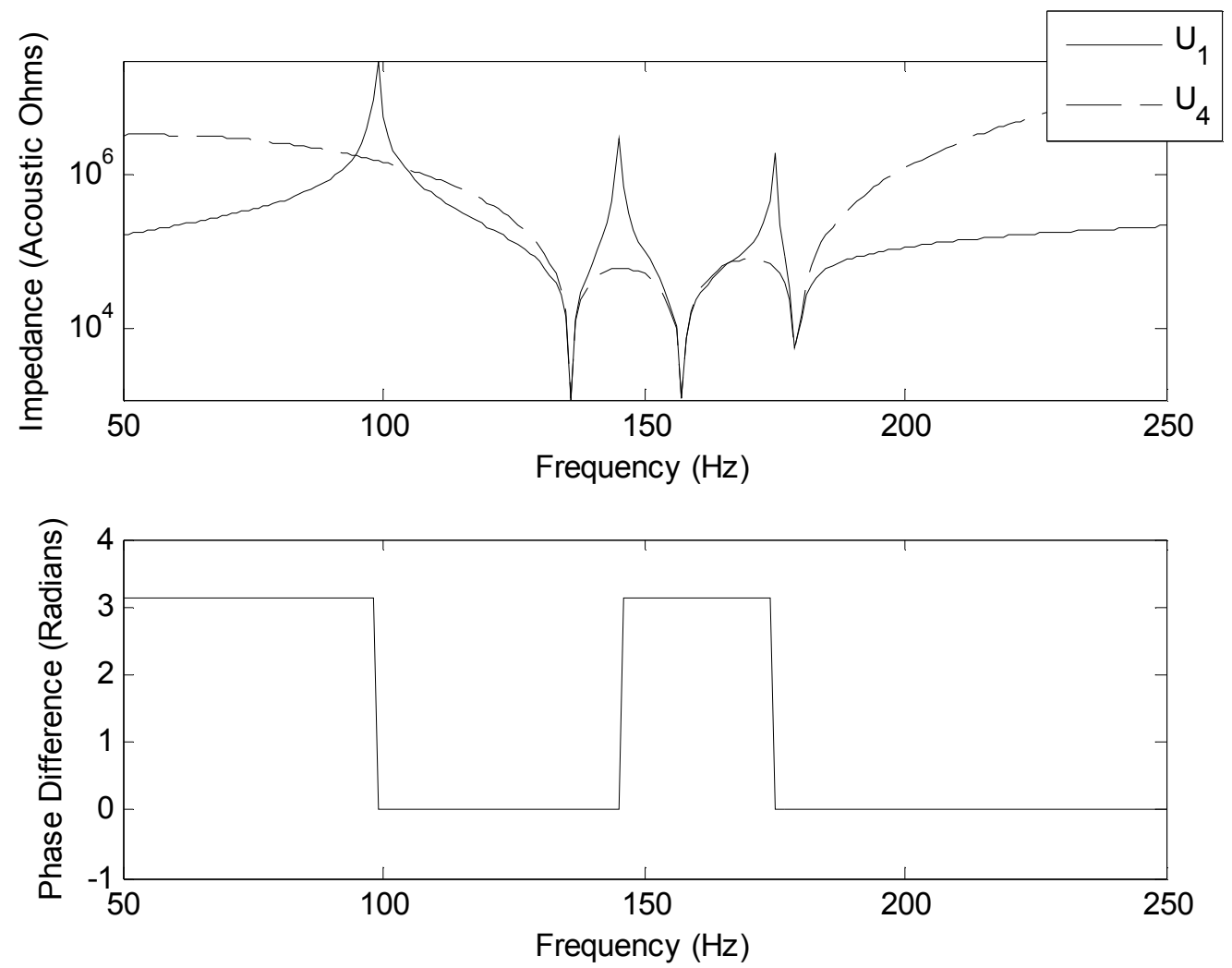

Figure 3-11: Frequency response for pulsejet engines connected with a half-wave tube.

\subsubsection{Connection via Helmholtz Chamber}

It has been suggested that two engines may be operated in anti-phase by placing a Helmholtz chamber between them, i.e. by connecting the combustion chambers via short ducts and a chamber, as shown in Fig. 3-12. This effectively forms a Helmholtz resonator between the engines, and it is possible that this will result in a preferred anti-phase mode of the system. The acoustic system/circuit of such an arrangement is shown in Fig. 3-13. 


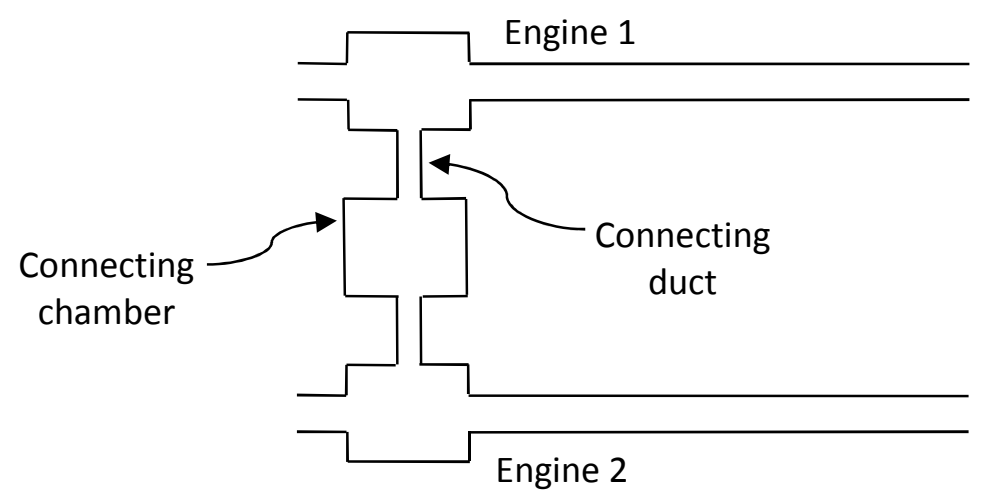

Figure 3-12: Pulsejets connected via a Helmholtz chamber.

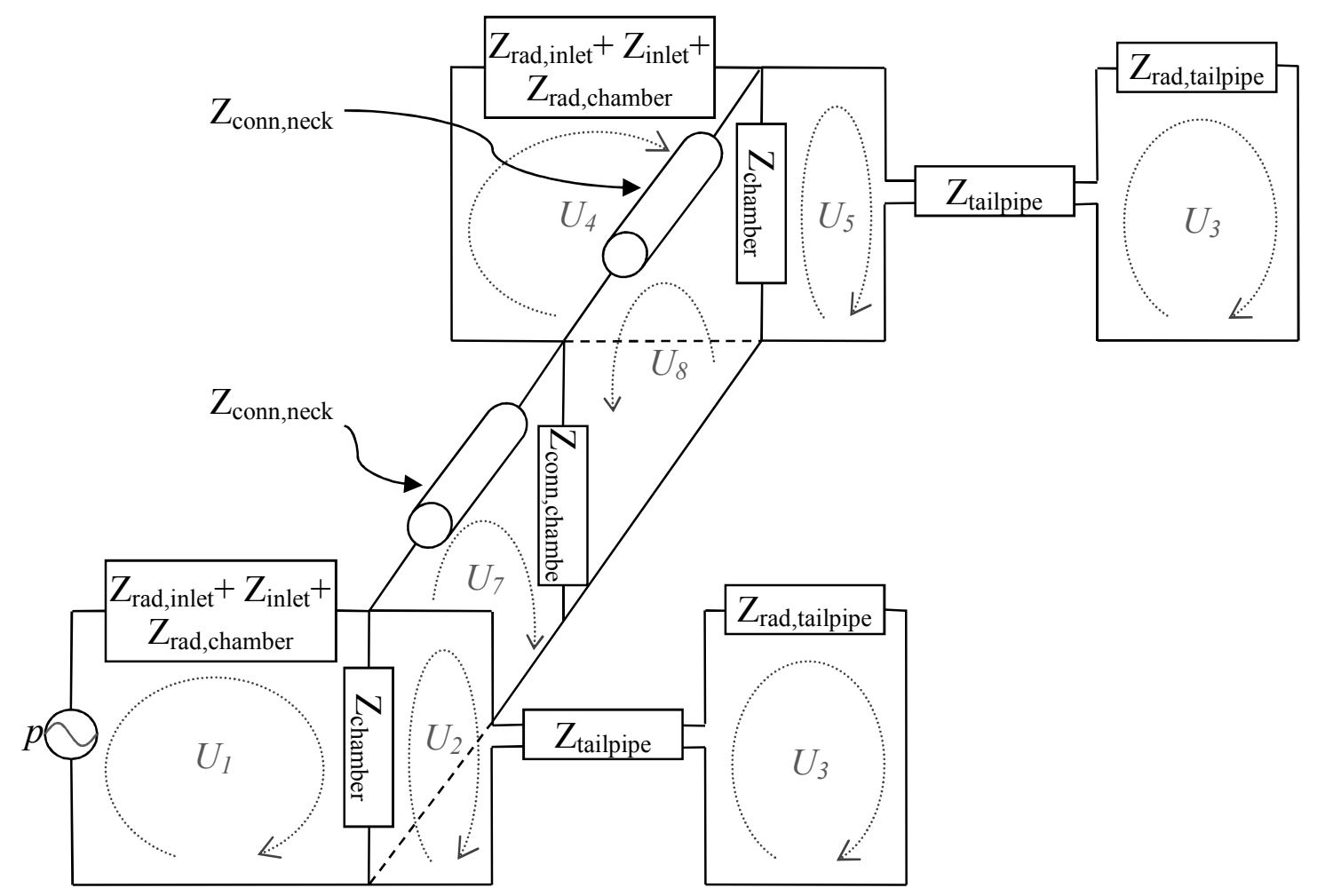

Figure 3-13: Acoustic system/circuit for pulsejet engines connected via a Helmholtz chamber. 
Eight current loops produce eight equations:

$$
\begin{array}{cc}
U_{1}\left(Z_{\text {rad,inlet }}+Z_{\text {inlet }}+Z_{\text {rad,chamber }}\right)+\left(U_{1}-U_{2}-U_{7}\right) Z_{\text {chamber }}=p & \text { Eq. (3-38) } \\
\left(U_{2}-U_{1}+U_{7}\right) Z_{\text {chamber }}+U_{2} Z_{\text {tailpipe }}^{22}+U_{3} Z_{\text {tailpipe }}^{23}=0 & \text { Eq. (3-39) } \\
U_{3} Z_{\text {rad,tailpipe }}+U_{3} Z_{\text {tailpipe }}^{33}+U_{2} Z_{\text {tailpipe }}^{32}=0 & \text { Eq. (3-40) } \\
U_{4}\left(Z_{\text {rad,inlet }}+Z_{\text {inlet }}+Z_{\text {rad,chamber }}\right)+\left(U_{4}-U_{5}-U_{8}\right) Z_{\text {chamber }}=0 & \text { Eq. (3-41) } \\
\left(U_{5}-U_{4}+U_{8}\right) Z_{\text {chamber }}+U_{5} Z_{\text {tailpipe }}^{55}+U_{6} Z_{\text {tailpipe }}^{56}=0 & \text { Eq. (3-42) } \\
U_{6} Z_{\text {rad,tailpipe }}+U_{6} Z_{\text {tailpipe }}^{66}+U_{5} Z_{\text {tailpipe }}^{65}=0 & \text { Eq. (3-43) } \\
\left(U_{7}+U_{2}-U_{1}\right) Z_{\text {chamber }}+U_{7} Z_{\text {conn }, \text { neck }}+\left(U_{7}+U_{8}\right) Z_{\text {conn }, \text { chamber }}=0 & \text { Eq. (3-44) } \\
\left(U_{8}+U_{5}-U_{4}\right) Z_{\text {chamber }}+U_{8} Z_{\text {conn }, \text { neck }}+\left(U_{8}+U_{7}\right) Z_{\text {conn }, \text { chamber }}=0 & \text { Eq. (3-45) }
\end{array}
$$

For calculation purposes, it was assumed that the short connecting ducts are half the diameter and length of the inlet, while the connecting chamber is of the same volume as the combustion chamber - these dimensions are in keeping with an experiment that will be described later in this chapter. The gas conditions inside the connecting ducts and chamber were assumed to be the same as inside the combustion chamber. Figure 3-14 shows the frequency response of the system. In-phase and anti-phase modes are obvious, however, unlike the previous arrangements, the original mode of the individual, isolated pulsejet $(\sim 157 \mathrm{~Hz})$ is not possible to recover with this arrangement. It is unlikely that this mode can be recovered with any such arrangement because the connecting chamber acts as a compliance/capacitor and will always accept additional flow from the combustion chambers. This will result in outflows and inflows that differ from those of the natural, isolated modes. Given this information, it is unlikely that two pulsejets connected via a Helmholtz chamber will 
start because none of the resonant modes of the system are compatible with the resonant mode of a single, isolated pulsejet.
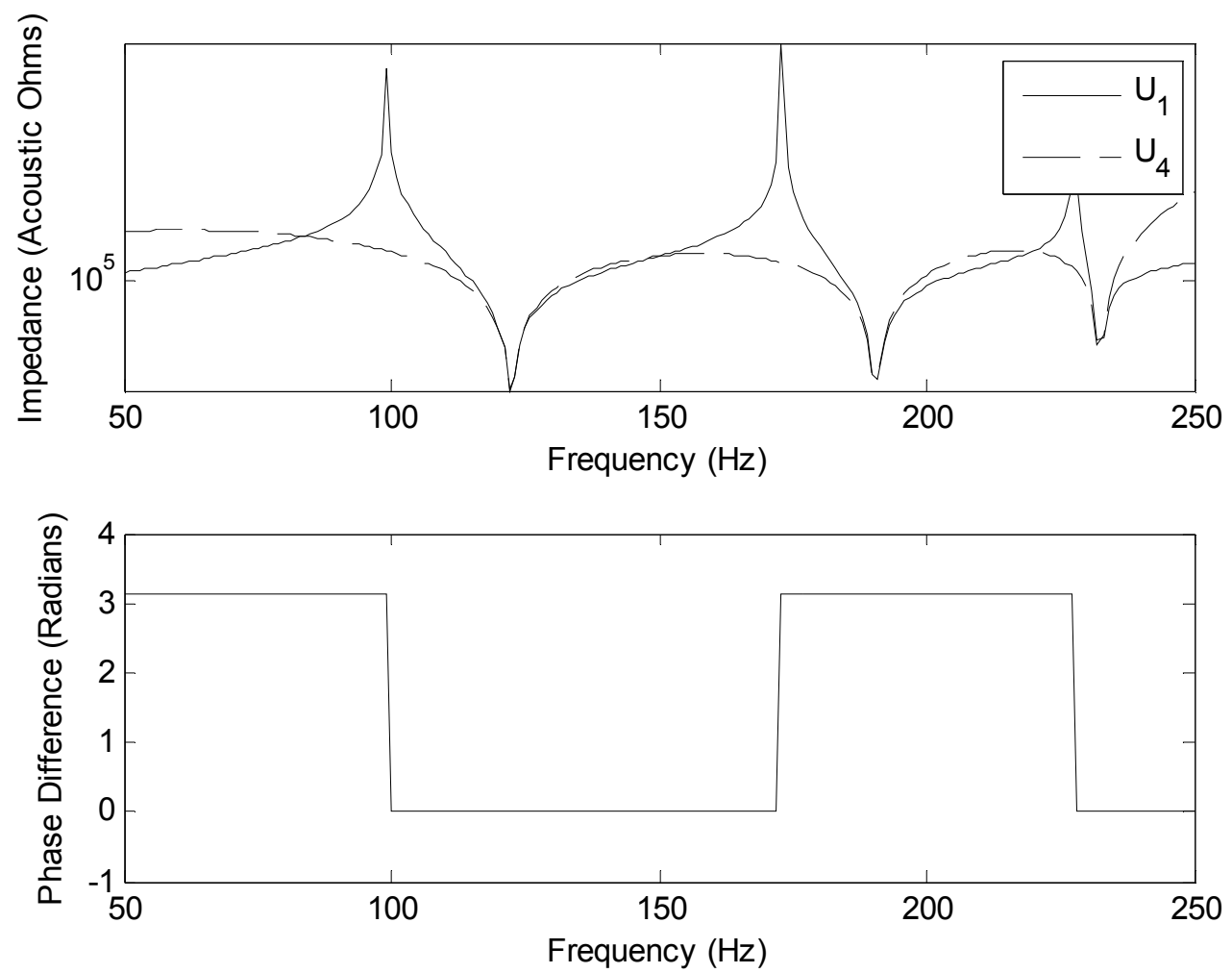

Figure 3-14: Frequency response for pulsejet engines connected with a Helmholtz chamber.

\subsection{Experimental Verification of Acoustic System Analysis}

\subsubsection{Experiment Setup}

So far we have seen that acoustic system/circuit analysis is able to explain experimental results in the literature. While helpful for establishing the validity of the theory, a set of smaller valveless pulsejet engines was constructed (smaller than the test article of chapter 2) in order to provide additional data for validation. Smaller pulsejets were chosen over the larger engine from chapter 2 in order to keep noise, 
smoke, and vibration levels within reasonable limits inside the laboratory. The pair of smaller engines also consumes less fuel than a pair of larger engines. This is important because the lab propane source, LPG tanks, might not be able to maintain the required fuel flow rate without encountering icing problems.

The engines considered here have a 2.1 in. $(5.3 \mathrm{~cm})$ diameter, 4.9 in. $(12.4 \mathrm{~cm})$ long iron combustion chambers (Figs. 3-15 and 3-16) welded to 0.63 in. (1.6 cm) long tapered sections that reduce the diameter to $1.05 \mathrm{in} .(2.7 \mathrm{~cm})$ for attachment to the tailpipe. The tailpipe is 1.05 in. $(2.7 \mathrm{~cm})$ in diameter, 12.5 in. $(41.9 \mathrm{~cm})$ long, and terminated by a flare to $1.48 \mathrm{in} .(3.8 \mathrm{~cm})$ over a length of 1 in. $(2.5 \mathrm{~cm})$. The other end of the combustion chamber is externally threaded. A pipe reducing assembly is screwed onto this end which enables different lengths of $1 / 2$ " NPT pipe to be attached and used as inlets to the combustion chamber. All tests were performed with an inlet diameter of 0.63 in. $(1.6 \mathrm{~cm})$ and length of 2.2 in. $(5.6 \mathrm{~cm})$. All dimensions are internal. Figure 3-16 is a picture of a single engine in operation.

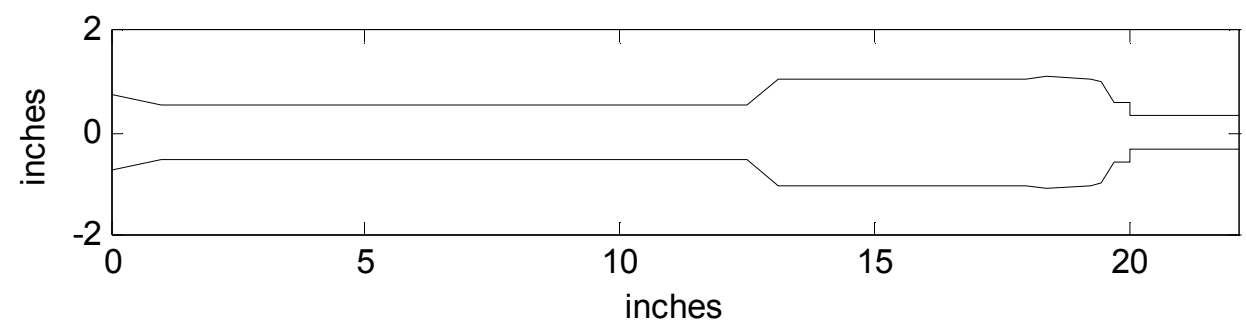

Figure 3-15: Pulsejet configuration for interaction studies. 


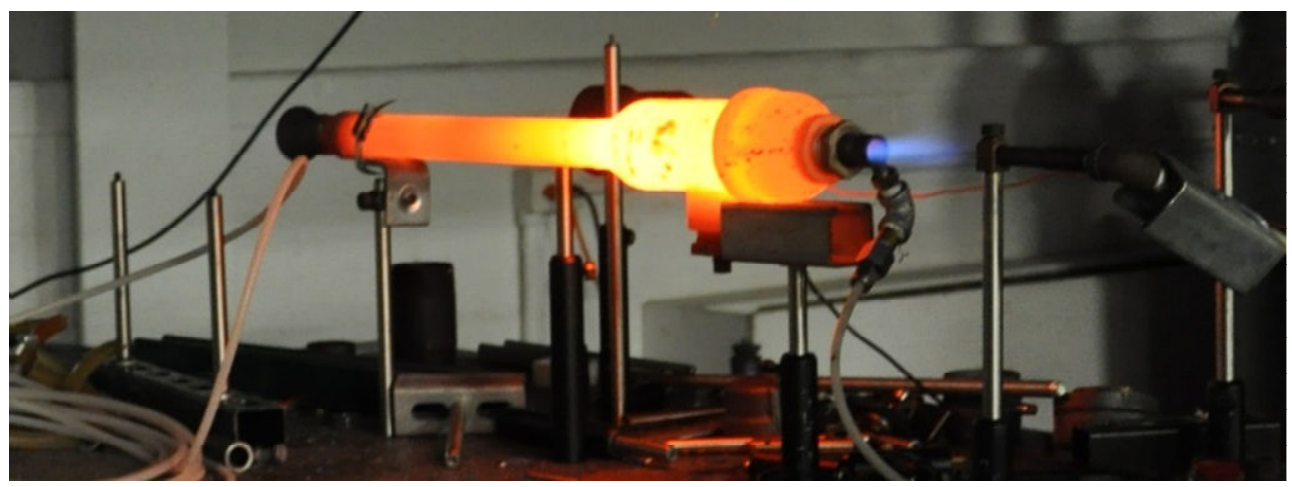

Figure 3-16: Pulsejet in operation.

Propane is supplied from a plenum held at 4 psig and injected through a 0.18 in. (0.46 $\mathrm{cm})$ diameter hole in the inlet tube $0.25 \mathrm{in} .(0.64 \mathrm{~cm})$ downstream of the combustor entrance. The combustors are also equipped with ports for connecting them to the combustion chamber of the other engine, and to water-cooled ports for measuring pressure using Kistler 211B5 pressure transducers. As with the larger engine, compressed air and a spark plug are used for starting but are turned off once selfsustaining operation is achieved (usually within a few seconds).

\subsubsection{Connection via Short Duct}

Two pulsejets were connected via a 0.25 in. $(0.64 \mathrm{~cm})$ diameter, 4 in. $(10.2 \mathrm{~cm})$ long duct (Fig. 3-17) in order to test theoretical predictions of short-duct-coupled system behavior. Theory (section 3.3.1) predicts in-phase and anti-phase modes. The inphase mode corresponds to the natural operating mode of a single, isolated, pulsejet whereas the anti-phase mode should occur at a higher frequency. Theory predicts that the system will select the mode associated with uncoupled (isolated) operation, i.e. inphase operation. This has also been confirmed by other experiments reported in the literature [44] [76]. However, the prior section (section 3.3.1) has suggested that it 
may be possible to force the system into the higher, anti-phase, mode by operating only one engine. The experimental results in Fig. 3-18 confirm this prediction: when both engines are operational, they lock in-phase at $237 \mathrm{~Hz}$. But when only one engine is operational, the combustion chamber pressures are in anti-phase at a slightly higher frequency $(258 \mathrm{~Hz})$ just as the theory predicts.

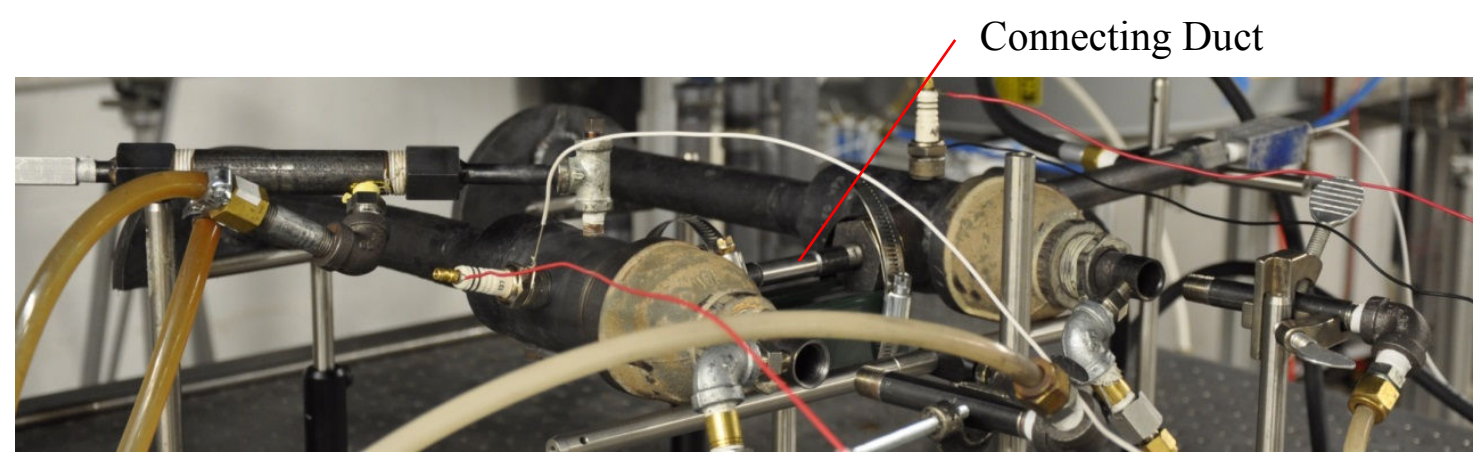

Figure 3-17: Pulsejets inter-connected with a short duct. 

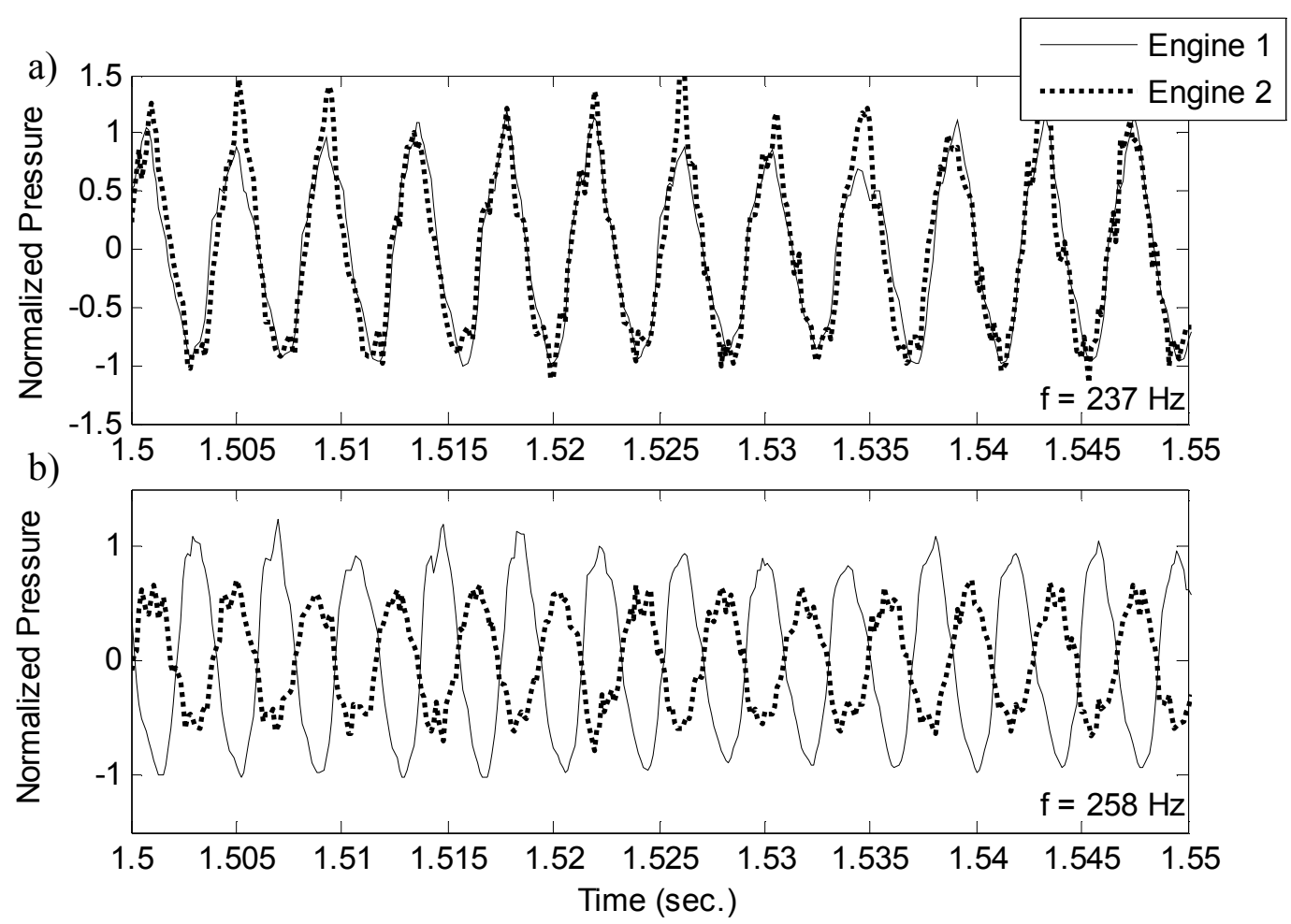

Figure 3-18: Experimental chamber pressure measurements for interconnected engines: (a) both engines operational $(237 \mathrm{~Hz})$, and (b) one engine operational (258 $\mathrm{Hz})$.

It is worth mentioning here that the single engine (anti-phase) mode can be difficult to achieve because it is an unnatural mode of operation, not associated with isolated engine operation, as explained in section 3.4. This unnatural (anti-phase) mode of operation is typically only achieved if the engine is hot, i.e. warmed up from a prior natural mode (in-phase) run. 


\subsubsection{Connection via Decoupling Chamber}

This case has been studied experimentally by a number of researchers [80] [9] [73], and is therefore not reproduced here. All studies have demonstrated anti-phase behaviour, in keeping with the results of the preceding impedance analysis.

\subsubsection{Connection via Half-Wave Tube}

Theory predicts that two pulsejets connected at their combustion chambers via a halfwave tube will operate in anti-phase (section 3.3.4). To test this prediction, two pulsejets were connected via a 0.25 in. $(0.64 \mathrm{~cm})$ diameter, 36 in. $(91.4 \mathrm{~cm})$ long tube (Fig. 3-19). The connecting tube was bent in order to achieve practical engine spacing but care was taken to ensure that the bend radius was large enough to permit acoustic waves to propagate easily. Figure 3-20 shows that the engines are operating in antiphase as predicted by the theory. 


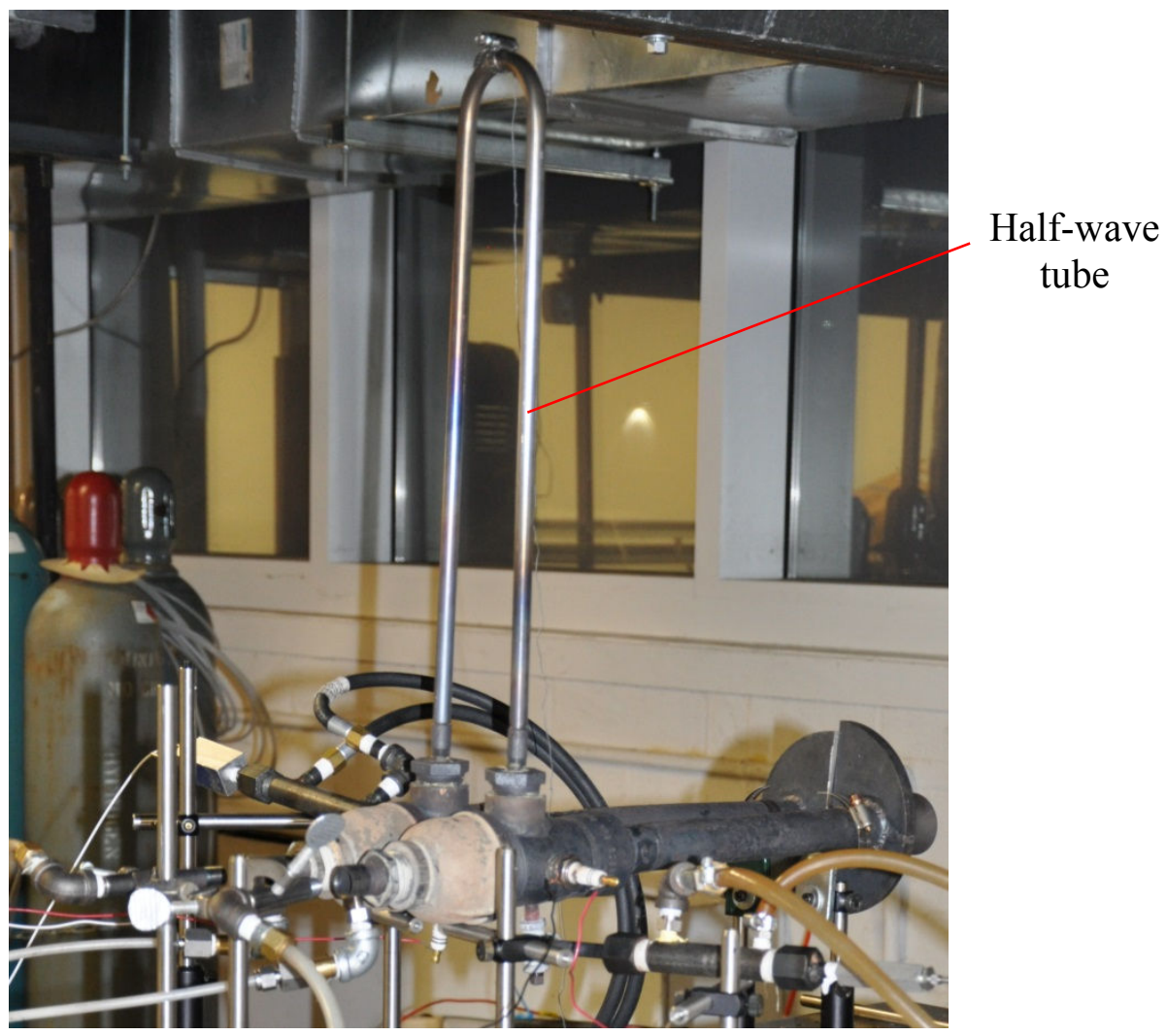

Figure 3-19: Pulsejets connected with a half-wave tube

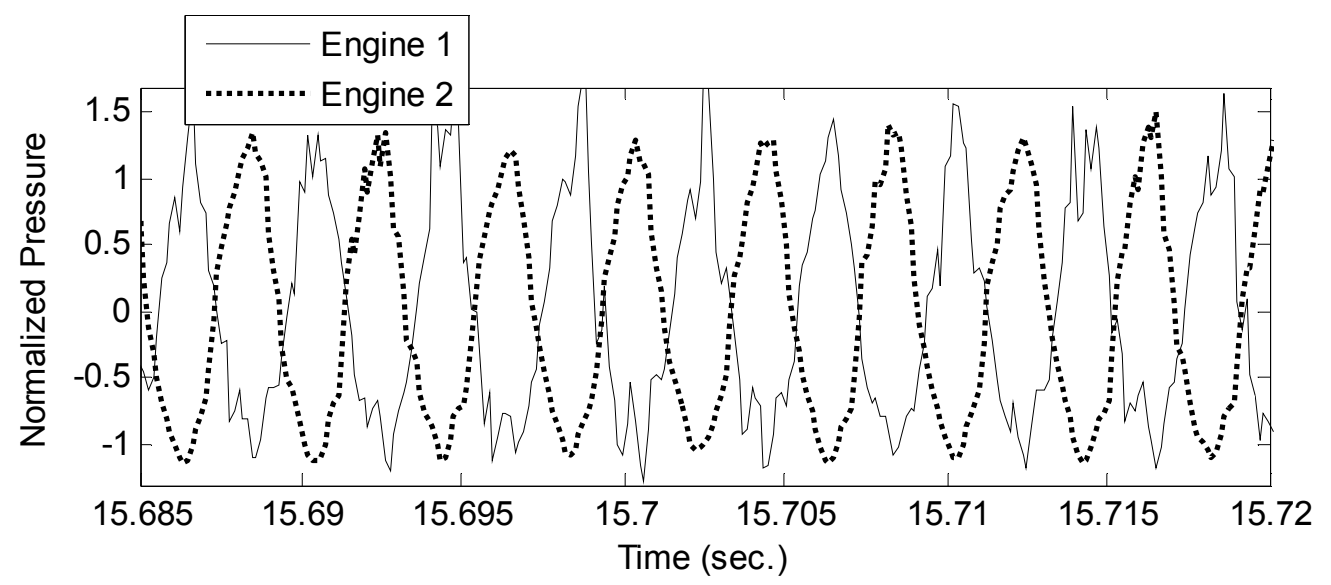

Figure 3-20: Chamber pressure measurements for pulsejets connected with a halfwave tube. 


\subsubsection{Connection via Helmholtz Chamber}

To explore the theoretical results of two valveless pulsejets connected via a Helmholtz chamber (section 3.3.5), two pulsejets were connected via two 0.25 in. $(0.64 \mathrm{~cm})$ diameter, 2 in. $(10.2 \mathrm{~cm})$ long ducts, and a chamber with the same volume as the combustion chambers (Fig. 3-21). Impedance analysis suggested that it would be impossible (or at least very difficult) to start the engines in this configuration, and this was also observed experimentally - the engines would not start.

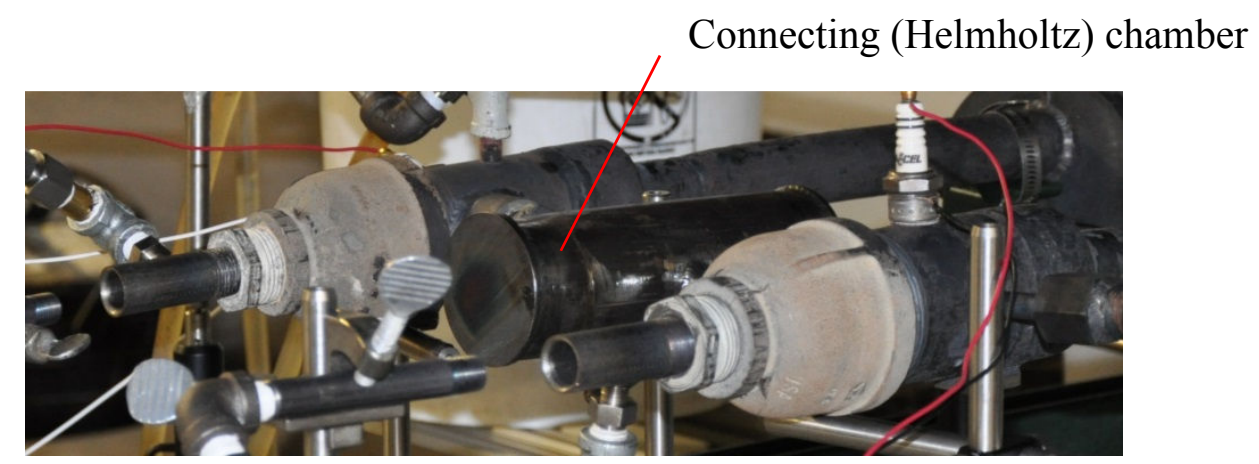

Figure 3-21: Pulsejets connected with a Helmholtz chamber.

\subsection{Summary of Results}

Several different ways of coupling pulsejets have been explored using an impedance analysis technique to explain experimental results. This provides an experimentallyvalidated theoretical framework with which the interaction of pulsejets can be explained and predicted, which is essential not just for noise and vibration control, but also for maintaining predictable and steady force distributions in arrayed applications (such as the Boeing PETA/VTOL concept). The results are summarized in Table 3-2. 
Table 3-2: Summary of engine interaction results.

\begin{tabular}{|c|c|c|}
\hline Connection Type & Impedance Analysis Result & Experimental Result \\
\hline Short Duct & In-phase & In-phase [44] [76] \\
\hline Decoupling Chamber & Anti-phase & Anti-phase [80] [9] [73] \\
\hline Half-wave Tube & Anti-phase & Anti-phase \\
\hline Helmholtz Chamber & No start & No start \\
\hline
\end{tabular}




\section{Chapter 4: Effect on Noise}

\subsection{Introduction}

The first chapter of this thesis described the history and potential of pulsejet engines along with the challenges of noise and vibration that have held it back for decades. It also described the existing theories and modelling approaches for these engines, the shortcomings of the theories, and prior attempts at noise and vibration suppression. Among the proposed techniques for noise and vibration suppression, the idea of forcing two engines to operate in anti-phase looked promising but did not yield the dramatic results that were hoped for. Now we know why: It is primarily because the acoustic waveform generated by valveless pulsejets is not perfectly sinusoidal; it contains significant harmonic content. The net result is that, while anti-phasing may cancel the fundamental, significant energy remains in the harmonics which not only do not cancel but can actually add to produce even more noise. In addition, most pulse jets operate in the $50-200 \mathrm{~Hz}$ range where the human ear is less sensitive than in the $500-2000 \mathrm{~Hz}$ range. This means that eliminating the fundamental component has little effect on perceived noise (but is important for vibration control). Finally, the existing methods for achieving anti-phasing kill propulsive performance so a technique must be found by which two engines can be made to operate out-of-phase without a significant thrust penalty. 
We have shown that two steps are required to reduce/eliminate noise in valveless pulse jets:

1) Remove or mitigate the harmonic content in the acoustic signal, i.e. make it 'more sinusoidal'.

2) Force the engines to operate in anti-phase so as to cancel the surviving fundamental peak in the noise spectrum without interfering with the natural flow path or operation of the engine.

The last two chapters have addressed these issues by building and experimentally verifying theories to explain the individual and coupled operations of valveless pulsejet engines, and then using these theories to propose ways of achieving the two noise and vibration cancellation objectives. The key conclusions from chapters 2 and 3 respectively are:

1) Attaching a Helmholtz resonator tuned to the frequency of a higher mode to the tailpipe of a valveless pulsejet should eliminate that mode within the engine. This removes or reduces harmonic content within the engine essentially 'cleaning' the signal.

2) Coupling two valveless pulsejets with a half-wave tube causes them to operate in anti-phase without the need for thrust killing chambers at the inlet and/or exhaust. 
The objective of this chapter is to assess the effect of these modifications on the acoustic output of a valveless pulsejet.

\subsection{Noise Measurement Setup}

Noise measurements were made at three angular locations around the engine at a radial distance of 47 in. $(119.4 \mathrm{~cm})$ from the center of the engine assembly as illustrated in Fig. 4-1. Location 1 is along the centerline of the engine assembly, 32 in. $(81.3 \mathrm{~cm})$ downstream of the exhaust plane but 9 in. $(22.9 \mathrm{~cm})$ below the engine axis plane (i.e. the plane defined by the axes of the engines which should be parallel) to avoid the jet exhaust. This places it approximately 22 exhaust diameters from the exhaust plane. The other two locations are in the engine axis plane at $60^{\circ}$ and $120^{\circ}$ from engine assembly centerline. 
a)

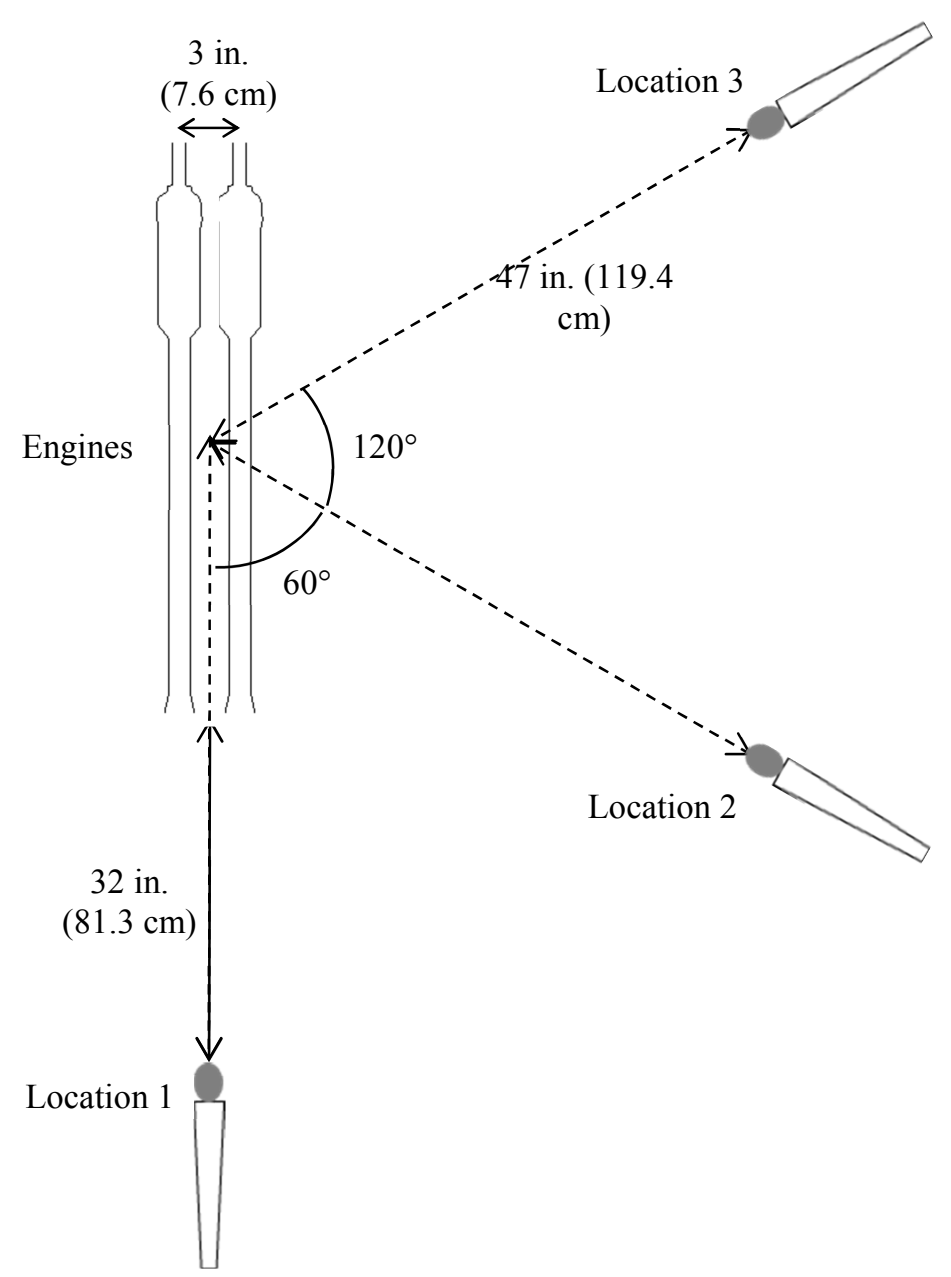

b)

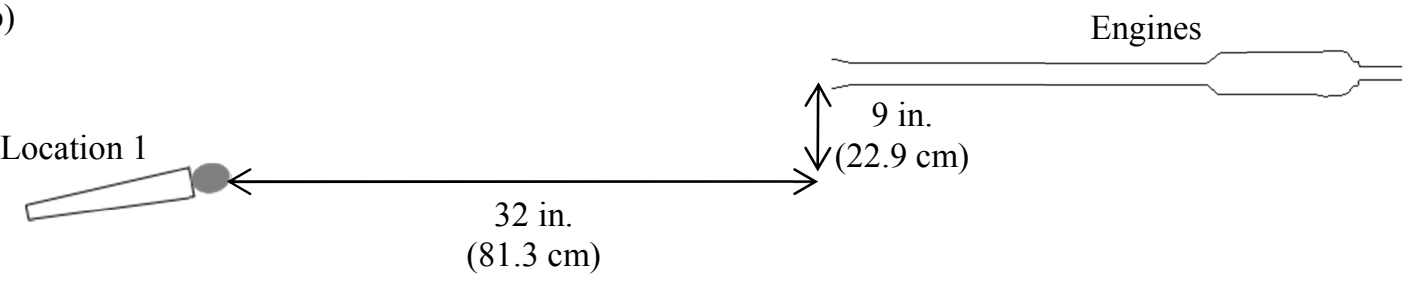

Figure 4-1: Noise measurement locations: (a) top view, (b) side view for Location 1.

Sound recordings were made using a Shure SM58 dynamic microphone, and A- and C-weighted noise level (Sound Pressure Level) measurements were made using an Extech Instruments 407730 sound level meter. The Shure SM58 microphone was 
selected because of its approximately flat frequency response in the region of interest, $0.1-1 \mathrm{kHz}$, where the fundamental and relevant harmonics can be found.

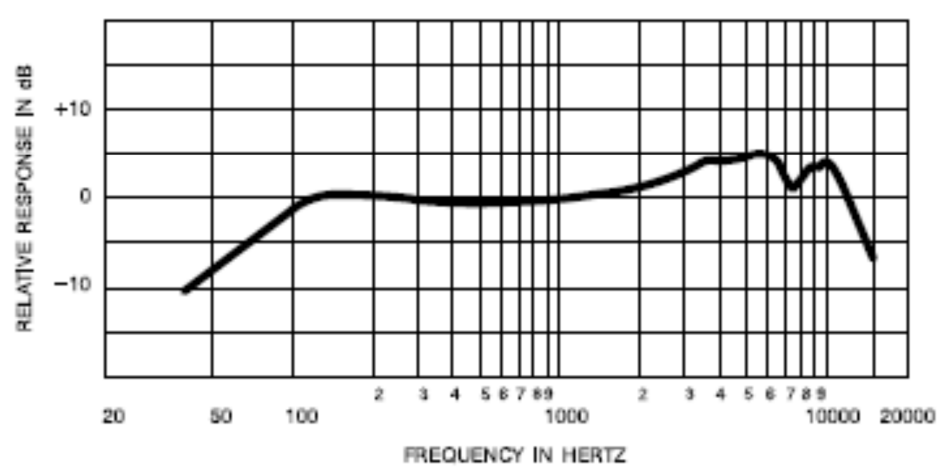

Figure 4-2: Frequency response of Shure SM58 microphone. Adapted from ref. [107].

\subsection{Test Articles}

The engines used in this chapter are the same as those described in chapter 3 for exploring interaction behavior. The only difference is the tailpipe length, which is now longer at 16 in. $(40.6 \mathrm{~cm})$, because it was found that the engines start and warm up faster with this longer tailpipe. The geometry is shown in Fig. 4-3.

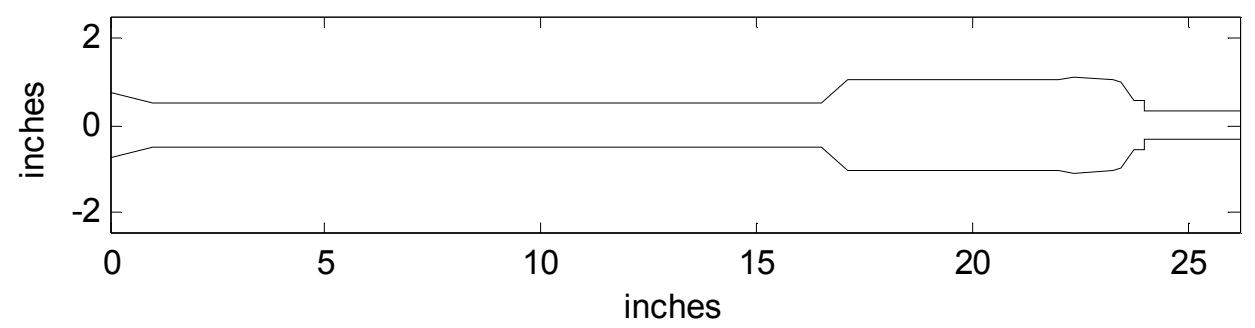

Figure 4-3: Geometry for noise reduction modifications. 
Helmholtz resonators were attached at the approximate the mid-point of the tailpipes (Fig. 4-4). The resonators have 0.63 in. $(1.6 \mathrm{~cm})$ diameter, 3.5 in. $(8.9 \mathrm{~cm})$ long necks which open to 2.07 in. $(5.25 \mathrm{~cm})$ diameter chambers. All dimensions are internal. The resonator is tuned by adjusting the position of a movable piston that forms the back of the chamber.

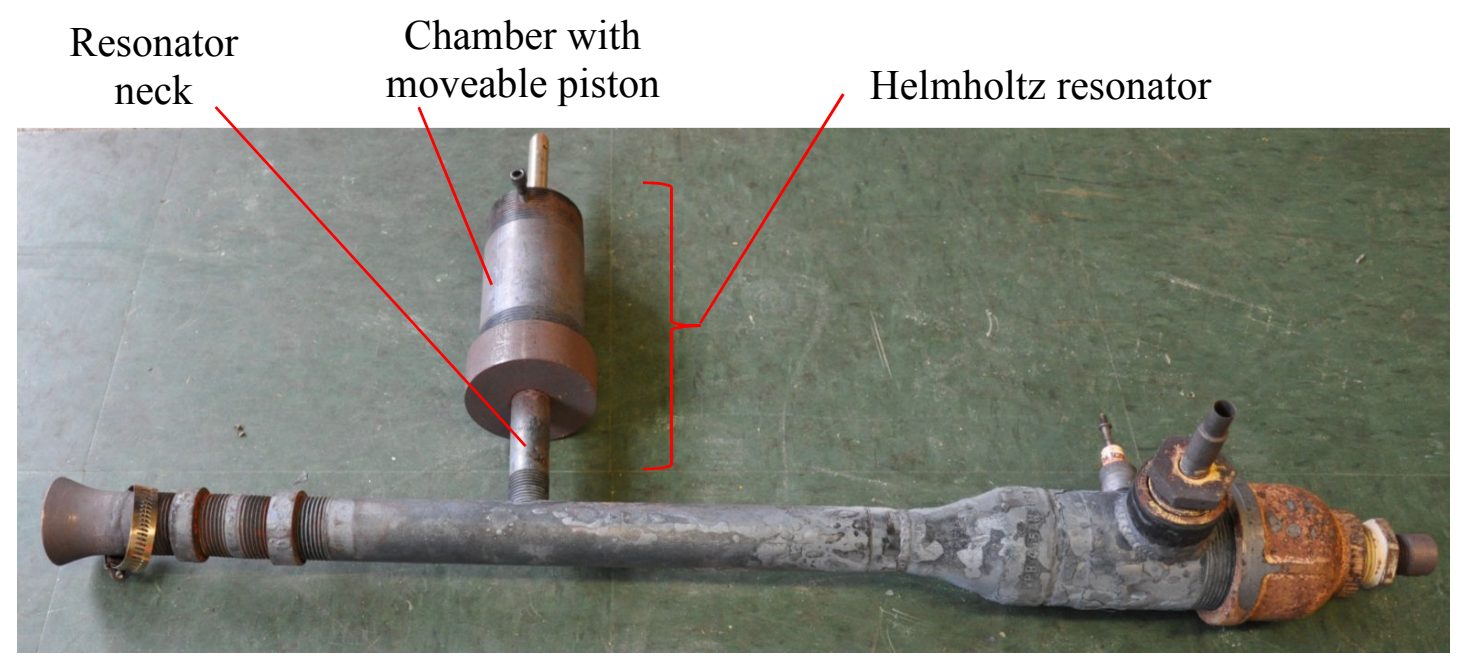

Figure 4-4: Helmholtz resonator attached to a single pulsejet engine.

\subsection{Noise Measurement Results}

\subsubsection{Effect of Helmholtz Resonator}

Noise measurements at location 1 were made first with the Helmholtz resonator port plugged and then with several different resonator chamber heights (volumes). Audio waveforms are shown in Figs. 4-5 $5^{4}$ and A-weighted sound pressure levels are listed in table 4-1. The figure shows that the unmodified pulsejet has a jagged waveform with multiple sub-peaks per firing cycle. These results are consistent with other studies

\footnotetext{
${ }^{4}$ A Samson M10 microphone was used to acquire the data presented in this particular figure.
} 
[65] [64]. The figure also shows that the high-frequency content is responsible for much of the perceived (A-weighted) noise. Increasing the resonator volume causes more of the high frequency content to be attenuated and the signal becomes smoother and closer to a pure sinusoid. At a chamber volume of $10.4 \mathrm{in}^{3}$ (chamber height of 3 in. $(7.6 \mathrm{~cm}))$, the signal is sufficiently sinusoidal that some positive effect from antiphasing can be realized. The engine can be difficult to start beyond this volume (at next investigated chamber height of $3.5 \mathrm{in} .(8.9 \mathrm{~cm}))$ so a chamber volume of $10.4 \mathrm{in}^{3}$ (chamber height of 3 in. $(7.6 \mathrm{~cm})$ ) is chosen for the acoustic experiments.

It is worth noting that the frequency of the engine decreases slightly (by approximately $20 \mathrm{~Hz}$ ) as the volume of the chamber is increased. This is likely because suppressing acoustic modes affects the combustion process: less rapid pressure fluctuations inside the engine result in less turbulence, slower mixing, and thus a slower overall combustion process. And, we know from Rayleigh's criterion [18] that changing the heat release rate changes the instability frequency. 


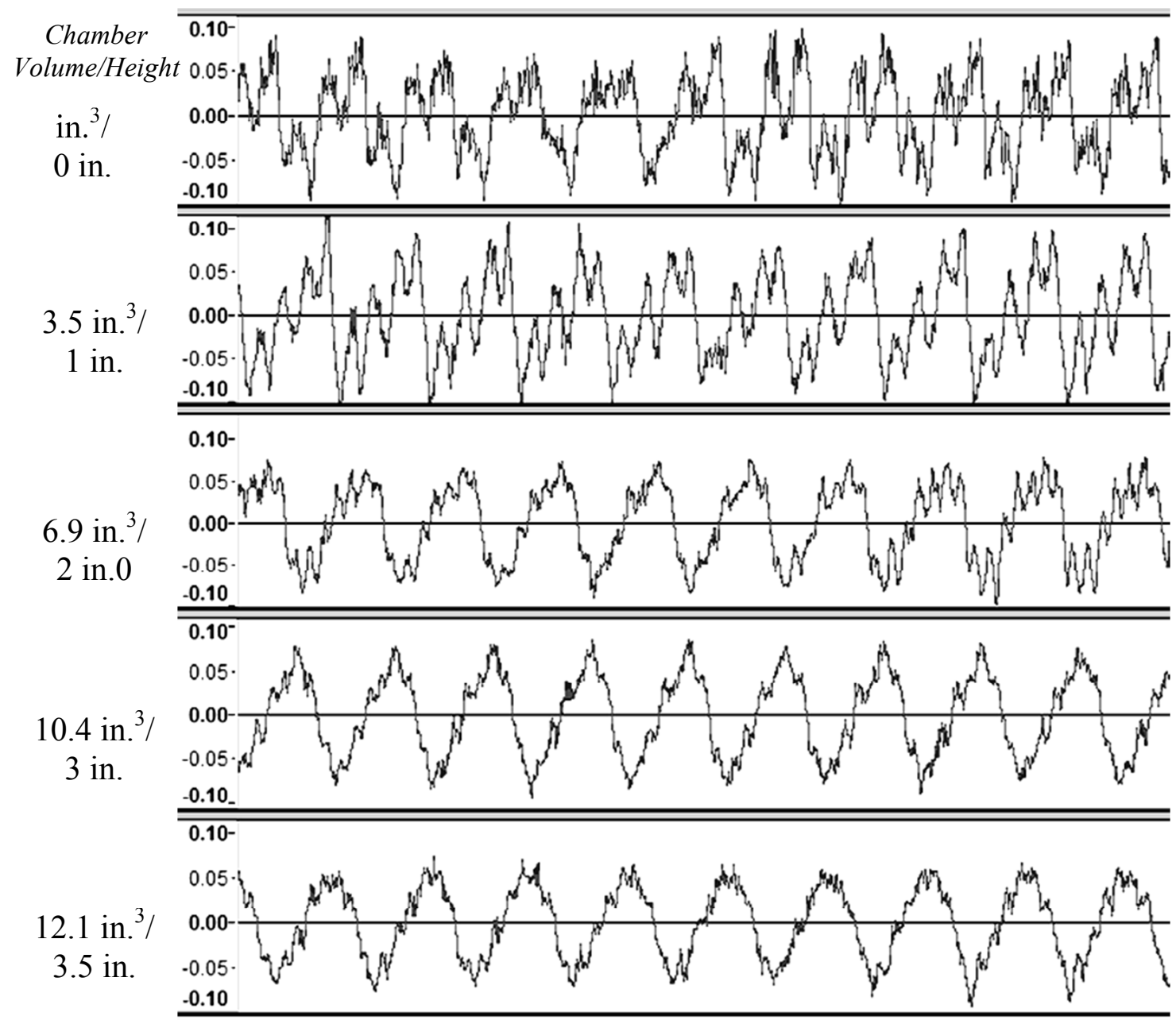

Figure 4-5: Audio waveforms with increasing Helmholtz resonator chamber heights.

Table 4-1: A-weighted noise level versus Helmholtz resonator chamber heights.

\begin{tabular}{|c|c|c|c|c|c|}
\hline Chamber Height (inches) & 0 & 1 & 2 & 3 & 3.5 \\
\hline Chamber Volume (inches $^{3}$ ) & 0 & 3.5 & 6.9 & 10.4 & 12.1 \\
\hline Sound Pressure Level (dBA) & 113.5 & 112 & 108.5 & 106.5 & 105 \\
\hline
\end{tabular}

One must also consider the effect of this modification on thrust production. It was shown in chapter 2 that a pulsejet is an acoustic duct which hosts oscillation modes and uses them to produce thrust. While the fundamental is the strongest mode in a pulsejet, and produces the majority of the thrust, higher modes also carry energy and 
produce thrust independently, so it stands to reason that removing some modes (by making them inaccessible) should result in a corresponding loss of thrust. Therefore, it is relevant to measure what this loss is.

This was accomplished by first rectifying the inlet flow using an external U-shaped duct, so that the jet (exhaust) coming out of the inlet end is turned towards the tailpipe end, and both the inlet and exhaust/tailpipe are producing thrust in the same direction. Then the engines were mounted on a thrust stand, which consisted of an optical (threaded) breadboard supported by steel flexures. The steel flexures behave as a spring and were pre-loaded by tightening a bolt between the thrust stand and a Transducer Techniques LSP-5 load cell.

The engines were mounted on the thrust stand and thrust measurements at several resonator chamber volumes were made. The engines produced thrust of approximately $1 \mathrm{~N}$ at the throttle level used for the acoustic studies - it should be kept in mind that these are small engines that were in no way designed for thrust production. Figure 4-6 shows the throttle level, as a percentage of the mean throttle level for each engine at 0 in. $^{3}$ resonator chamber volume, versus the resonator chamber height/volume. 


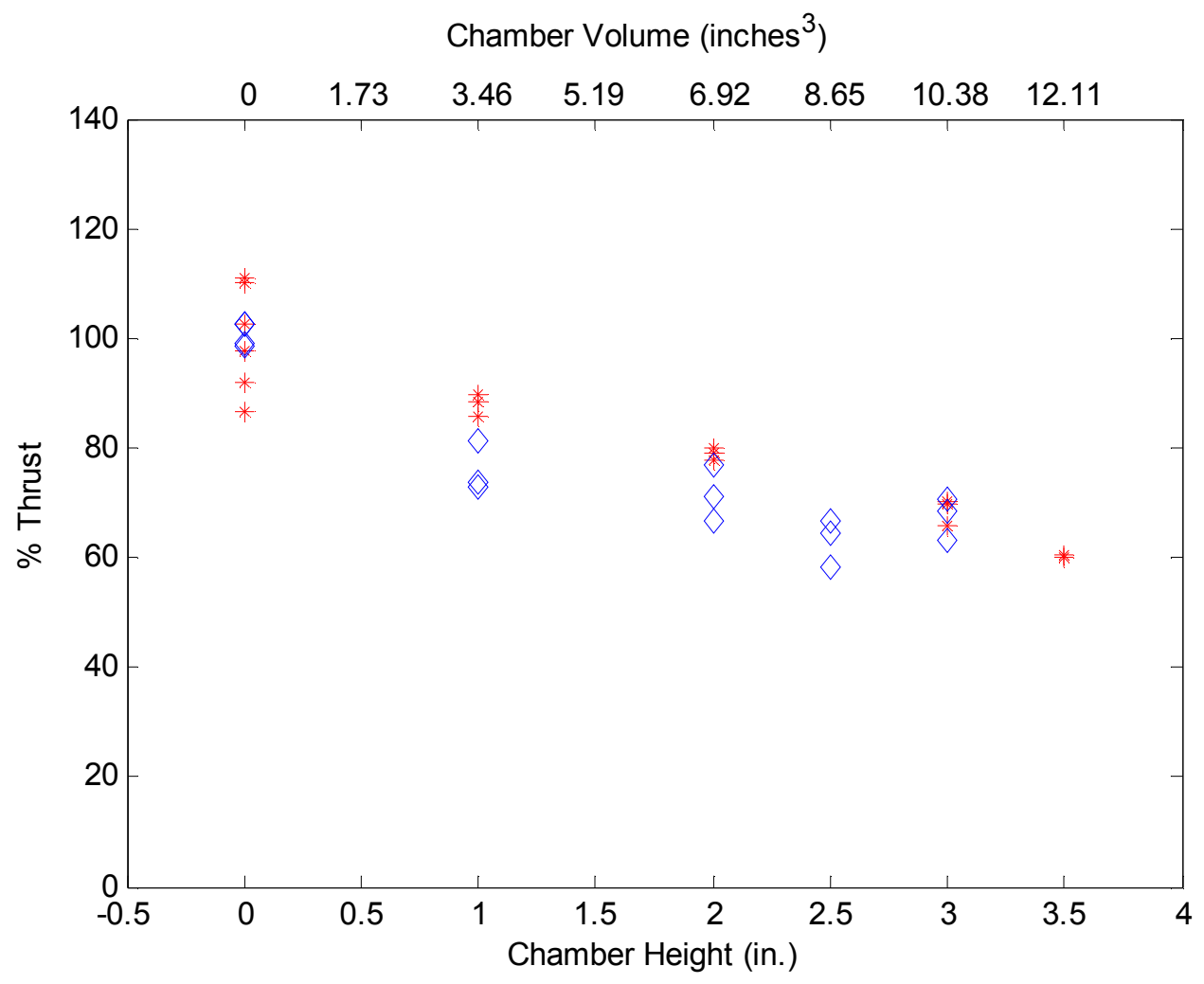

Figure 4-6: Thrust as a function of resonator chamber height/volume.

Figure 4-6 shows at least $30 \%$ loss of thrust as chamber volume is adjusted between 0 and 10.38 in.3 (3 in. height). So preparing the engines for acoustic cancellation carries a thrust penalty, but there are ways to avoid this loss of thrust using active fuel injection methods, which will be discussed later.

\subsubsection{Effect of Half-Wave Tube}

With the chambers of both Helmholtz resonators set to 10.4 in. $^{3}$ ( 3 in. height), the acoustic waveform should destructively interfere with itself to some degree. The two engines, with resonator chambers set at 10.4 in. $^{3}$ ( 3 in. height), were connected via a 42 in. $(106.7 \mathrm{~cm})$ wave tube to achieve anti-phase operation (Fig. 4-7). This is longer 
than the 36 in tube used in the previous chapter because adding the Helmholtz resonators has lowered the operating frequency of the engines from approximately $235 \mathrm{~Hz}$ to $195 \mathrm{~Hz}$.

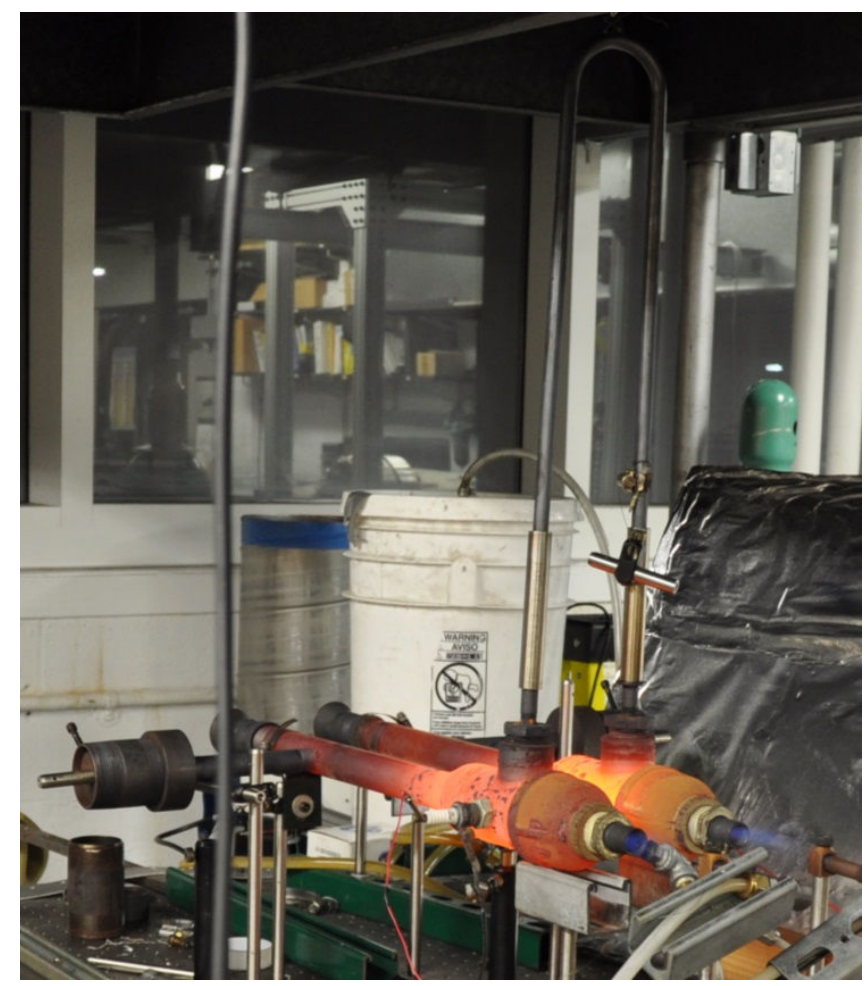

Figure 4-7: Paired engines in anti-phase operation.

Anti-phasing results in a further decrease in noise level by approximately $2 \mathrm{dBA}$, to produce an overall noise level reduction of $9 \mathrm{dBA}$. Figure 4-8 summarizes the effects of these engine modifications on acoustic output. It shows acoustic waveforms for (a) the conventional pulsejet, (b) the pulsejet equipped with a Helmholtz resonator chamber set to 10.4 in. $^{3}$ ( 3 in. height), and (c) two resonator-equipped pulsejets operating in anti-phase. Adding the Helmholtz resonators reduces acoustic output by approximately $7 \mathrm{dBA}$ - by removing higher frequency harmonics to which the human 
ear is more sensitive - and operating the engines in anti-phase achieves an additional 2 dBA for a total reduction of approximately 9 dBA. Figure 4-9 shows corresponding spectra. The reduction in harmonic content/peaks is clearly visible between (a) and (b), while anti-phase cancellation of the fundamental component and resulting amplitude decrease is evident between (b) and (c).

a)

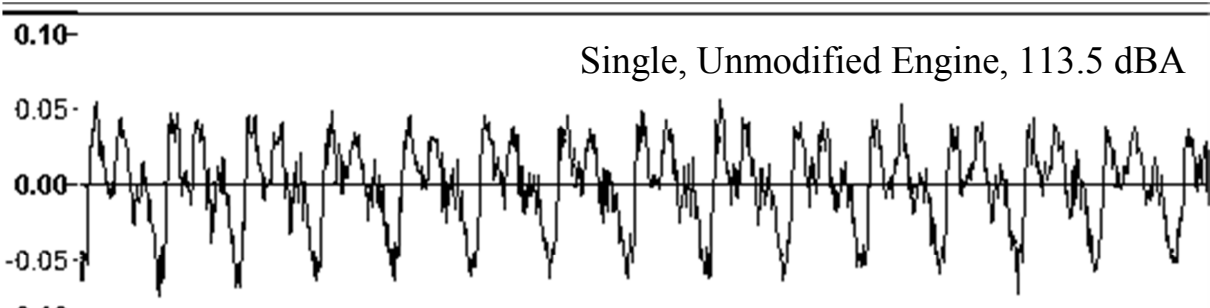

$-0.10$

b)

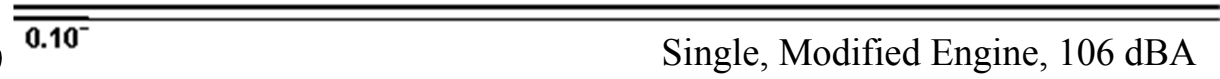

0.05

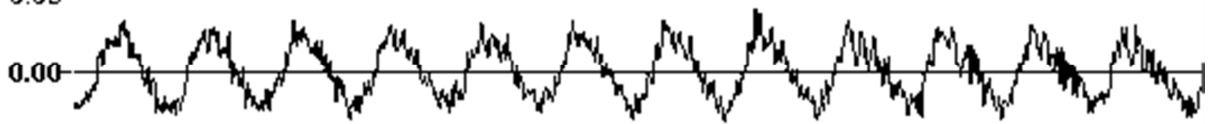

-0.05 .

c)

$\frac{-0.10}{0.10^{-}}$

0.05

Dual, Modified Engines, 104.5 dBA

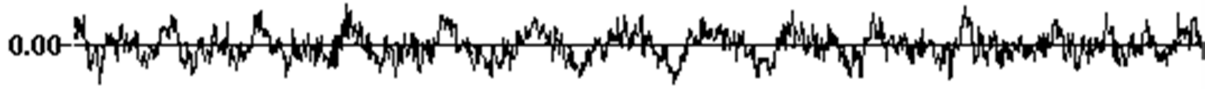
$-0.05$

$-0.10$

Figure 4-8: Acoustic waveforms: (a) single, unmodified engine (113.5 dBA), (b) single, modified engine with resonator chamber height 3 in. (106 dBA), and (c) two modified, anti-phased engines (104.5 dBA). 


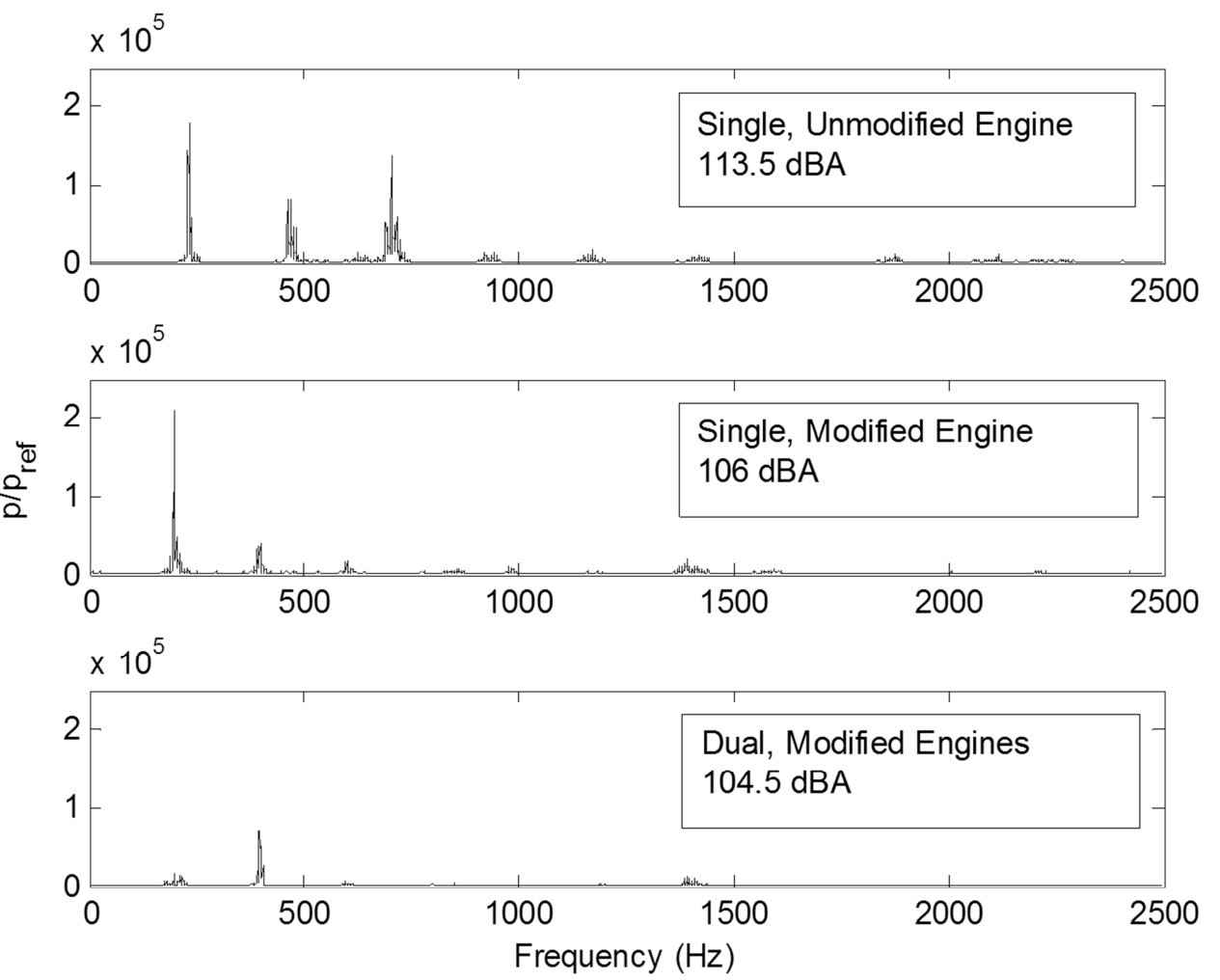

Figure 4-9: Spectra for (a) single, unmodified engine (113.5 dBA), (b) single, modified engine with resonator chamber height 3 in. (106 dBA), and (c) two modified, anti-phased engines (104.5 dBA).

\subsubsection{Summary of Results}

The combined effects of tuning the Helmholtz resonators and anti-phase operation is summarized in Fig. 4-10. It can be seen that (A-weighted) acoustic output decreases monotonically with resonator volume and that anti-phasing provides another $\sim 2 \mathrm{dBA}$ reduction. The overall noise reduction is $9-10 \mathrm{dBA}$ compared to a single, unmodified engine. Figure 4-11 shows A- and C-weighted sound pressure level measurements at all 3 locations to show that the noise reduction is global in nature and not confined to location 1. 


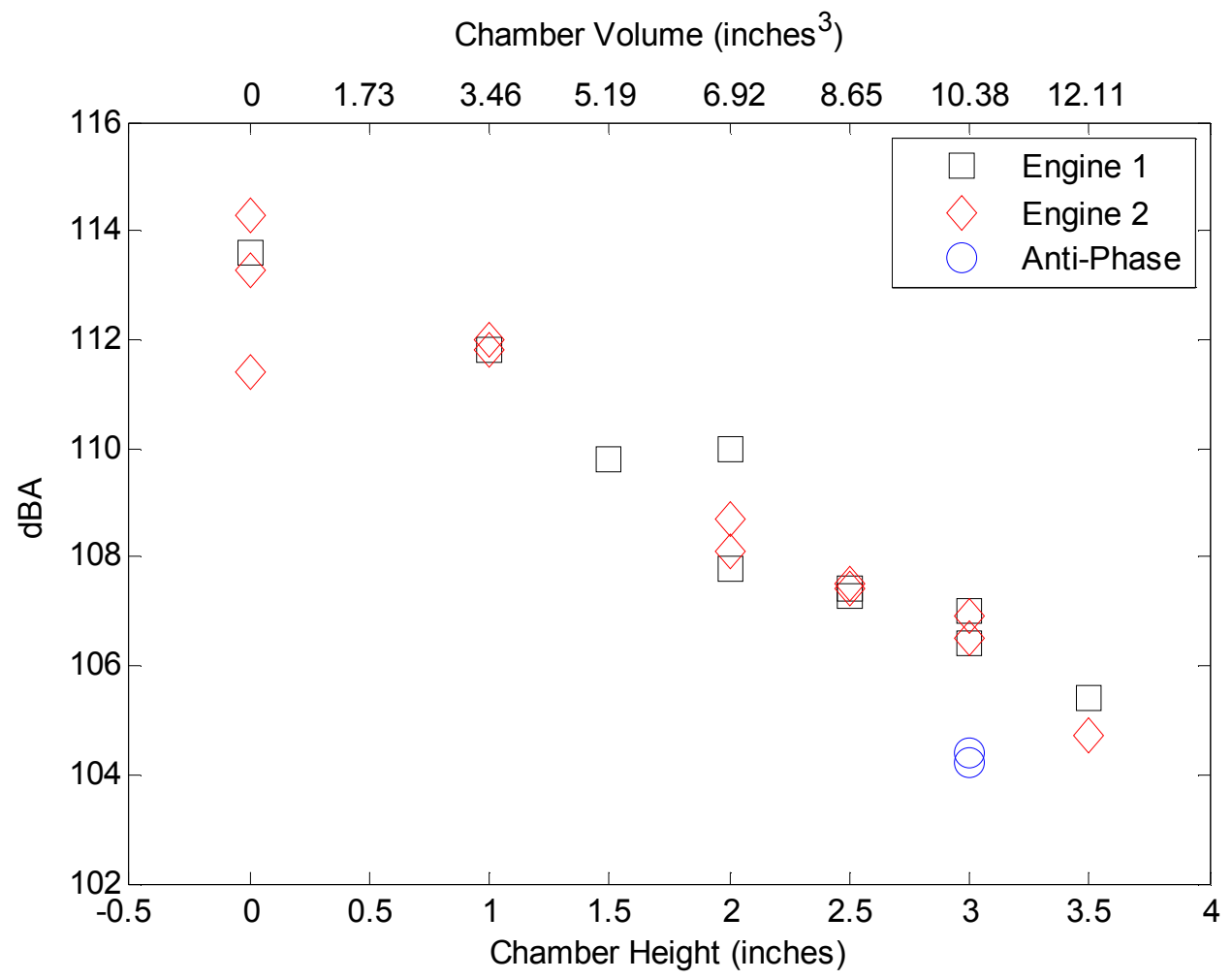

Figure 4-10: Effect of modifications on noise level at location 1. 


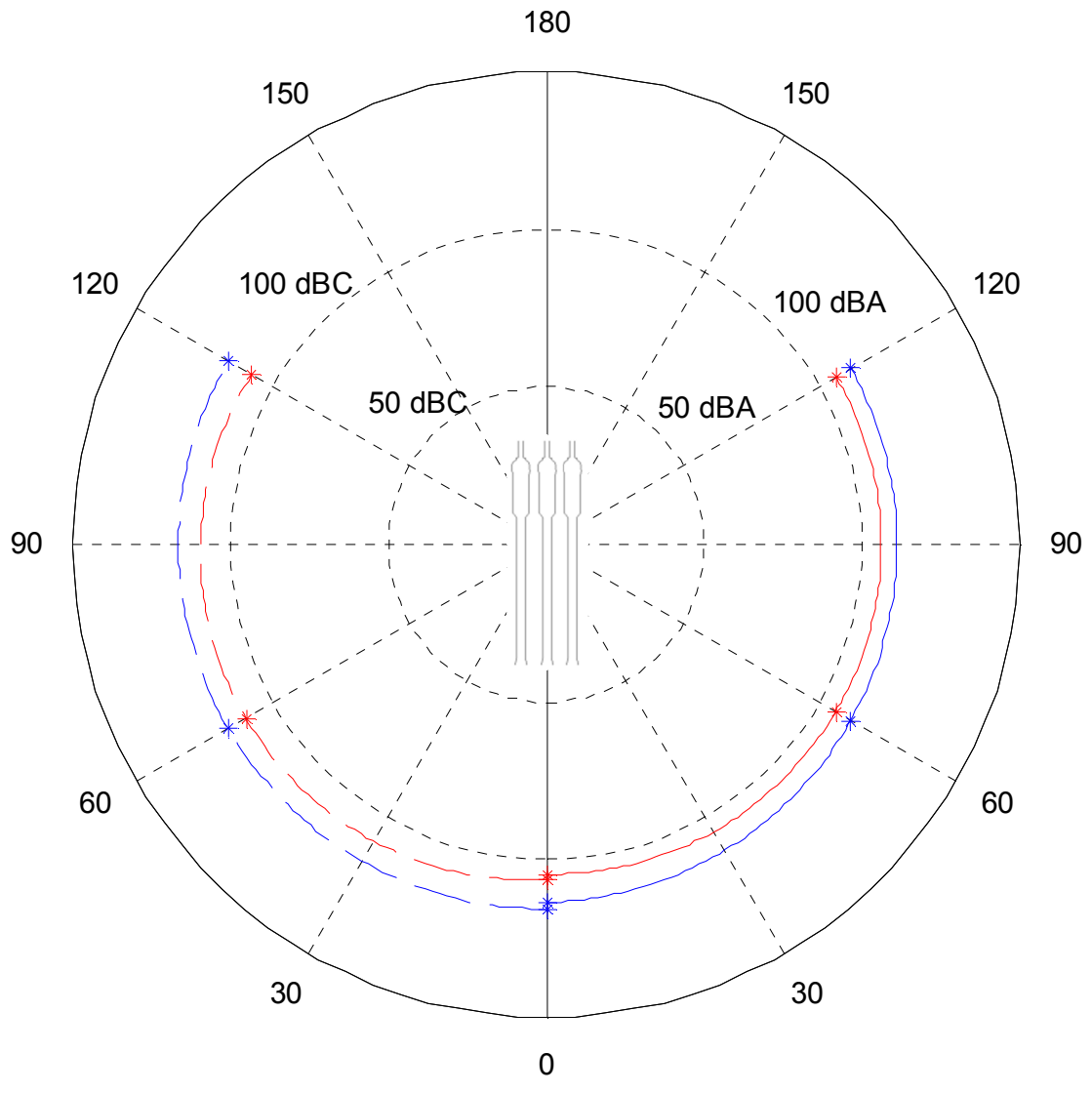

Figure 4-11: A- and C-weighted sound pressure level measurements around a single, unmodified engine (blue), and modified, anti-phased engines (red).

Quantifying the effect on vibration of the modifications described above is less straightforward than quantifying noise reduction for the following reason: Signals from accelerometers attached to the engine are also influenced by the frequency response of the structure to which it is attached so great care must be taken to account for interaction effects between the engine and structure. A much simpler approach is to estimate vibration reduction using the noise data. This is accomplished by approximating the pulsejet noise production mechanism as a piston in an infinite baffle radiating into the atmosphere. In this case, the pressure disturbance is 
proportional to the velocity amplitude, which, in turn, is proportional to the unsteady thrust (vibration) amplitude. This implies that the reduction in vibration is of approximately the same amplitude as the flat-weighted (C-weighted) noise reduction. We have observed a $9-10 \mathrm{~dB}$ reduction which corresponds to an approximately $2 / 3^{\text {rds }}$ reduction in amplitude. This reduction is also visible in Fig. 4-8. 


\section{Chapter 5: Conclusion}

\subsection{Conclusions}

This thesis has made the following conclusions:

1) Noise reduction from destructive interference by anti-phasing two valveless pulsejets is difficult to achieve because of two reasons:

a. There is no reliable process to operate two engines in anti-phase without interfering with their flow path and degrading performance, and

b. The acoustic waveforms produced by valveless pulsejets contain significant harmonic content and often display multiple peaks over of one combustion cycle. This makes useful destructive interference - and thus noise reduction - unlikely.

2) Existing models for analyzing valveless pulsejets cannot explain nonsinusoidal pressure fluctuations inside a pulsejet engine. 
3) Acoustic duct analysis predicts valveless pulsejet operating frequencies to with $6 \%$, whereas existing methods are much less accurate.

4) Acoustic duct analysis predicts higher oscillation modes in valveless pulsejets that supposedly are responsible for multiple pressure peaks over the course of a combustion cycle.

5) Acoustic duct analysis correctly predicts the effects of modifications like tone holes and Helmholtz resonators.

6) Higher modes can be suppressed by making geometrical modifications that include attaching Helmholtz resonators. The efficacy of this strategy has been demonstrated theoretically and experimentally.

7) Current methods for predicting the interaction of multiple valveless pulsejet engines are qualitatively inaccurate and cannot identify all possible interactions (modes).

8) The valveless pulsejet can be analyzed as an acoustic network.

9) The acoustic network analysis provides a comprehensive framework for explaining and predicting interactions between multiple engines. 
10) Connecting the combustion chambers of two pulsejets with a half-wave tube (based on the fundamental operating frequency) forces the two engines to operate in anti-phase without interfering with their individual flow paths. This has been shown theoretically and experimentally.

11) Helmholtz resonators can be added to valveless pulsejet engines to produce pressure (acoustic) signals with minimal harmonic content, thus suitable for cancellation. Reducing the harmonic content reduces acoustic output by 7-8 dBA. The Helmholtz resonators also reduce the operating frequency slightly, most likely by slowing down the heat release process, as per Rayleigh's criterion.

12) Adding Helmholtz resonators to each engine and connecting their combustion chambers with a half-wave tube, to force anti-phase operation, reduces acoustic output by 9-10 dBA.

13) While this work has measured only noise reduction, similar reductions in vibration are also expected since the mechanisms for noise and unsteady thrust production in a pulsejet are essentially the same.

14) It has been demonstrated theoretically and experimentally that simple strategies involving Helmholtz resonators and coupling with $1 / 2$-wave tubes can significantly reduce the acoustic output of pulsejet engines. Thus, the 
noise and vibration challenge for valveless pulsejet engines is not insurmountable. Refining the acoustic analysis methods and using them to identify new noise reduction methodologies should enable further significant reductions in noise and vibration.

\subsection{Academic Contributions}

This thesis has made the following academic contributions:

1) Developed and experimentally validated an acoustic theory for valveless pulsejet operation with the following advantages over existing models for valveless pulsejet operation:

a. More accurate frequency predictions.

b. More accurate engine pressure profile (mode shape) calculations.

c. The ability to analyze more complicated geometries, such as diverging tailpipes.

d. The ability to predict the amplitudes and shapes of higher oscillation modes.

e. The ability to accommodate modifications such as tone holes and acoustic filters (e.g. Helmholtz resonators).

2) Produced a well characterized experimental data set that can be used for validating other theories and numerical models.

3) Identified and explained inaccuracies in prior methods of analysis. 
4) Developed technologies for removing harmonic content in valveless pulsejets. These technologies have been explained theoretically and verified experimentally.

5) Developed and experimentally validated a comprehensive theory for the acoustic behavior of multiple interacting valveless pulsejets.

6) Developed a method for operating two engines in anti-phase without interfering with their flow paths. The performance of the method has been explained theoretically and verified experimentally.

7) Demonstrated experimentally that significant noise reduction (9-10dBA) is possible using paired valveless pulsejets operating in anti-phase.

\section{$\underline{5.3 \text { Future Work }}$}

1) Apply the principles and noise reduction strategies described in this thesis to larger, full-scale, thrust-producing engines to assess the ultimate practical potential of these technologies.

2) The present, passive method of suppressing higher modes (using Helmholtz resonators attached to the engines) results in some thrust loss. In order to retain all the thrust that the device offers, active control methods such as timed or secondary fuel injection should be implemented. 
3) The preceding analyses, particularly, the impedance analysis of chapter 3 yields considerable insight into the operation of these engines, and using this information, it is possible to conceive some additional engine configurations that may provide alternatives to the configurations studied earlier in this thesis. The following engine configurations warrant further investigation:

- Alternative Anti-Phasing Configuration

It is an objective of this thesis to devise configurations that produce anti-phase operation of two or more engines. Several such configurations were studied in chapters 1 and 3 . There is, however, another configuration that is expected to produce anti-phase operation: if two pulsejet engines are connected via a short duct at or near their exhaust (tailpipe) ends (Fig. 5-1), this should serve the same purpose as a decoupling chamber, i.e. forcing a common pressure node and thereby producing anti-phase operation. Another way of making the same argument is that this configuration is essentially the same as the half-wave tube studied in section 3.3.4, but instead of having a dedicated (separate) half-wave tube connecting the combustion chambers, this configuration uses the tailpipes to form a half-wave tube between the combustion chambers. 


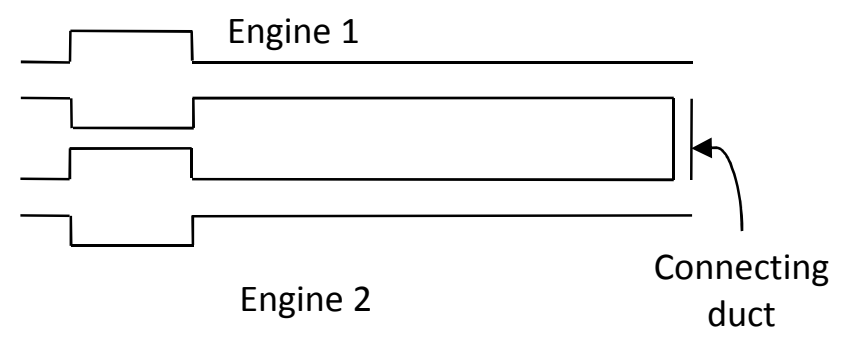

Figure 5-1: Alternative configuration for anti-phasing.

- Alternative Engine Configuration

When viewed as an acoustic system/circuit, as in chapter 3, a valveless pulsejet may be interpreted as the following: The inlet and the combustion chamber form a resonant circuit and the tailpipe serves as a transformer that provides a favorable impedance match between the combustion chamber and the atmosphere in a way that is similar to how quarter-wave transformers are used in radio-frequency circuits. Alternatively, one could imagine that the main purpose of the combustion chamber is to provide an oscillating pressure source. A transformer (tailpipe) is needed to convert the energy in this source to a high speed jet in order to produce thrust. A much shorter inlet duct is needed to induct fresh air and produce the oscillating combustion/pressure inside the combustion chamber. This shorter duct provides a poor impedance match between the chamber and the atmosphere and thus is an inefficient converter of the high pressure to high velocity. This would seem to explain why, in the Hiller engines, the exhaust produces approximately $60 \%$ of the thrust, despite having 
only $40 \%$ of the area connecting to the combustion chamber ( $40 \%$ of the total cross-sectional area of ducts connecting to the combustion chamber, the other $60 \%$ being the cross-sectional area of the inlet) [2]. Said another way, the combustion chamber produces high pressure gas, which is let out both the inlet and exhaust/tailpipe ends. In spite of the fact that the exhaust/tailpipe side has only $40 \%$ of the total flow area, it produces $60 \%$ of the thrust because it offers a better impedance match with the combustion chamber and therefore expands the gas more efficiently.

This line of reasoning enables one to envision another engine concept as illustrated in Fig. 5-2. It is a Helmholtz resonator in which a thermo-acoustic instability is excited and sustained by combustion events. Such combustors are often referred to as "Reynst combustors" in the literature [17]. So far, this engine is the same as the front-end of a valveless pulsejet, i.e. in theory, it is the inlet side of a pulsejet separated by a wall at the "plane of acoustic symmetry" as in Fig. 210. The short duct connecting the combustion chamber to the atmosphere (which serves as both inlet and exhaust in this case) presents a poor impedance match and is therefore not expected to produce an efficient device. However, if this inlet pipe is then placed at or near the entrance of a larger-diameter duct, which is of length 
one-quarter wavelength, there are several reasons to believe that the performance of this device can be greatly improved:

1) The larger diameter $1 / 4$-wave duct serves as an augmenter which can double the thrust of the device (and correspondingly halve the SFC) [2] [46] [47] [48].

2) The Reynst combustor, which forms the 'core' of the engine, serves to energize a $1 / 4$-wave mode of the larger diameter duct, with the pressure anti-node at the combustor end, and the pressure node at the open (far) end. This implies that the larger diameter duct does not allow the gas coming out of the engine 'core' to expand fully, but then expands it through its own $1 / 4$-wave mode, providing a better impedance match for the remaining expansion, and therefore more efficient operation.

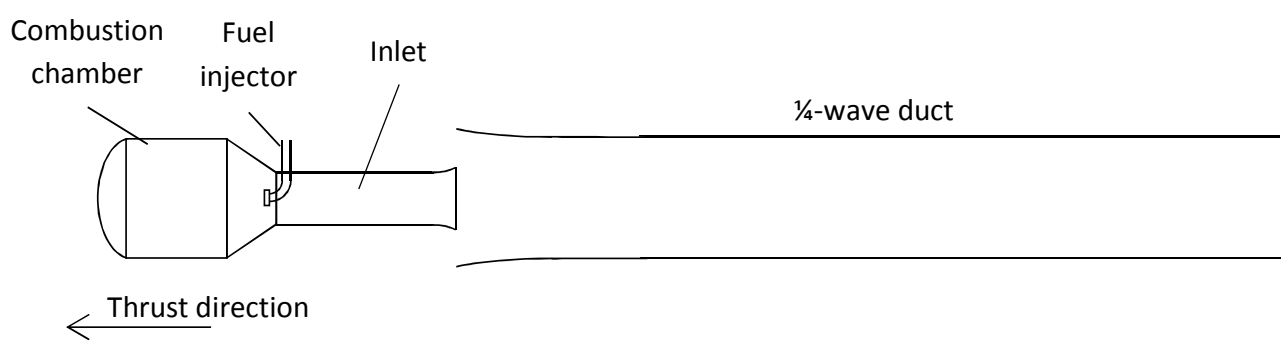

Figure 5-2: Wave engine concept with $1 / 4$-wave duct.

While comparing the efficiency of the preceding wave engine concept (Fig. 5-2) with a valveless pulsejet would require experimental study, 
there is no doubt that it is more compact and more 'airframe-friendly' than a traditional valveless pulsejet because it does not require the engine to be bent in a U-shape.

Lastly, other configurations based on the same principle are also possible. The premise of the concept in Fig. 5-2 is that the Reynst combustor itself only serves to energize a prescribed mode of a resonance tube which provides better impedance matching than the short duct of the Reynst combustor alone. Another possible configuration is a Reynst combustor exhausting at the pressure antinode of a half-wave tube. One way to realize this is to extend the $1 / 4-$ wave duct in Fig. 5-2 over the engine core (the Reynst combustor) with the appropriate area increase such that the exhaust of the engine core is coincident with the pressure anti-node of the larger diameter duct (Fig. 5-3). This arrangement allows the engine core to energize the $1 / 2$-wave mode of the larger diameter duct for thrust production and may be better than the standard configuration (Fig. 5-2) because it can allow for ram air pressure recovery and/or better entrapment of the acoustic energy coming out the engine core. 


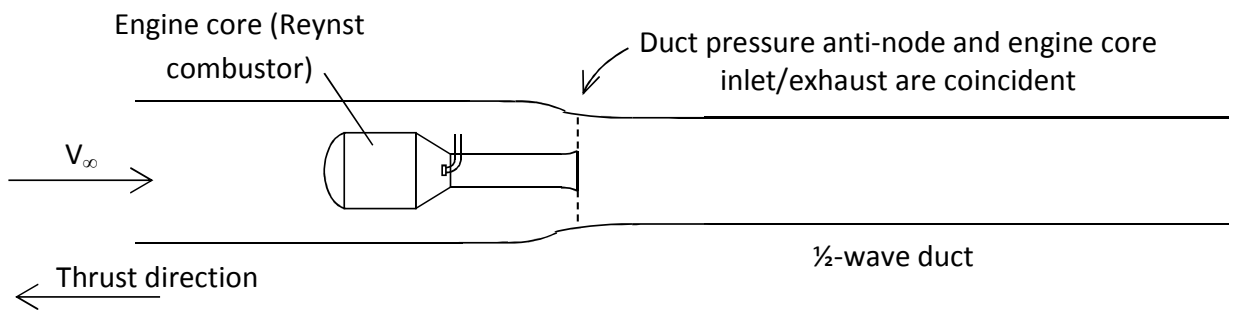

Figure 5-3: Wave engine concept with $1 / 2$-wave duct.

These engine concepts, while only notional at this stage, could provide some direction for how to better configure wave engines (pulsejets) for more comfortable airframe integration and improved high-speed performance. 


\section{Appendix A: Analytical Impedance Expressions}

Analytical expressions for the impedance of loop $U_{1}$ in section 3.3.1:

((zchamber*ztailpipe22^2 - zchamber*ztailpipe23^2 + zinlet*ztailpipe22^2 -

zinlet*ztailpipe $23^{\wedge} 2+$ zradc $^{*}$ ztailpipe $22^{\wedge} 2-$ zradc $^{*}$ ztailpipe $23^{\wedge} 2+$

zradi*ztailpipe22^2 - zradi*ztailpipe23^2 + zchamber* zinlet*zradex +

zchamber*zinlet*ztailpipe $22+$ zchamber*zradc*zradex + zchamber*zradi*zradex +

zchamber*zradc*ztailpipe 22 + zchamber*zradi*ztailpipe $22+$

zchamber*zradex*ztailpipe $22+$ zinlet*zradex*ztailpipe $22+$

zradc*zradex*ztailpipe $22+$

zradi*zradex* ztailpipe22)*(zchamber*zconnect*ztailpipe $22^{\wedge} 2$ -

zchamber*zconnect* ztailpipe $23^{\wedge} 2+2 *$ zchamber*zinlet*ztailpipe $22^{\wedge} 2$ -

$2 *$ zchamber* zinlet*ztailpipe $23^{\wedge} 2+$ zconnect* $^{*}$ zinlet*ztailpipe $22^{\wedge} 2-$

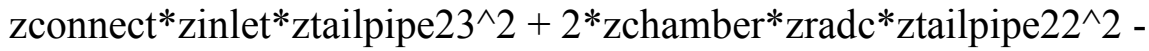

$2 *$ zchamber* ${ }^{*}$ zadc $*$ ztailpipe $23^{\wedge} 2+2 *$ zchamber* zradi*ztailpipe $22^{\wedge} 2$ -

$2 *$ zchamber* zradi*ztailpipe $23^{\wedge} 2+$ zconnect*$^{*}$ zradc $^{*}$ ztailpipe $22^{\wedge} 2-$

zconnect* zradc $^{*}$ ztailpipe $23^{\wedge} 2+$ zconnect*$^{*}$ zradi*$^{*}$ ztailpipe $22^{\wedge} 2$ -

zconnect*zradi*ztailpipe $23^{\wedge} 2+$ zchamber* zconnect*zinlet*zradex +

zchamber*zconnect*zinlet*ztailpipe $22+$ zchamber*zconnect*zradc*zradex +

zchamber*zconnect*zradi*zradex + zchamber*zconnect*zradc*ztailpipe $22+$

zchamber*zconnect*zradi*ztailpipe $22+$ zchamber* zconnect*zradex*ztailpipe $22+$

$2 *$ zchamber*zinlet*zradex*ztailpipe $22+$ zconnect*zinlet*zradex*ztailpipe $22+$

$2 *$ zchamber*zradc*zradex*ztailpipe $22+2 *$ zchamber*zradi*zradex*ztailpipe $22+$

zconnect*zradc*zradex*ztailpipe $22+$

zconnect*zradi*zradex ${ }^{*}$ ztailpipe 22$\left.)\right) /\left(\right.$ zchamber $^{\wedge} 2 *$ ztailpipe $22^{\wedge} 4+$

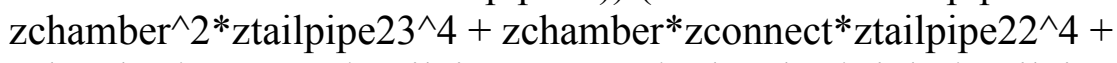

zchamber*zconnect*ztailpipe $23^{\wedge} 4+2 *$ zchamber*zinlet*ztailpipe $22^{\wedge} 4+$

$2^{*}$ zchamber*zinlet*ztailpipe $23^{\wedge} 4+$ zconnect*$^{*}$ zinlet*ztailpipe $22^{\wedge} 4+$

zconnect*zinlet*ztailpipe $23^{\wedge} 4+2 *$ zchamber*zradc*ztailpipe $22^{\wedge} 4+$

$2 *$ zchamber*zradc*ztailpipe $23^{\wedge} 4+2 *$ zchamber*zradi*ztailpipe $22^{\wedge} 4+$

$2^{*}$ zchamber*zradi*ztailpipe $23^{\wedge} 4+$ zconnect*$^{*}$ zradc $^{*}$ ztailpipe $22^{\wedge} 4+$

zconnect*zradc*ztailpipe $23^{\wedge} 4+$ zconnect*zradi*ztailpipe $22^{\wedge} 4+$

zconnect* ${ }^{*}$ radi*ztailpipe $23^{\wedge} 4+$ zchamber $^{\wedge} 2^{*}$ zconnect*ztailpipe $22^{\wedge} 3+$

$2 *$ zchamber ${ }^{*} *_{\text {zinlet }}^{*}$ ztailpipe $22^{\wedge} 3+2 *$ zchamber $^{\wedge} 2 *$ zradc $^{*}$ ztailpipe $22^{\wedge} 3+$

$2 *$ zchamber ${ }^{\wedge} 2^{*}$ zradi*ztailpipe $22^{\wedge} 3+2^{*}$ zchamber ${ }^{\wedge}{ }^{*}$ zradex ${ }^{*}$ ztailpipe $22^{\wedge} 3+$

zchamber $^{\wedge} 2 *$ zradex $^{\wedge} 2 *$ ztailpipe $22^{\wedge} 2-2 *^{*}$ zchamber $^{\wedge} 2 *$ ztailpipe $22^{\wedge} 2 *$ ztailpipe $23^{\wedge} 2+$

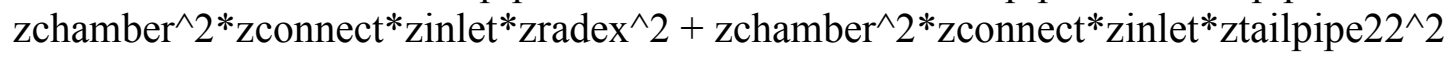

+ zchamber $^{\wedge} 2 *$ zconnect $^{*}$ zradc $^{*}$ zradex $^{\wedge} 2+$ zchamber $^{\wedge} 2 *$ zconnect $^{*}$ zradi $^{*}$ zradex $^{\wedge} 2+$

zchamber ${ }^{\wedge}{ }^{*}$ zconnect*zradc*ztailpipe $22^{\wedge} 2+$

zchamber $^{\wedge} 2 *$ zconnect* ${ }^{*}$ zradi*ztailpipe $22^{\wedge} 2+$

zchamber*zconnect* ${ }^{*}$ zradex $^{\wedge} 2^{*}$ ztailpipe $22^{\wedge} 2+$

$2{ }^{*}$ zchamber ${ }^{\wedge} 2 *$ zconnect ${ }^{*}$ zradex ${ }^{*}$ ztailpipe $22^{\wedge} 2+$

zchamber ${ }^{\wedge} 2 *$ zconnect* $^{*}$ zradex $^{\wedge} 2 *$ ztailpipe 22 -

zchamber $^{\wedge} 2 *$ zconnect*zradex ${ }^{*}$ ztailpipe $23^{\wedge} 2$ - 
$2 *$ zchamber*zconnect*ztailpipe $22^{\wedge} 2 *$ ztailpipe $23 \wedge 2$ -

zchamber^ $2 *$ zconnect*ztailpipe $22^{*}$ ztailpipe $23^{\wedge} 2+$

$2 *$ zchamber*zinlet*zradex ${ }^{\wedge}{ }^{*}$ ztailpipe $22^{\wedge} 2+$

$4 *$ zchamber^ $2 *$ zinlet*zradex $*$ ztailpipe $22^{\wedge} 2+$

$2 *$ zchamber^ $2 *$ zinlet* ${ }^{*}$ zradex ${ }^{\wedge} 2 *$ ztailpipe 22 -

$2 *$ zchamber^ $2 *$ zinlet*zradex*ztailpipe $23 \wedge 2+$

zconnect*zinlet*zradex ${ }^{\wedge} 2 *$ ztailpipe $22^{\wedge} 2$ -

$4 *$ zchamber*zinlet*ztailpipe $22^{\wedge} 2 *$ ztailpipe $23^{\wedge} 2$ -

$2 *$ zchamber ${ }^{\wedge}{ }^{*}$ zinlet $^{*}$ ztailpipe $22 *$ ztailpipe $23^{\wedge} 2$ -

$2 *$ zconnect*zinlet*ztailpipe $22^{\wedge} 2 *$ ztailpipe $23^{\wedge} 2+$

$2 *$ zchamber*zradc*zradex ${ }^{\wedge}{ }^{*}$ ztailpipe $22^{\wedge} 2+$

$4 *$ zchamber^ $2 *{ }^{*}$ zradc $^{*}$ zradex ${ }^{*}$ ztailpipe $22^{\wedge} 2+$

$2 * z^{*}$ chamber ${ }^{\wedge} 2 * \operatorname{zradc}^{*} \operatorname{zradex}^{\wedge} 2 *$ ztailpipe 22 -

$2 *$ zchamber^ $2 *$ zradc $^{*}$ zradex $*$ ztailpipe $23^{\wedge} 2+$

$2^{*}$ zchamber*zradi*zradex ${ }^{\wedge} 2^{*}$ ztailpipe $22^{\wedge} 2+$

$4 *$ zchamber^ $2 *$ zradi*zradex ${ }^{*}$ ztailpipe $22^{\wedge} 2+$

$2 *$ zchamber ${ }^{\wedge} 2 *$ zradi*zradex ${ }^{\wedge} 2 *$ ztailpipe 22 -

$2 *$ zchamber $^{\wedge} 2 *$ zradi $^{*}$ zradex ${ }^{*}$ ztailpipe $23^{\wedge} 2+$

zconnect*zradc*${ }^{*}$ zradex $^{\wedge} 2^{*}$ ztailpipe22^2 ${ }^{\star}$ zconnect*zradi*zradex^2*ztailpipe22^2 -

$4 *$ zchamber*zrade*ztailpipe $22^{\wedge} 2^{*}$ ztailpipe $23^{\wedge} 2$ -

$2 *$ zchamber ${ }^{*} * \mathrm{zradc}^{*}$ ztailpipe $22 *$ ztailpipe $23^{\wedge} 2$ -

$4 *$ zchamber*zradi*ztailpipe $22^{\wedge} 2 *$ ztailpipe $23^{\wedge} 2$ -

$2 *$ zchamber^ $2 *$ zradi*ztailpipe $22 *$ ztailpipe $23 \wedge 2$ -

$2 *$ zchamber^ $2 *$ zradex*ztailpipe $22^{*}$ ztailpipe $23^{\wedge} 2$ -

$2 *$ zconnect* ${ }^{*}$ radc*${ }^{*}$ ztailpipe $22^{\wedge} 2 *$ ztailpipe $23^{\wedge} 2$ -

$2 *$ zconnect* ${ }^{*}$ zradi*ztailpipe $22^{\wedge}{ }^{2}{ }^{*}$ ztailpipe $23^{\wedge} 2+$

$2 *$ zchamber*zconnect*zinlet*ztailpipe $22^{\wedge} 3+$

$2 *$ zchamber*zconnect*zradc*${ }^{*}$ ztailpipe $22^{\wedge} 3+$

$2 *$ zchamber*zconnect*zradi*ztailpipe $22^{\wedge} 3+$

$2 *$ zchamber*zconnect*zradex*ztailpipe $22^{\wedge} 3+$

$4 *$ zchamber*zinlet*zradex*ztailpipe2 $2 \wedge 3+2 *$ zconnect*zinlet*zradex*ztailpipe $22^{\wedge} 3$

$+4 *$ zchamber*zradc* ${ }^{*}$ radex $*$ ztailpipe $22^{\wedge} 3+$

$4 *$ zchamber*zradi*zradex*ztailpipe22^3 $32^{*}{ }^{*}$ zconnect*zradc*zradex*ztailpipe22^3

$+2 *$ zconnect*zradi*zradex*ztailpipe $22^{\wedge} 3+$

4*zchamber*zconnect*zinlet*zradex*ztailpipe $22^{\wedge} 2+$

$2 *$ zchamber*zconnect*zinlet*zradex ${ }^{\wedge} 2 *$ ztailpipe $22+$

$2 *$ zchamber^ $2 *$ zconnect*zinlet*zradex*ztailpipe 22 -

$2 *$ zchamber*zconnect*zinlet*zradex*ztailpipe $23^{\wedge} 2$ -

$2 *$ zchamber*zconnect*zinlet*ztailpipe $22 *$ ztailpipe $23^{\wedge} 2+$

$4 *$ zchamber*zconnect*zradc*zradex*ztailpipe $22^{\wedge} 2+$

$2 *$ zchamber*zconnect*zradc*zradex ${ }^{\wedge} 2 *$ ztailpipe $22+$

$2 *$ zchamber^ $2 *$ zconnect*zradc*zradex*ztailpipe 22 -

$2 *$ zchamber*zconnect*zradc*zradex*ztailpipe $23^{\wedge} 2+$

$4 *$ zchamber*zconnect*zradi*zradex*ztailpipe $22^{\wedge} 2+$

$2 *$ zchamber*zconnect*zradi*zradex ${ }^{\wedge} 2 *$ ztailpipe $2+$

$2 *$ zchamber ${ }^{\wedge} 2 *$ zconnect* ${ }^{*}$ zradi*zradex*ztailpipe22 - 
$2 *$ zchamber*zconnect*zradi*zradex*ztailpipe $23^{\wedge} 2$ -

$2 *$ zchamber*zconnect*zradc*ztailpipe $2{ }^{*}{ }^{*}$ ztailpipe $23^{\wedge} 2$ -

$2 *$ zchamber*zconnect*zradi*ztailpipe $2{ }^{*}$ ztailpipe $23^{\wedge} 2$ -

$2 *$ zchamber*zconnect*zradex*ztailpipe $22^{*}$ ztailpipe $23^{\wedge} 2$ -

$4 *$ zchamber*zinlet*zradex*ztailpipe22*ztailpipe $23^{\wedge} 2$ -

$2 *$ zconnect*zinlet*zradex*ztailpipe $22^{*}$ ztailpipe $23 \wedge 2-$

$4 *$ zchamber*zradc*zradex*ztailpipe22*ztailpipe $23 \wedge 2$ -

$4 *$ zchamber*zradi*zradex*ztailpipe $22^{*}$ ztailpipe $23^{\wedge} 2$ -

$2 *$ zconnect*zradc*zradex*ztailpipe $2{ }^{*}$ ztailpipe $23^{\wedge} 2$ -

$2{ }^{*}$ zconnect*zradi*zradex*ztailpipe $2{ }^{*}$ ztailpipe $23{ }^{\wedge} 2$ )

Analytical expressions for the impedance of loop $\mathrm{U}_{4}$ in section 3.3.1:

-((zchamber*ztailpipe22^2 - zchamber*ztailpipe23^2 + zinlet*ztailpipe22^2 -

zinlet*ztailpipe $23^{\wedge} 2+$ zradc$^{*}$ ztailpipe $22^{\wedge} 2-$ zradc$^{*}$ ztailpipe $23^{\wedge} 2+$

zradi*ztailpipe $22^{\wedge} 2$ - zradi*ztailpipe $23^{\wedge} 2+$ zchamber*zinlet*zradex +

zchamber*zinlet*ztailpipe $22+$ zchamber*zradc*zradex + zchamber*zradi*zradex +

zchamber*zradc*ztailpipe $22+$ zchamber*zradi*ztailpipe $22+$

zchamber*zradex*ztailpipe22 + zinlet*zradex*ztailpipe $22+$

zradc*zradex*ztailpipe $22+$

zradi*zradex*ztailpipe22)*(zchamber*zconnect*ztailpipe $22^{\wedge} 2$ -

zchamber*zconnect*ztailpipe $23^{\wedge} 2+2 *$ zchamber*zinlet*ztailpipe22^2 -

$2^{*}$ zchamber*zinlet*ztailpipe $23^{\wedge} 2+$ zconnect*zinlet*ztailpipe $22^{\wedge} 2$ -

zconnect*zinlet*ztailpipe $23^{\wedge} 2+2 *$ zchamber*zradc*ztailpipe $22^{\wedge} 2-$

$2 *$ zchamber*zradc*ztailpipe $23^{\wedge} 2+2 *$ zchamber*zradi*ztailpipe $22^{\wedge} 2-$

$2 *$ zchamber*zradi*ztailpipe $23^{\wedge} 2+$ zconnect*zradc*ztailpipe $22^{\wedge} 2$ -

zconnect*zradc*ztailpipe $23^{\wedge} 2+$ zconnect*$^{*}$ zradi* $^{*}$ ztailpipe $22^{\wedge} 2$ -

zconnect*zradi*ztailpipe $23^{\wedge} 2+$ zchamber*zconnect*zinlet*zradex +

zchamber*zconnect*zinlet*ztailpipe $22+$ zchamber*zconnect*zradc*zradex +

zchamber*zconnect*zradi*zradex + zchamber*zconnect*zradc*ztailpipe $22+$

zchamber*zconnect*zradi*ztailpipe22 + zchamber*zconnect*zradex*ztailpipe22 + $2 *$ zchamber*zinlet*zradex*ztailpipe $22+$ zconnect*zinlet*zradex*ztailpipe $22+$

$2 *$ zchamber*zradc*zradex *ztailpipe $22+2 *$ zchamber*zradi*zradex*ztailpipe $22+$ zconnect*zradc*zradex*ztailpipe $22+$

zconnect*zradi*zradex*ztailpipe22) $) /\left(\right.$ zchamber^ $2 *\left(\right.$ ztailpipe $22^{\wedge} 2+$

zradex*ztailpipe22 - ztailpipe23^2)^2) 


\section{Appendix B: Acoustic Duct MATLAB Script}

First run the engine geometry generator:

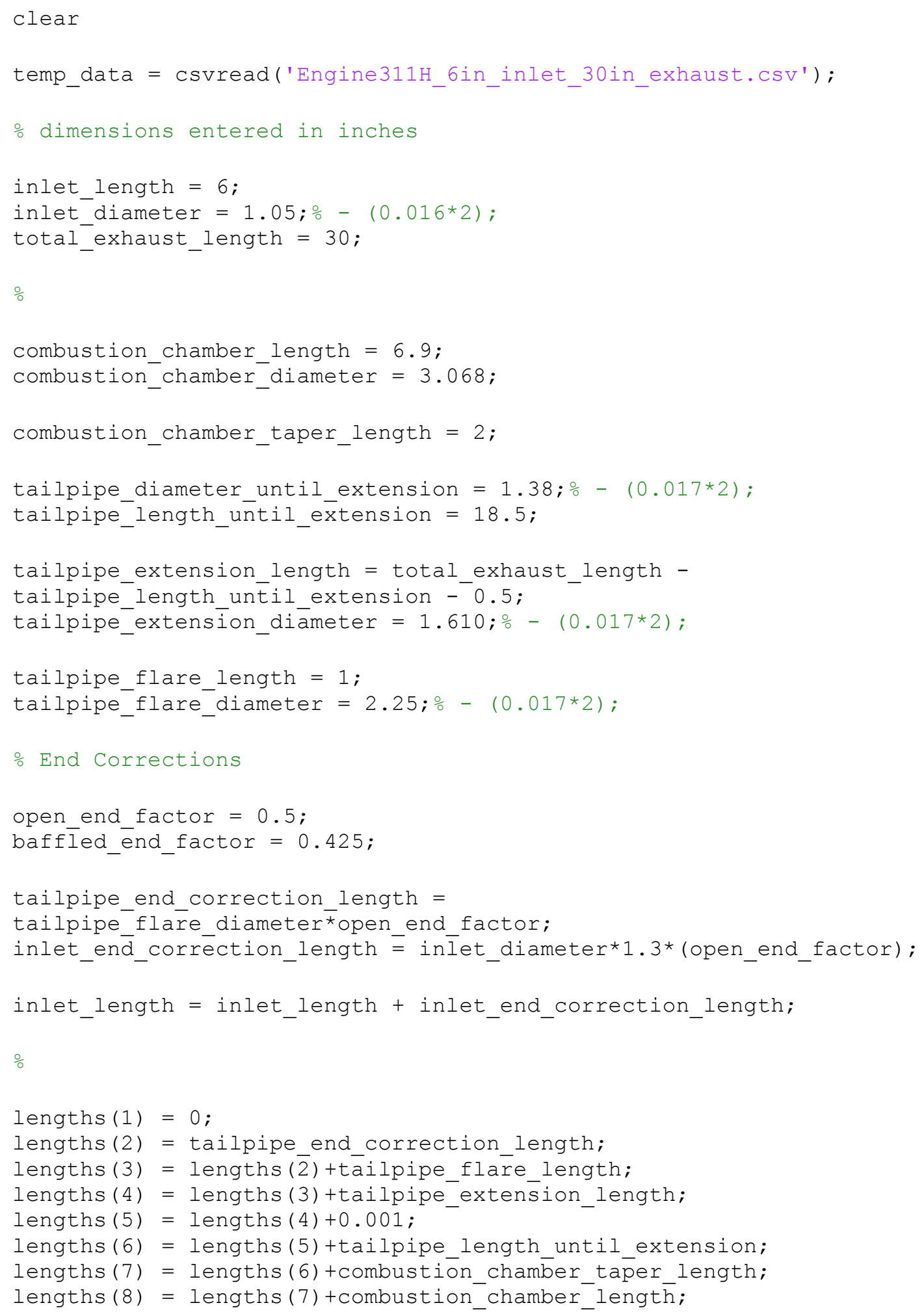




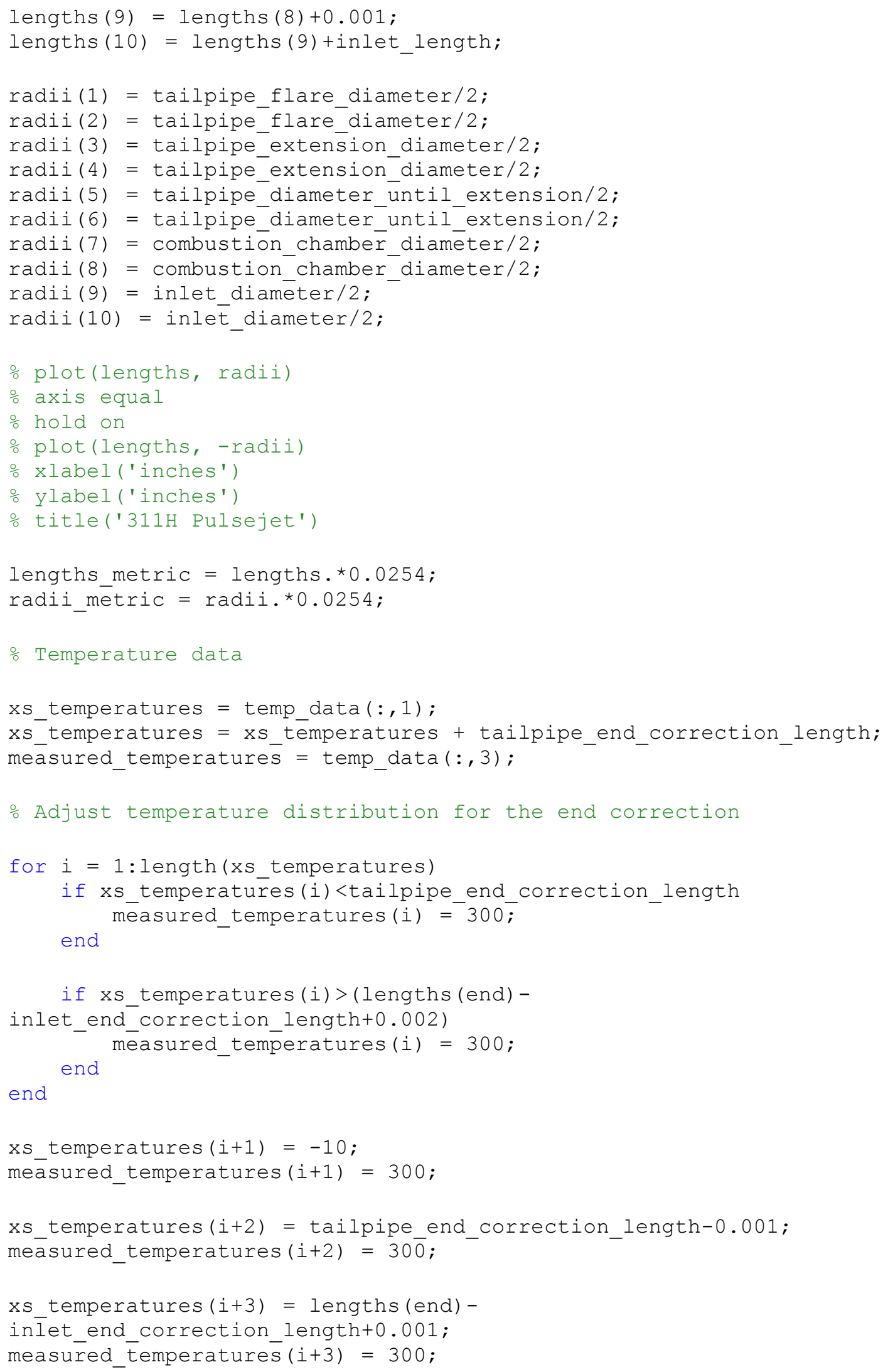




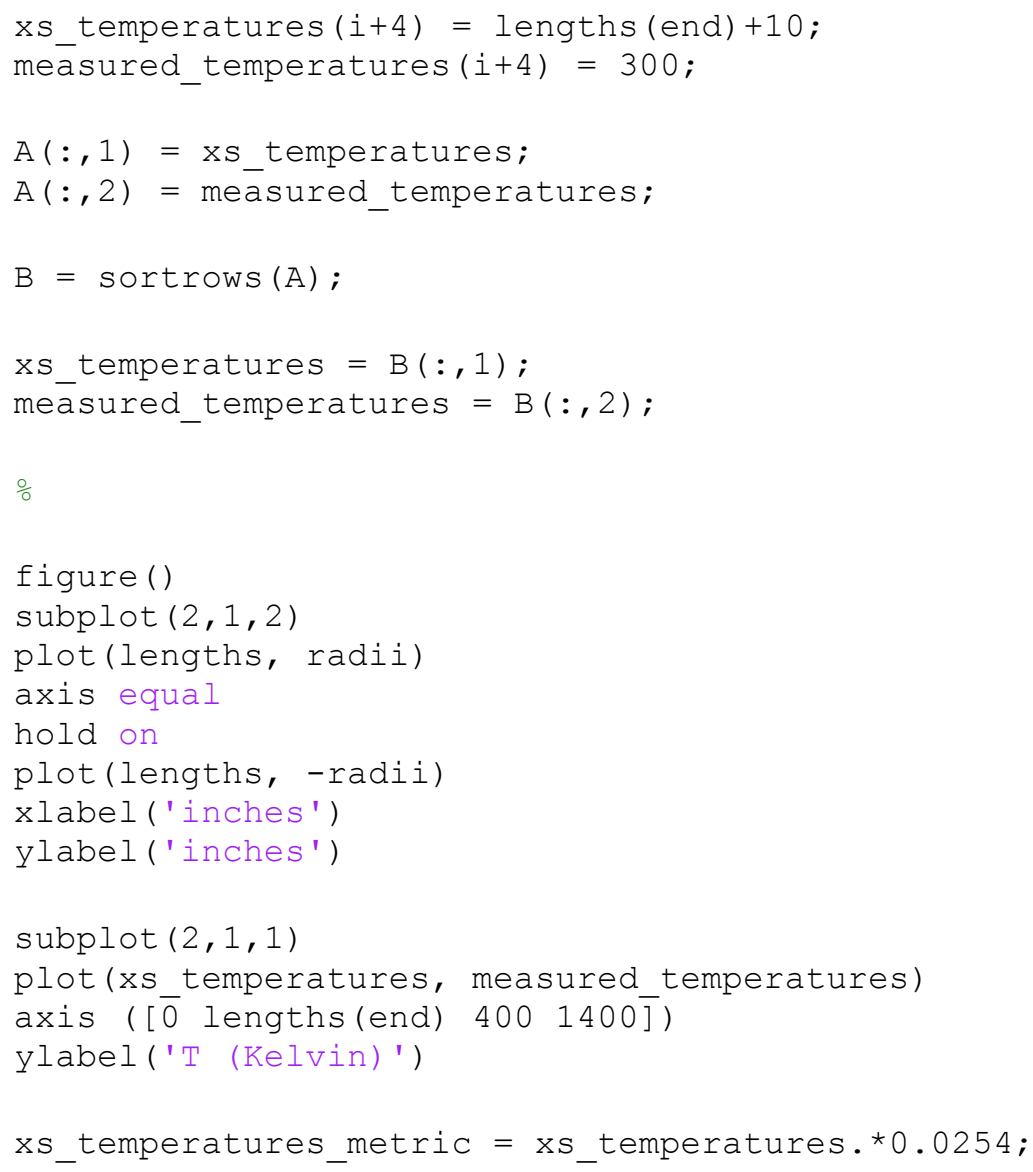

\section{Then run:}

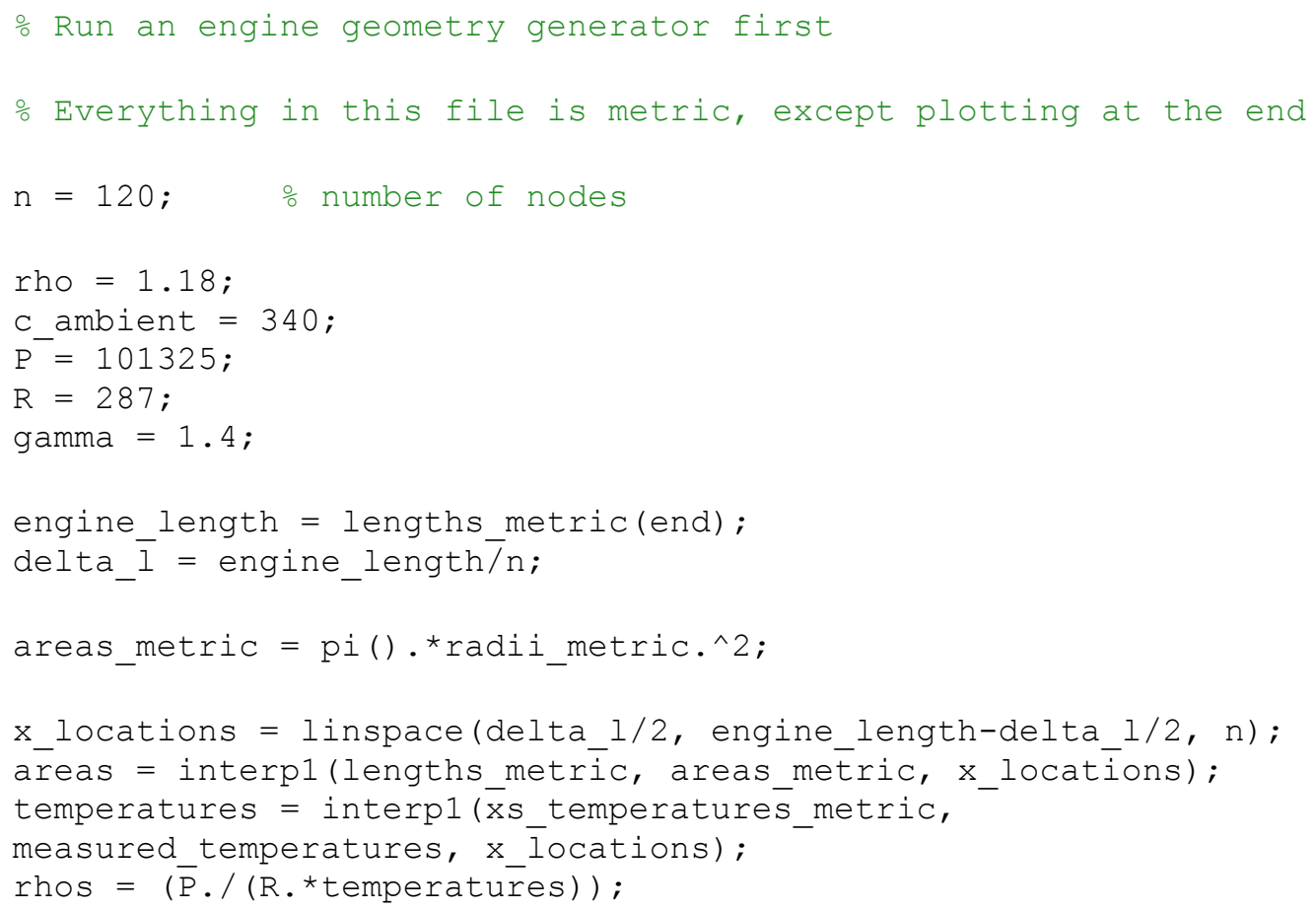




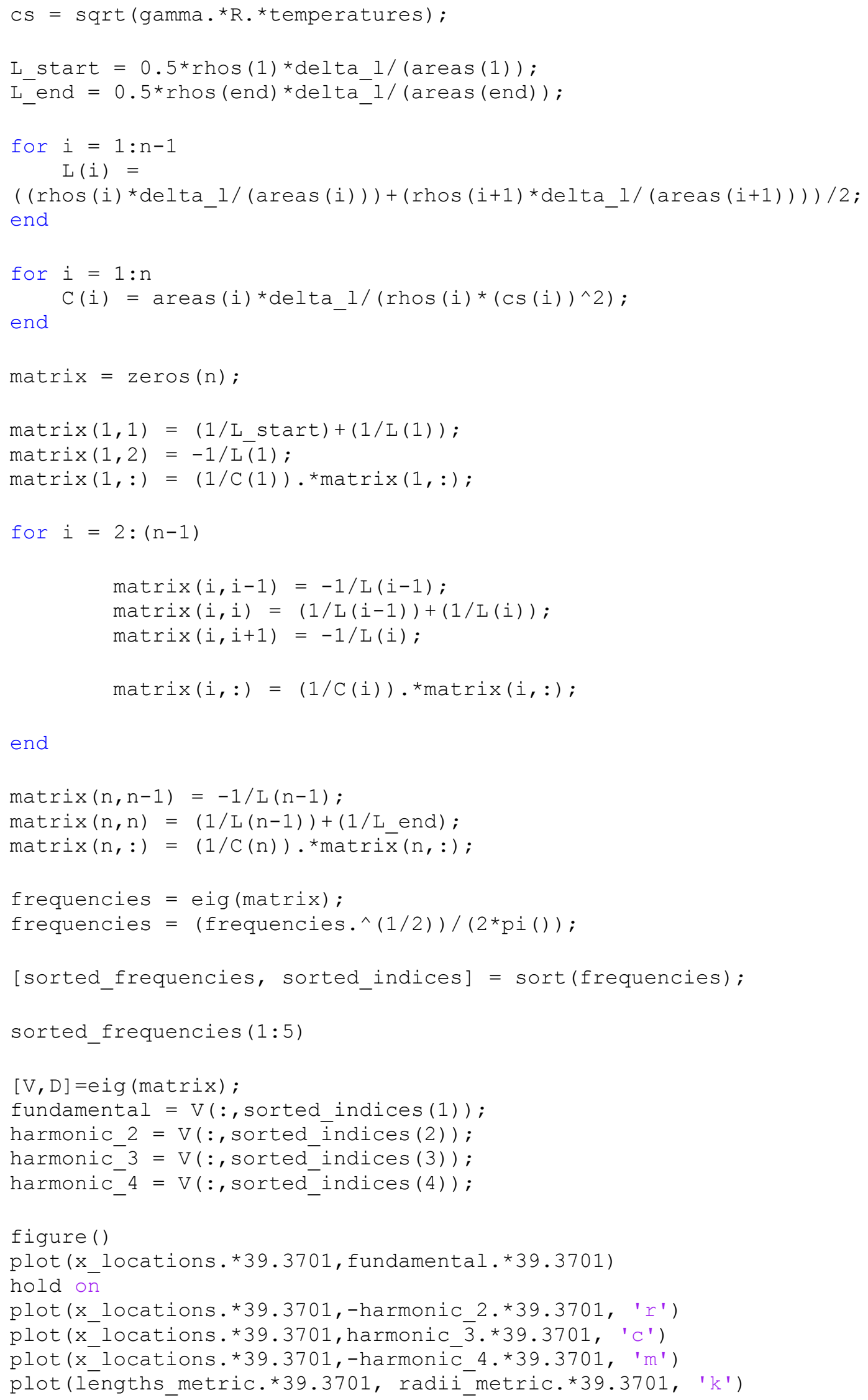




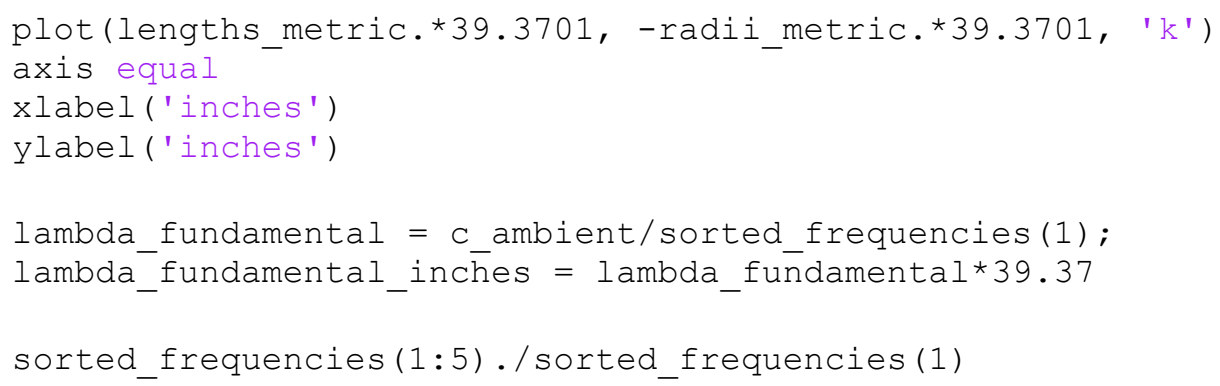




\section{Appendix C: Acoustic System/Circuit MATLAB Script}

\section{Run the engine geometry generator (first file) in Appendix B first.}

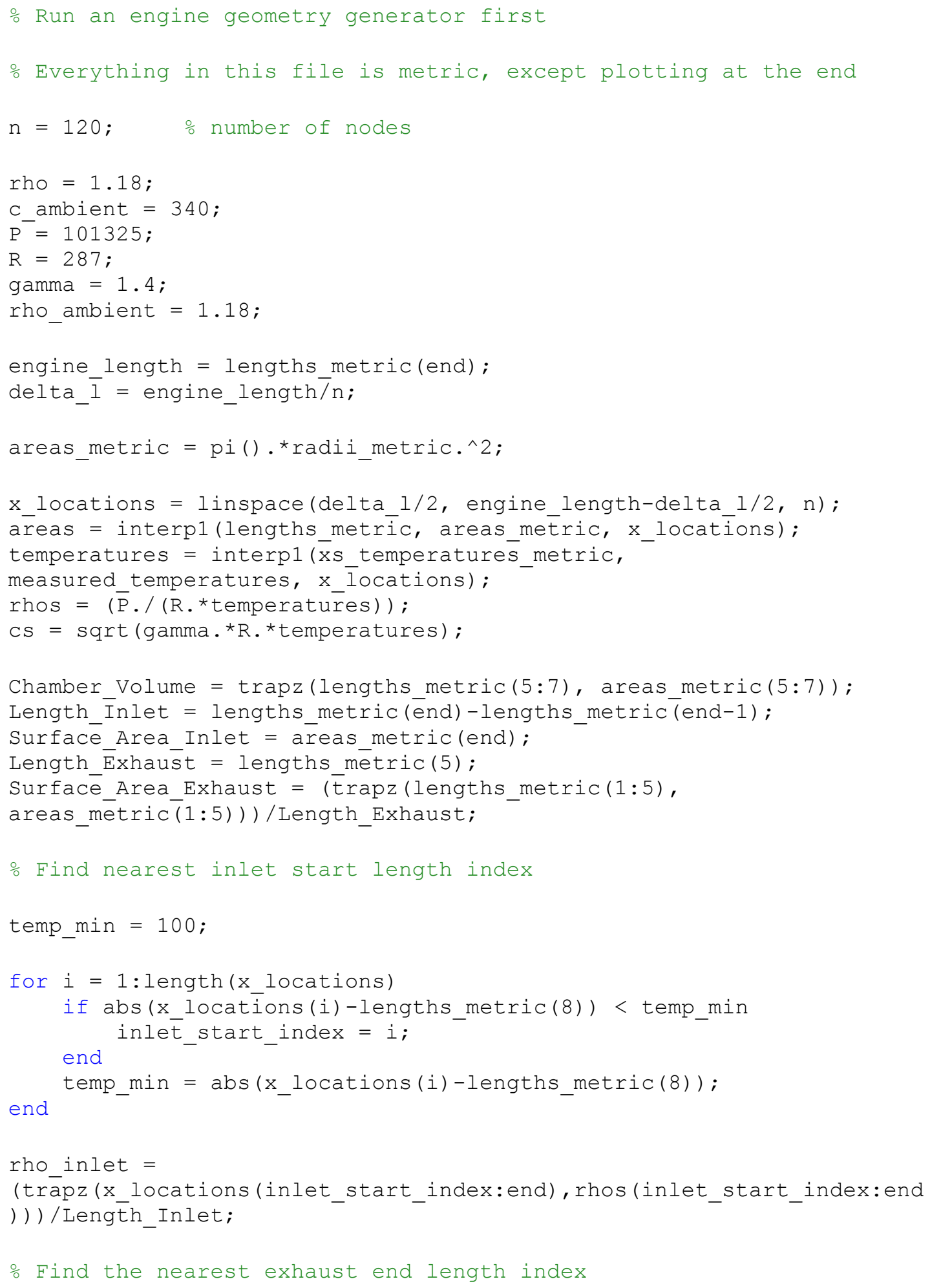




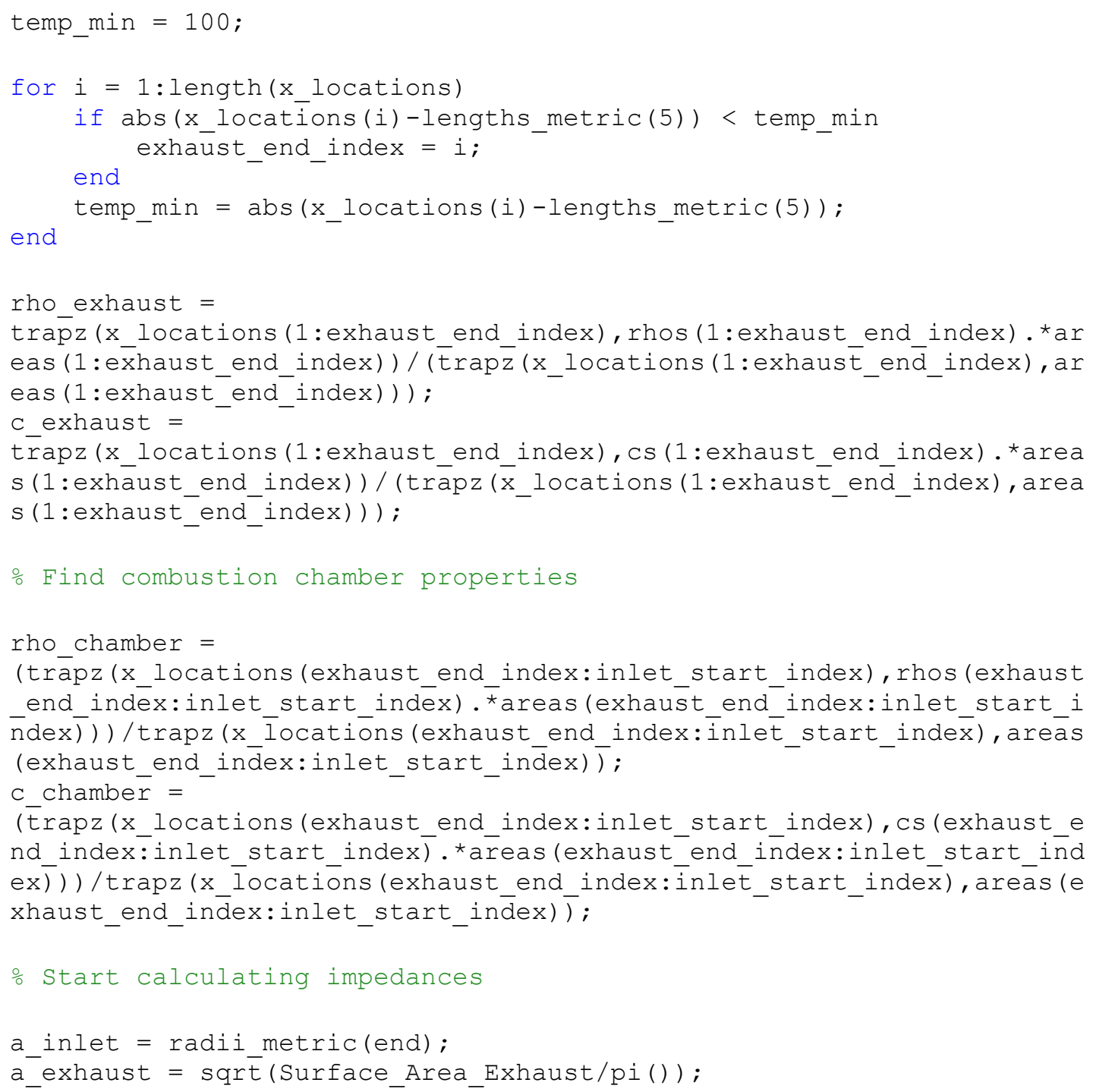

\section{\% Connecting duct}

connecting_duct_radius $=$ a_inlet $/ 2$;

connecting_duct_area $=p i()^{*}$ connecting_duct_radius^2;

rho_connecting_duct $=$ rho_chamber;

conñecting_duct_length $=\overline{\text { Length_Inlet; }}$

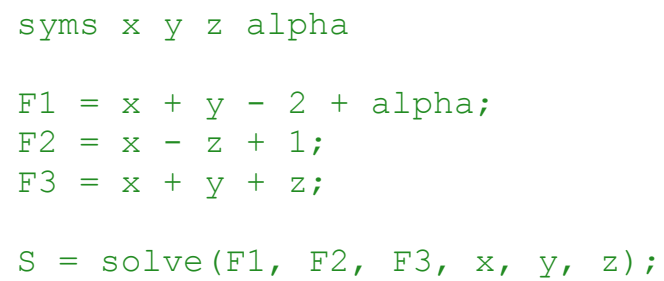




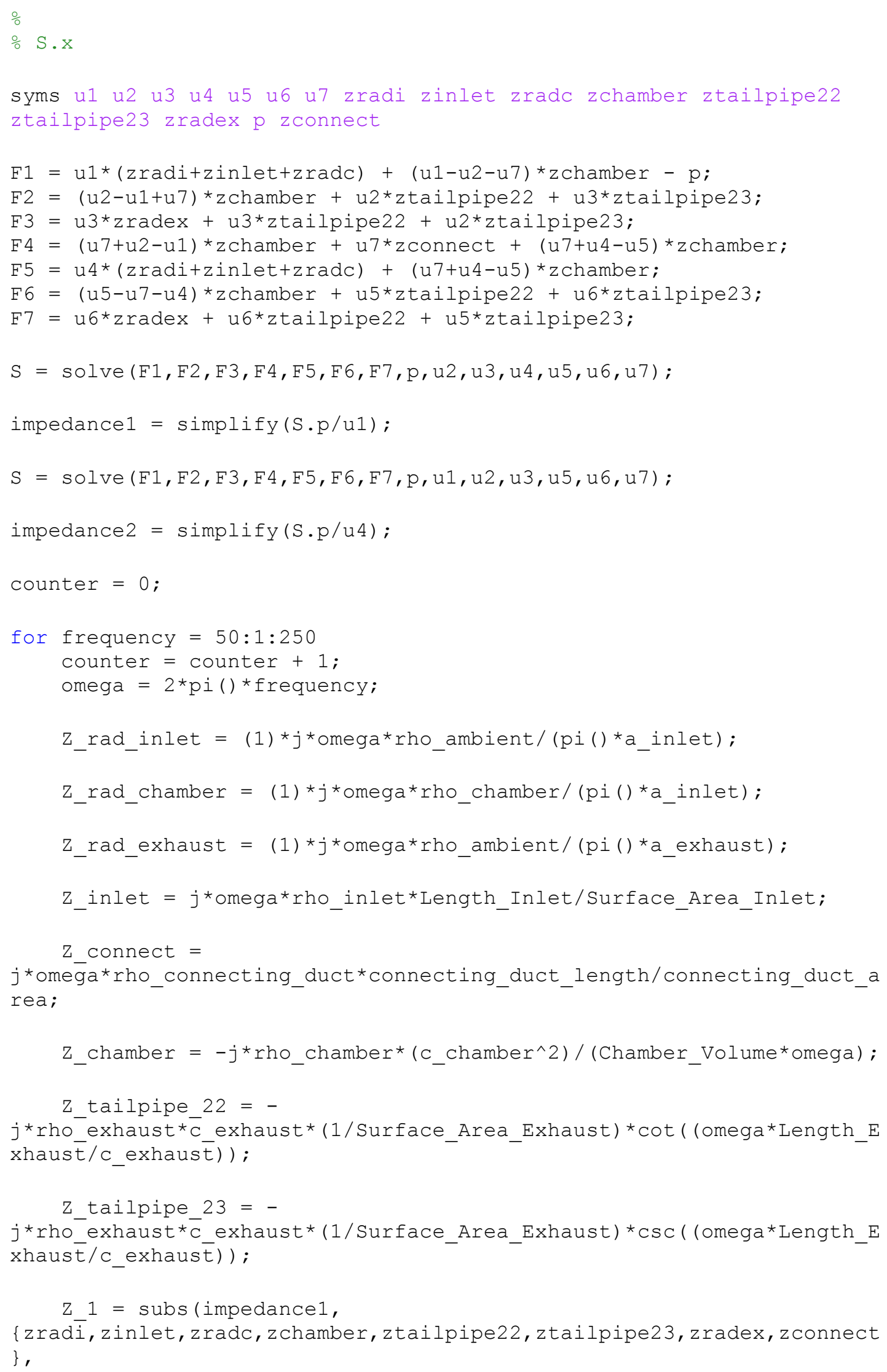




\section{Bibliography}

1. Antony L Kay, J R Smith. German Aircraft of the Second World War. s.1. : Putnam Aeronautical Books, 2002.

2. Lockwood, R M. Hiller Pulse Reactor Lift Engine Final Report. 1963. Advanced Research Report. ARD 308.

3. Bertin, J H. Quelques Proprietes de la Combustion Pulsatoire. Advanced Combustion Problems. s.1. : Butterworths Scientific Publications, 1954.

4. Logan, Joseph G. Summary Report on Valveless Pulse Jet Investigation. October, 1951. Project Squid Technical Memorandum. CAL-42.

5. Noise Characteristics of Pulse-Jet Engines. Veneklasen, Paul S. 3, May, 1953,

The Journal of the Acoustical Society of America, Vol. 25, pp. 378-379.

6. Progress Towards a Pressure-Generating Combustion Chamber for Gas Turbines.

Kentfield, J A C. [ed.] D J Brown. 1971. Proceedings of First International

Symposium on Pulsating Combustion. Paper 11.

7. Ejector Enhanced Pulsejet Based Pressure Gain Combustors: An Old Idea With a New Twist. Daniel E Paxson, Kevin Dougherty. Tucson, AZ : s.n., 10-13 July, 2005. 41st AIAA/ASME/SAE/ASEE Joint Propulsion Conference \& Exhibit. AIAA 2005-4216.

8. Experimental and Numerical Investigation of an 8-cm Valveless Pulsejet. T Geng, F Zheng, A P Kiker, A V Kuznetsov, W L Roberts. 2007, Experimental Thermal and Fluid Science, Vol. 31, pp. 641-647. 0894-1777.

9. Development of Twin Valveless Pulse Combustors for Space Heating. Ichiro Hongo, Kazuo Saito. 1992, Transactions of ASHRAE.

10. A Numerical Investigation of the Effect of Energy Addition Processes on Pulsejet Wave Engine Performance. R Erickson, Ben T Zinn. Reno, Nevada : s.n., 2004. AIAA Aerospace Sciences Meeting and Exhibit, Jan 5-8,2004. AIAA 2004-1210.

11. Combined Numerical and Experimental Investigation of a Hobby-Scale Pulsejet. T Geng, A Kiker Jr., R Ordon, A V Kuznetsov, T F Zeng, W L Roberts. 1, Tucson, Arizona : s.n., 2007, AIAA Journal of Propulsion and Power, Vol. 23, pp. 186-193. AIAA 2005-4378.

12. Computational Study of Pulsejet-Driven Pressure Gain Combustors at High-

Pressure. Shaye Yungster, Daniel E Paxson, Hugh D Perkins. San Jose, CA : s.n., July 14-17, 2013. 49th AIAA/ASME/SAE/ASEE Joint Propulsion Conference. AIAA 2013-3709.

13. Wojcicki, Stanislaw. Pulsejet, Jet and Rocket Engines. 1962.

14. Greatrix, David R. Powered Flight: The Engineering of Aerospace Propulsion. s.l. : Springer, 2012.

15. Blackstock, David T. Fundamentals of Physical Acoustics. s.1. : WileyInterscience, 2000. 16. Modeling of Acoustic Streaming for Micro-Air Vehicle Propulsion and Flow Control. Mina R Mankbadi, Vladimir V Golubev. Orlando, FL : s.n., 5-8 January, 2009. 47th AIAA Aerospace Sciences Meeting. AIAA 2009-284. 
17. Reynst, François Henri. Pulsating Combustion: The Collected Works of F.H. Reynst. s.1. : Pergamom Press, 1961.

18. Zinn, Benjamin T. Advanced Combustion Methods. [book auth.] Felix J Weinberg. Advanced Combustion Methods. s.l. : Academic Press, 1986.

19. Pulse Combustion. A A Putnam, F E Belles, J A C Kentfield. 1986, Progress in Energy and Combustion Science, Vol. 12, pp. 43-79.

20. Foa, J V. Elements of Flight Propulsion. s.l. : John Wiley \& Sons, Inc., 1960.

21. Kentfield, John A C. Thrust Augmenting Fluid Rectifier for a Pulsed Combustor.

CA 1034508 Al/US 4033120 A US \& Canada, 1977.

22. Pulse Jet One-way Valve Performance. John L Loth, Leon Montgomery, Ravi

Chandran. Nashville, Tennessee : s.n., July 6-8, 1992. AIAA/SAE/ASME/ASEE 28th Joint Propulsion Conference and Exhibit. AIAA-92-3169.

23. Escopette Pulsejet. Flight Magazine. January 25, 1952, pp. 101-102.

24. Rayleigh, Lord John W S B. The Theory of Sound. s.l. : MacMillan \& Co., 1878.

25. Reuter, Claus. The V2 and the German, Russian and American Rocket Program.

s.l. : German Canadian Museum/S.R. Research \& Publishing, 2000.

26. Powell, Evan. Now: $96 \%$ Efficient Pulse-Combustion Furnace. Popular Science.

September 1982, pp. 97-99.

27. Burner Oscillations of the Gauze-Tone Type. A A Putnam, W R Dennis. 5, 1954, Journal of the Acoustical Society of America, Vol. 26, pp. 716-725.

28. Nijoboer, Donald. Meteor I Vs VI Flying Bomb: 1942. s.1. : Osprey Publishing, 2012.

29. Gasdynamische Untersuchungen am Verpuffungstrahlrohr (Gas Dynamic

Investigations of the Pulse Jet Tube). Shultz-Grunow, F. 1/2, 1943/1944,

Forschungsbericht, Vol. 2105. Translation: NACA TM-1131, 1947.

30. Zaloga, Steven J. V-1 Flying Bomb 1942-52: Hitler's Infamous 'Doodlebug'. s.1. : Osprey Publishing, 2005.

31. The SNECMA Escopette Pulse-Jet. Bertin, J H. 1953, Interavia, Vol. 8, pp. 343347.

32. The Le Bourget Fête. Flight Magazine. July 6, 1951, p. 3.

33. Flight Magazine. April 9, 1954, p. 465.

34. Atar Volant. Flight Magazine. June 14, 1957, p. 792.

35. French High-Speed V/STOL Concepts of the Twentieth Century. Michael J.

Hirschberg, Thomas Müller, Alexis Rocher. Williamsburg, Virginia : s.n., 5-7

November, 2002. 2002 Biennial International Powered Lift Conference and Exhibit. AIAA 2002-5978.

36. Flight Magazine. May 11, 1956, p. 583.

37. Aviolanda's New Target Drone. Flight Magazine. November 4, 1955, p. 722.

38. Servanty, P. Test Report on New Types of Pulse-Reactors Developed for Hiller

Aircraft Corporation. SNECMA. 1962/1963. Order No. 30694 E, Contract No. 0226-C.

39. MacDonald, J K L. A Gas Dynamical Formulation for Waves and Combustion in Pulse-Jets. June, 1946. Project Squid Report. AMG-NYU No. 151.

40. Schubert, W. Design, construction and testing of a 6-inch valveless resojet.

1944. Naval Eng. Expt. Sta. EES-B-5350-As(b). 
41. Hett, J H. Report on Full Scale Pulse Jet Testing. 1951. Project Squid Technical Memorandum. NYU-12.

42. Logan, Joseph G. Valveless Pulse Jet Investigations, Part I: Tests of Small Scale Models. May, 1949. Project Squid Technical Memorandum. CAL-27.

43. Anthony L Russo, Joseph G Logan, Jr. Summary Report of Valveless Pulsejet Investigations on the C.A.L. 10-foot Whirling Arm. Cornell Aeronautical Laboratory, Inc. March, 1957. DD-801-A-1.

44. Joseph R. Cloyd. Summary Report on Investigation of Miniature Valveless Pulsejets. Hiller Aircraft Company. February, 1964. TRECOM Technical Report. 6420.

45. Pulse-Reactor Low Cost Lift-Propulsion Engines. Lockwood, R M. Wichita, Kansas : s.n., 25-27 May, 1964. AIAA General Aviation Aircraft Design \& Operations Meeting. AIAA-64-172.

46. Raymond M Lockwood, W G Patterson. Interim Summary Report Covering the Period from 1 April 1961 to 30 June 1962 on Investigation of the Process of Energy Transfer from an Intermittent Jet to Secondary Fluid in an Ejector-Type Thrust Augmenter. Hiller Aircraft Company. 30 June, 1962. Report No. ARD-305. 47. Unsteady Ejector Performance: An Experimental Investigation Using a Pulsejet Driver. Daniel E Paxson, Jack Wilson, Kevin T Dougherty. Indianapolis, IN : s.n., 7-10, July 2002. 38th AIAA/ASME/SAE/ASEE Joint Propulsion Conference \& Exhibit. AIAA 2002-3915.

48. Experimental and Numerical Investigation of Thrust Augmentation on a Micro Valveless Pulsejet. J A Scroggins, F Zheng, J S Sayres, N L Cousineau, T L

Turner, W L Roberts. Washington, D.C. : s.n., December 1-4, 2009. PowerMEMS. 0-9743611-5-1.

49. H S Tsien (Editor). Jet Propulsion, Daniel Guggenheim Aeronautical Laboratory, California Institute of Technology. s.l. : Air Technical Services Command, 1946.

50. The Propulsive Duct. Tharratt, C E. 11, 1965, Aircraft Engineering and Aerospace Technology, Vol. 37, pp. 327-337.

51. A New Acoustic Model for Pulsejets with Valves. J T Travis, T D Scharton, A V Kuznetsov, W L Roberts. Vienna, Austria : s.n., July 2-6, 2006. The Thirteenth International Congress on Sound and Vibration.

52. Smith, Dudley E. The Synchronous Injection Ignition Valveless Pulsejet.

Department of Aerospace Engineering, University of Texas at Arlington. December, 1987. Doctoral Thesis.

53. A New Acoustic Model for Valveless Pulsejets and Its Application to Optimization Thrust. F Zheng, R L Ordon, T D Scharton, A V Kuznetsov, W L Roberts. July, 2008, ASME Journal of Engineering for Gas Turbines and Power, Vol. 130. 0415012.

54. Computational and Experimental Investigation on 50-cm Valveless Pulsejet. F

Zheng, R L Ordon, T Geng, $T$ D Scharton, A V Kuznetsov, W L Roberts. Vienna, Austria : s.n., 2-6 July, 2006. The Thirteenth International Congress on Sound and Vibration.

55. Thomas D Rossing, Neville H Fletcher. Principles of Vibration and Sound. s.1. : Springer, 2004. 
56. On Modeling of Pulse Combustors. Bogdan Ponizy, Stanislaw Wojcicki. s.1. : The Combustion Institute, 1984, Twentieth Symposium (International) on Combustion, pp. 2019-2024.

57. Improving the Performance of a Valveless Pulse Combusto using Unsteady Fuel Injection. Tom Offord, Robert J Miller, James R Dawson, Jonathan J H Heffer, Sam Mason, Mark Taylor. Reno, NV : s.n., 7-10 January, 2008. 46th AIAA Aerospace Sciences Meeting and Exhibit. AIAA 2008-120.

58. Numerical Simulation of Valveless Pulsed Combustors. J A Olorunmaiye, J A C Kentfield. 8, 1989, Acta Astronautica, Vol. 19, pp. 669-679. 0094-5765/8.

59. Marzouk, E S. A Theoretical and Experimental Investigation of Pulsed PressureGain Combustion. The University of Calgary. Calgary, Canada : s.n., 1974. Ph.D.

Thesis.

60. Mathematical Model of a Pulsating Combustor. P H Clarke, J G Craigen. 1976. Sixth Thermodynamics and Fluid Mechanics Convention, I. Mech. E. C54/76.

61. Erickson, Robert R. A Numerical Investigation on the Influence of Engine Shape and Mixing Processes on Wave Engine Performance. School of Aerospace Engineering, Georgia Institute of Technology. 16 December, 2004. Ph.D. Thesis. 62. R Kee, J Miller, T Jefferson. Chemkin: A General-Purpose, Problem Independent, Transportable, Fortran Chemical Kinetics Code Package. Sandia National Labs. 1980. Technical Report. SAND80-8003.

63. Pulse Combustion: Demonstration of the Characteristic Mixing Time in a Commercial Burner. J Keller, P Barr, T Bramlette. 1989, Combustion Science and Technology, Vol. 66, pp. 127-137.

64. Fluid Mechanics of Pulse Pressure-Gain Combustors. Sam A Mason, Robert J Miller, Mark D Taylor. Reno, NV : s.n., 7-10 January, 2008. 46th AIAA Aerospace Sciences Meeting and Exhibit. AIAA 2008-118.

65. Combined Numerical and Experimental Investigation of a 15-cm Valveless Pulsejet. T Geng, M A Schoen, A V Kuznetsov, W L Roberts. 1, January, 2007, Flow, Turbulence and Combustion, Vol. 78, pp. 17-33.

66. Numerical Investigation of Components Length of China-Type Valveless Pulsejet. Cai Wenxiang, Wu Xiaosong, Wei Tao, Sun Bo. Wuhan, China : IEEE, 11-13 December, 2009. Computational Intelligence and Software Engineering. 978-1-42444507-3.

67. Valveless Gas-Turbine Combustors with Pressure Gain. Porter, C D. s.1. : ASME, 1958. 58-GTP-11.

68. Performance of Pressure-Gain Combustors Without Moving Parts. J A C

Kentfield, A Rehman, J Cronje. 2, March-April, 1980, Journal of Energy, Vol. 4, pp. 56-63. 79-0998R.

69. The Potential of Valveless Pulsejets for Small UAV Propulsion Applications.

Kentfield, J A C. 1998. 34th AIAA/ASME/SAE/ASEE Joint Propulsion Conference and Exhibit. AIAA 1998-3879.

70. Philip M Morse, Uno Ingard. Theoretical Acoustics. s.1. : Princeton University Press, 1987.

71. Pulse Combustion: Recent Applications and Research Issues. Zinn, Ben T. s.1. : The Combustion Institute, 1992. Twenty-Fourth Symposium (International) on Combustion. pp. 1297-1305. 
72. Development of Small Twin-Valveless Pulse Combustors: Effect of Injection System. Ichiro Hongo, Kazuo Saito. 1993, Combustion Science and Technology, Vol. 94, pp. 43-55.

73. The Characteristic Noise of Valveless Pulsed Combustors. Kentfield, J A C. Palo Alto, CA : s.n., 5-7 October, 1981. AIAA 7th Aeroacoustics Conference. AIAA 812056.

74. A Study of Unvalved Pulse Combustors. al., Briffa et. London, England :

Institution of Gas Engineers, November, 1971. 37th Autumn Research Meeting.

75. O'Brien, John G. The Pulsejet Engine: A Review of Its Development Potential.

Monterey, CA : Naval Postgraduate School, June, 1974. Master's Thesis.

76. Noise Reduction Using Paired Pulse Combustors. Robert D Giammar, Abbott

A Putnam. 5, Sep.-Oct., 1978, AIAA Journal of Energy, Vol. 2, pp. 319-320.

77. Nonlinear Analysis of a Pulse Combustor Model with Exhaust Decoupler and

Vent Pipe. Li-jun Yang, Zhi-ren Yin, Ming He, Run-ze Duan, Fang-yan Li. 2013, Combustion and Flame, Vol. 160, pp. 2866-2878. 0010-2180.

78. Fundamental Operating Mechanism for a Twin Valveless Pulse Combustor.

Kazuo Saito, Kunihisa Eguchi, Mitsuo Gomi, Toshihiko Saito. 1993, Combustion Science and Technology, Vol. 94, pp. 11-24.

79. Development of a Low Noise Pulse Combustor. Isao Inui, Kenji Okamoto, Mitsuyoshi Nakamoto, Masato Hosaka. 1987, Combustion Science and Technology, Vol. 52, pp. 107-119.

80. Pulse Jet Orchard Heater System Development: Part I. Design, Construction, and Optimization. R G Evans, A S Alshami. 2, 2009, Transactions of the ASABE, Vol. 52, pp. 331-343.

81. Pulse Jet Orchard Heater System Development: Part II. System Scaling and Application. A S Alshami, R G Evans. 2, 345, Transactions of the ASABE, Vol. 52, p. 355.

82. Active Control of Twin-Pulse Combustors. Michael Zeutzius, Kunio Terao, Toshiaki Setoguchi, Shigeru Matsuo, Toshihiro Nakano, Yasuyuki Fujita. 5, May, 1998, AIAA Journal, Vol. 36, pp. 823-829.

83. Experimental Study of Twin Pulse Jet Engines for Power Plant Application.

Toshihiro Nakano, Shigeru Matsuo, Toshiaki Setoguchi, Shen Yu. 2, 2003, Journal of Thermal Science, Vol. 12, pp. 179-184.

84. Roskam, Jan. Roskam's Airplane War Stories: An Account of the Professional Life and Work of Dr. Jan Roskam, Airplane Designer and Teacher. s.1. :

Darcorporation, 2002.

85. Myhra, David. Messerschmitt Me 328. s.l. : RCW Technology \& Ebook

Publishing, 2013.

86. Le Bourget 1953. Flight Magazine. July 1953, p. 52.

87. Aero Engines 1954. Flight Magazine. April 9, 1954, p. 465.

88. Here and There: V.T.O. in France. Flight Magazine. March 4, 1955, p. 262.

89. Military Airlift, Catching the Next Wave. John Skorupa (The Boeing

Company). Dayton, OH : s.n., 15 July, 2003. AIAA International Air and Space

Symposium and Exposition: The Next 100 Years.

90. Richard P Ouellette, Aaron J Kutzmann (The Boeing Company). Vertical takeoff and landing aircraft. US6824097 B1 United States, November 30, 2004. 
91. Company), Yueping Guo (The Boeing. Low-noise pulse jet engine.

US20070028593 A1 United States, February 8, 2007.

92. Richard P Ouellette, Aaron J Kutzmann (The Boeing Company). Pulsejet augmentor powered VTOL aircraft. US6793174 B2 United States, September 21, 2004.

93. Personal Air Vehicles: A Rural/Regional and Intra-Urban On-Demand

Transportation System. Moore, Mark D. Dayton, OH : s.n., 14-17 July, 2003.

AIAA/ICAS International Air and Space Symposium and Exposition: The Next 100 Years. AIAA 2003-2646.

94. Lassiter, Leslie W. Noise From Intermittent Jet Engines and Steady-Flow Jet

Engines with Rough Burning. NACA. August, 1952. Technical Note 2756.

95. Acoustic Characteristics of Model Pulsed Jets. Stanley K Oleson, Uno Ingard.

10, October, 1957, The Journal of the Acoustical Society of America, Vol. 29, pp. 1145-1146.

96. Paul S Veneklasen, R W McJones. Pulsejet Noise Analysis. American

Helicopter. 15 November, 1954. 1949B-471.

97. A Mathematical Model of Low Amplitude Pulse Combustion Systems Using a

Helmholtz Resonator-Type Approach. J H Lee, B Dhar, W Soedel. 3, 1985, Journal of Sound and Vibration, Vol. 98, pp. 379-401.

98. French, A P. Vibrations and Waves (MIT Introductory Physics Series). 1965.

99. Pain, H John. The Physics of Vibrations and Waves. s.1. : John Wiley \& Sons, 2013.

100. Thomas Rossing, Neville H Fletcher. Principles of Vibration and Sound. s.1. : Springer-Verlag, 1995.

101. Termination Impedance of Open-Ended Cylindrical Tubes at High Sound

Pressure Level. Merouane Atig, Jean-Pierre Dalmont, Joel Gilbert. 4, 2004, Comptes Rendus de 1 Academie des Sciences - Series IIB - Mechanics, Elsevier, Vol. 332, pp. 299-304.

102. Nonlinear Acoustic Damping Induced by a Half-wave Resonator in an Acoustic Chamber. I-Sun Park, Chae Hoon Sohn. s.1. : Elsevier, 2010, Aerospace Science and Technology, Vol. 14, pp. 442-450.

103. Active Control of Combustion Instability. W Lang, T Poinsot, S Candel. 1987, Combustion and Flame, Vol. 70, pp. 281-289.

104. Impact of Linear Coupling on the Design of Active Controllers for the Thermoacoustic Instability. A M Annaswamy, M Fleifil, J P Hathout, A F

Ghoneim. 1997, Combustion Science and Technology, Vol. 128, pp. 131-180.

105. Rossing, T. Springer Handbook of Acoustics. s.1. : Springer, 2014.

106. Bies, David A, Hansen, Colin H. Engineering Noise Control: Theory and Practice. s.l. : Spon Press, Taylor and Francis Group, 2009.

107. Incorporated, Shure. Shure Model SM58 Dynamic Microphone Specification Sheet.

108. Heat Release Timing in a Nonpremixed Helmholtz Pulse Combustor. Y M Tang, G Waldherr, J I Jagoda, B T Zinn. 1995, Combustion and Flame, Vol. 100, pp. 251-261. 0010-2180/9.

109. Improving the Performance of a Valveless Pulse Combustor using Unsteady Fuel Injection. Tom Offord, Robert J Miller, James R Dawson, Jonathan J H 
Heffer, Sam Mason, Mark Taylor. Reno, NV : s.n., 7-10 January, 2008. 46th AIAA Aerospace Sciences Meeting and Exhibit. AIAA 2008-120.

110. Resonant Frequencies of Cylindrical Helmholtz Resonators. Ronald L Panton, John M Miller. 6, Part II, June, 1975, Journal of the Acoustical Society of America, Vol. 57, pp. 1533-1535.

111. A Numerical Investigation of the Effect of Energy Addition Processes on Pulsejet Wave Engine Performance. R. Erickson, Ben T. Zinn. Reno, Nevada : s.n., 2004.

AIAA Aerospace Sciences Meeting and Exhibit, Jan 5-8,2004. AIAA 2004-1210. 
